\title{
Fuel Film Temperature and Thickness Measurements on the Piston Crown of a Direct-Injection Spark-Ignition Engine
}

by

Soochan Park

A dissertation submitted in partial fulfillment of the requirements for the degree of

Doctor of Philosophy

(Mechanical Engineering)

at the

University of Wisconsin-Madison

2003 


\title{
Fuel Film Temperature and Thickness Measurements on the Piston Crown of a Direct-Injection Spark-Ignition Engine
}

\author{
Soochan Park \\ Under the supervision of Associate Professor Jaal B. Ghandhi \\ At the University of Wisconsin-Madison
}

The fuel film thickness and temperature on the piston crown of a direct-injection spark-ignition (DISI) engine were measured using a fiber-based laser induced fluorescence (LIF) method. The engine investigated employed a wall-guided swirl-type system using a high-pressure swirl injector impinging onto the piston crown. The fuel used was isooctane with a small amount of a fluorescent liquid dopant. The measured fluorescence intensity was transformed to the fuel film thickness by way of the equations based on photophysics and the fiber optic properties. However, the fluorescence of the fuel mixture showed a strong dependency on the fuel temperature and this information was needed in the fuel film thickness calculation. The fuel film temperature, which may differ from the piston surface temperature, was measured by using a fiber-based fluorescence thermometry method.

Engine tests were performed for motored and fired conditions under the late injection stratified mode. The results of the fuel film temperature measurement showed that the mean fuel film temperature follows the piston surface temperature and the convection heat transfer from the compressed hot air directly affected the mean fuel film temperature during the compression and expansion stroke. The fuel film thickness measurement results showed that the boiling point of the liquid dopant should be much higher than that of the main fuel to 
meet the co-evaporation condition. The fuel film persisted during the expansion stroke and started to evaporate actively from the exhaust valve opening crank angle for both motored and fired conditions. The fuel film thickness from the fuel injection to just before the occurrence of pool fires was the same level for motored and fired engine conditions although the piston temperature was higher for the fired condition. The spark ignition and the main flame before the pool fires do not affect the fuel film thickness. The duration and thickness of the fuel film was strongly affected by the boiling point of the fuel. The fuel film evaporates quicker for a fuel having a lower boiling point. 


\section{Acknowledgements}

First, I would like to thank Professor Jaal Ghandhi for his support during the long journey toward the degree. His academic guidance always showed me the way to a better solution when a difficult problem occurred.

I would like to thank the other ERC professors, David Foster, Rolf Reitz, and Patrick Farrell, and Riccardo Bonazza of the Engineering Mechanics Department for reviewing the thesis and serving as committee members.

I would like to thank other ERC staff and graduate students. Matt Wiles, Andy Bright, and Yoshio Tagawa were a great officemates and they were always willing to help me when I needed it. I especially want to thank Ralph Brown for helping me time and again.

I want to give my special thanks to my parents and parents-in-law. They were always supportive during my stay in the US and encouraged me in pursuing my Ph.D. My sister Soojung and brother Soohyun and their families always gave my family special regard and I really appreciate that.

Words cannot express my gratitude to my loving wife, Hyejin Lee. She made every sacrifice for me and our children while I was wrapped up in my work. I and my wife have been blessed with two wonderful daughters, Hyoin and Yerin, during our time at Madison. I will love my daughters always and my love for my wife will last forever and I would like to dedicate this thesis to them. 


\section{Table of Contents}

Abstract

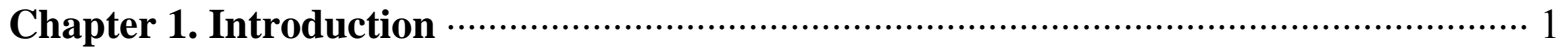

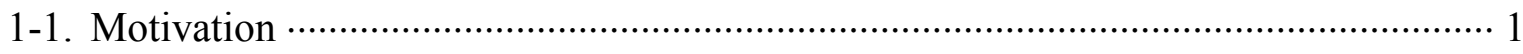

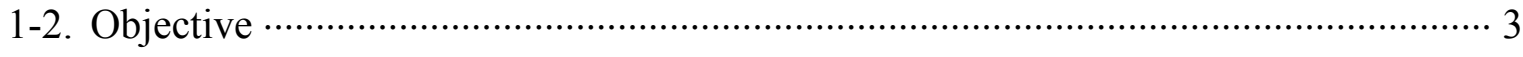

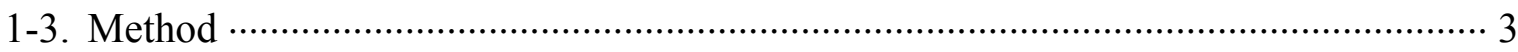

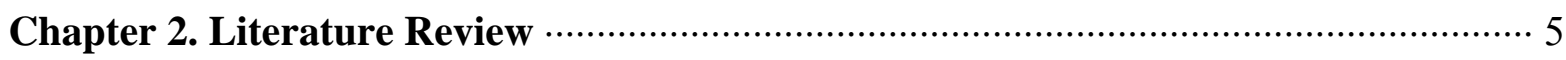

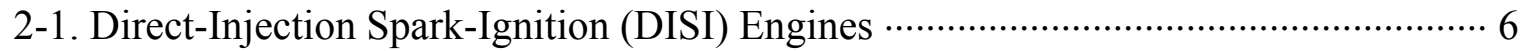

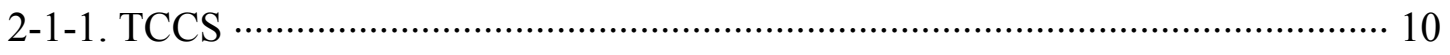

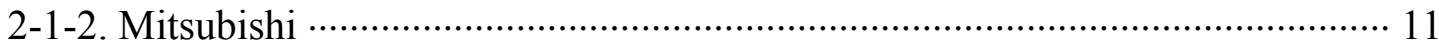

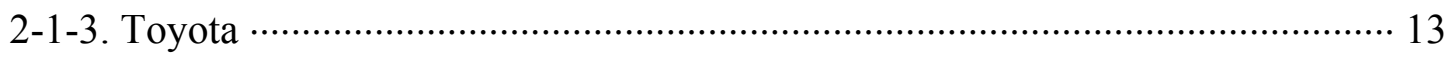

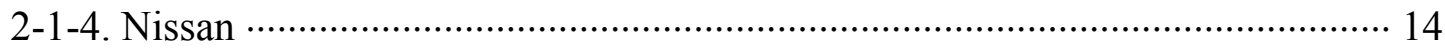

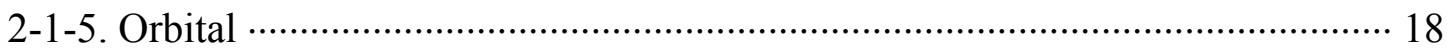

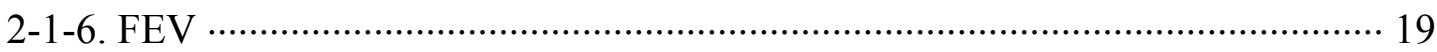

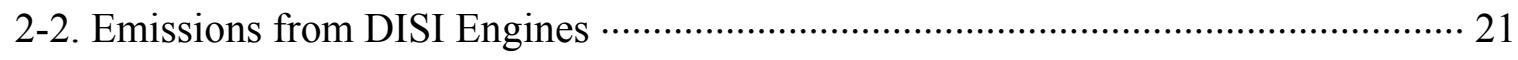

2-3. The Effect of Piston Fuel Film on HC and Particulate Emissions …..................... 27

2-3-1. Fuel Impingement on the Piston Crown ……............................................ 27

2-3-2. Piston Fuel Film Behavior and the Effect on Emissions …........................... 31

2-4. Fuel Film Thickness Measurements ………...................................................... 35

2-4-1. Laser-Induced Fluorescence (LIF) Technique ….................................... 35 
2-4-2. Fiber Optic Fluorescence Method ……………………………………… 39

2-5. Fluorescence-Based Liquid-Phase Thermometer (FBLPT) ………………………... 45

Chapter 3. Thickness Measurement by Fiber-based LIF Method …………………...... 47

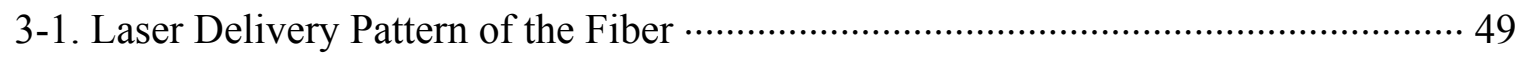

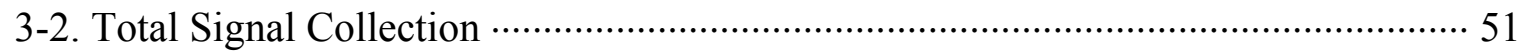

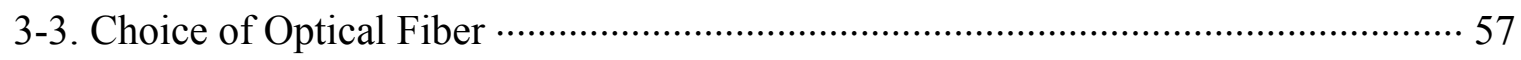

3-4. Effect of Fuel Spray …………………………………………………………… 59

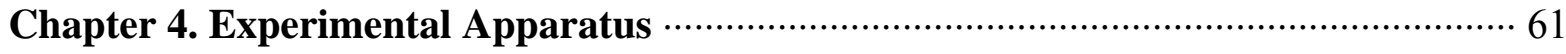

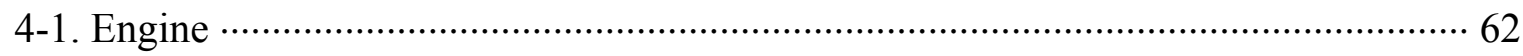

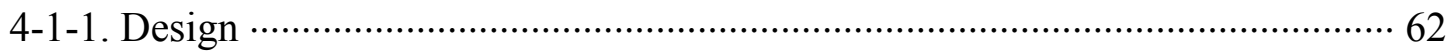

4-1-2. Data Acquisition and Engine Control Systems …………………………….... 67

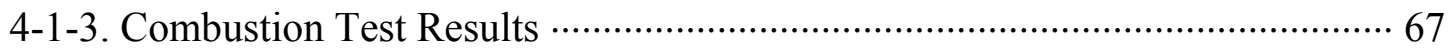

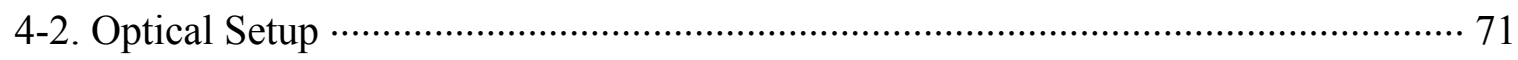

4-2-1. Optical Fiber Installation ………………………………………………….... 71

4-2-2. Fuel Film Temperature Measurement ……………………………………... 74

4-2-3. Fuel Film Thickness Measurement ………………………………………... 78

Chapter 5. Results of Fuel Film Temperature Measurement ……….......................... 80

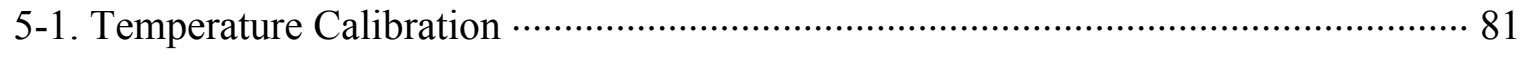

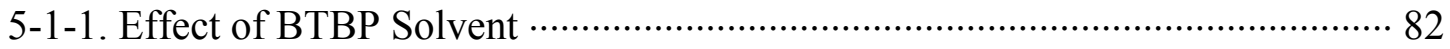

5-1-2. Effect of Laser Power and BTBP Concentration …………………………..... 87

5-1-3. Effect of Photobleaching ……………………………………………………... 90

5-1-4. Effect of Fuel Pressure ………………………………………………………. 91

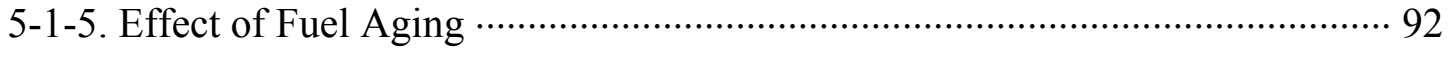

5-1-6. Effect of Fiber and Laser Focusing ……………………………………….... 94

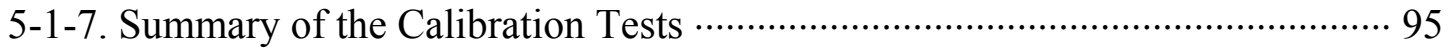




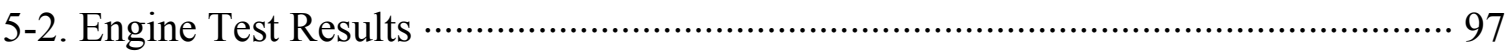

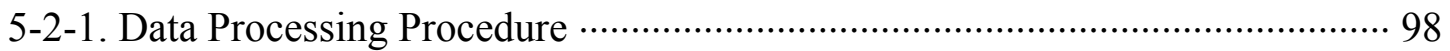

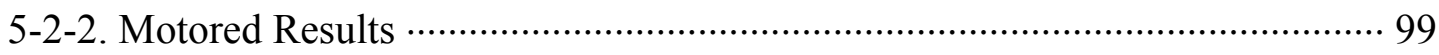

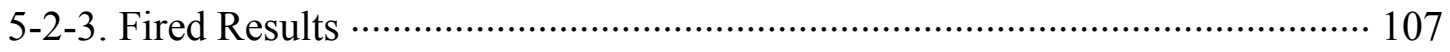

5-2-4. Uncertainty Analysis …………………………………………………… 112

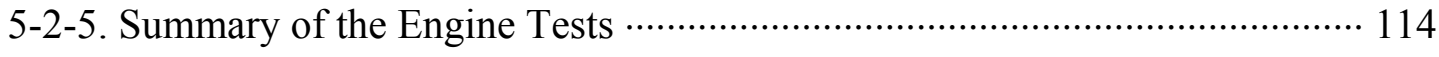

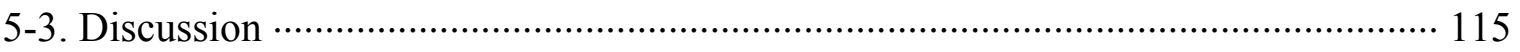

Chapter 6. Results of Fuel Film Thickness Measurement ………………………… 126

6-1. Qualitative Measurement with BTBP ………………………………………….... 128

6-1-1. Engine Test Results for Isooctane/BTBP …………………………………. 128

6-1-2. Engine Test Results for n-Pentane/BTBP ………………………………….... 144

6-1-3. Engine Test Results for n-Decane/BTBP ………………………………... 145

6-2. Fuel Film Thickness Measurement using 2,3-hexanedione as a Dopant …………. 149

6-2-1. Preliminary Tests ………………………………………………………….. 149

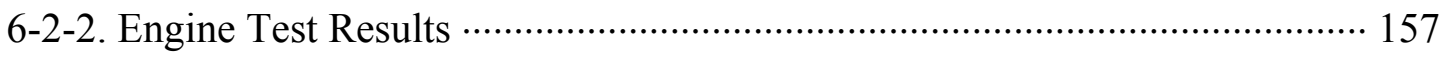

6-3. Fuel Film Thickness Measurement using Biacetyl as a Dopant …………………... 166

6-3-1. Preliminary Tests ………………………………………………………. 166

6-3-2. Engine Test Results ……………………………………………………… 167

6-4. Summary of the Fuel Film Thickness Measurement ……………………………... 172

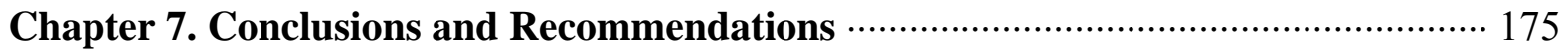

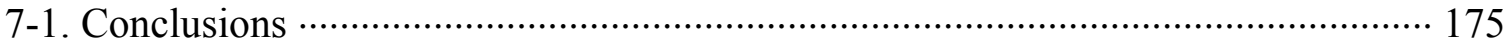

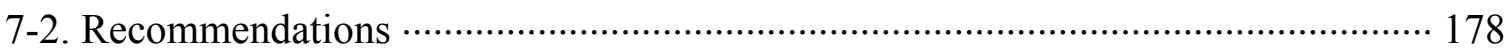

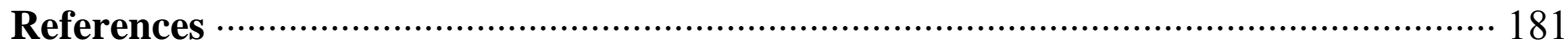




\section{List of Tables}

Table 2-1. Comparison of the specifications of different DISI engine systems …............... 8

Table 2-2. Specifications of the test vehicles and the test results ……............................ 26

Table 3-1. Area and volume of the Gaussian distribution function at each distance …........ 50

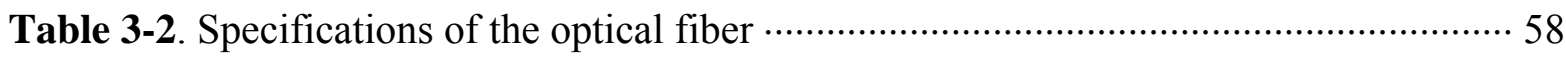

Table 4-1. Specifications of the research DISI engine …............................................. 64

Table 5-1. Summary of the uncertainty analysis with 95\% confidence level …................ 113

Table 6-1. Percentage uncertainty levels of the averaged signal intensities at

$10^{\circ} \mathrm{BTDC}$ for isooctane/BTBP 


\section{List of Figures}

Figure 2-1. Combustion system classification of DISI engines [Geiger et al., 1999] …........ 9

Figure 2-2. Texaco Controlled-Combustion System [Mitchell and Alperstein, 1973] …....... 9

Figure 2-3. Behavior and the requirements of the fuel spray characteristics for each combustion modes [Kume et al., 1996] …….......................................... 12

Figure 2-4. Fuel spray pattern at different ambient pressures [Iwamoto et al., 1997] ……... 12

Figure 2-5. Schematic view of the Toyota D-4 combustion chamber configuration [Harada et al., 1997] ……......................................................................... 14

Figure 2-6. Combustion strategy of Toyota direct injection system [Harada et al., 1997] ‥ 14

Figure 2-7. Fuel spray and piston cavity configuration of Toyota NCP

[Kanda et al., 2000] …...................................................................... 15

Figure 2-8. Nissan direct injection gasoline engine [Takagi et al., 1998] …....................... 17

Figure 2-9. Schematics of Orbital's air-assisted fuel injection system [Cathcart and Zavier, 2000]

Figure 2-10. FEV charge motion controlled combustion system [Geiger et al., 1999] ….... 20

Figure 2-11. BSHC emission as a function of air-fuel ratio at 1500rpm, 2.62 bar BMEP, and MBT spark timing [Brehob et al., 1998]

Figure 2-12. Fuel spray image and the schematic representation of the spray for the typical high-pressure swirl injector [Zhao et al., 2002]

Figure 2-13. Effect of fuel temperature on spray development for a pressure-swirl injector.

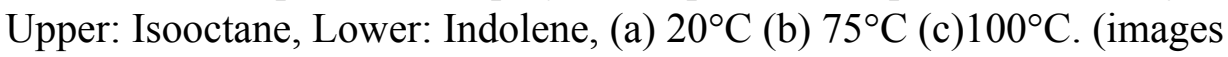
taken at $1.5 \mathrm{~ms}$ after SOI, 0.1 MPa ambient pressure) [Zhao et al., 2002] … 30

Figure 2-14. Effects of ambient pressure $\left(\mathrm{P}_{\mathrm{amb}}\right)$ and injection pressure $\left(\mathrm{P}_{\text {inj }}\right)$ on the crosssections of fuel sprays from a swirl injector (images taken at $40 \mathrm{~mm}$ from the tip and $4 \mathrm{~ms}$ after SOI) [Zhao et al., 2002] 
Figure 2-15. Time-resolved $\mathrm{HC}$ emissions from a two-stroke direct-injection engine.

$2000 \mathrm{rpm}$, air-fuel ratio of 30:1. [Hudak and Ghandhi, 1999]

Figure 2-16. Energy-state diagram illustrating the processes of absorption and subsequent emission of fluorescence [Sharma and Schulman, 1999]

Figure 2-17. Schematics of the transmitting and receiving cones of two fibers

[Hentschel et al., 1997]

Figure 2-18. Geometry of the optical fiber probe [Ghandhi, 2000]

Figure 2-19. Single fiber probe results [Ghandhi, 2000]

a) Modified collection solid angle as a function of distance from the fiber face

b) Collapse of data by choosing the appropriate non-dimensional scaling

Figure 2-20. Single fiber probe results [Ghandhi, 2000] 44

a) Cumulative signal

b) Cumulative signals for small distances compared to a linear response

Figure 2-21. Fluorescence spectra of BTBP in air-saturated solution at different temperatures [Bai and Melton, 1997] 46

Figure 3-1. Laser intensity distribution at three different distances from the fiber surface and the corresponding Gaussian distribution curve

Figure 3-2. Laser power distribution 52

Figure 3-3. Calculation results of modified collection solid angle for different fiber diameter and numerical aperture

Figure 3-4. Non-dimensional form of the modified collection solid angle for different fiber diameter and numerical aperture

Figure 3-5. Non-dimensional form of the modified collection solid angle for even and Gaussian light intensity distribution

Figure 3-6. Calculation result of the cumulative signal for even and Gaussian

laser intensity distribution

(a) Log scale for the $\mathrm{x}$-axis for longer distance

(b) Normal scale for closer look

Figure 3-7. Comparison of the calculated cumulative signal, which assumed a

Gaussian intensity distribution, and the measured total signal 56 


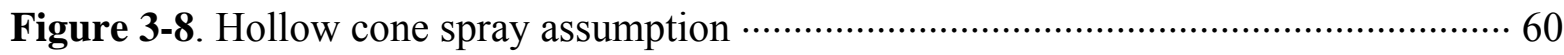

Figure 4-1. Top view of the cylinder head and combustion chamber …......................... 65

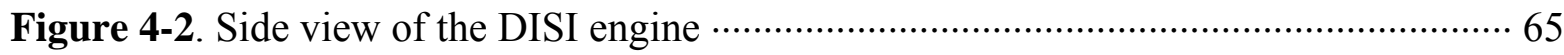

Figure 4-3. Schematic diagram of the engine coolant circuit …..................................6 66

Figure 4-4. Results of engine mapping test for the high-pressure swirl injector at $600 \mathrm{rpm}$. $\Phi=0.3, \mathrm{~T}_{\text {coolant }}=73^{\circ} \mathrm{C}$, isooctane, 100 cycles averaged …….................... 69

Figure 4-5. Results of engine mapping test for high-pressure swirl injector at $1200 \mathrm{rpm}$. $\Phi=0.3, T_{\text {coolant }}=73^{\circ} \mathrm{C}$, isooctane, 100 cycles averaged

Figure 4-6. Combustion chamber pressures of the DISI engine at the selected End Of Injection (EOI) and Spark Timing (ST) conditions determined from the mapping tests when $\Phi=0.3$

Figure 4-7. P-v diagram of the motored and fired engine conditions

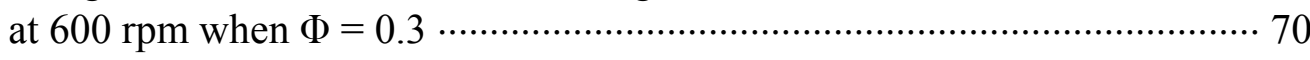

Figure 4-8. Optical fibers and a thermocouple positions in the piston bowl (Top view) …. 71

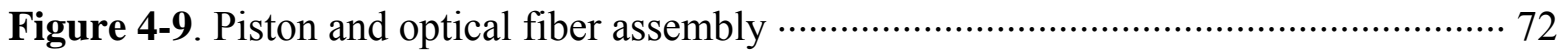

Figure 4-10. Optical fiber connection to the outside of the engine …............................ 73

Figure 4-11. Optical setup for fuel film temperature measurement …….......................... 76

Figure 4-12. Relationship between A-pulse and the generated flip-flop signal, which makes the laser beam blinks …….............................................. 77

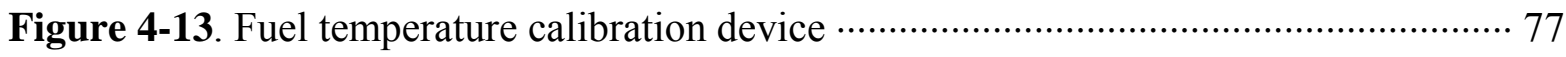

Figure 4-14. Optical setup for fuel film thickness measurement …............................... 79

Figure 5-1. BTBP concentration effect on the intensity ratio when 1-heptanol

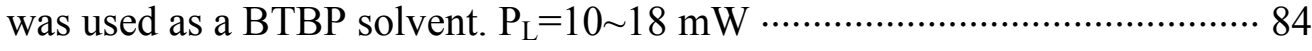

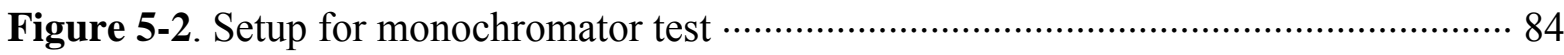


Figure 5-3. Effect of laser power and fuel pre-heating on fluorescent spectra for 1-heptanol solvent. $\mathrm{T}=22^{\circ} \mathrm{C}$, isooctane $+2 \times 10^{-6} \mathrm{M}$ BTBP 85

Figure 5-4. Concentration effect on fluorescent intensity spectra for 1-heptanol solvent. $\mathrm{T}=22^{\circ} \mathrm{C}$, isooctane $+2 \times 10^{-6} \mathrm{M}$ BTBP

Figure 5-5. Concentration effect on (a) fluorescent intensity spectra and

(b) normalized intensity spectra when $0.5 \%$ 2-butanol was used as a solvent for BTBP. Fuel was isooctane 86

Figure 5-6. Effect of fuel flow rate on the intensity ratio 88

Figure 5-7. Effect of laser power on signal intensities and the intensity ratio 88

Figure 5-8. Effect of laser power on the intensity ratio at elevated temperature 89

Figure 5-9. Effect of BTBP concentration on the intensity ratio 89

Figure 5-10. Effect of laser power and BTBP concentration on I_515 without fuel flow in the calibration device

Figure 5-11. Effect of fuel pressure on the intensity ratio 92

Figure 5-12. Effect of fuel aging on signal intensities and the intensity ratio 93

Figure 5-13. PMT unit and the fluorescence beam focusing 94

Figure 5-14. Non-dimensional form of the modified collection solid angle versus distances from the fiber surface

Figure 5-15. 203-cycle averaged signal intensity, intensity ratio, fuel film temperature, and normalized standard deviation of intensity ratio for motored condition at $600 \mathrm{rpm}, \mathrm{T}_{\text {Coolant }}=38^{\circ} \mathrm{C}, \mathrm{T}_{\mathrm{P}}=71^{\circ} \mathrm{C}$. The horizontal bar in each graph represents the region for which $\mathrm{s} / \mu<20 \%$

Figure 5-16. 192-cycle averaged signal intensity, intensity ratio, fuel film temperature, and normalized standard deviation of intensity ratio for motored condition at $600 \mathrm{rpm}, \mathrm{T}_{\text {Coolant }}=55^{\circ} \mathrm{C}, \mathrm{T}_{\mathrm{P}}=84^{\circ} \mathrm{C}$

Figure 5-17. 167-cycle averaged signal intensity, intensity ratio, fuel film temperature, and normalized standard deviation of intensity ratio for motored condition at $600 \mathrm{rpm}, \mathrm{T}_{\text {Coolant }}=71^{\circ} \mathrm{C}, \mathrm{T}_{\mathrm{P}}=101^{\circ} \mathrm{C}$ 
Figure 5-18. 241-cycle averaged signal intensity, intensity ratio, fuel film temperature, and normalized standard deviation of intensity ratio for motored condition at $1200 \mathrm{rpm}, \mathrm{T}_{\text {Coolant }}=71^{\circ} \mathrm{C}, \mathrm{T}_{\mathrm{P}}=113^{\circ} \mathrm{C}$

Figure 5-19. 40-cycle averaged separated $\mathrm{I}_{515}$ chopped signal, signal intensity, intensity ratio, fuel film temperature, and normalized standard deviation of intensity ratio for fired condition. $600 \mathrm{rpm}, \mathrm{T}_{\text {Coolant }}=71^{\circ} \mathrm{C}, \mathrm{T}_{\mathrm{P}}=112^{\circ} \mathrm{C}$

Figure 5-20. Pool fire images at $10^{\circ}$ ATDC when $\Phi=0.3$ $\left(48^{\circ} \mathrm{BTDC}\right.$ EOI, $15^{\circ} \mathrm{BTDC}$ ST $)$

Figure 5-21. Three sets of 40-cycle averaged fuel film temperature and average of them for fired condition. $600 \mathrm{rpm}, \mathrm{T}_{\text {Coolant }}=71^{\circ} \mathrm{C}$

Figure 5-22. Comparison of fuel film temperature for motored and fired condition. $600 \mathrm{rpm}, \mathrm{T}_{\text {Coolant }}=71^{\circ} \mathrm{C}$

Figure 5-23. Temperature calibration curve for isooctane $+2 \times 10^{-6} \mathrm{M}$ BTBP

Figure 5-24. Measured in-cylinder pressure for motored $600 \mathrm{rpm}$ and calculated air temperature and the boiling point changes according to the pressure for isooctane 118

Figure 5-25. Nodes for 1-D FDM of the piston 118

Figure 5-26. Measured heat flux data for $\mathrm{CR}=15.2$ and 12.5, and extrapolated heat flux for $\mathrm{CR}=10.600 \mathrm{rpm}$ motored condition

Figure 5-27. Calculated piston surface temperature for two convection boundary conditions

Figure 5-28. Nodes of 1-D FDM in the fuel film

Figure 5-29. Calculated mean fuel film temperatures for two convection boundary conditions and two initial fuel film temperature conditions $\left(70,100^{\circ} \mathrm{C}\right) \cdots \cdot 123$

Figure 5-30. Effect of engine speed on the convection heat transfer to the fuel film 124

Figure 6-1. Fluorescence intensity at four fiber locations for the mixture of isooctane and $2 \times 10^{-6} \mathrm{M}$ BTBP for motored condition at $600 \mathrm{rpm}$ 
Figure 6-2. Effect of droplet impingement on the fluorescence intensity during the fuel injection. Test was performed outside of the engine and the fuel was n-dodecane/BTBP

Figure 6-3. Formation of initial fuel slug on the surface $1 \mathrm{~ms}$ after the fuel injection

Figure 6-4. Schematic drawing of the fuel footprint observed after the engine test at $600 \mathrm{rpm}$

Figure 6-5. Shape of the fuel film $30 \mathrm{~ms}$ after isooctane injection for different surface temperatures (upper: $25^{\circ} \mathrm{C}$, lower: $72^{\circ} \mathrm{C}$ ). Injection duration was $3.6 \mathrm{~ms}$

Figure 6-6. Fluorescence intensity at four fiber locations for the mixture of isooctane and $2 \times 10^{-6} \mathrm{M}$ BTBP for fired condition at $600 \mathrm{rpm}$

Figure 6-7. Separated signals when the laser is turned on and off for fired condition at $600 \mathrm{rpm}$. Figure 6-6 shows the difference between the two signals (net fluorescence)

Figure 6-8. Comparison of the fluorescence intensity for motored and fired conditions at $600 \mathrm{rpm}$

Figure 6-9. Fluorescence intensity at four fiber locations for the mixture of isooctane and $2 \times 10^{-6} \mathrm{M}$ BTBP for motored condition at $1200 \mathrm{rpm}$

Figure 6-10. Fluorescence intensity at four fiber locations for the mixture of isooctane and $2 \times 10^{-6}$ M BTBP for fired condition at $1200 \mathrm{rpm}$

Figure 6-11. Comparison of the fluorescence intensity for motored and fired conditions at $1200 \mathrm{rpm}$

Figure 6-12. Fluorescence intensity at four fiber locations for the mixture of n-pentane and $2 \times 10^{-6} \mathrm{M}$ BTBP for motored condition at $600 \mathrm{rpm}$ 146

Figure 6-13. Fluorescence intensity at four fiber locations for the mixture of n-pentane and $2 \times 10^{-6} \mathrm{M}$ BTBP for motored condition at $1200 \mathrm{rpm}$

Figure 6-14. Fluorescence intensity at fiber 3 location for the mixture of n-decane and $2 \times 10^{-6} \mathrm{M}$ BTBP for motored condition at $600 \mathrm{rpm}$ 
Figure 6-15. Comparison of the measured fluorescence intensity and the calculated cumulative signal for thick fuel thicknesses. Fuel was a mixture of isooctane and 4\% 2,3-hexanedione

Figure 6-16. Fuel temperature and aging effects on the fluorescence intensity.

Fuel was a mixture of isooctane and 4\% 2,3-hexanedione

Figure 6-17. Fuel pressure effect on the fluorescence intensity. Fuel was a mixture of isooctane and $4 \%$ 2,3-hexanedione

Figure 6-18. Dopant co-evaporation test. Fuel was a mixture of isooctane and 4\% 2,3-hexanedione

Figure 6-19. Fuel film thickness at four fiber locations for the mixture of isooctane and 2,3-hexanedione for motored condition at $600 \mathrm{rpm}$

Figure 6-20. Fuel film thickness at four fiber locations for the mixture of isooctane and 2,3-hexanedione for fired condition at $600 \mathrm{rpm}$

Figure 6-21. Comparison of the fuel film thickness for motored and fired conditions at $600 \mathrm{rpm}$ for the mixture of isooctane and 2,3-hexanedione

Figure 6-22. Fuel film thickness at four fiber locations for the mixture of isooctane and 4\% 2,3-hexanedione for motored condition at $1200 \mathrm{rpm}$

Figure 6-23. Comparison of the fuel film thickness for motored and fired conditions at $1200 \mathrm{rpm}$ for the mixture of isooctane and 2,3-hexanedione

Figure 6-24. Fuel temperature and aging effects on the fluorescence intensity. Fuel was a mixture of isooctane and $4 \%$ biacetyl

Figure 6-25. Fuel film thickness for motored and fired conditions at $600 \mathrm{rpm}$ for the mixture of isooctane and $4 \%$ biacetyl

Figure 6-26. Fuel film thickness for motored and fired conditions at $1200 \mathrm{rpm}$ for the mixture of isooctane and $4 \%$ biacetyl 


\section{Nomenclature}

\begin{tabular}{|c|c|}
\hline$A_{1}$ & Surface area of fiber \\
\hline$A_{3}$ & Surface area of the illuminated circle at a distance $\mathrm{z}$ from the fiber surface \\
\hline $\mathrm{ABDC}$ & After BDC \\
\hline ATDC & After TDC \\
\hline$B$ & Bore of an engine \\
\hline $\mathrm{BDC}$ & Bottom dead center \\
\hline $\mathrm{BBDC}$ & Before BDC \\
\hline$B i$ & Finite-difference form of the Biot number \\
\hline BTDC & Before TDC \\
\hline$c_{p}$ & Specific heat at constant pressure $(\mathrm{J} / \mathrm{kg}-\mathrm{K})$ \\
\hline $\mathrm{CA}$ & Crank angle (degree) \\
\hline $\mathrm{COV}$ & Coefficient of variation \\
\hline$\dot{E}$ & Laser power \\
\hline EOI & End of injection \\
\hline EVC & Exhaust valve closing \\
\hline EVO & Exhaust valve opening \\
\hline Fo & Finite-difference form of the Fourier number \\
\hline$h_{c}$ & Convection heat transfer coefficient $\left(\mathrm{W} / \mathrm{m}^{2}-\mathrm{K}\right)$ \\
\hline$I^{*}$ & Gaussian intensity distribution function \\
\hline$\widetilde{I}_{1}$ & Cumulative signal \\
\hline IVC & Intake valve opening \\
\hline IVO & Intake valve closing \\
\hline$k$ & Thermal conductivity $(\mathrm{W} / \mathrm{m}-\mathrm{K})$ \\
\hline $\mathrm{L}$ & Stroke of an engine \\
\hline M & Molar concentration, Molarity (moles/liter) \\
\hline MAP & Manifold absolute pressure \\
\hline$N$ & Number density or Number of data or engine speed \\
\hline
\end{tabular}




$\begin{array}{ll}N A_{1} & \text { Numerical aperture of fiber } \\ \text { NMEP } & \text { Net mean effective pressure } \\ \mathrm{P}, \mathrm{p} & \text { Pressure } \\ \mathrm{P}_{\mathrm{L}} & \text { Laser power } \\ \text { PMT } & \text { Photomultiplier tube } \\ \mathrm{R} & \text { Distance between the differential area elements } d A_{3} \text { and } d A_{1} \\ r_{1} & \text { Radius of fiber } \\ \mathrm{rpm} & \text { Revolution per minute } \\ s & \text { Standard deviation } \\ \bar{S} & \text { Mean piston speed } \\ S_{1} & \text { Total signal collection for a single fiber } \\ s g & \text { Specific gravity } \\ \mathrm{ST} & \text { Spark timing } \\ \mathrm{T} & \text { Temperature } \\ \mathrm{T}_{\mathrm{bp}} & \text { Boiling point }\left({ }^{\circ} \mathrm{C}\right) \\ \mathrm{TDC} & \text { Top dead center } \\ w & \text { Average cylinder gas velocity } \\ X & \text { Mole fraction } \\ \Delta \bar{x} & \text { Uncertainty } \\ Z & \text { Normal distance from the fiber surface } \\ \widetilde{Z} & \text { Non-dimensional form of the normal distance from the fiber surface }\end{array}$

\section{Greek Letters}

$\alpha$

$\beta$

$\delta^{*}$

$\varepsilon$

$\phi$

$\eta$
Thermal diffusivity $\left(\mathrm{m}^{2} / \mathrm{s}\right)$

Angle of incidence between the differential element $d A_{1}$ and $d A_{3}$

Collection function of the fiber. 0 for $\beta>\theta_{1}$ or 1 for $\beta<\theta_{1}$

Molar extinction coefficient

Fluorescence quantum efficiency

Detection efficiency 


$\begin{array}{ll}\mu & \text { Mean value } \\ \theta & \text { Spray Cone angle } \\ \theta_{1} & \text { Angle of acceptance defined by the } N A_{1} \text { of the fiber } \\ \rho & \text { Density } \\ \sigma_{a b s} & \text { Absorption cross-section } \\ \Phi & \text { Equivalence ratio } \\ \Omega_{r e f, 1} & \text { Reference collection solid angle } \\ \Omega_{1}^{*} & \text { Modified collection solid angle } \\ \widetilde{\Omega}_{1} & \text { Non-dimensional form of the modified collection solid angle }\end{array}$

\section{Subscripts}

1 Indicating the fiber

3 Illuminated circle at a distance $z$ from the fiber surface

L Surface (interface) condition

$m \quad$ Node number index in the FDM

p Piston

ref Reference

$\infty \quad$ Free stream condition

\section{Superscripts}

$p \quad$ Previous time in transient FDM

$p+1 \quad$ New time in transient FDM 


\section{Chapter 1}

\section{Introduction}

\section{1-1. Motivation}

Direct-injection spark-ignition (DISI) engines received a great deal of attention during the 1990s, although the concept was first introduced during the 1920s. The main cause of the interest is the significant potential for fuel economy improvement, especially at part load, with the additional benefit of low $\mathrm{CO}_{2}$ emissions. The improved fuel economy of the DISI engine comes from the ability to run the engine at overall lean conditions by realizing mixture stratification within the combustion chamber. This leads to unthrottled operation of the engine at part loads, and reducing the pumping losses in DISI engines. Furthermore, fuel injection during the compression stroke reduces the mixture temperature before combustion. This reduces the occurrence of knock and allows the compression ratio to increase from one to two points, thereby the thermal efficiency is also improved. Overall, it is reported that 
DISI engines can improve the fuel economy more than $30 \%$ at part loads [Iwamoto et al., 1997]. Furthermore, with early injection at higher loads, the engine volumetric efficiency is increased by the charge cooling mechanism.

In spite of the advantages of DISI engines, they are not applied extensively until now because of the higher hydrocarbon (HC) and oxides of nitrogen (NOx) emissions than port fuel injection (PFI) engines. For NOx, the engine-out emissions are lower than PFI engines because of the overall lean operation and the use of exhaust gas recirculation (EGR) system. However, the tailpipe emissions are much higher because the conversion efficiency of the lean NOx converter is extremely low. Currently, active research is focused on developing more efficient lean NOx converters.

The HC emissions from DISI engines are higher than PFI engines at charge stratified operation. The main causes of high HC emissions known today are the flame quenching at the lean outer boundaries of the stratified zones, and fuel wetting on the piston crown and cylinder walls [Hudak and Ghandhi, 1999; Casarella and Ghandhi, 1998; Stanglmaier and Matthews, 1999]. Almost all DISI engines developed until now have adopted the wall-guided spray delivery system. The fuel is injected toward the piston crown and the vaporized fuel is guided to the spark plug with the help of a cavity on the piston and air motion. Significant fuel wetting on the piston top is unavoidable for these types of DISI engines. Recent research has shown that the fuel impinged to the piston crown does not evaporate completely before combustion, and can survive during or after the expansion stroke, and is exhausted as unburned and partial-burned HC [Hudak and Ghandhi, 1999; Alger et al., 2001; Stevens and Steeper, 2000]. 


\section{1-2. Objective}

The objective of this research is to develop a method to quantify the fuel film thickness on the piston crown of a wall-guided type DISI engine when the engine is operated at a stratified condition. The fuel film temperature, which is required for inferring the fuel film thickness, is to be measured at the same condition. Measurements of the fuel film thickness are required to understand the fuel film evaporation phenomena during the engine cycle. These measurements will aid in the analysis of trends of fuel film vaporization from the piston crown, and its effect on HC emissions seen in the literatures.

\section{1-3. Method}

Fuel film thickness was measured on a piston crown of a DISI engine by using an optical fiber-based Laser-Induced Fluorescence (LIF) technique. In this research, optical fibers were mounted flush on the surface of the piston crown and they were connected to the optical setup installed outside of the engine through a mirror passage of the see-through engine. The $457.9 \mathrm{~nm}$ argon-ion laser was introduced to the piston crown through the optical fiber to excite fluorescence from the fuel that impinges on the piston crown. The fluorescence signal was returned through the same fiber, and the intensities were measured using a photomultiplier tube (PMT). The fuel used was isooctane and a liquid dopant, 2,3hexanedione or 2,3-butanedione (biacetyl), was added because isooctane does not fluoresce 
at the chosen wavelength. The measured fluorescence intensity was converted to the fuel film thickness through the equations based on photophysics and the optical properties of the fiber. The absorption cross-section and fluorescence quantum efficiency, which are a function of the fuel temperature, were calibrated before the thickness calculation in a calibration device.

To calculate the fuel film thickness the fuel film temperature, which could be different from the piston temperature, is needed. It was measured by adopting a fluorescencebased liquid-phase thermometry. The dopant used for the method was BTBP [N,N'-bis(2,5di-tert-butylphenyl)-3,4,9,10-perylenedicarboximide] and it was excited with a $488 \mathrm{~nm}$ argon-ion laser through the same fibers used in the fuel film thickness measurement test. The fluorescent spectra of BTBP shifts according to the change in temperature, and this phenomenon was used to determine the fuel film temperature by measuring the fluorescence at two selected wavelengths. 
Chapter 2

\section{Literature Review}

This chapter starts with the introduction of several variations of direct-injection spark-ignition (DISI) engines from the Texaco controlled-combustion system (TCCS), one of the original implementations, to the modern production engines. The emission characteristics of DISI engines are then reviewed and compared with conventional port fuel injection (PFI) engines. The effect of fuel impingement on $\mathrm{HC}$ and particulate emissions is presented, and finally, fuel film thickness and temperature measurement techniques are surveyed. This is focused on the laser-induced fluorescence (LIF) and fiber optic fluorescence techniques, which are directly related to this research. 


\section{2-1. Direct-Injection Spark-Ignition (DISI) Engines}

The resurgence of interest in DISI engines during the nineties was mainly due to its ability to improve fuel economy. Mixture stratification around the spark plug enables extremely lean operation up to overall air-fuel ratio of 50:1. The potential for fuel economy improvement comes from the possibility of unthrottled operation during part load conditions, which reduces the pumping losses of the engine. However, for production engines throttle control is necessary at partial loads to provide intake vacuum for EGR and brake boost, to increase the exhaust gas temperature for the proper function of the catalytic converter, and to prepare homogeneous mixture for cold starting [Harada et al., 1997].

Most of the recent DISI engine systems have applied the multi-mode fuel injection scheme. At partial loads, fuel is injected during the compression stroke (late injection) just before the spark ignition to improve the fuel stratification. A homogeneous mixture is preferred at the higher loads and fuel is injected during the intake stroke (early injection) to provide enough time for evaporation and mixing.

Higher volumetric efficiency and anti-knock characteristics are obtained through the early injection because of the charge cooling by the injected fuel. Another advantage of DISI engines is the higher acceleration response and superior transient drivability even under cold temperature conditions because of the direct fuel injection into the cylinder rather than to the valves and port walls as in conventional multi-point port fuel injection (PFI) engines. However, there are some difficulties as listed below that have to be solved to realize the introduction of the DISI engines [Harada et al., 1997]. 
- Preparing suitable stratified mixture around the spark-plug over the wide range of engine operating conditions

- Soot formation caused by the fuel rich mixture

- High unburned and partially-burned hydrocarbon (HC) emissions caused by the flame quenching and wall wetting of the injected fuel

- High NOx emissions during the stratified charge operations

- $\quad$ Spark-plug fouling

Different types of DISI engines have been developed that have realized improvement in fuel economy and comparable emissions levels compared with the conventional multipoint PFI engines. The various DISI systems can be classified as shown in Figure 2-1 on the basis of their mixture formation and stratification strategies. The Texaco and Orbital systems can be categorized as a jet-controlled system. The distance between the fuel injector and spark plug is short (narrow spacing) for the jet-controlled system compared with the other systems. Japanese companies such as Mitsubishi, Toyota, and Nissan have incorporated the wall-controlled system, and FEV has applied the charge motion controlled system. The comparison of the specifications of each system is summarized in Table 2-1 and detailed system features are presented in the rest of this section. 
Table 2-1. Comparison of the specifications of different DISI engine systems.

\begin{tabular}{|c|c|c|c|c|c|c|c|}
\hline & \multirow{2}{*}{$\begin{array}{c}\text { Mitsubishi } \\
\text { GDI }\end{array}$} & \multicolumn{2}{|c|}{ Toyota } & \multirow{2}{*}{ Nissan } & \multirow{2}{*}{ FEV } & \multirow{2}{*}{$\begin{array}{c}\text { Orbital } \\
\text { OCP }\end{array}$} \\
\hline & & & D-4 & NCP & & & \\
\hline \multicolumn{2}{|c|}{ Displacement (cc) } & 1834 & 1998 & 1998 & 1998 & $\mathrm{n} / \mathrm{a}$ & 1796 \\
\hline \multicolumn{2}{|c|}{ Bore x Stroke $(\mathrm{cm})$} & $81 \times 89$ & $86 \times 86$ & $86 \times 86$ & $86 \times 86$ & $\mathrm{n} / \mathrm{a}$ & $80 \times 88$ \\
\hline \multicolumn{2}{|c|}{ Cylinder Type } & Inline 4 & Inline 4 & Inline 4 & Inline 4 & $\mathrm{n} / \mathrm{a}$ & Inline 4 \\
\hline \multicolumn{2}{|c|}{ Compression Ratio } & 12 & 10 & 10.3 & 10.5 & $\mathrm{n} / \mathrm{a}$ & 10.4 \\
\hline \multicolumn{2}{|l|}{ Valves } & $4 \mathrm{~V}$ & $4 \mathrm{~V}$ & $4 \mathrm{~V}$ & $4 \mathrm{~V}$ & $4 \mathrm{~V}$ & $4 \mathrm{~V}$ \\
\hline \multirow{2}{*}{$\begin{array}{l}\text { Fuel } \\
\text { system }\end{array}$} & Injector & Swirl & Swirl & Slit nozzle & $\begin{array}{l}\text { Hollow } \\
\text { cone spray }\end{array}$ & $\mathrm{n} / \mathrm{a}$ & $\begin{array}{c}\text { Air- } \\
\text { assisted }\end{array}$ \\
\hline & Pressure & 50 bar & 120 bar & 120 bar & 70 bar & $\mathrm{n} / \mathrm{a}$ & 6.5 bar \\
\hline \multicolumn{2}{|c|}{ Charge motion } & $\begin{array}{l}\text { Reverse } \\
\text { Tumble }\end{array}$ & Swirl & - & Swirl & Tumble & - \\
\hline \multicolumn{2}{|c|}{$\begin{array}{l}\text { Exhaust emission } \\
\text { control }\end{array}$} & $\begin{array}{l}\text { Electric EGR } \\
\text { Lean-NOx } \\
\text { Catalyst }\end{array}$ & $\begin{array}{l}\text { EGR } \\
\text { NOx Storage- } \\
\text { Release } \\
\text { Catalyst }\end{array}$ & $\begin{array}{l}\text { EGR } \\
\text { NOx Storage- } \\
\text { Release } \\
\text { Catalyst }\end{array}$ & EGR & $\begin{array}{l}\text { EGR } \\
\text { NOx-- } \\
\text { adsorber }\end{array}$ & EGR \\
\hline \multicolumn{2}{|c|}{ Production (year) } & 1996 & 1996 & - & Prototype & - & - \\
\hline \multicolumn{2}{|c|}{ References } & $\begin{array}{l}\text { Iwamoto } \\
\text { et al. (1997) }\end{array}$ & $\begin{array}{l}\text { Harada et al. } \\
\quad \text { (1997) }\end{array}$ & $\begin{array}{l}\text { Kanda et al. } \\
\quad(2000)\end{array}$ & $\begin{array}{l}\text { Takagi } \\
\text { et al. } \\
(1998)\end{array}$ & $\begin{array}{l}\text { Geiger et al. } \\
\text { (1999) }\end{array}$ & $\begin{array}{c}\text { Houston } \\
\text { et al. } \\
(1998)\end{array}$ \\
\hline
\end{tabular}

1) ' - ' means not applicable

2) $n / a$ means not available 


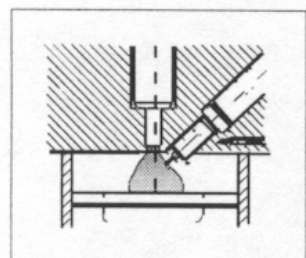

Jet Controlled

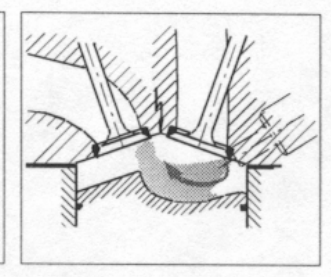

Wall Controlled

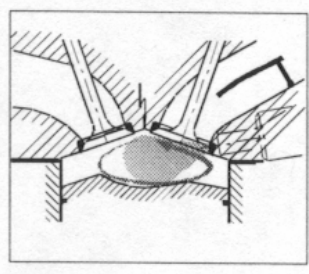

Charge Motion

Figure 2-1. Combustion system classification of DISI engines [Geiger et al., 1999].

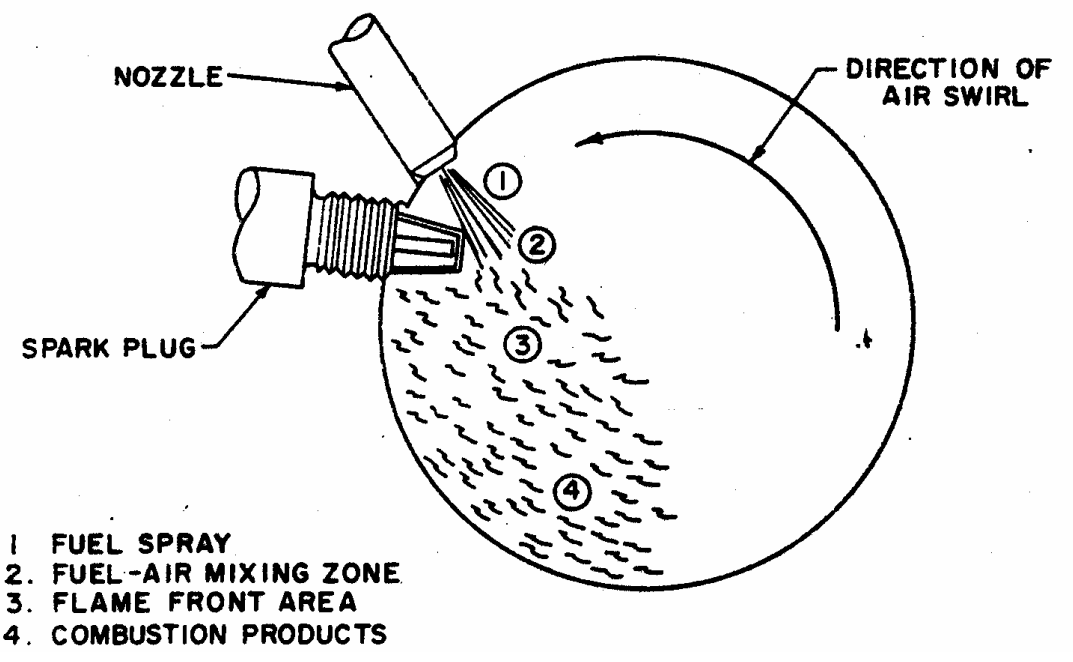

Figure 2-2. Texaco Controlled-Combustion System [Mitchell and Alperstein, 1973]. 


\section{2-1-1. TCCS}

The Texaco controlled-combustion system (TCCS) is a representative early directinjection stratified-charge engine developed before 1990 in which the engine components, sensors and electronic controls were not available to accommodate the combustion mode switching strategy between homogeneous and stratified combustion. The concept of the TCCS is illustrated schematically in Figure 2-2. The fuel is injected from the nozzle, which is located close to the spark plug, into the swirling airflow near the end of the compression stroke. The first increment of the fuel is ignited to establish a flame front immediately downstream from the nozzle. As injection continues, additional mixture is supplied to the flame front and burned nearly as rapidly as it is formed. The TCCS engine adopted a mechanical-type nozzle, which cannot be adjusted for the dual mode operations. Therefore, the mixing process at higher power conditions could not achieve air utilization as high as that available through premixing, and full load was restricted by the exhaust smoke limit.

The L-141 engine had four cylinders with a displacement of 2,320 cc. The bore size was $98.4 \mathrm{~mm}$ and stroke was $76.2 \mathrm{~mm}$. The compression ratio was $10: 1$ for a naturally aspirated configuration. This system achieved good fuel economy, improved cold startability, and better response with lower exhaust emissions [Mitchell et al., 1973]. However, spark plug fouling caused by the narrow spacing between the spark plug and the nozzle, and relatively high emissions compared with the modern gasoline engines prevented the widespread application of this system. 


\section{2-1-2. Mitsubishi}

Mitsubishi started the production of GDI (Gasoline Direct Injection) engines in 1996 and it marked the first mass production of DISI engines in the world. The GDI engine applied a wide spacing strategy to reduce the spark plug fouling problem, which had hindered the previous DISI engine systems. They also introduced the rapid switching scheme over the combustion modes, stratified and homogeneous, for the first time, which was not feasible until then because the mechanical injectors had been used. Stratified combustion was applied at partial loads to realize high fuel economy by injecting fuel during the compression stroke. At higher loads, the fuel was injected during the intake stroke to obtain increased full load performance by homogeneous combustion [Kume et al., 1996]. The schematic view of each combustion mode is shown in Figure 2-3.

To realize the stable stratified combustion, an upright straight intake port, electromagnetic swirl injector and spherical compact piston cavity were adopted. The upright straight intake port was adopted to generate reverse tumble to direct the fuel spray to the spark plug and to make enough space for the optimal injector positioning. The spherical compact piston cavity enhances the reverse tumble motion and guides the fuel spray to the spark plug. The swirl injector was optimized to make the required spray pattern for both late and early injection periods [Iwamoto et al., 1997]. Figure 2-4 shows the fuel spray pattern at low and high ambient pressure. A widely spread fuel spray is ideal for early injection and a

compact spray is required for late injection, and these targets were met by the inherent characteristics of the interaction between the fuel spray and the ambient air. 


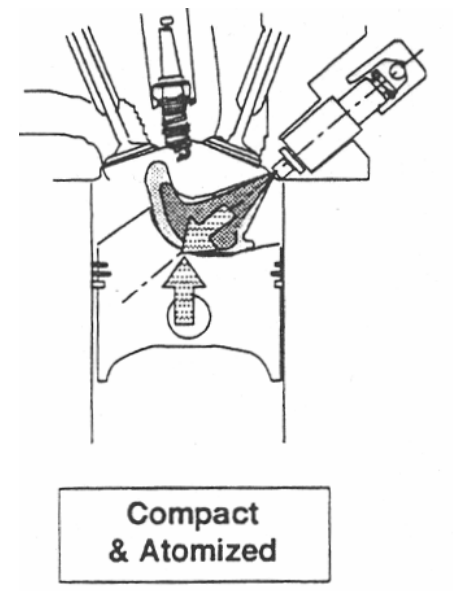

(a) Late Injection

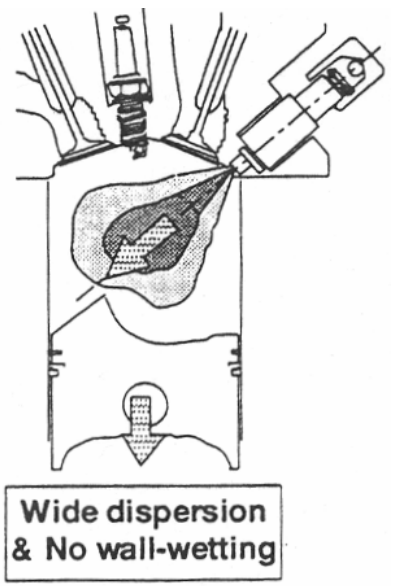

(b) Early Injection

Figure 2-3. Behavior and the requirements of the fuel spray characteristics for each combustion modes [Kume et al., 1996].

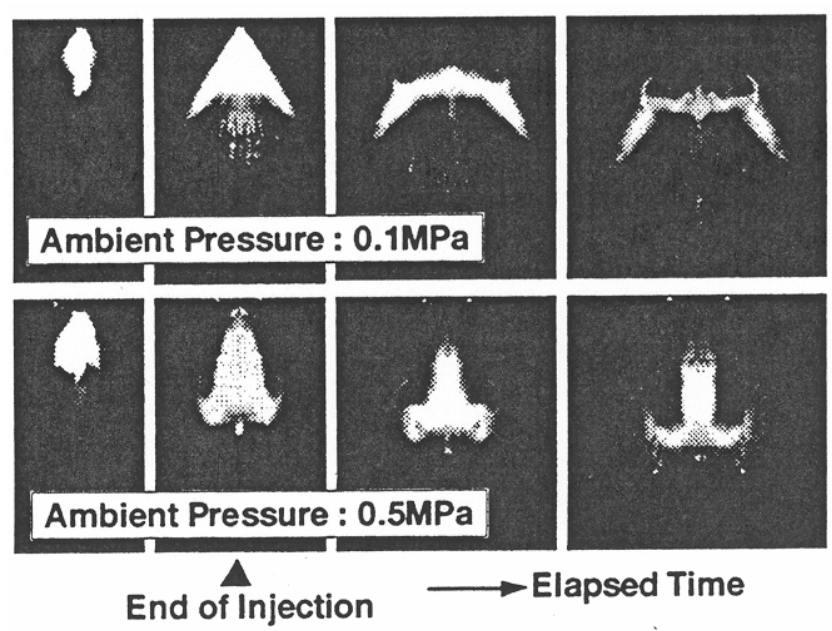

Figure 2-4. Fuel spray pattern at different ambient pressures [Iwamoto et al., 1997]. 
At partial loads, stable combustion was obtainable up to the air-fuel ratio of 40:1 and the fuel economy was increased $40 \%$ at partial load conditions compared with the base MPI engine. The full load performance was also improved $10 \%$ at all speed ranges. This was realized by the increased flow coefficient caused by using the upright straight intake port and the charge cooling incurred by the spray, which resulted in the increased volumetric efficiency and a large margin for spark timing advance. Charge cooling also enabled the increase in the compression ratio up to 12:1 compared with 10.5:1 of the base multi-point PFI engine. From droplet size measurements, large droplets with the SMD (Sauter Mean Diameter) exceeding $30 \mu \mathrm{m}$ existed at the center of the fuel spray. These droplets are captured by the piston cavity and do not travel to the spark plug. These droplets are evaporated on the high temperature piston surface, but some of them will be exhausted as unburned hydrocarbon emissions.

\section{2-1-3. Toyota}

The schematic view of the Toyota's D-4 DISI engine combustion chamber configuration [Harada et al., 1997] is shown in Figure 2-5. It adopted the intake port with swirl control valve (SCV) and helical port, high-pressure swirl injector, and piston with involute-shaped concave combustion chamber for the formation of the stratified mixture at the stratified-charge combustion mode. The injected fuel is guided to the spark plug through the wall of the involute-shaped combustion chamber and the flows are enhanced by the swirl, which is optimally controlled by the SCV according to the engine conditions. Three types of injection control modes are employed for different combustion conditions as shown in Figure 2-6. At partial loads, stratified-charge combustion was applied to improve the fuel economy 


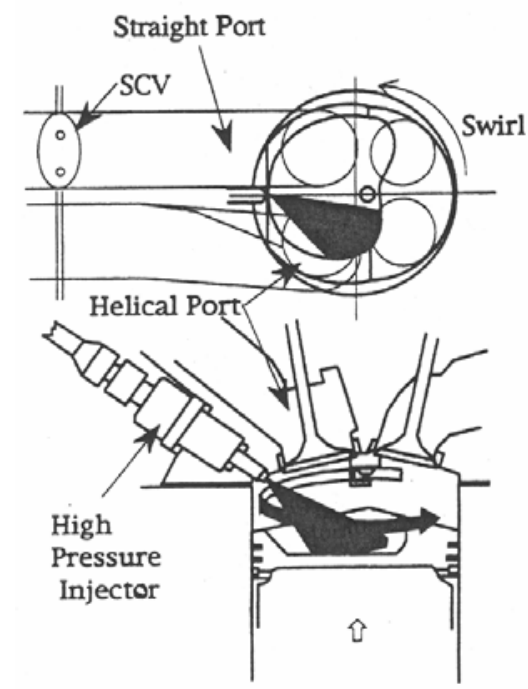

Figure 2-5. Schematic view of the Toyota D-4 combustion chamber configuration [Harada et al., 1997].

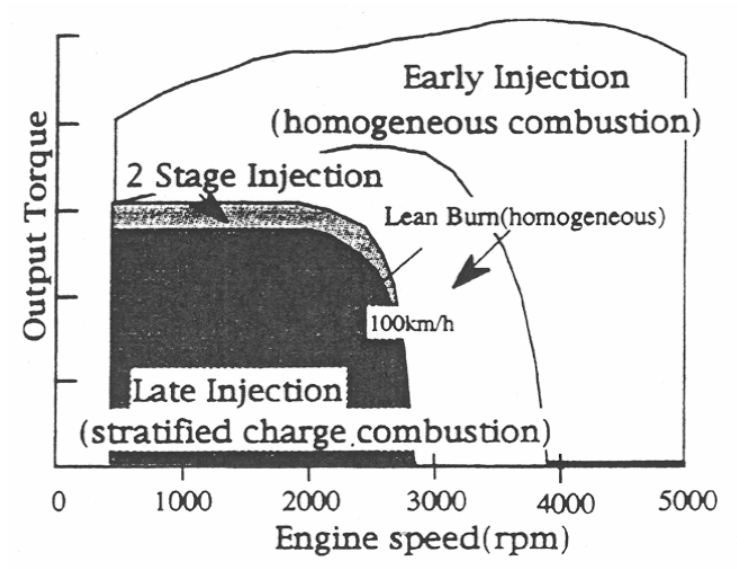

Figure 2-6. Combustion strategy of Toyota direct injection system [Harada et al., 1997]. 
and late injection was needed to achieve this goal. A homogeneous combustion mode was applied for the higher load conditions and the fuel was injected during the intake stroke to improve the homogeneity and vaporization of the mixture. Two-stage injection, in which fuel was supplied during the intake and compression stroke, was used between the stratified and homogeneous charge operations to provide a smooth torque transition.

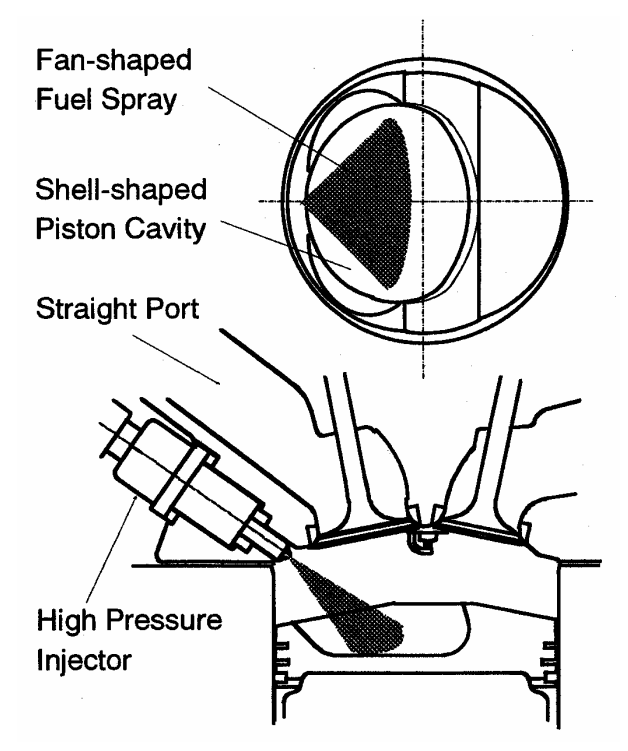

Figure 2-7. Fuel spray and piston cavity configuration of Toyota NCP [Kanda et al., 2000].

To improve the engine performance at higher load conditions, which was partially deteriorated by the helical port, a new stratified charge combustion system, New Combustion Process (NCP), has been developed [Kanda et al., 2000; Koike et al., 2000]. This system applied a fan-shaped fuel spray and a combustion chamber with a shell-shaped cavity in the piston as shown in Figure 2-7. The system does not require distinct charge motion such as tumble or swirl. Therefore, the swirl control valve (SCV) and helical port, which were adopted for the D-4 engine, were not applied to increase the higher load performance. The 
slit nozzle was optimized to make a thin fan-shaped spray, which has been proven to be more efficient for the formation of homogeneous mixtures. Through the optimization of the NCP system, Toyota achieved an improved fuel economy at partial loads, enlarged stratified combustion operating ranges, reduced emissions, and increased engine torque at full load engine conditions.

\section{2-1-4. Nissan}

The schematic drawing of Nissan prototype DISI engine is shown in Figure 2-8. It applied the same straight intake port as in the conventional MPI engine for high power output [Takagi et al., 1998]. A swirl control valve, which provides a maximum swirl ratio between 3 and 3.5, was incorporated for part load operations. The spark plug was positioned at the center of the combustion chamber. A round bowl was provided in the piston crown eccentrically to the intake valves. The injector was installed below the two intake ports at an angle of $36^{\circ}$ from the horizontal. The angle was chosen to balance wall wetting between cylinder wall and piston crown. The injector provided a hollow cone spray and the spray cone angle is $70^{\circ}$ at the fuel pressure of 100 bar.

The engine was stable up to an air-fuel ratio of 40:1 and the fuel consumption was reduced by more than $20 \%$ at the stratified-charge operation. The power at wide-open throttle operation was improved approximately $10 \%$ when the flat top piston was applied. When the round bowl was provided in the piston crown to facilitate stratified-charge combustion, the power improvement was reduced to $5 \%$. The reason was estimated to be the deterioration of 
mixture formation because some of rich mixture was trapped in the bowl, and intake air motion was suppressed by the bowl.

A wide spray cone angle was necessary for homogeneous charge combustion under high load operation. However, a smaller spray cone angle was required for stratified charge combustion in order to reduce excessive diffusion. A smaller spray cone angle was achieved by increasing the amount of the initial center spray, which was the amount of fuel present within $20^{\circ}$ spray angle. This made the pressure difference higher between the center of the spray and the outer air because the velocity at the center of the spray was higher for higher amounts of sprays. It makes the spray cone angle smaller especially at high ambient pressure because the pressure difference is proportional to the density of the air and the square of the air velocity.

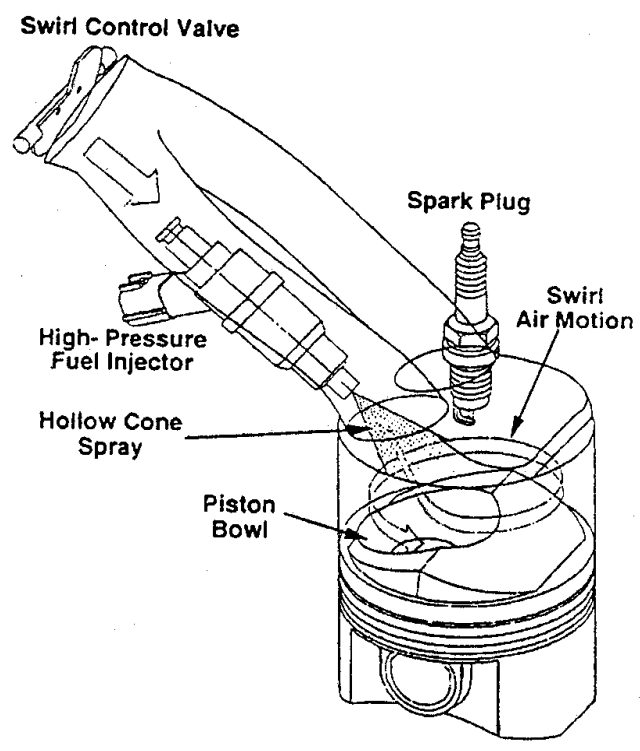

Figure 2-8. Nissan direct injection gasoline engine [Takagi et al., 1998]. 


\section{2-1-5. Orbital}

Orbital Engine Company has applied their stratified combustion system, originally developed for two-stroke applications, to four-stroke engines. The major features of the Orbital Combustion Process (OCP) can be summarized as follows [Houston et al., 1998].

- Low-pressure air-assisted fuel injection system mounted centrally in the cylinder head

- Spark-plug with extended electrode mounted close to the injector (narrow spacing)

- Customized piston bowl geometry to enhance fuel charge containment and stratification The low-pressure air-assisted fuel injector is comprised of an outwardly opening direct injector, a conventional multi-point fuel injector, and an interface region, which provides the path between the air and fuel as shown in Figure 2-9. The fuel is metered and delivered to the top of the air injector by a conventional multi-point fuel injector with a constant differential pressure of normally 1.0 to 1.5 bar. With some dwell time (typically 1.5 to $10 \mathrm{~ms}$ ) after the fuel metering, the fuel and air mixture is injected into the combustion chamber through the direct injector at the regulated air pressure of 6.5 bar gauge. Since the fuel-metering event is de-coupled from the direct injection event, the mass flux of injected fuel is not constant throughout the injection duration. And it results in a comparatively lean mixture toward the end of the injection event. This characteristic dramatically reduces the air-fuel ratio gradient near ignition timing, resulting in improved robustness.

The spray is highly optimized with a SMD of approximately $10 \mu \mathrm{m}$. These small particle sizes enable very fast evaporation of the fuel, minimizing the need for further preparation time inside the cylinder. Furthermore, the air-assisted injection system is able to maintain very small particle size with minimal pressure differences, enabling the system to 


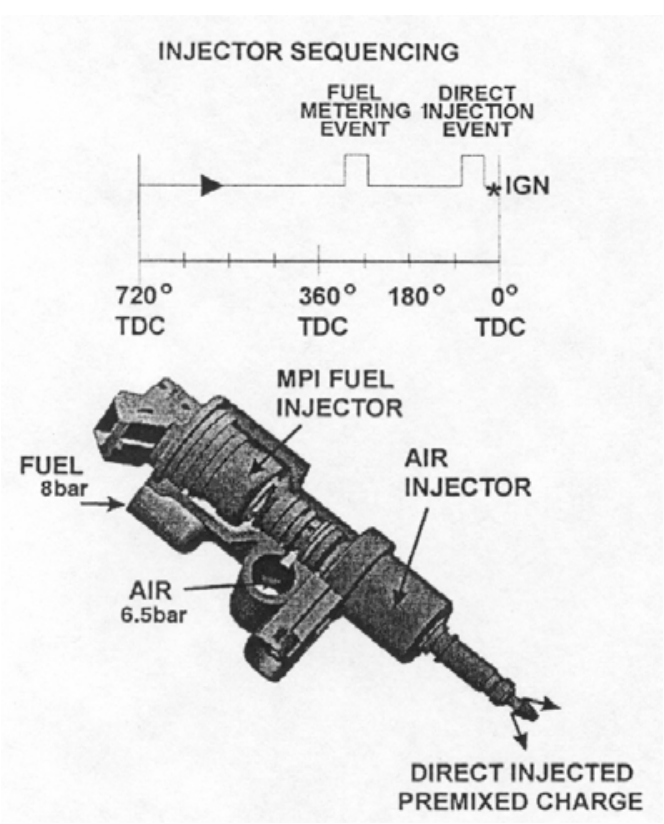

Figure 2-9. Schematics of Orbital's airassisted fuel injection system [Cathcart and Zavier, 2000].

maintain good charge preparation even at very late injection timings. These features enable the OCP to operate with no spark plug fouling problems and without the introduction of additional swirl or tumble motion. In order to minimize wall wetting and maximize stratification at partial loads, a low penetration and low dispersion spray is desired. This is an inherent quality of the low-pressure air-assisted injection system. This spray characteristic is transformed into a highly penetrating spray at early injection timings when the homogeneous combustion is essential for maximum engine performance.

\section{2-1-6. FEV}

Geiger et al. (1999) proposed a charge motion controlled combustion system as shown in the schematic cross-section of the combustion chamber in Figure 2-10. At stratified operation, the mixture formation and charge stratification is controlled by the tumble flow, 
which is generated by a continuous variable tumble system (CVTS) mounted at the intake port entry. The fuel is injected into the center of the combustion chamber and closer to the spark plug, although this does not result in a direct spray toward the electrodes. Then the spray is guided to the spark plug through the charge motion. The distance between the injector and the spark plug is large enough for the fuel to evaporate before ignition. This system minimizes wall wetting compared with the wall-controlled systems such as Mitsubishi and Toyota. The system is not sensitive to the variations of tumble intensity; therefore, the continuous control of the tumble according to the operating conditions is not needed. And stable combustion is possible up to high speed and high load conditions compared with the other systems. The CVTS is deactivated at homogeneous operation to allow high volumetric efficiency at full load condition. The compact combustion chamber design, coupled with the central spark plug position, resulted in good full load performance.

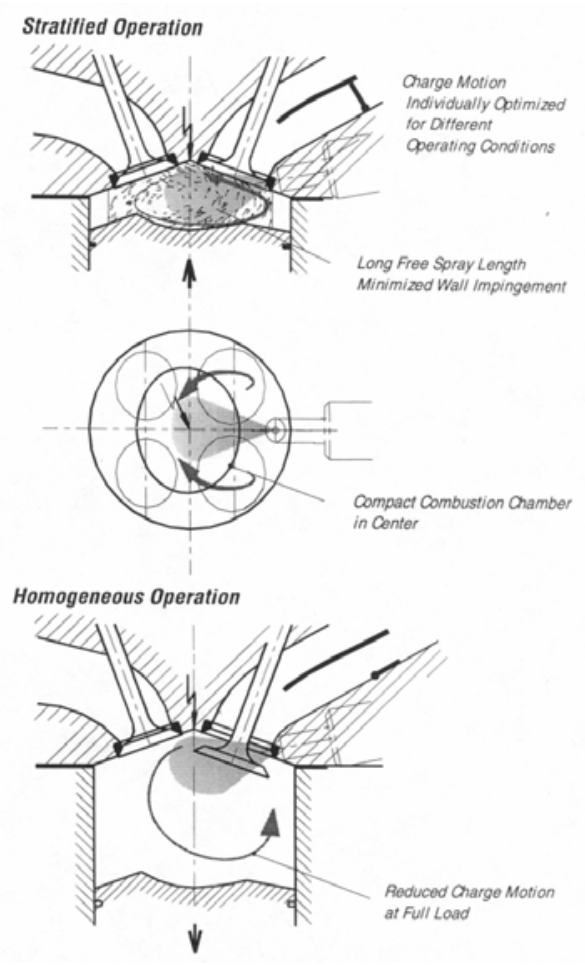

Figure 2-10. FEV charge motion controlled combustion system [Geiger et al., 1999]. 


\section{2-2. Emissions from DISI Engines}

The potential for fuel economy improvement of DISI engines is significant, and is comparable to high-speed direct-injection diesel engines [Borman and Ragland, 1998]. This potential comes primarily from the optimum design of the combustion system and delicate control of injection for late injection operation. DISI engines are characterized by direct injection of fuel to the combustion chamber, and stratified overall lean fuel distribution. However, these characteristics give rise to the potential for higher engine-out hydrocarbon (HC) and particulate emissions.

Giovanetti et al. (1983) found that HC emissions from several different DISI engines were especially high at light loads regardless of their engine speeds and proposed $\mathrm{HC}$ emissions mechanisms at light loads in a DISI engine. The combustion system used for the research was a similar to the TCCS having a cylindrical combustion chamber. One mechanism suggested was the fuel wetting on the cylinder head and piston cup. The fuel injected during the opening and closing of the injector had low momentum. Some of this fuel escaped the primary combustion zone and was trapped near the cylinder head. Furthermore, the large droplets injected during the main injection event impinged on the piston crown. The fuel on the cylinder head and piston cup evaporated and mixed with the bulk cylinder gas after combustion, but they could not ignite spontaneously because of the low temperatures caused by low heat release at light loads, and hence exhausted as $\mathrm{HC}$ emissions. Another possible mechanism was that small droplets distributed inside the piston cup evaporated and mixed with air beyond lean limit of combustion. This lean quenching also caused HC emissions. However, Giovanetti et al. could not quantify the relative importance of each 
mechanism. Also, how the relative significance of each mechanism changes with respect to different DISI engine concepts was unknown.

Engine-out emission measurements from the production Mitsubishi DISI engine were performed by Kaiser et al. (1999) and Maricq et al. (1999) for a number of operating parameters. Maricq et al. (1999) found that the particulate number emissions increase about a factor of 10-40 as the operating mode changed from homogeneous to stratified operation. Kaiser et al. (1999) investigated the regulated emissions (total HC, NOx and CO) and speciated $\mathrm{HC}$ emissions (by components analysis). The results of EOI swing test showed that all the regulated emissions vary sharply over small changes in EOI over the range from high to low stratification, suggesting that emissions are very sensitive to the evaporation, mixing, and motion of the stratified fuel cloud prior to ignition. The low $\mathrm{HC}$ emissions in some highly stratified regimes were accompanied by high level of particulate emissions [Maricq et al., 1999]. They postulated that a potential increase in HC emissions at high stratification was suppressed in part because potential HC emissions are exiting the engine as soot. From the speciated $\mathrm{HC}$ emissions analysis at the high stratification regime, they found a significant increase of olefin products, which are the major intermediate exhaust HC products from the partial combustion of paraffinic fuels. In this regime, the contributions of unburned paraffinic fuel components on $\mathrm{HC}$ emissions were low. Olefin products are formed by bulk quenching near the edge of stratified regions during stratified operation. It is also possible that the unburned fuel portion will decrease at higher stratification since less fuel is present in the overly lean regions. An increase in stratification will also reduce the amount of fuel stored in engine crevices, which contribute to $\mathrm{HC}$ emissions. 
The engine speed swing test at low stratification - homogeneous mode - showed that the $\mathrm{HC}$ emissions decrease while the NOx emissions increase for higher engine speeds. It is a typical trend of homogeneous charge PFI engines. However, the trend was opposite at high stratification. That is, the $\mathrm{HC}$ emissions were increased while the NOx emissions were decreased for higher engine speeds. This observation suggests that charge motion changes as the speed increases, possibly altering the average equivalence ratio and, therefore, peak combustion temperature, in the stratified region where combustion occurs.

From the parametric experiments, it was found that the combustion process in a DISI engine is strongly influenced by details of the fuel cloud evolution, including evaporation of liquid fuel, mixing, and the inlet air motion. This complex interaction, which affects the ignition and combustion processes, exerts a major influence on the engine-out emissions. The emissions trends, particularly for stratified operation, were very different from those observed in PFI engines.

Brehob et al. (1998) performed HC emissions tests for two types of DISI engines at a part load condition (1500 rpm/2.62 bar BMEP). The results for different air-fuel ratios are shown in Figure 2-11. Engine-A used the air-assisted injection system of Orbital to the base port fuel injection engine with no significant changes, and Engine-L was the Mitsubishi GDI engine. The specifications of the engines are summarized in Table 2-1. For Engine-A, the HC emissions of direct injection engines were higher than those of the PFI engine even for homogeneous operation. This may be due to fuel droplets and vapor clouds being forced into the vicinity of the piston surface, hence leading to hydrocarbons that are insufficiently mixed with air until late in the expansion stroke. For stratified combustion, the $\mathrm{HC}$ emissions were 
increased as the air-fuel ratio was increased. However, at the highest air-fuel ratio of 39 , the enhanced mixing caused the fuel cloud to disperse and lead to over-mixing causing high $\mathrm{HC}$ due to flame quenching. Engine-L also exhibited an increase in $\mathrm{HC}$ for the stratified modes compared with homogeneous operations. EGR reduced hydrocarbon emissions under some stratified conditions. This was in contrast to homogeneous operation in which EGR has a small negative effect on $\mathrm{HC}$ emissions. It was caused by the increase of air charge temperature aiding vaporization and mixing although EGR addition decreased the exhaust temperature.

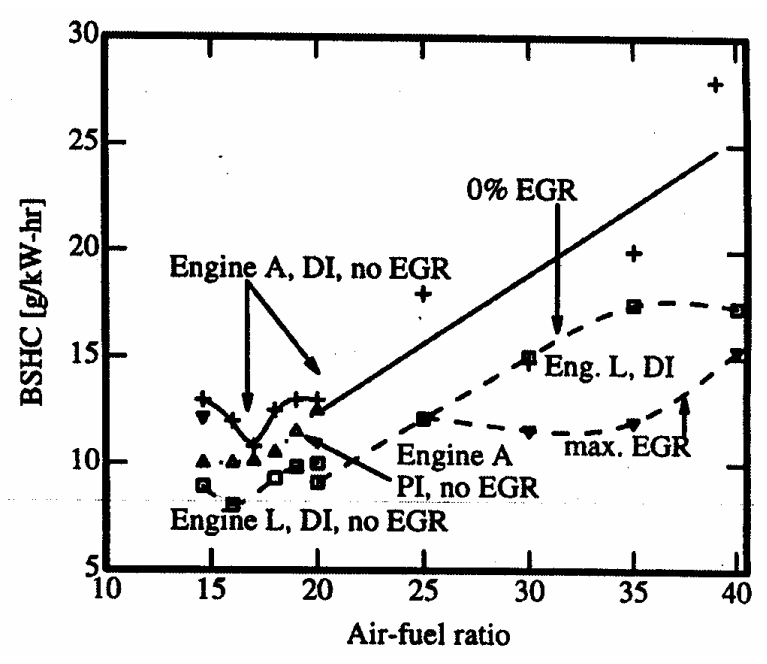

Figure 2-11. BSHC emission as a function of air-fuel ratio at 1500rpm, 2.62 bar BMEP, and MBT spark timing [Brehob et al., 1998].

The fuel economy and emissions from the vehicles, equipped with production DISI engines, were investigated by Cole et al. (1998) and Stovell et al. (1999). The specifications of the test vehicles, fuel economy, and tailpipe emission results are summarized in Table 2-2. Tests were performed on EPA's FTP-75 and highway fuel economy cycles. The vehicles were developed for the Japanese market where the emission regulations are less stringent 
than in the US. The emission results showed that NMHC (non-methane HC) and NOx could not meet the Tier II standards although $\mathrm{CO}$ did meet the regulation. Furthermore, the legislative regulations are for 50,000 and 100,000 miles and the Deterioration Factor (DF), which is greater than 1 , should have been considered in the tests for comparison. It seems that there remain challenges for the reduction of $\mathrm{HC}$ and $\mathrm{NOx}$ in both DISI engines. Especially, the conversion efficiency of the NOx catalytic converter was extremely low compared with the conventional PFI engines caused by the lean operation. The fuel economy results of Mitsubishi were compared with the same class vehicle, 2.0L Dodge Neon [Cole et al., 1998]. The fuel economy improvement was $22 \%$ for FTP-75 cycle and $24 \%$ for highway fuel economy cycle. However, the results of Toyota compared with the Corolla, which equipped with PFI engine calibrated for the US market, showed only $7 \%$ and $4 \%$ fuel economy improvement at each cycle [Stovell et al., 1999]. The lower improvements than the potential of the DISI engines are closely related with the penalty to reduce the emissions. 
Table 2-2. Specifications of the test vehicles and the test results.

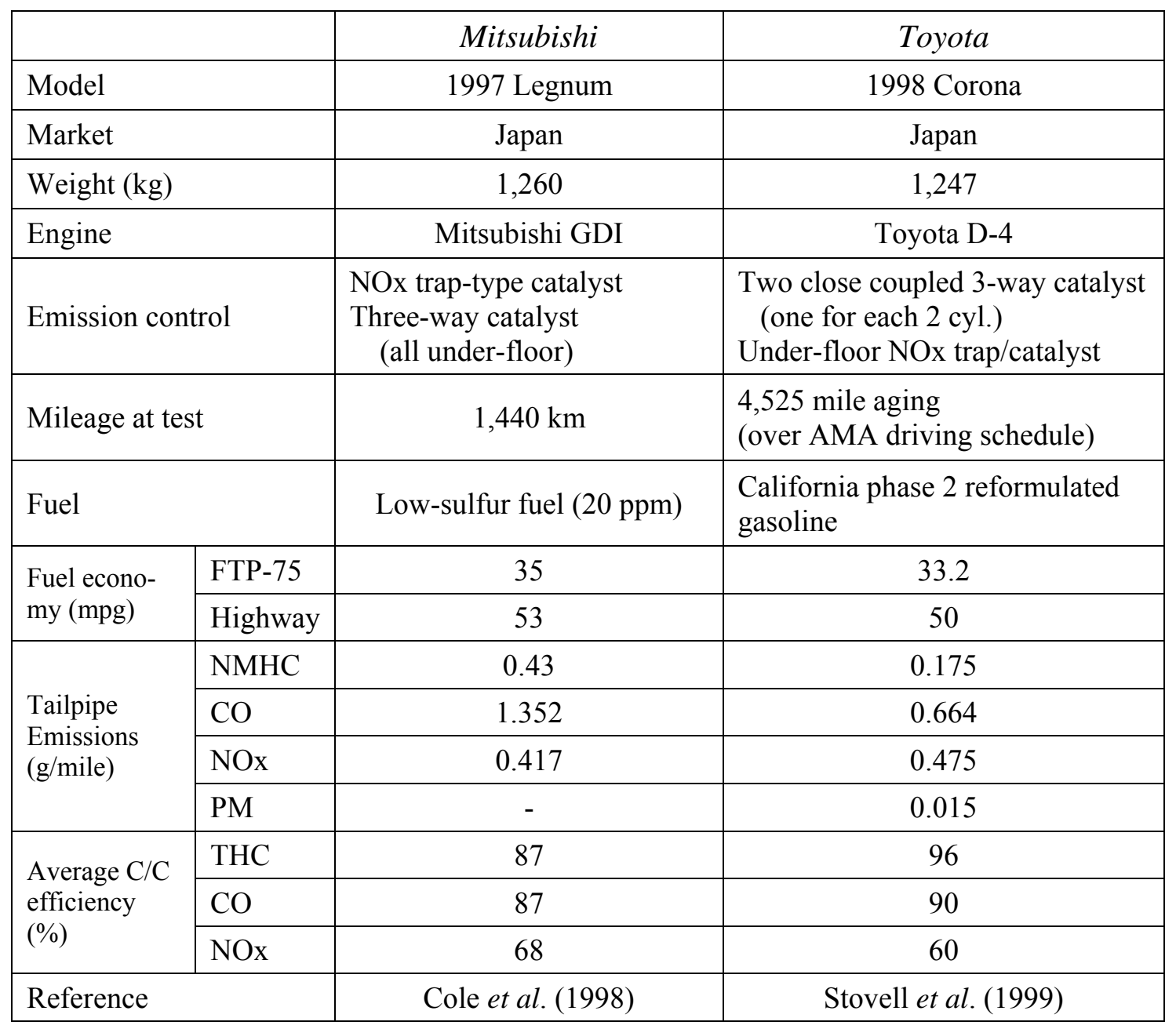




\section{2-3. The Effect of Piston Fuel Film on HC and Particulate Emissions}

Most of the production DISI engines have adopted the wall-controlled combustion system. However, wall wetting by fuel impingement on the piston crown and cylinder liner is known as a significant source of $\mathrm{HC}$ and particulate emissions in DISI engines [Zhao et al., 1999; Stevens and Steeper, 2001]. The fuel impingement of large droplets on the piston crown was proposed as one of the major source of $\mathrm{HC}$ emissions by Giovanetti et al. (1983). Salters et al. (1996) observed the formation of a fuel pool on the piston crown caused by fuel impingement from a high-pressure injector when the fuel was injected during the intake stroke. In the DISI engine design stage, the interaction between the spray tip penetration and piston trajectory for both late and early injection regimes were considered to minimize the fuel impingement [Kume et al., 1996]. The fuel impingement, the formation of fuel films, and the effect of them on the emissions of DISI engines at stratified operation are reviewed.

\section{2-3-1. Fuel Impingement on the Piston Crown}

A photographic image and a schematic representation of the fuel spray from a typical high-pressure swirl injector are shown in Figure 2-12. The initial large drops associated with the sac spray are evident in the photo. If the sac spray is present, the wetted footprint may contain two distinct portions as depicted in the schematics of the spray.

Salters et al. (1996) also observed an initial 'slug' of fuel that penetrated prior to the main spray cone formation that had a significant axial velocity and consisted of larger droplets, which impacted directly upon the piston crown. Mitsubishi [Kume et al., 1996] also 
reported that large droplets were observed at the center of the fuel spray during the early stage of injection. They proposed that this phenomenon could be improved by increasing injection pressure and swirl intensity.
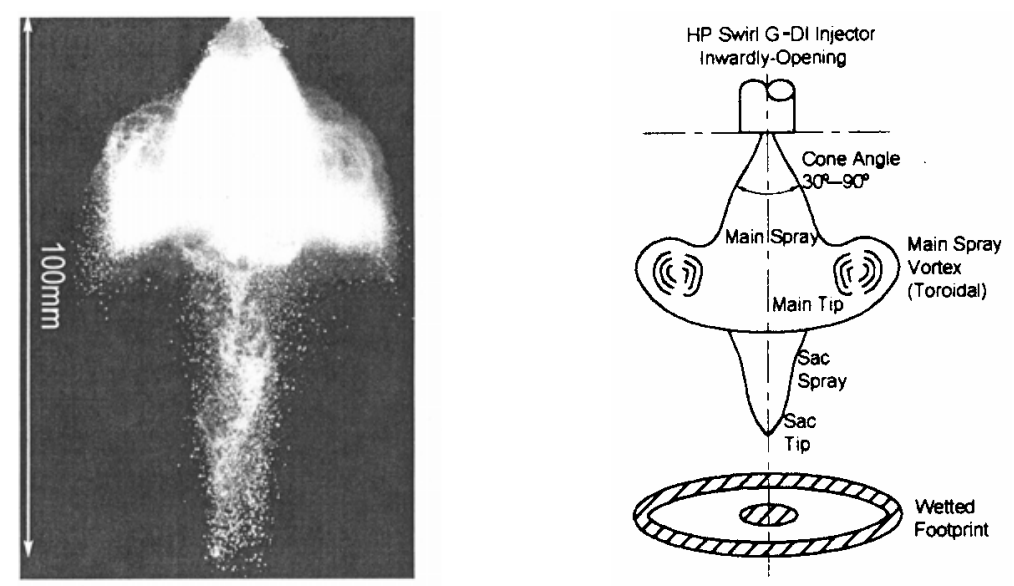

Figure 2-12. Fuel spray image and the schematic representation of the spray for the typical high-pressure swirl injector [Zhao et al., 2002].

The development of fuel spray is significantly affected by operating temperature, volatility of the fuel, and ambient pressure. The effects of fuel temperature and volatility on spray development for swirl-type injector are shown in Figure 2-13. The upper images are for isooctane and the lower images are for indolene. As the operating temperature increases, the cone begins to narrow and the spray penetration increases and the sac atomization increases. For indolene, the spray pattern changes more significantly at a lower temperature than that of isooctane because of the high volatility components in the fuel. There was no noticeable sac spray or toroidal vortex, and the main spray plume is very narrow and penetrating at $100^{\circ} \mathrm{C}$ 
operating temperature. The same spray tests were performed for n-dodecane, a very low volatility fuel, and the spray pattern showed no changes between $20^{\circ} \mathrm{C}$ and $100^{\circ} \mathrm{C}$.

The effect of ambient pressure on the fuel spray of a swirl-type injector was presented earlier in Figure 2-4. Transverse laser sheet photographs of the fuel spray for different fuel injection pressure and ambient pressure are shown in Figure 2-14. At higher injection pressure, the main effect is to fill the cone with more drops, decreasing the hollowness of the spray. Increasing the ambient pressure yields a more compact cross-section, which is indicative of a narrower spray, although the spray cone angle near the injector tip may not be significantly altered.

Park et al. (1999) characterized the direct-injection gasoline spray and wall interaction inside a heated, pressurized chamber by using various visualization techniques. The ambient and wall temperatures were $23^{\circ} \mathrm{C}$ for the cold condition, and the ambient temperature was $95^{\circ} \mathrm{C}$ and the plate temperature was $160^{\circ} \mathrm{C}$ for the hot condition. The chamber pressure was $335 \mathrm{kPa}$ (absolute) for both cases. The results showed that the upward spray vortex after impingement was more obvious at elevated temperature conditions due to the vaporization of small droplets and decreased air density. However, a fuel film build-up on the surface was observed for both cold and hot conditions. Shadowgraph results for an ambient pressure condition showed that even for the cold condition, vapor phase fuel appeared in the impingement zones and in the wake of the fuel spray, as the lighter and more volatile components in the gasoline fuel vaporized. 

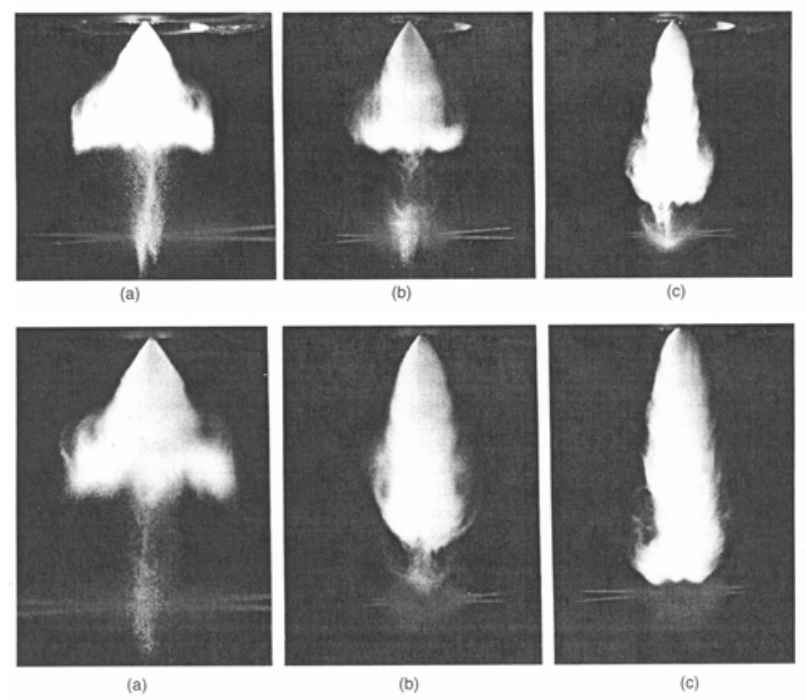

Figure 2-13. Effect of fuel temperature on spray development for a pressure-swirl injector. Upper: Isooctane, Lower: Indolene, (a) $20^{\circ} \mathrm{C}$ (b) $75^{\circ} \mathrm{C}$ (c) $100^{\circ} \mathrm{C}$. (images taken at $1.5 \mathrm{~ms}$ after SOI, 0.1 MPa ambient pressure) [Zhao et al., 2002].

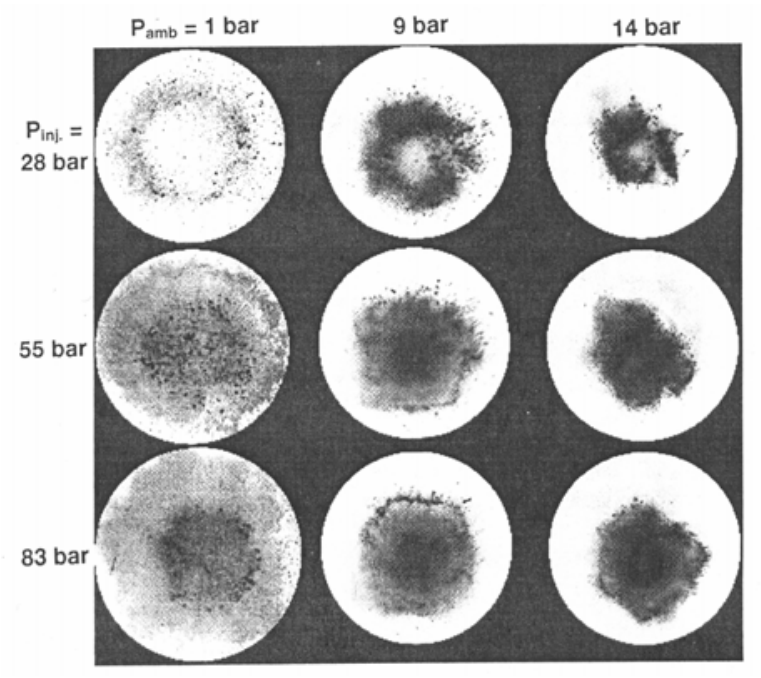

Figure 2-14. Effects of ambient pressure $\left(\mathrm{P}_{\mathrm{amb}}\right)$ and injection pressure $\left(\mathrm{P}_{\mathrm{inj}}\right)$ on the cross-sections of fuel sprays from a swirl injector (images taken at $40 \mathrm{~mm}$ from the tip and $4 \mathrm{~ms}$ after SOI) [Zhao et al., 2002]. 


\section{2-3-2. Piston Fuel Film Behavior and the Effect on Emissions}

Hudak and Ghandhi (1999) found a significant production of HC during the exhaust period from an experiment on a two-stroke direct-injection engine. Time-resolved measurements were made of the gas composition by using a high-speed sampling valve at the exhaust port. By using a dilution (from short-circuited air) factor calculated from the $\mathrm{CO}_{2}$ data, the diluted bulk gas $\mathrm{HC}$ concentrations at a subsequent time were predicted. The difference between this predicted diluted HC concentration and the measured concentration was considered to be the contribution which arose from sources that release HC late in the cycle. The results indicated that a significant fraction of the $\mathrm{HC}$ emissions can be attributed to the released HC late in the cycle as shown in Figure 2-15. They expected this slow release of $\mathrm{HC}$ is related to the surface wetting by the fuel spray, the sac volume of the injector and other crevices. Thus, it was considered that these effects are as significant to the total HC emissions as the bulk flame quenching mechanism and the other mechanisms discussed [Casarella and Ghandhi, 1998] for direct-injection engines under highly stratified operation.

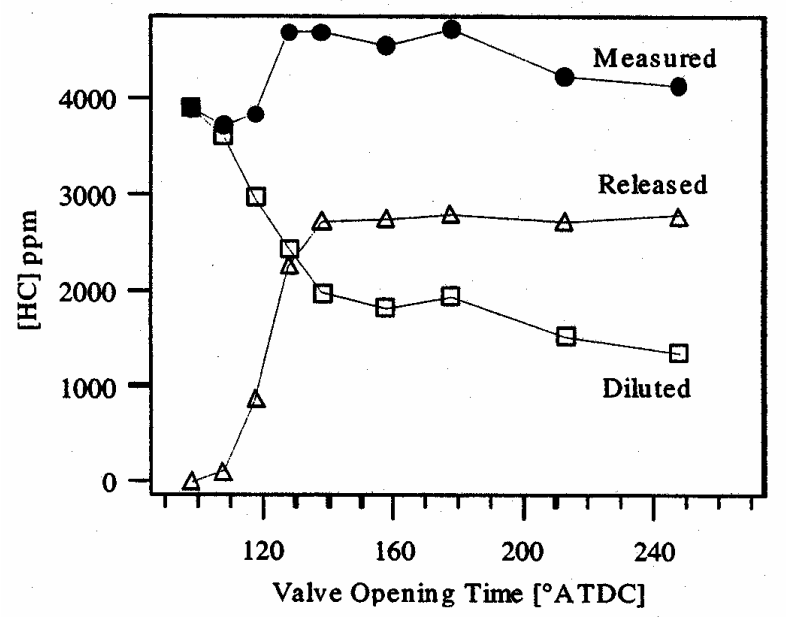

Figure 2-15. Time-resolved HC emissions from a two-stroke direct-injection engine. $2000 \mathrm{rpm}$, air-fuel ratio of 30:1. [Hudak and Ghandhi, 1999]. 
Extensive research on the effects of fuel film on $\mathrm{HC}$ emissions was performed at the University of Texas at Austin in cooperation with SwRI. The effect of combustion chamber wall-wetting locations on the $\mathrm{HC}$ emissions from a gasoline-fueled engine was investigated by Stanglmaier et al. (1999). They developed a spark plug-mounted directional injection probe to control the wetting location in the combustion chamber and to quantify its contribution to the $\mathrm{HC}$ emissions. With this probe, a controlled amount of liquid fuel was deposited at a given location within the combustion chamber at a desired crank angle while the engine was mainly operated on pre-mixed LPG. Thus, the HC emissions due to incylinder wall wetting were studied independently from all other $\mathrm{HC}$ emission sources. The results showed that the impingement of the liquid fuel on the piston crown and cylinder liner, especially on the exhaust side, was an important source of $\mathrm{HC}$ emissions from DISI engines. Also, the $\mathrm{HC}$ emissions were insensitive to the fuel injection timing and to the coolant temperature. This is indicative of low vaporization rates for the liquid gasoline on the combustion chamber surfaces. This weak dependence of HC emissions on coolant, and therefore piston surface, temperature led Frank and Heywood (1990) to conclude that piston crown wetting was not an important source of HC emissions from a TCCS equipped DISI engine. Through the same test method, Li et al. (1999) found that depositing $10 \%$ of the liquid gasoline (for $\lambda=1.1$ ) on the top of the piston resulted in $30 \%$ and $70 \%$ increase in $\mathrm{HC}$ emissions for an idle and a part load condition, respectively. An injector shut-off test was also performed to understand the lifetime of residual liquid fuel injected onto the piston crown. The test results showed that it took multiple cycles for the depletion of fuel vapor from the cylinder after the fuel shut-off. This slow depletion/vaporization of fuel film on the 
piston crown resulted in the insensitiveness of injection timing on the $\mathrm{HC}$ emissions in the test of Stanglmaier et al. (1999). Later, Stanglmaier et al. (2002) performed a fuel drop ( $\phi=2$ $\mathrm{mm}$ ) evaporation test on a heated surface for different ambient pressures. The vapor insulation (Leidenfrost phenomenon) was strongly dependent on the boiling point of the fuel, and was proposed to explain the higher $\mathrm{HC}$ emissions for the fuel having the lower boiling point in the test of Huang et al. (2001). The Leidenfrost phenomenon was clearly observed at low ambient pressures and the evaporation was inhibited in this regime. However, the vapor insulation was suppressed at high ambient pressures. From the results, they postulated that the fuel film evaporation during the intake stroke was minimal and all of the fuel film evaporates during the compression stroke. Then, they calculated the diffusion of the fuel vapor from the wall. The results showed that the fuel vapor was unable to diffuse towards the bulk gas region during the compression stroke. The mass diffusion only could occur during the expansion stroke. That was the reason why the $\mathrm{HC}$ emissions were insensitive to the injection timing in the previous tests. Their work suggests that there is no mechanism for preserving some of the fuel inside the cylinder for subsequent cycles as proposed by Li et al. (1999). Hence, they postulated that the existence of combustion chamber deposits provide a means for retaining a fraction of the fuel vapor within the combustion chamber. Alger et al. (2001) investigated the evaporation of the fuel film on the piston of a DISI engine. The directional injection probe was used to inject about $10 \%$ of the required fuel to the piston crown. The results showed that the fuel vaporizing off the piston top continued up to the exhaust stroke. This late vaporization causes an increase in $\mathrm{HC}$ emissions because the incylinder gas temperature was not high enough to oxidize the evaporated fuel. In the same 
engine condition, Warey et al. (2002) found that there is a close relationship between the amount of fuel wetting on the piston crown and the mass of the particulate matter emissions.

Stevens and Steeper (2001) also observed that fuel films persist through the expansion stroke up to the exhaust stroke, and they visualized pool fires from the fuel film with the late fuel injection conditions. Further, through the soot images, which persisted throughout the exhaust stroke, they concluded that these pool fires are a likely source of particulate emissions as well.

Drake et al. (2003) developed high-speed reflective-index-matching (RIM) image technique to quantify the fuel film mass on the piston crown of a wall-guided DISI engine. For a condition they tested ( $2000 \mathrm{rpm}, 95 \mathrm{kPa} \mathrm{MAP}, \Phi=0.36$, swirl injector, indolene), the maximum fuel film thickness was about $1 \mu \mathrm{m}$ and the fuel film volume was much smaller than previously assumed. Typically $1 \%$ of the fuel injected per cycle forms a piston fuel film. Vaporization of the thin fuel film was slow. Through the HC emissions test, they concluded that fuel films are not a major source of $\mathrm{HC}$ emissions at the test condition. They visualized pool fires and found that pool fires are the dominant source of soot emissions. Roughly $10 \%$ of the fuel film mass was converted to engine-out soot mass. 


\section{2-4. Fuel Film Thickness Measurements}

As described above, the fuel impingement on the piston crown is one of the major sources of $\mathrm{HC}$ emissions in DISI engines. Although significant research has been conducted on fuel film thickness measurement in the intake manifold and intake port of PFI engines, not many measurements have been performed on the piston crown of a direct-injection engine. Zhengbai et al. (1990) measured the fuel film thickness on the piston bowl surface of a direct-injection diesel engine using conductivity sensors. Drake et al. (2003) measured the fuel film thickness and fuel wetting area and quantified the mass of the fuel films on the piston crown of a DISI engine by using the reflective-index-matching (RIM) technique. Most of the other fuel film thickness measurements were performed adopting the laser-induced fluorescence technique. The basic principles of LIF and the fiber optic fluorescence methods are presented in this section.

\section{2-4-1. Laser-Induced Fluorescence (LIF) Technique}

Fluorescence is the result of a three-stage process that occurs in certain molecules called fluorophores or fluorescent dyes. The fluorescence processes of molecules are illustrated by the simple electronic-state diagram as shown in Figure 2-16 [Sharma and Schulman, 1999]. The first stage is the absorption (A) of energy from the lowest vibration level $(v=0)$ of the ground state $\left(S_{0}\right)$ to the various vibrational levels $(v=0,1,2,3)$ of the excited singlet states $\left(\mathrm{S}_{1}\right.$ and $\left.\mathrm{S}_{2}\right)$. Absorption occurs to all vibrational sublevels of the electronically excited singlet state because it is assumed that the exciting light contains a 
range of frequencies. In most molecules, electronic reorganization accompanying electronic transition occurs very fast $\left(\sim 10^{-15} \mathrm{~s}\right)$.

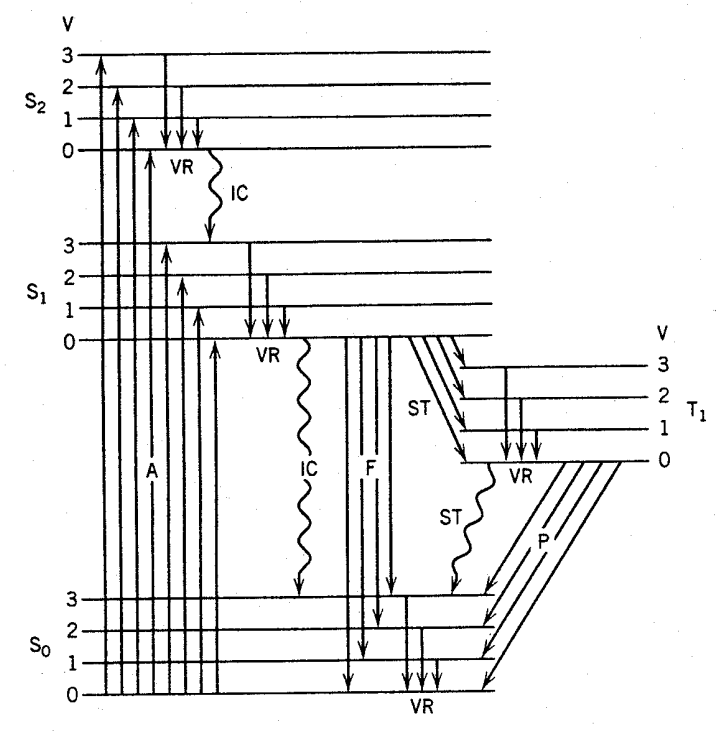

Figure 2-16. Energy-state diagram illustrating the processes of absorption and subsequent emission of fluorescence [Sharma and Schulman, 1999].

Absorption is followed by rapid, radiationless internal conversion (IC) and vibrational relaxation (VR) to the lowest vibrational level of $\mathrm{S}_{1}$. The final stage is the competition for deactivation of the lowest excited singlet $S_{1}$ among the radiationless internal conversion and singlet-triplet intersystem crossing (ST) as well as fluorescence (F). Alternative to intersystem crossing or internal conversion, the molecule may remain in the lowest vibrational level of the lowest excited singlet state for $10^{-10} \sim 10^{-7} \mathrm{~s}$ and then emit fluorescence. However, not all the molecules initially excited by absorption return to the ground state $\left(\mathrm{S}_{0}\right)$ by fluorescence emission. Other processes such as collisional quenching, fluorescence energy transfer and intersystem crossing may also depopulate $S_{1}$. The fluorescence quantum yield, which is the ratio of the number of fluorescence photons emitted to the number of photons absorbed, is a measure of the relative extent to which these 
processes occur. Due to energy dissipation during the excited-state lifetime, the energy of this fluorescence emission is lower, and therefore of longer wavelength, than that of the excitation. The entire fluorescence process is reversible. Unless the fluorophore is irreversibly destroyed in the excited state (photobleaching), the same fluorophore can be repeatedly excited and detected.

Laser-induced fluorescence has proven to be a powerful diagnostic for species concentration measurement. Much research has been executed by this technique to measure the fuel distribution in the combustion chamber [Ghandhi and Bracco, 1995, 1996; Fansler et al., 1995; Tabata et al., 2000], the fuel film thickness in the intake port and intake manifold, and the oil film thickness between the cylinder liner and piston [Hoult et al., 1988] in internal combustion engines. For the fuel distribution measurement in the combustion chamber, a planar laser sheet is introduced to the target region through optical windows. Generally, nonfluorescent fuel is used with a fluorescent dopant, although a commercial gasoline has been used with no dopant [Fansler et al., 1995]. The aromatic components in the commercial gasoline are known to fluoresce. Fluorescence images were captured by the intensified CCD camera. The images can be quantified on a pixel basis through the calibration for known airfuel ratios [Ghandhi and Bracco, 1995, 1996].

Hoult et al. (1988) proposed a method of calibration to obtain quantitative oil film thickness in an engine. In this work a quartz window in the cylinder liner was used for optical access, and a fluorescent dye was added to the oil.

Direct measurements of LIF from the surface of a metal wall were performed by Almkvist et al. (1995) to measure the fuel film thickness on the bifurcation wall of the intake 
port. The excitation source was the fourth harmonic of a Nd:YAG laser with a wavelength of $266 \mathrm{~nm}$. The laser light was formed to a thin sheet, which was directed to the bifurcation wall through a window in the intake port. The engine was run on isooctane with 3-pentanone as a dopant. The curvature effect of the wall, and the slight variation in the laser intensities along the light sheet were considered in the calibration stage. They claimed that the sensitivity of the technique was in the order of $1 \mu \mathrm{m}$, and the accuracy was estimated to be $10 \%$.

Senda et al. (1999) measured the 2-D distribution of the fuel film thickness formed on a flat plate by using the LIF technique at an atmospheric pressure and room temperature condition. The fuel was isooctane mixed with biacetyl ( $6 \%$ by volume) as a dopant. The fuel was injected through an injector onto a flat quartz wall. The laser light of a Nd:YAG laser (355 nm) was passed through the film from the bottom of a quartz plate. Then, the fluorescent emission from the film was photographed at an angle with respect to the incident laser axis below the wall. The fluorescent emission was filtered by using a band pass filter centered at $482.7 \mathrm{~nm}$ with bandwidth of $18 \mathrm{~nm}$. The emission intensity was amplified and photographed by a CCD camera. Each pixel has a dynamic range of 8 bits, thus for a given image a thickness scale range was found from the calibration results.

However, there are a number of questions in quantifying the measured fluorescence directly to the concentration and thickness. The fluorescence is affected by the elevated temperature and pressure. For example, the fluorescence yield of ketones was found to decrease with temperature for a $266 \mathrm{~nm}$ excitation and broadband collection [Ghandhi and Felton, 1996]. Another issue is whether the dopant co-evaporates with the base fuel when the 
mixture vaporizes. Han and Steeper (2002) reported that matching only the boiling points of the two fuels is not enough to assume that the mixture co-evaporate.

\section{2-4-2. Fiber Optic Fluorescence Method}

The small size and its electrical, chemical and thermal inertness enable an optical fiber to be used as a remote sensing element in harsh environments. Its high transmissivity also makes it suitable for fluorescence sensing applications.

Richardson and Borman (1991) applied optical fibers to gain optical access to the oil film between the piston and cylinder liner that was less invasive than the window used in the experiment of Hoult et al. (1988). They found that the oil naturally fluoresces when $442 \mathrm{~nm}$ Helium-Cadmium laser light strikes it. The laser beam was focused to the fiber end through an objective lens, and the laser was transferred through optical fibers. The fluorescent light of the oil was transferred to the photo-sensing unit through the same fiber. Ostroski (1998) developed a dual-fiber probe to investigate oil film thickness on the liner and piston of a heavy-duty diesel engine. One fiber delivered the laser light and collected laser-induced fluorescence from the oil films on the liner and piston, while the second fiber collected only LIF. Based on the geometry of the delivery and collection cones, the presence of oil on the liner, on the piston, or both was discerned from the LIF signals.

Johnen and Haug (1995) reported experimental investigations of spray formation and fuel film development in the intake of an SI engine. Fuel film thickness was measured by using the optical fiber-based LIF technique. Optical fiber bundles were flush mounted on the bottom surface of the intake where the injected fuel was expected to accumulate. The fibers, 
randomly distributed within the bundle, were branched into two bundles at the other end. One branch guided the excitation light to the measuring fuel, and the other bundle collected the emitted fluorescence from the fuel film. An argon ion laser tuned to $457.9 \mathrm{~nm}$ was used for excitation and the fluorescence intensities were measured with photomultiplier tubes. Isooctane with $5 \%$ of 2,3-butanedione (biacetyl) by volume as a dopant was used as the fuel. The calibration procedure was to measure the fluorescence intensities for different fuel film thicknesses and fuel temperatures. The error in reproducibility of the determined fuel film thickness during the calibration was within $5 \mu \mathrm{m}$.

Hentschel et al. (1997) performed fuel film thickness measurement test in an intake manifold of a production engine by applying the fiber-based LIF technique similar to the experiment of Johnen and Haug (1995). An argon ion laser (457.9 nm) and a bifurcated fiber bundle were used. An optical probe head made of plexiglass was used at the end of the fiber surface to suppress the minimum height to receive fluorescence light at the receiving fiber (Figure 2-17). Initially a standard gasoline whose $50 \%$ evaporation point was $109^{\circ} \mathrm{C}$ was used. The fluorescence from the gasoline was found to be generated mostly by naphthalene whose boiling point is $217^{\circ} \mathrm{C}$. The gasoline was not applicable for vaporizing conditions because the difference in boiling points of the multiple components led to an enrichment of the aromatics in the remaining fuel, causing an increased fluorescence and therefore, an unrealistically high fuel film thickness. Instead, isooctane with $4 \%$ additive of 2,3hexanedione $\left(\mathrm{T}_{\mathrm{bp}}=128^{\circ} \mathrm{C}\right)$ was used. The tracer was chosen based on the result of LeCoz and Baritaud (1994) that showed that the tracer needs to have a significantly higher boiling point than isooctane due to the increase of the tracer vapor pressure in the tracer/isooctane mixture 
compared to that of the pure liquid tracer. Crankangle-resolved measurements of the wall film thickness were made at different locations in the intake manifold. The estimation of the total fuel mass stored in the wall film was made based on the spatial distribution of the fuel film thicknesses.

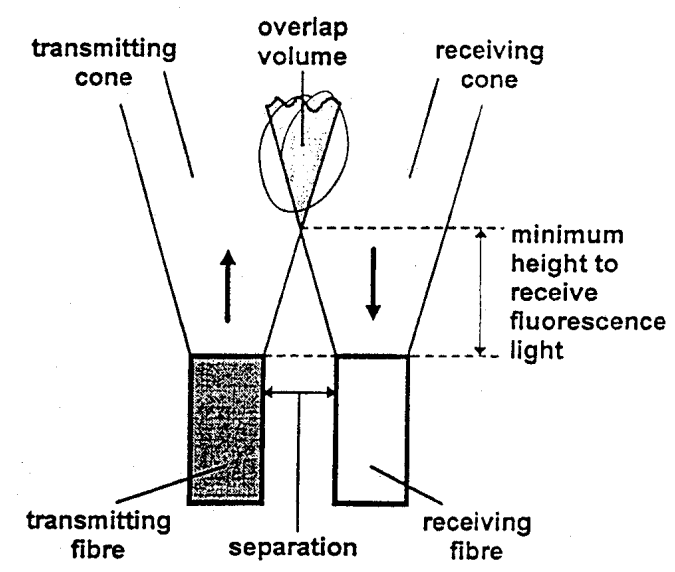

Figure 2-17. Schematics of the transmitting and receiving cones of two fibers [Hentschel et al., 1997].

The total signals collected by single and dual fiber systems were derived by Ghandhi (2000) on the assumption that the light delivery pattern is uniform within the numerical aperture of the fiber. The expression for the single fiber system in terms of the appropriate non-dimensional coordinates is as follows.

$$
S_{1}=\left[\dot{E} \sigma_{a b s} \phi \eta X N\right] \frac{r_{1} \Omega_{r e f, 1}}{\tan \theta_{1}}\left[\int_{0}^{\infty} \widetilde{\Omega}_{1} d \widetilde{z}\right]
$$

where $\dot{E}$ is the laser power, $\sigma_{a b s}$ is the absorption cross-section which is related to the molar extinction coefficient, $\varepsilon$ (liter/mole-cm), as $\sigma_{a b s}\left(\mathrm{~cm}^{2}\right)=3.8 \times 10^{-21} \varepsilon$ [Berlman, 1971], $\phi$ is the fluorescence quantum efficiency, $\eta$ is the detection efficiency, $X$ is the mole fraction of the scattering molecule if the process is species selective and $N$ is the number density. The 
reference collection solid angle, $\Omega_{\text {ref }, 1}$, is defined as the total amount of light that can be scattered into a cone defined by the fiber numerical aperture and it is given by

$$
\Omega_{\text {ref }, 1}=\frac{1}{2}\left(1-\cos \theta_{1}\right)
$$

where $\theta_{1}$ is the angle defined by the numerical aperture $\left(N A_{1}\right)$ of the optical fiber as follows.

$$
\theta_{1}=\sin ^{-1}\left(N A_{1}\right)
$$

$\widetilde{\Omega}_{1}$ and $\widetilde{z}$ are the non-dimensional forms of the modified collection solid angle, $\Omega_{1}^{*}$, and the normal distance from the fiber surface, $z$, respectively. They are

$$
\begin{aligned}
& \widetilde{\Omega}_{1} \equiv \frac{\Omega_{1}^{*}}{\Omega_{r e f, 1}} \\
& \Omega_{1}^{*}=\frac{1}{A_{3}} \iint_{A_{3}} d A_{3} \iint_{A_{1}} \frac{d A_{1}(\cos \beta) \delta^{*}}{4 \pi R^{2}} \\
& \widetilde{Z} \equiv \frac{Z \tan \theta_{1}}{r_{1}}
\end{aligned}
$$

The modified collection solid angle represents the fraction of the fluorescence light generated at a shell of surface $A_{3}$ which is successfully coupled into the fiber. $A_{3}$ is the area of the illuminated circle at a distance $z$ from the end surface of the fiber as shown in Figure 2-18. The bracketed terms in the equation (2-1) are independent of the fiber properties. Figure 2-19 shows the calculation result of the modified solid angles for several fibers having different radius and numerical aperture as a function of distance from the fiber face, and the same data in the non-dimensional scales as defined in equation (2-3). The results showed that the non-dimensionalization worked as intended. 
The spatial dependence of the total signal can be determined from the integral in equation (2-1), by defining a cumulative signal as

$$
\widetilde{I}_{1}(\widetilde{z}) \equiv \int_{0}^{\widetilde{z}} \widetilde{\Omega}_{1} d \widetilde{Z}^{*}
$$

The calculation result of the cumulative signal is shown in Figure 2-20.

From equation (2-1), all variables are known or measured $\left(S_{1}\right)$ except the second bracket term. Then, the fuel film thickness can be determined from the value of the term and Figure 2-20. These methods were adopted in this research and the details of the new formulation of the modified collection solid angle and the cumulative signal for non-uniform light delivery pattern is explained in the next chapter.

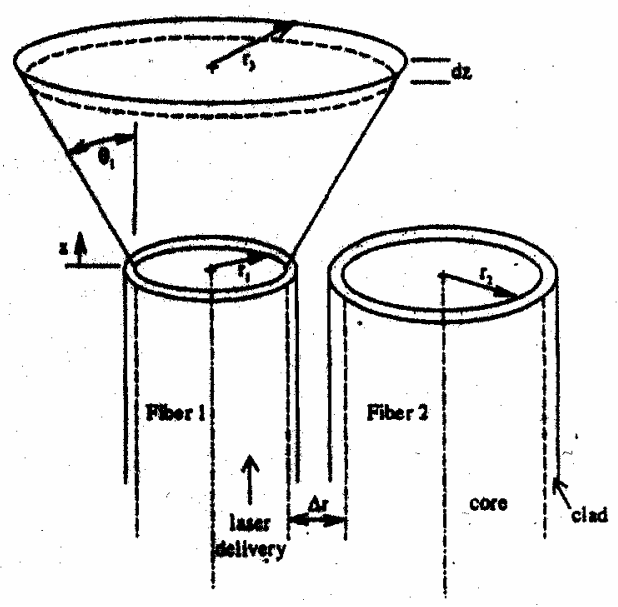

Figure 2-18. Geometry of the optical fiber probe [Ghandhi, 2000]. 

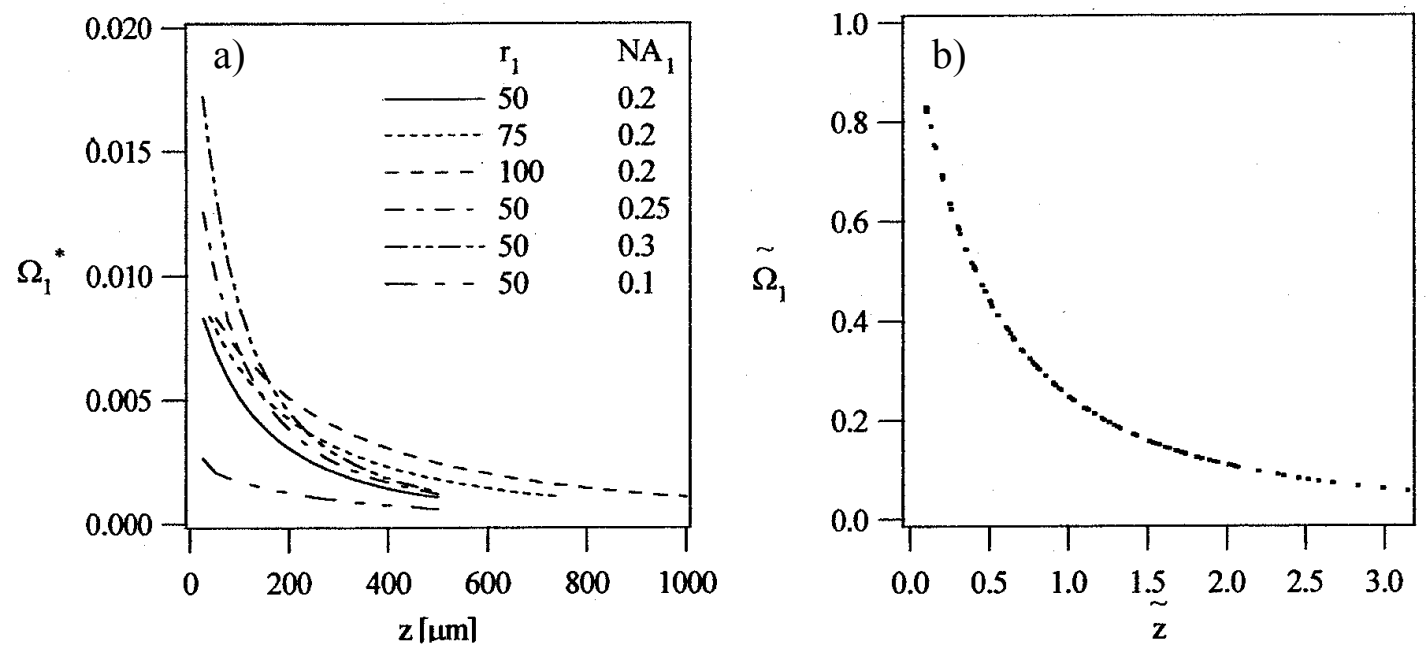

Figure 2-19. Single fiber probe results [Ghandhi, 2000].

a) Modified collection solid angle as a function of distance from the fiber face

b) Collapse of data by choosing the appropriate non-dimensional scaling
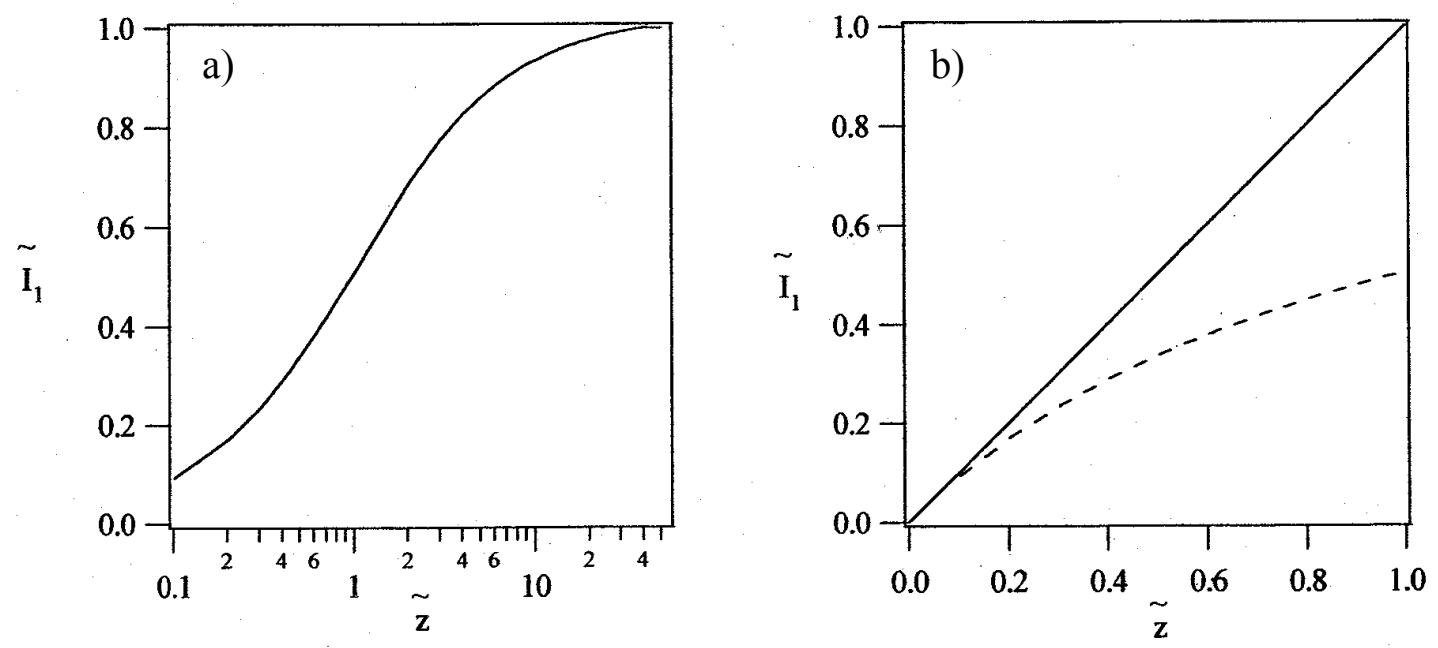

Figure 2-20. Single fiber probe results [Ghandhi, 2000].

a) Cumulative signal

b) Cumulative signals for small distances compared to a linear response 


\section{2-5. Fluorescence-Based Liquid-Phase Thermometer (FBLPT)}

Fluorescence-based liquid-phase thermometers rely on the changes in the fluorescence spectrum of a probe molecule with temperature. The changes in the fluorescence can be used to determine temperature through the measurement of absolute intensity or the shifts in the spectra. These fluorescence probes make possible monitoring of microscopic or hostile environments (high pressure or high temperature) where conventional thermometry, based on thermocouples, is impractical or impossible.

Schrum et al. (1994) reported that the shifts in the wavelength of the fluorescence maximum and intensity in the blue tail of the fluorescence of BTBP [N,N'-bis(2,5-di-tertbutylphenyl)-3,4,9,10-perylenedicarboximide] molecule dissolved in liquid methanol and mineral oil can be used as a thermometer over the temperature range of $15 \sim 70^{\circ} \mathrm{C}$.

Bai and Melton (1997) performed tests for several probe molecules as a FBLPT. They proposed four fluorescent molecules, including BTBP, as useful probe molecules for FBLPT. The molecules are oxygen-resistant and can be used up to high temperatures. The fluorescent spectra of BTBP for different temperatures are shown in Figure 2-21. The ratio of the integrated intensity in blue range to that in red range as a function of temperature has linear relations up to $173^{\circ} \mathrm{C}$ with temperature resolution of $4^{\circ} \mathrm{C}$ [Bai and Melton, 1997].

The BTBP-based FBLPT will be applied in this research to measure the fuel film temperatures on the piston crown. 


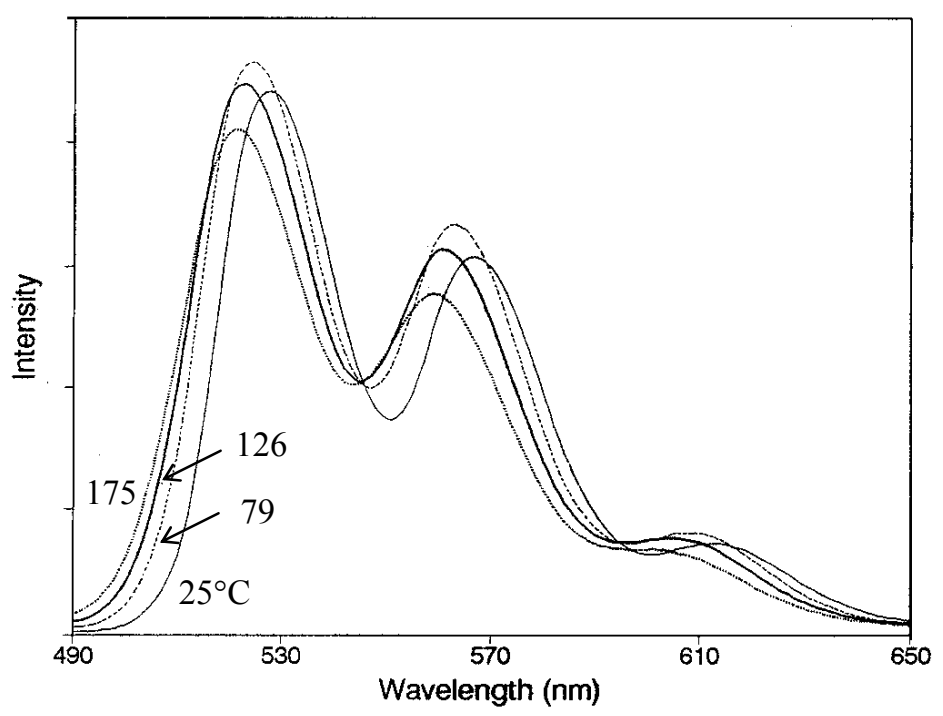

Figure 2-21. Fluorescence spectra of BTBP in air-saturated solution at different temperatures [Bai and Melton, 1997]. 


\section{Chapter 3}

\section{Thickness Measurement by Fiber-based LIF Method}

The main goal of the present research is to measure the fuel film thickness on the piston crown of a DISI engine. The engine has a wall-guided combustion system and the fuel film is formed by direct fuel impingement on the piston.

The optical fiber-based LIF method was used in this research. The use of an optical fiber enables the application of the LIF method on the moving piston. The determination of the fuel film thickness is based on the derivation of Ghandhi (2000) as discussed in section 24. The total signal collected by the single fiber, $S_{1}$, can be expressed in terms of the nondimensional parameters as shown in equation (2-1), where all the variables are known except for the last bracketed term. The bracketed term, defined as the cumulative signal, represents the spatial dependence of the total signal and it is a function of non-dimensional thickness, $\tilde{z}$, only. The equation (2-1) can be rewritten as the following simple form

$$
S_{1}(T, \tilde{Z})=C(T) \cdot \tilde{I}_{1}(\tilde{Z})
$$


where, $C(T)$ is a constant which depends on the temperature and $\tilde{I}_{1}(\tilde{z})$ is the cumulative signal. If we measure the total fluorescent signal, $S_{1}$, from the fuel film through the experiment, we can determine the fuel film thickness with respect to an infinitely thick fuel film from the following ratio equation.

$$
\frac{S_{1}(T, \tilde{z})}{S_{1}\left(T_{\text {ref }}, \infty\right)}=\frac{C(T)}{C\left(T_{\text {ref }}\right)} \cdot \frac{\tilde{I}_{1}(\tilde{z})}{\tilde{I}_{1}(\infty)}
$$

where, $T_{\text {ref }}$ is the reference temperature where the measurement were performed for a thick (infinite) fuel film. The fuel film temperature affects the fluorescent signal because $\sigma_{a b s} \phi$ term in $C(T)$ is a function of temperature. The $C(T) / C\left(T_{r e f}\right)$ term must be calibrated versus temperature beforehand. Then in the last term only $\tilde{I}_{1}(\tilde{z})$ is a function of $\tilde{z}$, and the fuel film thickness can be obtained from the graph of the cumulative signal vs. film thickness.

The fuel film temperature on the piston crown, which is, in general, different from the piston temperature, is to be measured through fluorescence-based liquid-phase thermometry (FBLPT). BTBP was used as the fuel dopant.

The derivation of Ghandhi (2000) for the total signal collection in the fiber assumed that the laser power was evenly distributed within the numerical aperture at any distance from the fiber surface. However, it was found that the beam profile is not evenly distributed [Ostroski, 1998] and in that case the modified collection solid angle and cumulative signal should be changed. In the following sections, the fiber collection properties for a Gaussian distribution is developed, optical fiber selection and potential interference from the fuel spray are discussed. 


\section{3-1. Laser Delivery Pattern of the Fiber}

The laser delivery pattern of the optical fiber was measured in a simple way. A Semitransparent paper was placed at a known distance from the fiber surface and the light intensity images on the paper were taken by a CCD camera from the opposite side. The tested distances were 5, 7, and $9 \mathrm{~mm}$ from the fiber surface. The light intensities across the center of the images were measured by using an image-processing program. The light intensity distribution curves at three different distances and the corresponding curve-fitted Gaussian (normal) distribution curves are shown in Figure 3-1. The Gaussian fit follows the original curve very well.

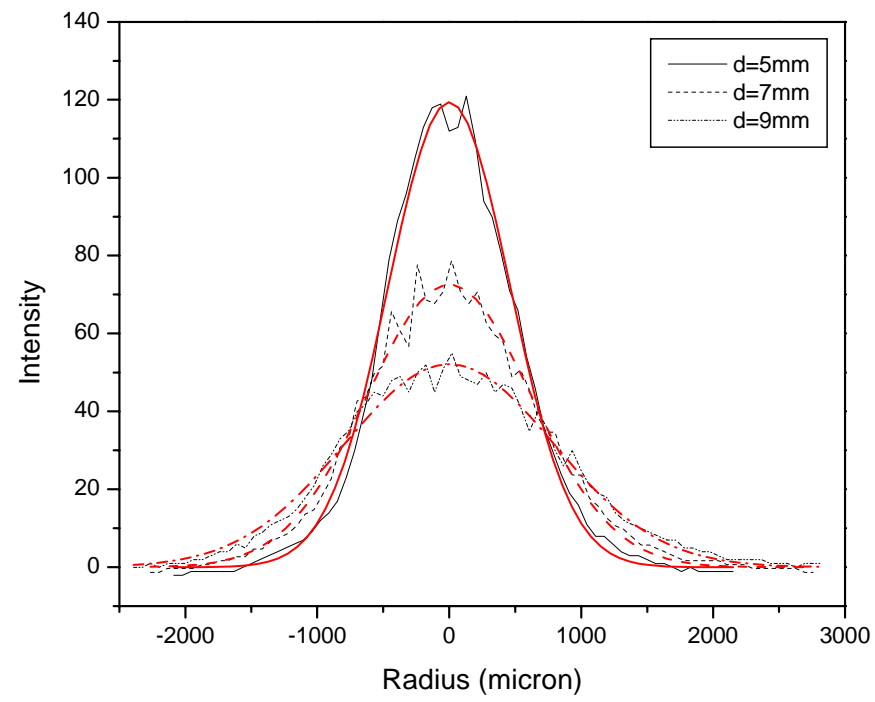

Figure 3-1. Laser intensity distribution at three different distances from the fiber surface and the corresponding Gaussian distribution curve. 
Table 3-1. The area and volume of the Gaussian distribution function at each distance.

\begin{tabular}{|c|c|c|}
\hline Distance & Area & Volume \\
\hline $5 \mathrm{~mm}$ & 1 & 1 \\
\hline $7 \mathrm{~mm}$ & 0.78 & 0.96 \\
\hline $9 \mathrm{~mm}$ & 0.66 & 0.90 \\
\hline
\end{tabular}

The area and volume under the Gaussian distribution curves at each distance from the fiber surface were calculated and then normalized with respect to the result of the $5 \mathrm{~mm}$ case. The results are shown in Table 3-1. As expected, the light intensity distribution is almost constant in volume, which represents the total laser power, at different distances. The decrease in the volume as the distance increases may be caused by the fact that the transparent paper does not have constant transmittance characteristics according to the light intensity. In the following section, it was assumed that the volume of the light intensity distribution is constant at any distance from the fiber surface for the derivation of the total signal collection in the fiber. 


\section{3-2. Total Signal Collection}

Based on the result that the light intensity shows a Gaussian distribution and the volume of the light distribution is constant at any distance from the fiber surface, the equation for the modified collection solid angle and cumulative signal should be re-derived. For the new light distribution function, the contribution to the total signal from an arbitrary differential volume in a distance $z$ from the fiber surface is described based on the result of Ghandhi (2000) as

$$
d S_{1}=C^{\prime}(T)\left[\iint_{A_{3}} I^{*} d A_{3} \iint_{A_{1}} \frac{d A_{1}(\cos \beta) \delta^{*}}{4 \pi R^{2}}\right] d z
$$

where, $C^{\prime}(T)=\sigma_{a b s} \phi \eta X N$ and $I^{*}$ is the laser power intensity distribution function as shown in Figure 3-2.

The intensity distribution function, $I^{*}(z, r)$, can be obtained from the following relation

$$
I(z) \cdot A_{3}=\int_{0}^{\infty} 2 \pi r \cdot I^{*}(z, r) \cdot d r
$$

where, $\quad I(\mathrm{z})=\frac{\dot{E}}{A_{3}(\mathrm{z})}$

$$
I^{*}(z, r)=\frac{K(z)}{s \sqrt{2 \pi}} e^{-\frac{r^{2}}{2 s^{2}}} \quad: \text { Gaussian distribution function }
$$

and $\dot{E}$ is the laser power and $s$ is the standard deviation of the Gaussian distribution function and it is a function of $z$ only. 


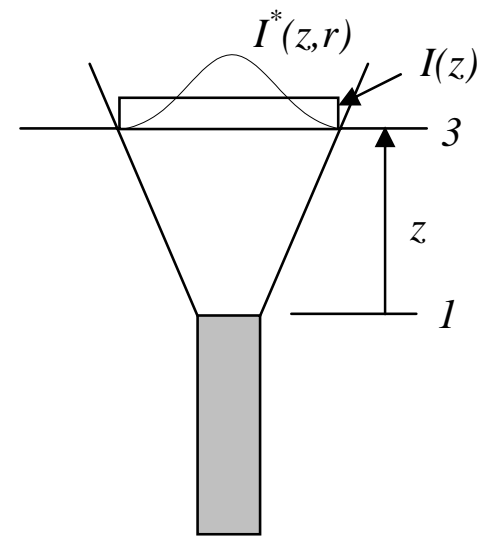

Figure 3-2. Laser power distribution.

After some manipulation, the equation for $K(\mathrm{z})$, which scales the intensity in the Gaussian distribution function, can be expressed as

$$
K(z)=\frac{\dot{E}}{s \sqrt{2 \pi}}
$$

and the intensity distribution function at an arbitrary distance from the fiber surface becomes

$$
I^{*}(z, r)=\frac{\dot{E}}{2 \pi \mathrm{s}^{2}} e^{-\frac{r^{2}}{2 s^{2}}}
$$

Then, the signal contribution equation (3-3) at an arbitrary distance can be written as

$$
d S_{1}=C(T) \cdot \Omega^{*}(z) d z
$$

where the new equation for the modified collection solid angle, $\Omega^{*}(z)$, and the constant $C(T)$ is

$$
\begin{aligned}
& \Omega^{*}(z)=\iint_{A_{3}} \frac{1}{2 \pi \mathrm{S}^{2}} e^{-\frac{r^{2}}{2 s^{2}}} d A_{3} \iint_{A_{1}} \frac{d A_{1}(\cos \beta) \delta^{*}}{4 \pi R^{2}} \\
& C(T)=C^{\prime}(T) \cdot \dot{E}=\sigma_{a b s} \phi \eta X N \dot{E}
\end{aligned}
$$


The same non-dimensionalization as discussed in section 2-4-2 can be applied and the form of the cumulative signal is the same as the equation (2-4).

The calculation results of the modified collection solid angle, $\Omega^{*}(z)$, for different optical fiber specifications (diameter, numerical aperture) are shown in Figure 3-3. The nondimensional form of the modified collection solid angle, $\widetilde{\Omega}$, collapses to the same curve as in the even distribution case described in chapter 2 (Figure 3-4). The comparison of the nondimensional form of the modified collection solid angle for even and Gaussian intensity distributions is shown in Figure 3-5, and shows significant differences. Figure 3-6 shows the calculation results of the cumulative signal for both even and Gaussian intensity distributions.

To determine whether the measured signal intensities will follow the trend of the calculated cumulative signals the total signal intensities were measured on a plate where an optical fiber was installed normal to the surface. The fuel film thickness was changed by using supports of known thickness to hold a quartz window at a fixed distance above the plate. A mixture of isooctane and $4 \%$ of 2,3-hexanedione was injected into the clearance and the total signals were measured for different thicknesses. The measured signals were scaled by the maximum cumulative signal for comparison. The result (Figure 3-7) shows that the measured total signals closely matched the calculated cumulative signal, which assumed a Gaussian intensity distribution. 

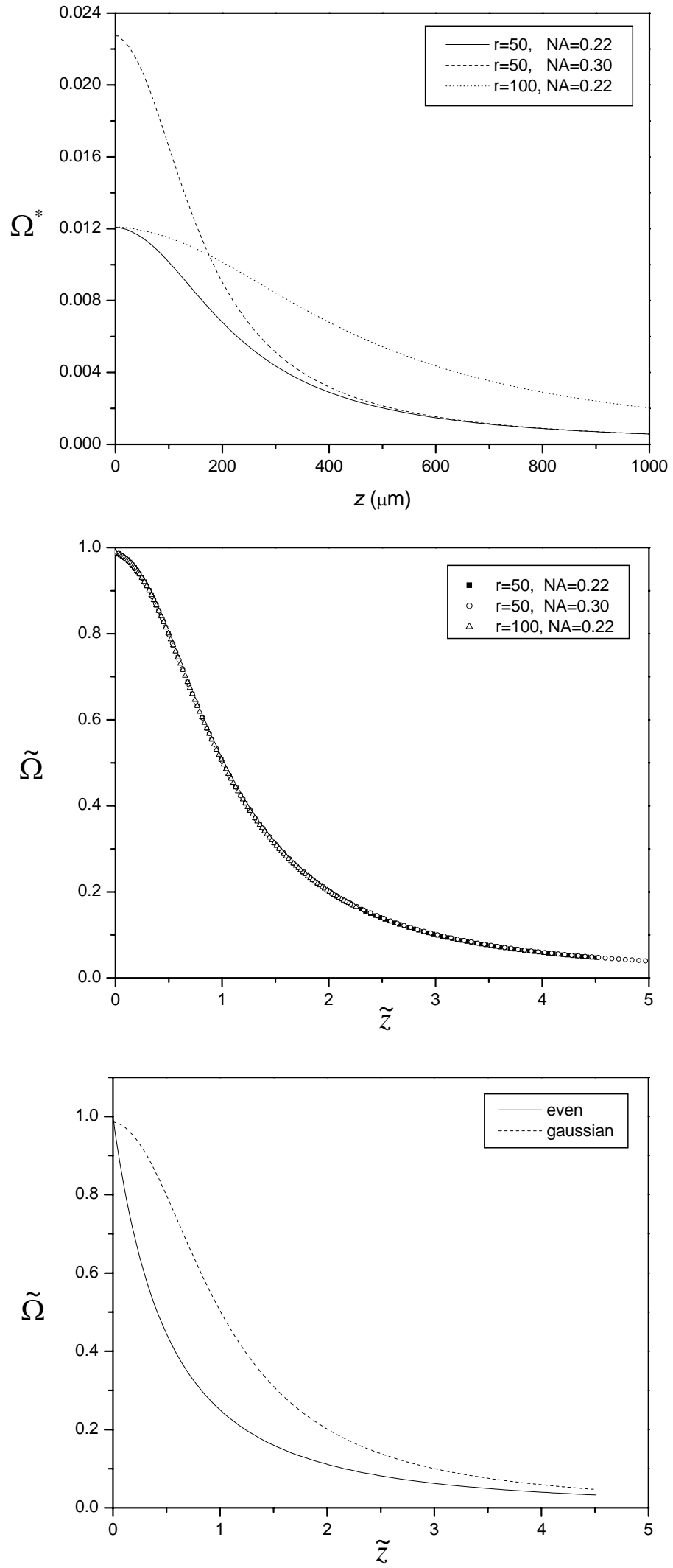

Figure 3-3. Calculation results of modified collection solid angle for different fiber diameter and numerical aperture.
Figure 3-4. Non-dimensional form of the modified collection solid angle for different fiber diameter and numerical aperture.
Figure 3-5. Non-dimensional form of the modified collection solid angle for even and Gaussian light intensity distribution. 
(a)

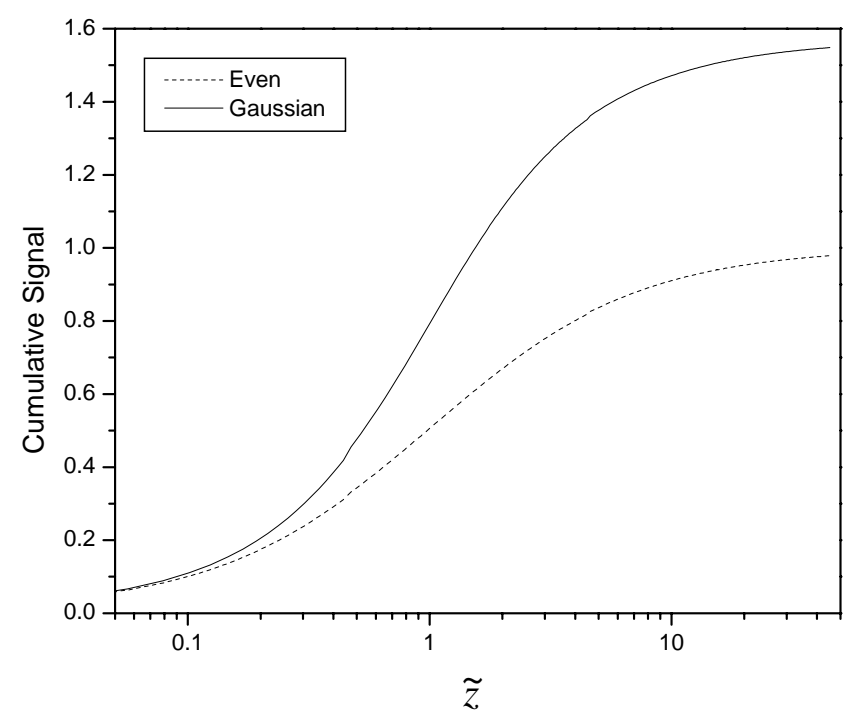

(b)

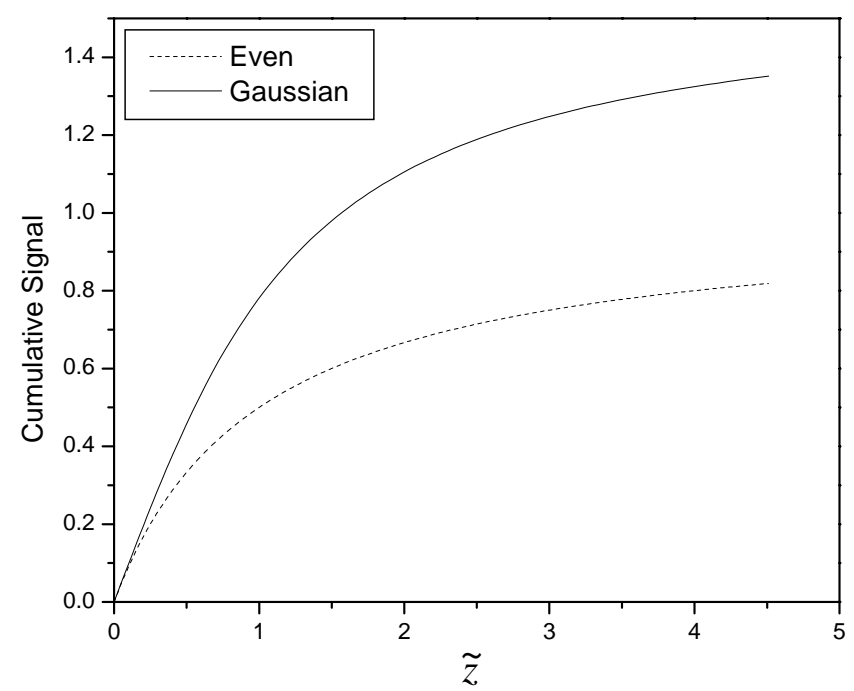

Figure 3-6. Calculation result of the cumulative signal for even and Gaussian laser intensity distribution.

(a) Log scale for the $\mathrm{x}$-axis for longer distance

(b) Normal scale for closer look 


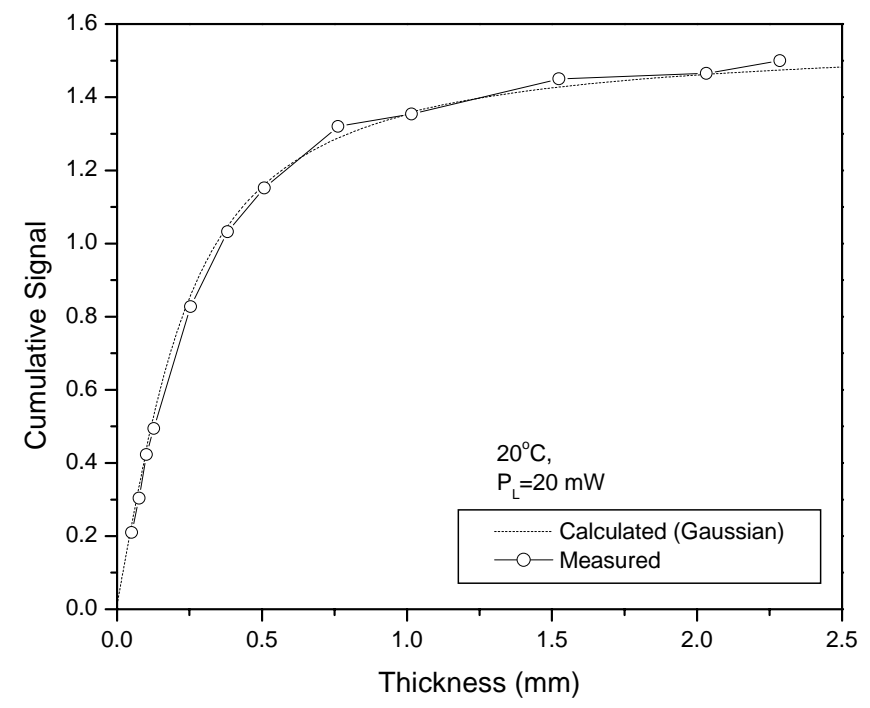

Figure 3-7. Comparison of the calculated cumulative signal, which assumed a Gaussian intensity distribution, and the measured total signal. 


\section{3-3. Choice of Optical Fiber}

The environment where the optical fibers were exposed was very harsh. The fibers were installed on the surface of the piston crown and directly exposed to high temperature conditions. The specifications of the optical fiber (Polymicro Technologies) used in this experiment are shown in Table 3-2. The buffer was aluminum, which is suitable for harsh environment like engines. The operating temperature range is high enough for the current application. The recommended minimum bend radius of the optical fiber is 100 times of its diameter. Therefore, a small diameter was required in this research because the fibers were installed in the moving piston. For $150 \mu \mathrm{m}$ fiber outer diameter, the bending radius should be greater than $15 \mathrm{~mm}$.

The total signal from the fiber, equation (2-1), is linearly proportional to the fiber radius, and related to the numerical aperture through $\Omega_{r e f, 1} / \tan \theta_{1}$ where $\Omega_{r e f, 1}$ is given by equation (2-2). The angle maximizing the total signal, $S_{1}$, is $51.8^{\circ}$ and it corresponds to a numerical aperture of 0.78 . Thus, the maximum signal is achieved with the highest available numerical aperture. Furthermore, from the viewpoint of probe sensitivity for thin fuel films, higher numerical aperture is recommended as discussed below. The graph of cumulative signal $\tilde{I}_{1}(\widetilde{Z})$ of equation (2-4) shows that approximately $10 \%$ of the signal is achieved at $\widetilde{z}=0.1$. The $50 \%$ and $95 \%$ levels are achieved at $\widetilde{z}=1.0$ and $\widetilde{z}=12.5$, respectively. If we

look at the non-dimensional coordinate $\tilde{z}$ from equation (2-3), it can be seen that the spatial extent over which the probe is sensitive can be decreased by increasing the numerical aperture of the fiber. 
Table 3-2. Specifications of the optical fiber.

\begin{tabular}{|l|l|c|}
\hline \multicolumn{2}{|l|}{ Type } & $\begin{array}{l}\text { Silica / Silica Optical Fiber } \\
\text { - High OH Silica Core } \\
\text { - Doped Silica Clad }\end{array}$ \\
\hline \multirow{3}{*}{ Dimensions } & Core dia. & $100 \pm 7 \mu \mathrm{m}$ \\
\cline { 3 - 3 } & Cladding dia. & $110 \mu \mathrm{m}$ \\
\cline { 2 - 3 } & Buffer dia. & $150 \mu \mathrm{m}$ \\
\hline Numerical Aperture (NA) & $0.22 \pm 0.02$ \\
\hline Wavelength range & $180 \sim 1150 \mathrm{~nm}$ \\
\hline Operating temperature & $-55^{\circ} \mathrm{C} \sim 500^{\circ} \mathrm{C}$ \\
\hline
\end{tabular}




\section{3-4. Effect of Fuel Spray}

The present method is justified by the theoretical results of Ghandhi (2000) which have shown that the total collection signal through a circular fiber has a unique relationship with the fuel film thickness, although it is not linear as shown in Figure 2-20. However, there is one point that should be considered beforehand, the effect of the fuel spray above the fuel film surface on the signal.

The fuel spray above the fuel film can fluoresce and will affect the measured signal. It is expected that the fuel film thickness on the piston crown is less than $50 \mu \mathrm{m}$, which corresponds to $\widetilde{z}=0.225$ for the fibers used in this research (numerical aperture of 0.22 and core diameter of $100 \mu \mathrm{m})$. The cumulative signal, shown in Figure 3-6, at this fuel film thickness is about $15 \%$ of the total signal that this system can accumulate if the fuel film thickness is infinite. From this figure, $50 \%$ of the maximum signal comes when the fuel film thickness is $0.22 \mathrm{~mm}(\tilde{z}=1)$ and more than $90 \%$ of the maximum signal comes when the fuel film thickness is $1.3 \mathrm{~mm}(\tilde{z}=5.5)$. This means that the liquid fuel droplets which are more than $2 \mathrm{~mm}$ from the fiber surface do not contribute to the signal. Moreover, the signal from the spray will be slight because the region occupied by the spray is less dense than the fuel film itself. Furthermore, the duration of the influence is expected to be very short because the spray will reach the fuel film in a short time caused by the spray momentum and piston movement.

The effect of the fuel spray on the signal intensity was calculated on the assumption that the fuel was distributed evenly in a hollow cone spray as shown in Figure 3-8. The fuel 
considered was isooctane and the amount of fuel injection was equivalent to the equivalence ratio of 0.3 . The density of the fuel in the hollow cone assuming uniformity is $4.26 \mathrm{~kg} / \mathrm{m}^{3}$, which is less than $1 \%$ of that for isooctane $\left(692 \mathrm{~kg} / \mathrm{m}^{3}\right)$. In this case, the fuel film equivalent cumulative signal can be expressed as only a function of number density of the fluorescent molecules, $N$, from the equation (2-1).

$$
\tilde{I}_{1, e q}(\tilde{z})=\frac{N_{\text {spray }}}{N_{\text {fuel }}}
$$

The contribution of the spray on the fuel film thickness is, thus, less than $1 \%$ of the fuel film in this calculation. Therefore, the spray above the fuel film will not appreciably affect the measurement.

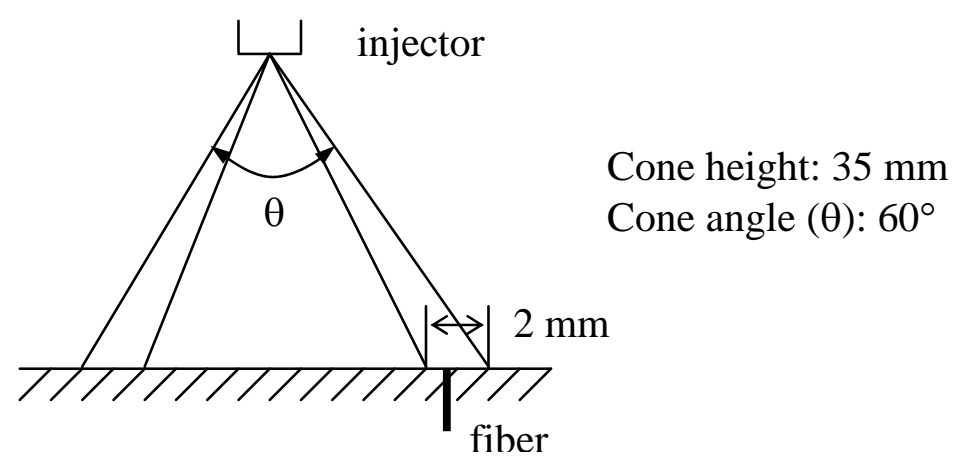

Figure 3-8. Hollow cone spray assumption. 


\section{Chapter 4}

\section{Experimental Apparatus}

The main parts of the experimental apparatus are the DISI engine and the optical setup for the fuel film thickness and temperature measurement. The cylinder head and piston bowl shape were newly designed for stratified DISI engine operation. Fuel injection and spark timing mapping tests were performed to find the optimum conditions for stratified operation. The main components of the optical setup are the laser, optical fiber, optical filters, and signal sensing device. The optical setups for the measurement of fuel film temperature and fuel film thickness were different although they use the same fibers installed on the piston crown. The details of the fiber installation method and optical setups for each measurement are explained in the following sections. 


\section{4-1. Engine}

The engine used for the experiment is four-stroke direct-injection spark-ignition (DISI) engine built on the crankcase of a GM Triptane single-cylinder research engine. The specifications of the engine are shown in Table 4-1. The cylinder head and piston bowl were designed for swirl directed wall-guided DISI operation in a late injection mode.

\section{4-1-1. Design}

The top view of the cylinder head and the combustion chamber is shown in Figure 41. It is a two-valve engine and the intake port was designed to generate a counterclockwise swirl flow. The piston has a flat top with a $10 \mathrm{~mm}$ deep reentrant off-centered circular bowl. The spark plug is positioned at the center of the combustion chamber, but it is not in the center of the piston bowl. The injector position and the angle of installation, $20^{\circ}$ from the vertical axis, were chosen to direct the injected fuel spray into the edge of the piston bowl when the engine is running at a stratified, late injection mode. The injected fuel spray is directed toward the spark-plug position by the wall of the piston bowl and the swirl flow. The spark plug has an extended electrode to place the electrode inside the piston bowl at the time

of ignition. The hole for injector installation was designed to accommodate two types of injectors by using adaptors for each injector. Therefore, both a high-pressure swirl injector and a low-pressure air-assisted injector can be installed conveniently.

Figure 4-2 is the side view of the engine showing the cylinder head, cylinder block, and the spacer between them. The spacer was designed to hold four quartz windows for 
passing a laser sheet. The detachable piston crown element is placed at the top of the Bowditch-type extended piston and it was held tight by a threaded piston cap and a locking pin. Therefore, the combustion chamber geometry can be modified conveniently by changing the shape of the piston crown.

One compression ring (Vespel) was used at the top groove of the piston cap and two rider rings (bronze filled Teflon) were used at the bottom grooves of the extended piston. Another rider ring was installed at the bottom of the Bowditch-type piston for alignment purposes. The oil ring was changed from metal to Vespel with an expander inside the ring. No engine oil was delivered to the combustion chamber during the engine test. The design compression ratio in Table 4-1 is based on the assumption that the top compression ring seals the gas perfectly. However, it was found from the motored in-cylinder pressure data that there were some leaks.

The schematic diagram of the engine coolant circuit is shown in Figure 4-3. The coolant temperature can be controlled by controlling the cold water flow in the heat exchanger. The mass flow rate of air into the engine was controlled by choked orifices upstream of the intake system. 
Table 4-1. Specifications of the research DISI engine.

\begin{tabular}{|c|c|c|}
\hline \multicolumn{2}{|c|}{ Displacement (cc) } & 511 \\
\hline \multicolumn{2}{|l|}{ Bore (mm) } & 92.4 \\
\hline \multicolumn{2}{|l|}{ Stroke $(\mathrm{mm})$} & 76.2 \\
\hline \multicolumn{2}{|c|}{ Connecting rod length (mm) } & 145.2 \\
\hline \multicolumn{2}{|c|}{ Design compression ratio } & 10.1 \\
\hline \multirow{4}{*}{ Valve timing } & IVO & $20^{\circ} \mathrm{BTDC}$ \\
\hline & IVC & $70^{\circ} \mathrm{ABDC}$ \\
\hline & EVO & $90^{\circ} \mathrm{BBDC}$ \\
\hline & EVC & $45^{\circ} \mathrm{ATDC}$ \\
\hline \multicolumn{2}{|c|}{$\begin{array}{l}\text { High-pressure swirl injector: } \\
\text { - Injection Pressure (bar gauge) } \\
\text { - Injection Cone Angle }\end{array}$} & $\begin{array}{c}52(750 \text { psig }) \\
60^{\circ}\end{array}$ \\
\hline
\end{tabular}




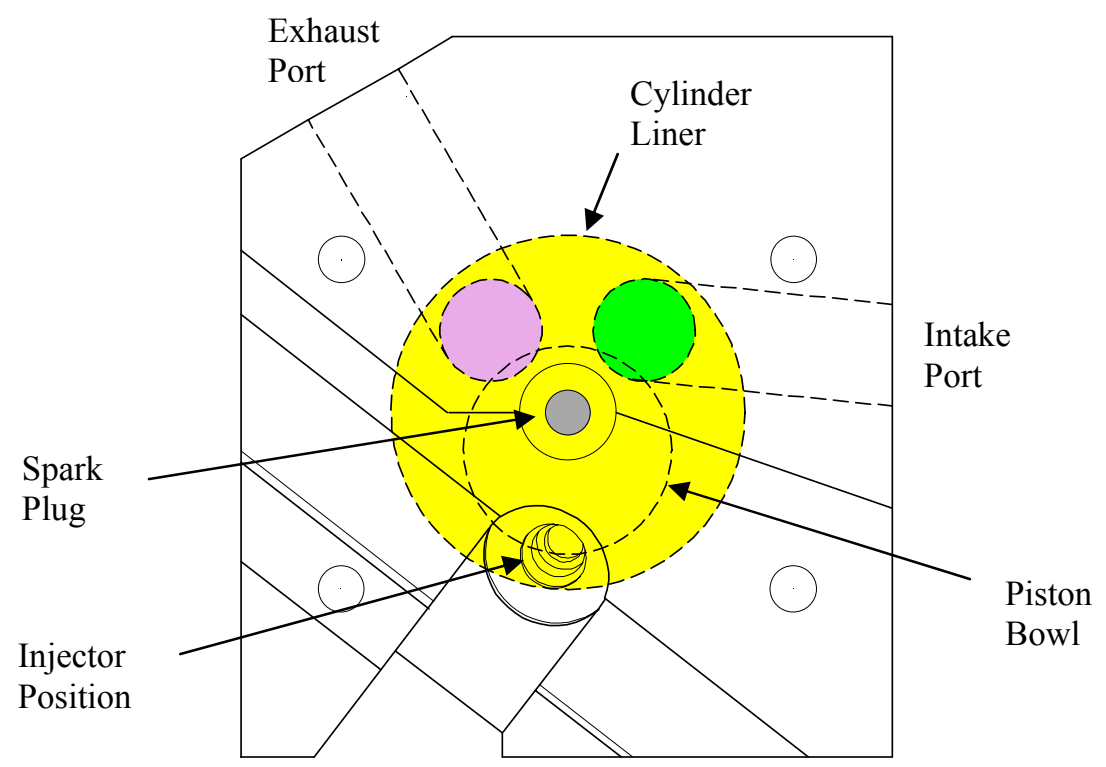

Figure 4-1. Top view of the cylinder head and combustion chamber.

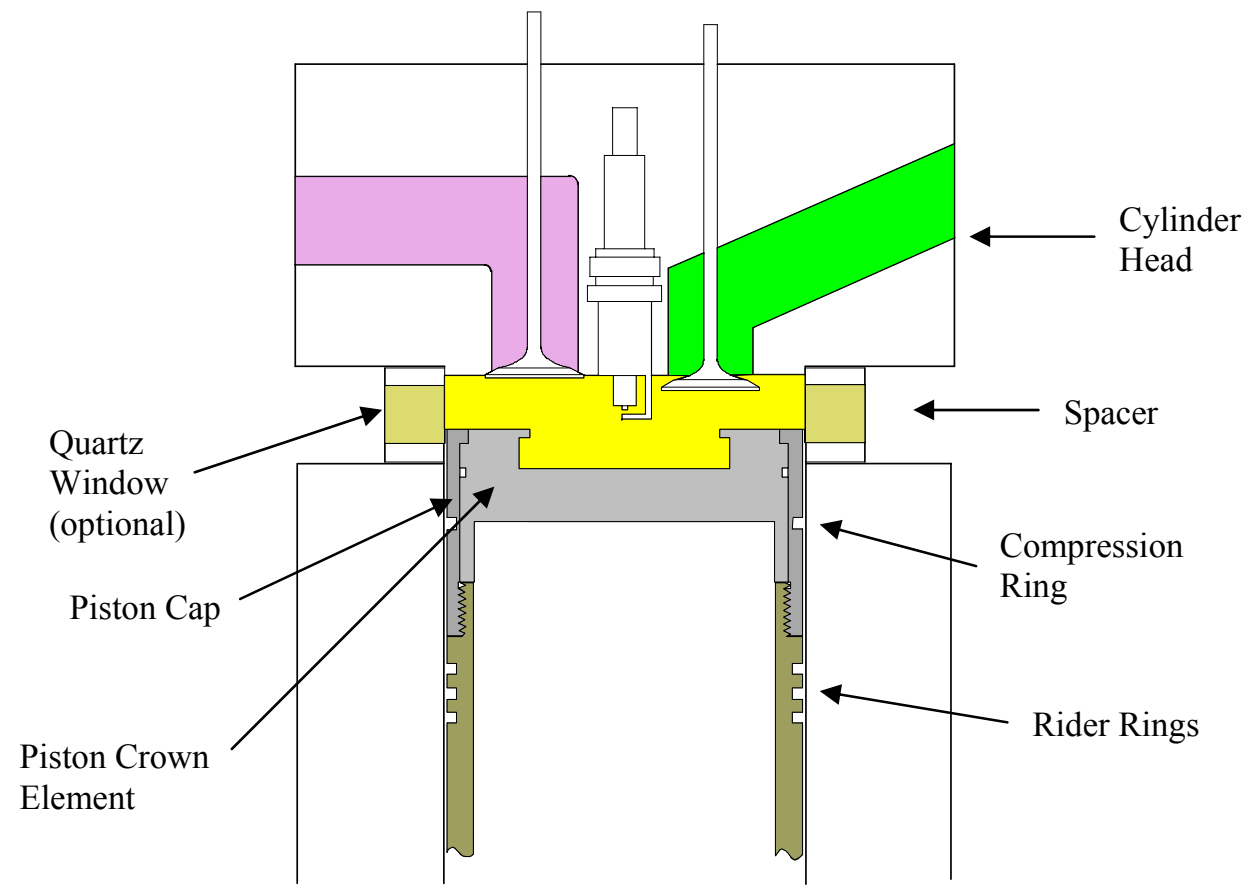

Figure 4-2. Side view of the DISI engine. 


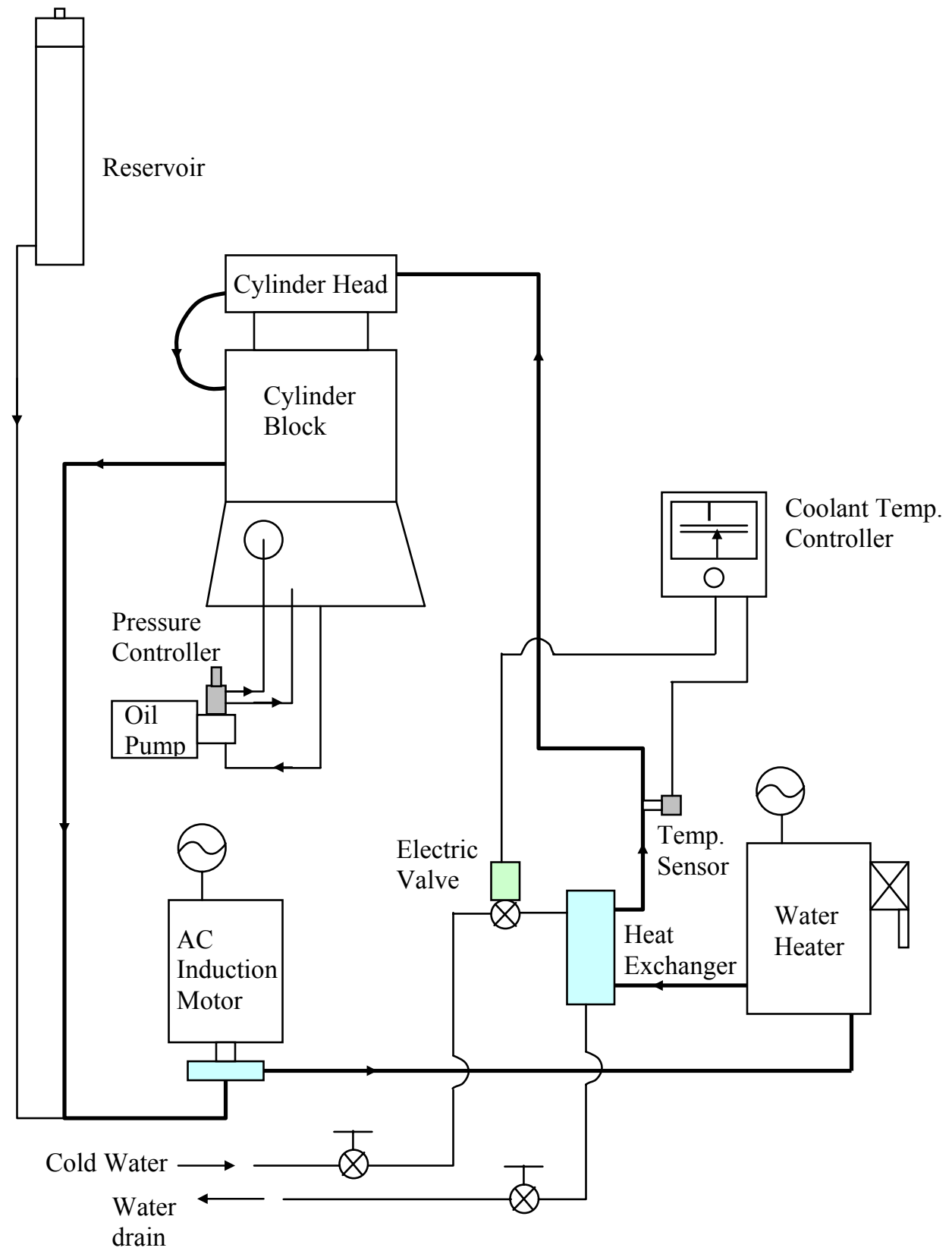

Figure 4-3. Schematic diagram of the engine coolant circuit. 


\section{4-1-2. Data Acquisition and Engine Control Systems}

A water-cooled Kistler 7063A piezoelectric pressure transducer was used for the measurement of in-cylinder pressure with a Kistler 5004 dual mode amplifier. An 8-channel, 14 bit PC-controlled data acquisition and analysis system (HT600, High-Techniques Inc.) was used for the data acquisition.

The spark and injection timings of the engine were controlled by a high speed engine controller, designed to solve timing and control problems of internal combustion engines. The controller has eight TTL output channels which can be independently controlled to turn on or off at specific crank angles through a computer program. Crank angle position was sensed by a rotary incremental encoder (Type H25, BEI), which has a resolution of four pulses per degree.

\section{4-1-3. Combustion Test Results}

DISI engine operation in a stratified combustion mode is significantly affected by the timing of fuel injection and spark ignition. Therefore, mapping tests were performed to find the optimum operating conditions at $600 \mathrm{rpm}$ and $1200 \mathrm{rpm}$ for the Chrysler high-pressure swirl injector. The end of injection (EOI) and spark timings (ST) were varied, and the NMEP (Net Mean Effective Pressure) and COV (Coefficient of Variation) of NMEP were measured at each engine operating condition. Figure 4-4 and Figure 4-5 show the results at $600 \mathrm{rpm}$ and $1200 \mathrm{rpm}$ at an overall equivalence ratio $(\phi)$ of 0.3 . The amount of fuel injected was 12 $\mathrm{mg}$ and it corresponds to a $1.9 \mathrm{~ms}$ injection duration for 52 bar fuel pressure. The results show that the maximum NMEP regions coincide with the minimum COV of NMEP regions 
at both engine speeds. The best operating condition at $600 \mathrm{rpm}$ was $43^{\circ} \mathrm{BTDC}$ EOI and $10^{\circ}$ BTDC ST, and it was $58^{\circ}$ BTDC EOI and $22^{\circ}$ BTDC ST at $1200 \mathrm{rpm}$. The combustion chamber pressures for these operating conditions are shown in Figure 4-6 along with the pressures at the motored condition.

Figure 4-7 shows the p-v diagram of the motored pressure and the combustion pressure at $600 \mathrm{rpm}$ for the Chrysler high-pressure swirl injector on a log-log scale. The curve of the motored pressure should be straight for both the compression and expansion strokes, and they should coincide with each other. However, the curve is not straight at the end of compression stroke, which can happen if the combustion chamber volume is incorrect as pointed out by Lancaster et al. (1975). Further, we can see that there are significant pressure differences between the compression and expansion strokes. This problem is caused by air leakage through the compression ring because the ring does not seal the air perfectly. Therefore, the peak combustion pressure is also lowered.

The DISI engine was run at the above mentioned stratified operating conditions for the fuel film temperature and thickness measurements. 

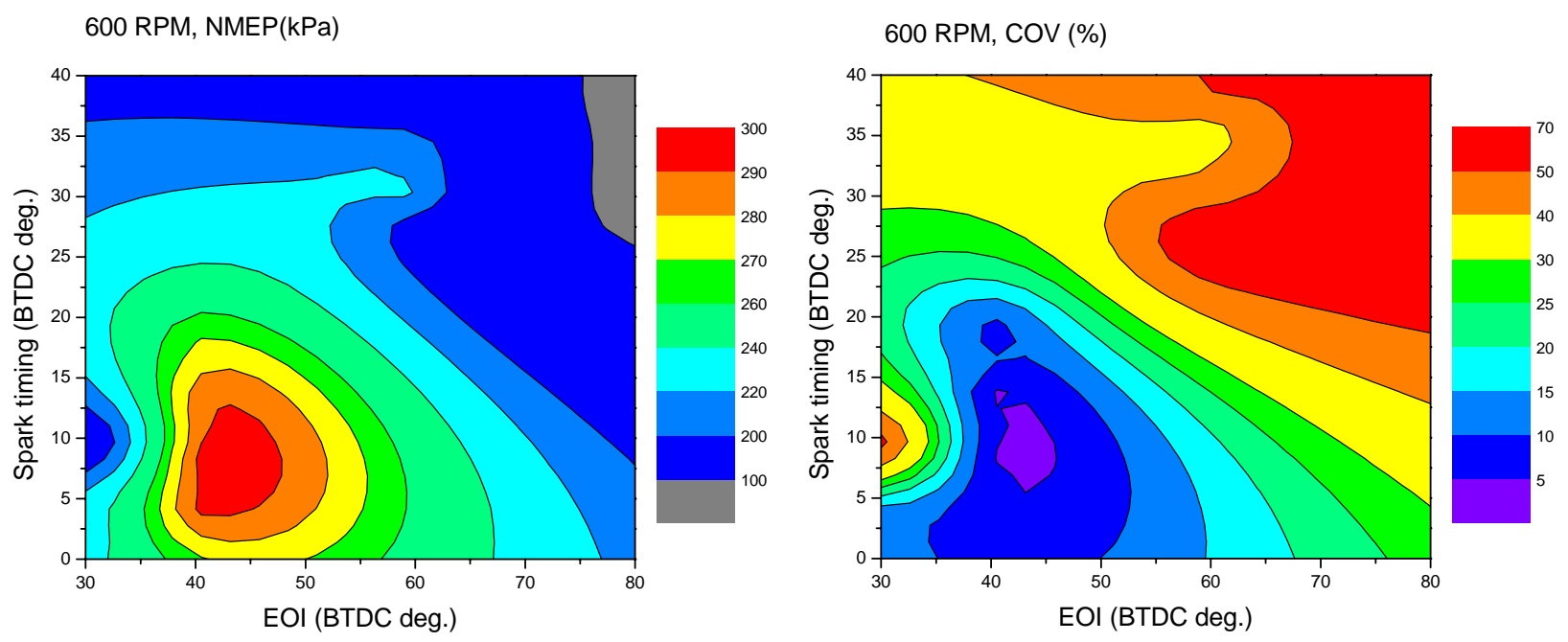

Figure 4-4. Results of engine mapping test for the high-pressure swirl injector at $600 \mathrm{rpm}$. $\Phi=0.3, \mathrm{~T}_{\text {coolant }}=73^{\circ} \mathrm{C}$, isooctane, 100 cycles averaged.

1200 RPM, NMEP(kPa)

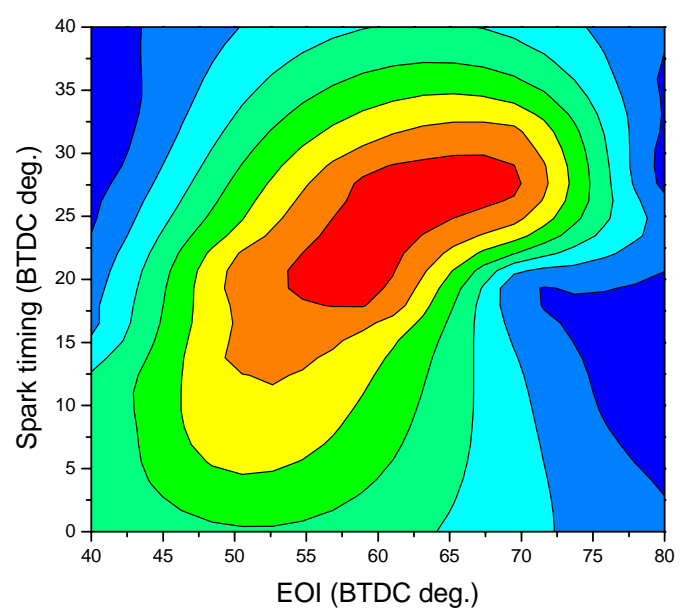

1200 RPM, COV(\%)

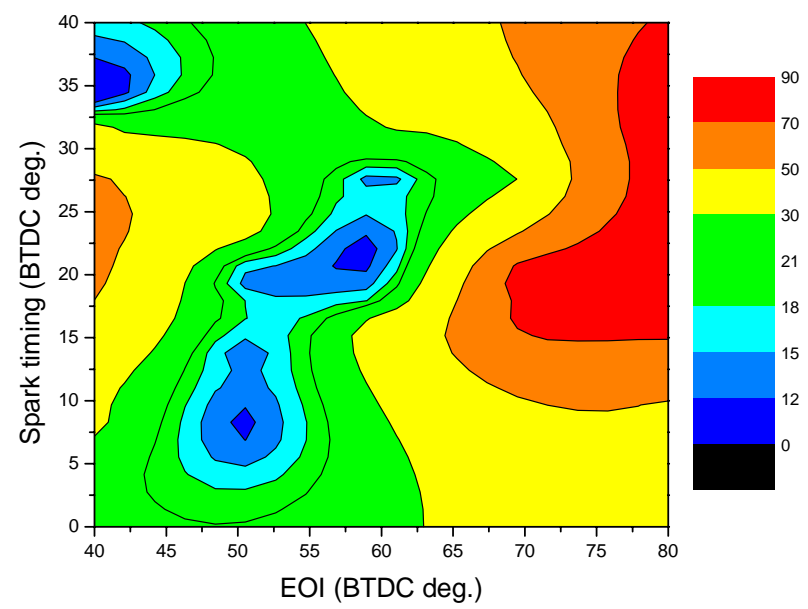

Figure 4-5. Results of engine mapping test for high-pressure swirl injector at $1200 \mathrm{rpm}$. $\Phi=0.3, \mathrm{~T}_{\text {coolant }}=73^{\circ} \mathrm{C}$, isooctane, 100 cycles averaged. 

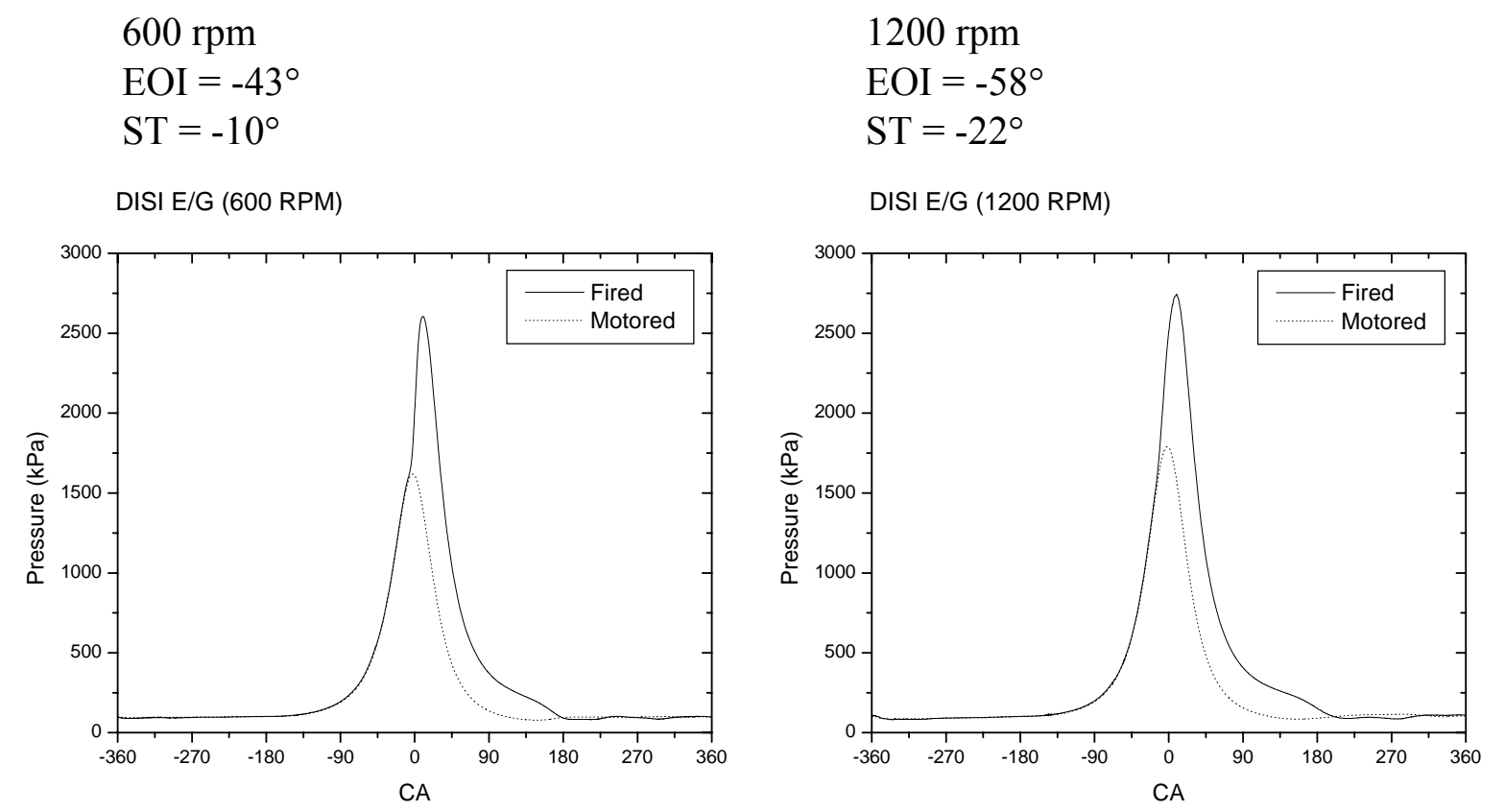

Figure 4-6. Combustion chamber pressures of the DISI engine at the selected End Of Injection (EOI) and Spark Timing (ST) conditions determined from the mapping tests when $\Phi=0.3$.
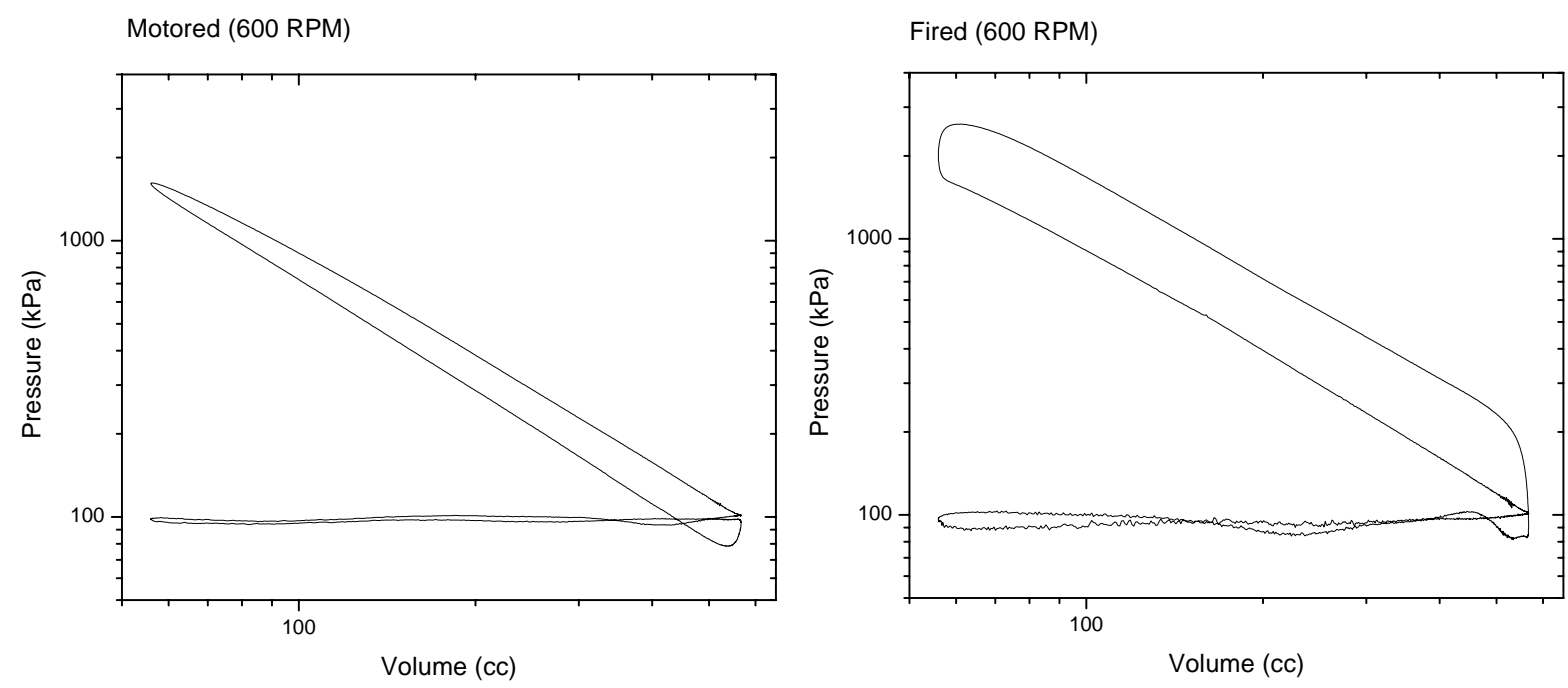

Figure 4-7. P-v diagram of the motored and fired engine conditions at $600 \mathrm{rpm}$ when $\Phi=0.3$. 


\section{4-2. Optical Setup}

\section{4-2-1. Optical Fiber Installation}

Four optical fibers and a thermocouple were installed in the piston bowl. Their positions are shown in Figure 4-8. The line of the fiber positions is coincident with the axis of the fuel injection. The fiber installation procedures were as follows. The fibers are inserted through the small holes in the piston crown. Aluminum putty (Aremco Pyro-putty 1000) was used to fill the clearance between the fiber and the hole. The fibers are guided from the lower side of the piston crown to the fiber support through a aluminum-alloy micro round tubing for protection. A transition junction style J-type thermocouple (Omega) was installed $1 \mathrm{~mm}$ below the piston crown. A thermocouple amplifier (Analog Devices, AD594CD) was used to convert the thermocouple signal to temperature.

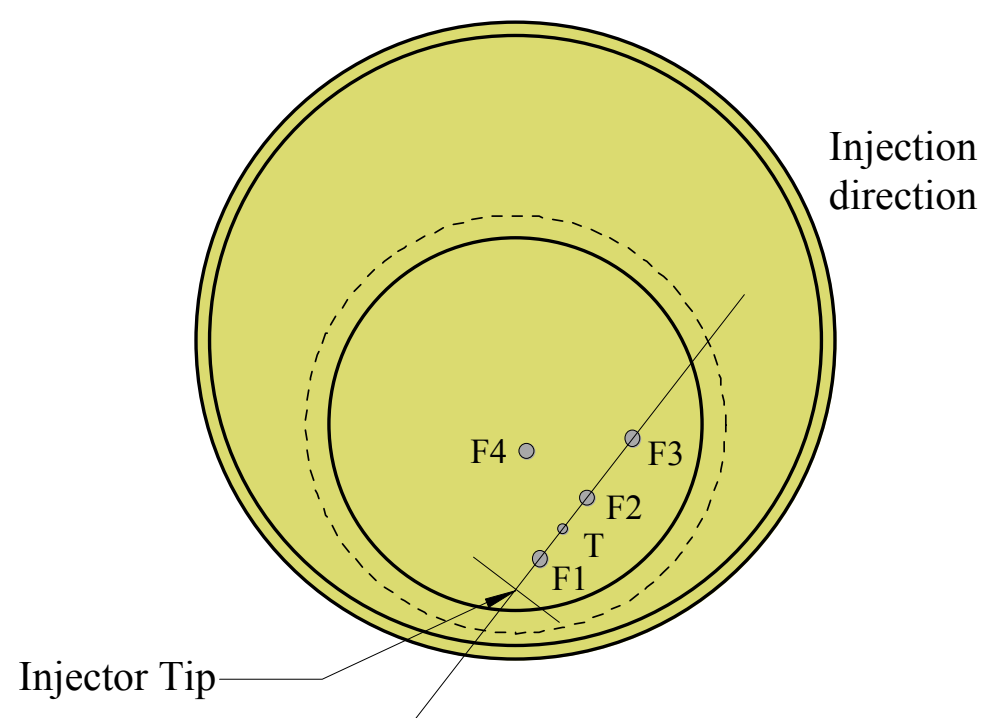

$52.5^{\circ}$

Figure 4-8. Optical fibers and a thermocouple positions in the piston bowl (Top view). 
The optical fibers and the thermocouple wire were shielded by using a flexible convoluted Teflon TFE tubing attached to the fiber support, which extends from the bottom of the piston to guide the fibers without breakage. Figure 4-9 shows the piston and optical fiber assembly. The fibers are connected to the outside of the engine through the mirror passage of the see-through engine as shown in Figure 4-10. The minimum bend radius of the optical fiber is usually 100 times its diameter. As shown in Figure 4-10, the optical fibers can sustain enough curvature during piston movement and it has been proven subsequently that the fibers can withstand flexure during the experiment. The fiber ends on the piston crown were polished flush with $0.3 \mu \mathrm{m}$ lapping film. SMA connectors (Thorlab) were used at the other ends of the fibers for easy connection at the fiber coupler of the optical setup. The fiber ends were polished by using a polishing tool kit (Thorlab).

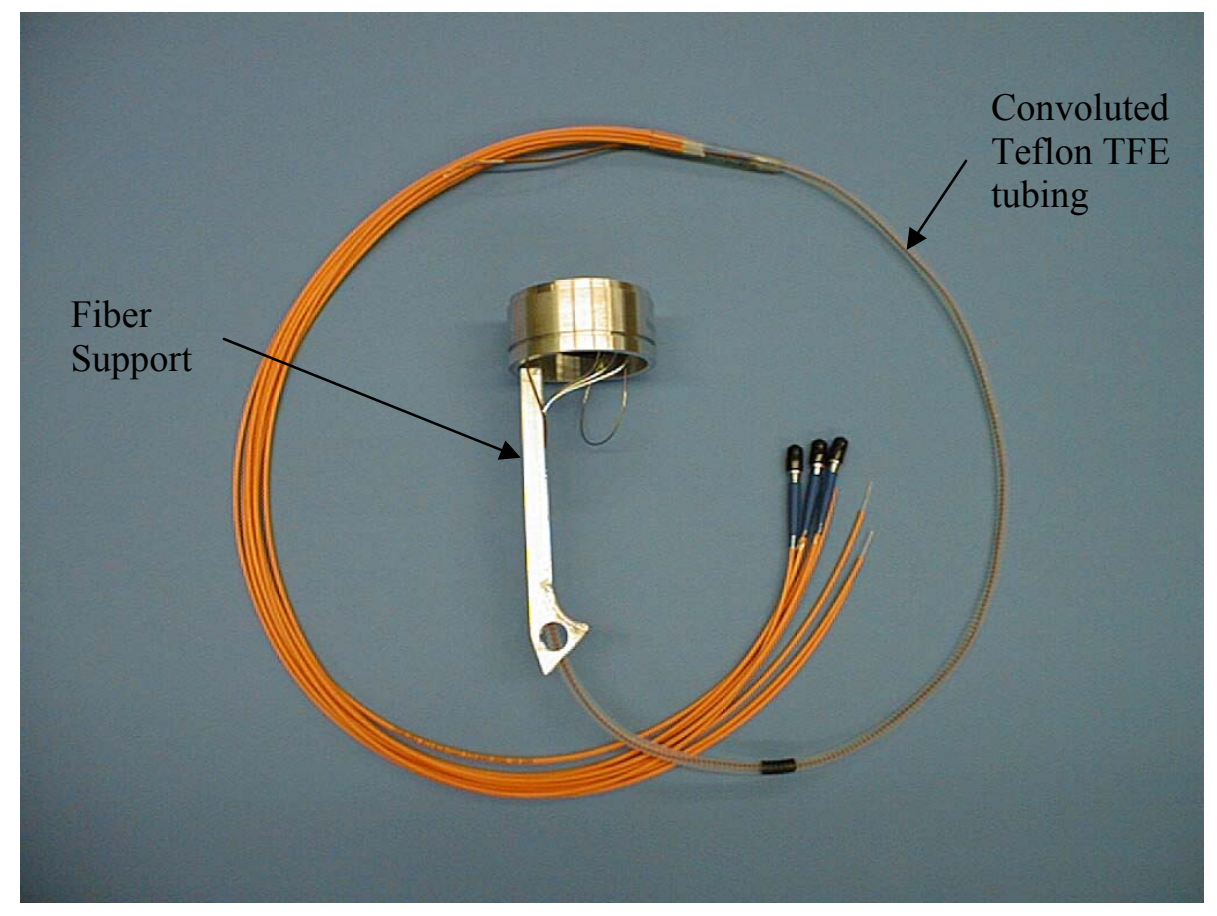

Figure 4-9. Piston and optical fiber assembly. 

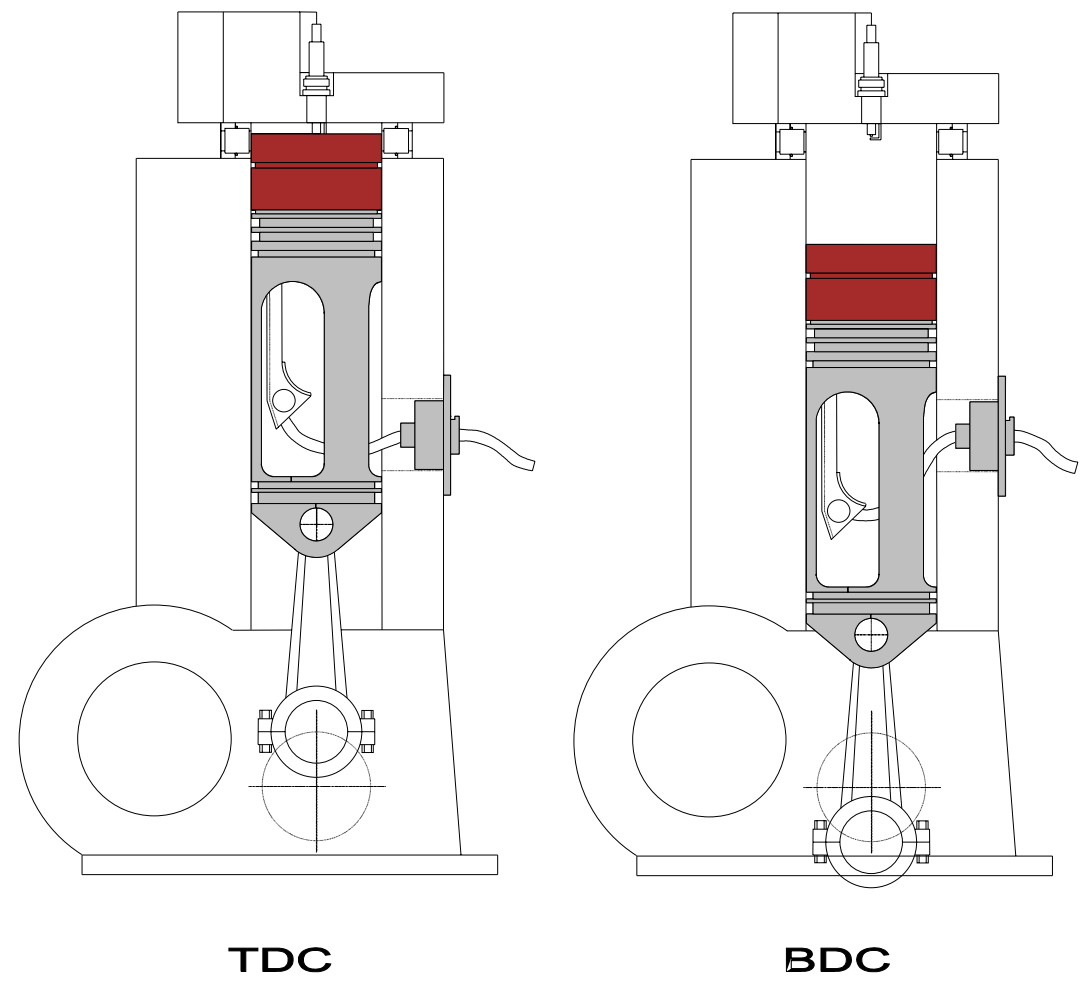

Figure 4-10. Optical fiber connection to the outside of the engine. 


\section{4-2-2. Fuel Film Temperature Measurement}

Fuel film temperature on the piston crown was measured by way of the fluorescencebased liquid-phase thermometer (FBLPT) as presented in the literature review. BTBP [N,N'Bis(2,5-di-tert-butylphenyl)-3,4,9,10-perylenedicarboximide] was chosen as a probe molecule, and was excited with a $488 \mathrm{~nm}$ argon ion laser (Lexel Model 95). The BTBP was first dissolved by small amount $(0.05 \%$ of fuel by volume $)$ of 2 -butanol $\left(\mathrm{T}_{\mathrm{bp}}=99^{\circ} \mathrm{C}\right)$ and mixed with isooctane $\left(\mathrm{C}_{8} \mathrm{H}_{18}\right)$. Then the fuel was heated up to the boiling point to help dissolution of BTBP and to reduce the amount of 2-butanol by evaporation. Isooctane is not fluorescent at the chosen wavelength of the laser and it has similar properties in terms of evaporation and combustion characteristics as the mid-point components of gasoline. The concentration of BTBP was $2 \times 10^{-6} \mathrm{M}$ (moles/liter). All the chemicals were obtained from Sigma-Aldrich.

The optical setup is shown schematically in Figure 4-11. The laser beam passes through a $500 \mathrm{~nm}$ short-pass edge filter to reduce the broadband plasma radiation of the laser tube. An Acousto-Optic Modulator usually called Bragg cell (IntraAction AOM-405, ME42R) was used to chop the laser to discern the fluorescent signals from the combustion luminosity during the engine firing conditions. The Bragg cell trigger signal was made by a J-ㅡ positive-edge-triggered flip-flop (SN74LS109AN) based on the B-pulse of the engine encoder. The output pulse of the flip-flop is shown in Figure 4-12. The laser beam "blinks" based on the flip-flop signal and alternating fluorescent signals were taken at the rising edge of each A-pulse. 
The laser beam was focused to the end of the fiber through an infinity-corrected microscopic objective lens (Newport L-10X) in a fiber coupler. The other end of the fiber can be mounted flush on the piston crown or a calibration device. The fluorescence from the BTBP in the fuel came out through the same fiber and was reflected to the photo-sensing unit by a blue additive filter (Andover 505FD64). The strong $488 \mathrm{~nm}$ laser light was filtered out by using a holographic notch filter (Kaiser HNF-488.0-1.0) before it was introduced to the photo-sensing unit. The fluorescent light was divided by a beam-splitter, which was inside the PMT unit. The split fluorescent lights were passed through $515 \mathrm{~nm}$ and $532 \mathrm{~nm}$ bandpass filters, respectively. The bandwidth of the $515 \mathrm{~nm}$ filter was $10 \mathrm{~nm}$ and that of the $532 \mathrm{~nm}$ filter was $3.4 \mathrm{~nm}$.

The intensity of the fluorescent light was measured by using photomultiplier tubes (PMT). The two PMTs used in this experiment have different model numbers (H5783-03 for $515 \mathrm{~nm}$ and H6780-03 for $532 \mathrm{~nm}$ ) and different sensitivities although both of them were made by Hamamatsu. The control voltages were adjusted to $0.75 \mathrm{~V}$ for both PMTs. The resistances used to convert the negative current output from the PMTs to voltage were $10 \mathrm{k} \Omega$. The resistance was low enough to provide sufficient time response of the signal up to 1200 rpm in the engine. The maximum allowable output current of the PMT is $100 \mu \mathrm{A}$, giving a maximum voltage output of $-1.0 \mathrm{~V}$. Ratios of the signal intensity at $515 \mathrm{~nm}$ over that of 532 $\mathrm{nm}$ were measured on the crank angle basis during the whole engine cycle. Then the ratios were converted to temperatures by using the calibration result performed in a calibration device. 
For temperature calibration, the fiber in the optical setup was changed to the fiber of the calibration device as shown in Figure 4-13. A type K thermocouple was used to measure the fuel temperature and the optical fiber was installed near the thermocouple position. The fuel flows in a $0.3 \mathrm{~mm}$ thick channel with a small flow-rate to eliminate the possibility of photobleaching during the calibration. Heating elements are inserted in the calibration device and fuel temperature was controlled by using a temperature controller. The ratios were measured as a function of temperature and the calibrated curve was used as a reference for the fuel film temperature measurement on the piston crown.

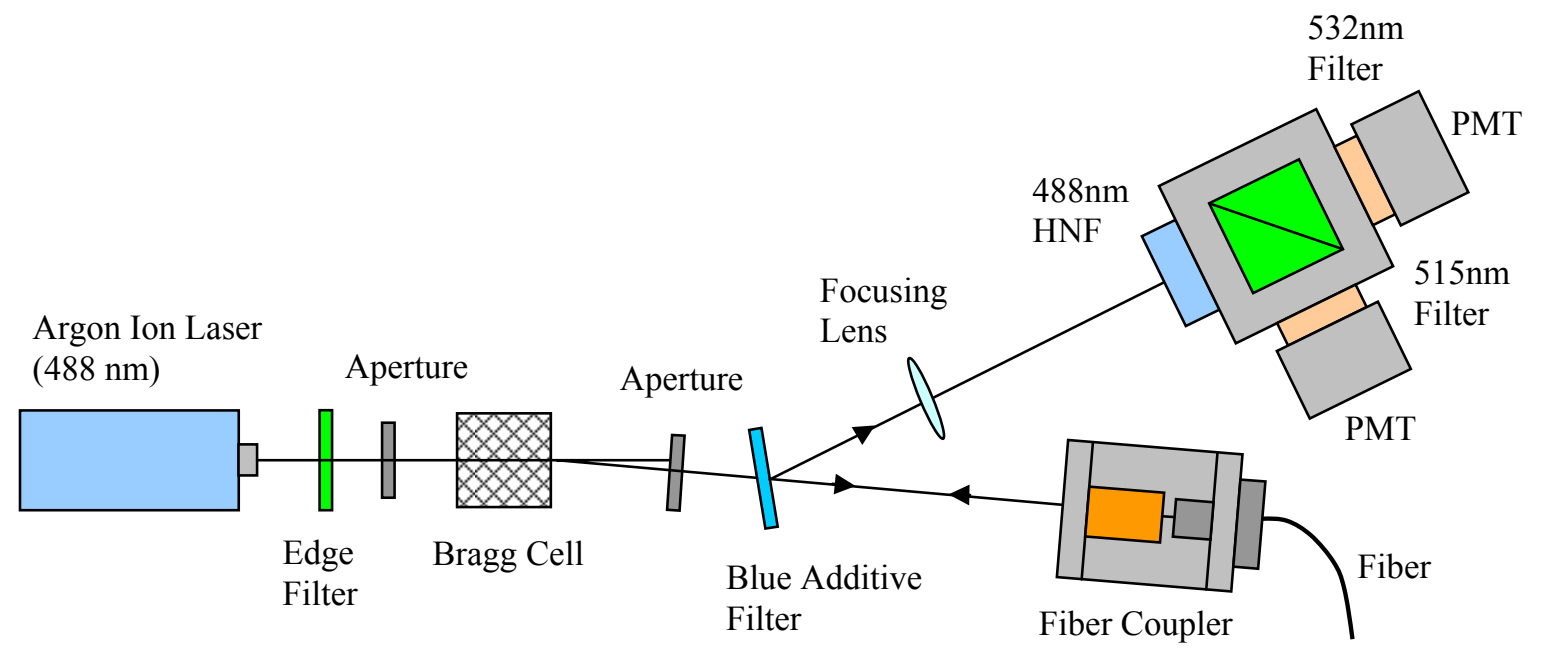

Figure 4-11. Optical setup for fuel film temperature measurement. 


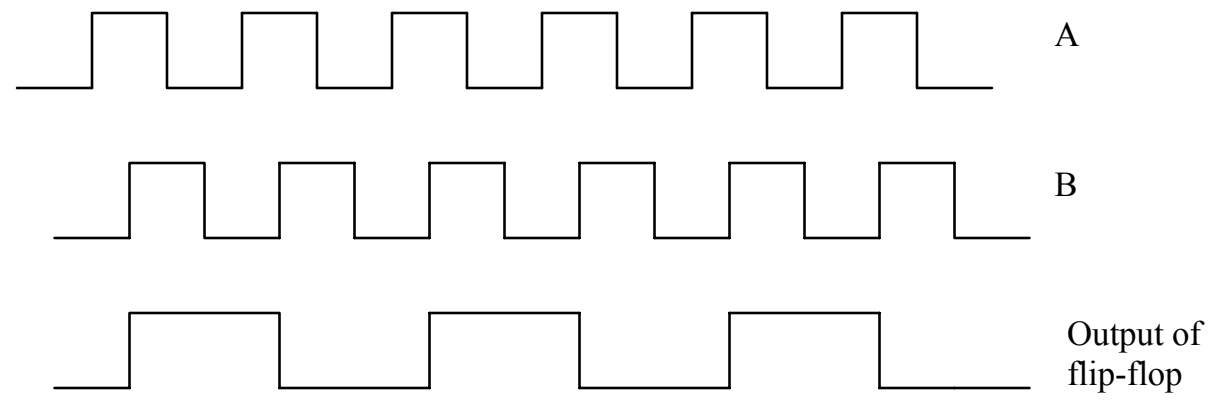

Figure 4-12. Relationship between A-pulse and the generated flip-flop signal, which makes the laser beam blinks.

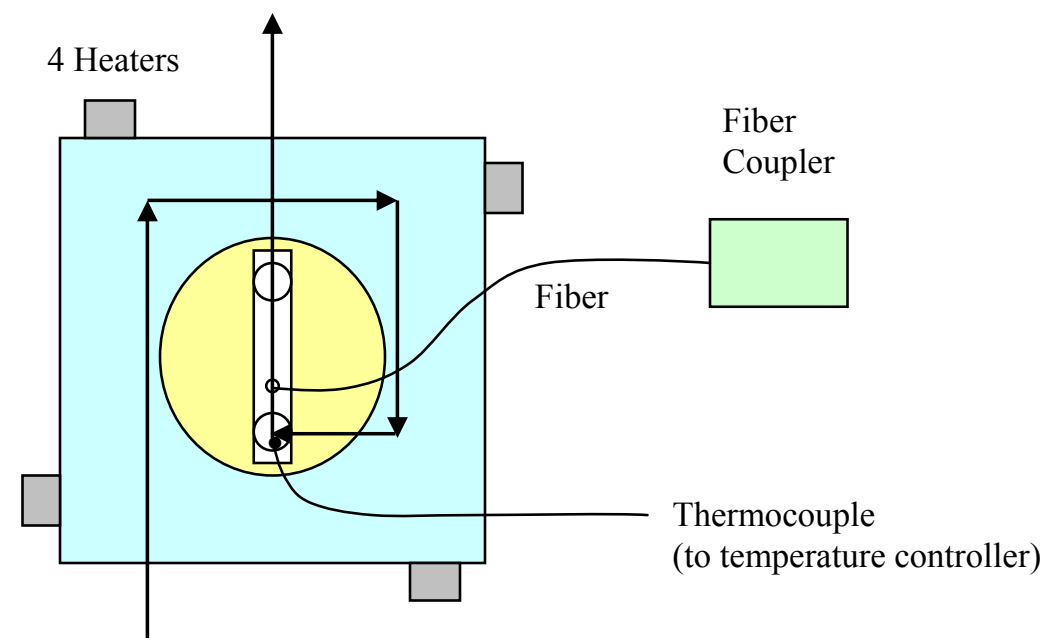

Fuel flow path

Figure 4-13. Fuel temperature calibration device. 


\section{4-2-3. Fuel Film Thickness Measurement}

The fuel film thickness on the piston crown was obtained using the laser-induced fluorescence (LIF) technique, which is well established for detecting and identifying specific species. The optical setup of the fiber-based LIF is shown in Figure 4-14. The basic setup from the laser to the aperture just after the Bragg cell is the same as that of the temperature measurement. The same fiber coupler is used, also. The $457.9 \mathrm{~nm}$ beam of argon ion laser (Lexel Model 95) was used to excite the fluorescent molecules in the fuel. The beam was reflected to the fiber coupler through a blue reflective filter (Andover 475FD68). The optical fiber was connected from the fiber coupler to the piston crown. Laser-induced fluorescent light from the fuel returned through the same fiber used to deliver the laser beam to the piston. From there it was reflected into the PMT through the blue reflective filter designed to pass only the light whose wavelength is higher than $475 \mathrm{~nm}$ (50\% point) and a color subtractive filter (CVILaser, CP-SM-550) to reduce the presence of $457.9 \mathrm{~nm}$ laser light. A holographic notch filter (Kaiser HNF-457.9-1.0) was used in front of the PMT to filter out the scattered $457.9 \mathrm{~nm}$ laser light. The total LIF signal was measured by the PMT during the whole engine cycle and this signal was used to calculate the fuel film thickness using the method described in the previous chapter. 


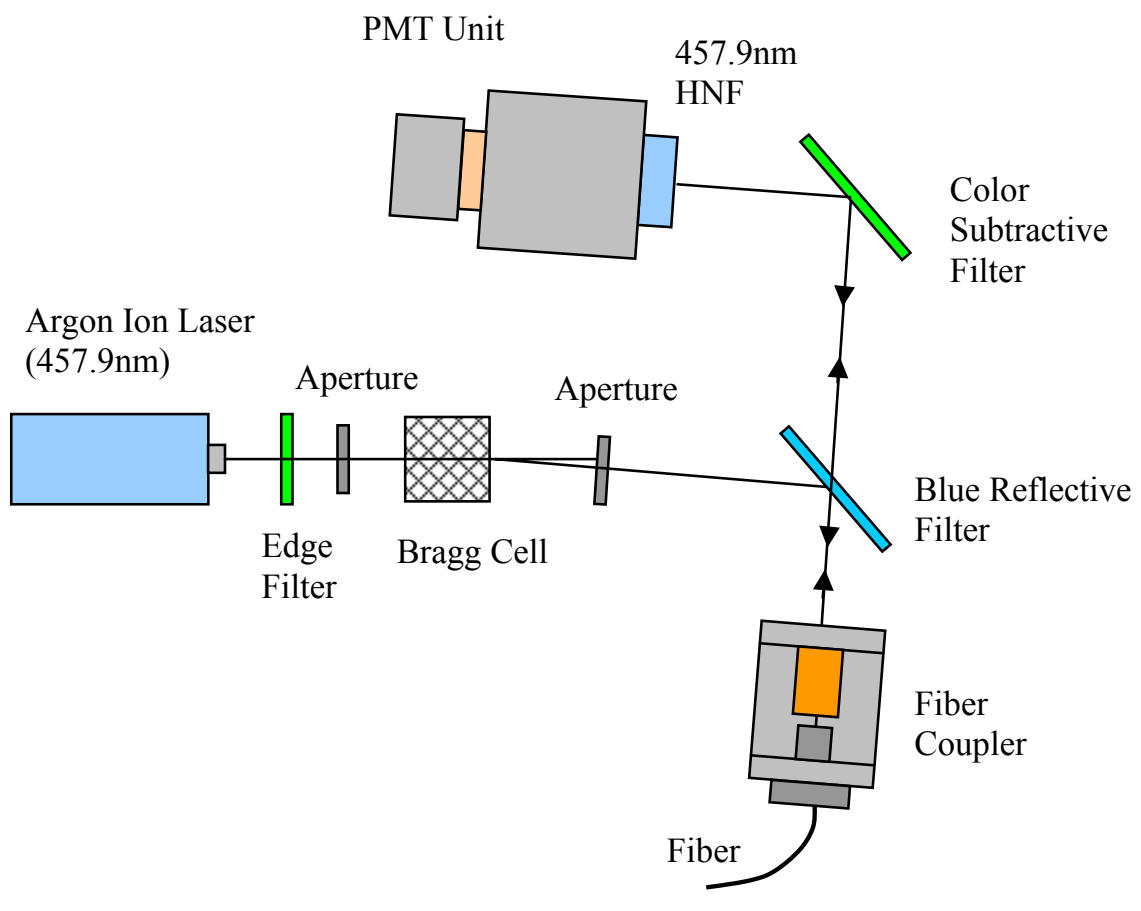

Figure 4-14. Optical setup for fuel film thickness measurement. 


\section{Chapter 5}

\section{Results of Fuel Film Temperature Measurement}

Fuel film temperatures on the piston crown of a DISI engine were measured using the fiber-based liquid-phase LIF method. The fuel was a $2 \times 10^{-6} \mathrm{M}$ solution of BTBP in isooctane. Calibration of the BTBP fluorescence with temperature was performed in a calibration device. Then, the method was applied to the DISI engine and the fuel film temperatures were measured through the whole engine cycle under motored and fired conditions at 600 and $1200 \mathrm{rpm}$. 


\section{5-1. Temperature Calibration}

BTBP was dissolved into isooctane and the solution was used for temperature calibration in the setup shown in Figure 4-13. Continuous fluorescent signals having center wavelengths of $515 \mathrm{~nm}$ and $532 \mathrm{~nm}$ were measured and the intensity ratio of the two signals, $I_{515} / I_{532}$, was a function of temperature. The background signal, the intensity when there was no fuel, was subtracted from the measured fluorescent intensity.

The data acquisition system utilized during the calibration test was either an oscilloscope (Tektronix TDS 380) or the HT600. The calibration result from the scope mode without laser chopping was the same as the one from engine running condition where laser was chopped. Therefore, calibrations in this section were performed in a scope mode without laser chopping. The measured voltages were slightly lower than the real ones because of the high input impedance of the measuring equipment. However, it did not affect the ratio of the two output signals, which is the desired output.

Several tests were performed before the final calibration to investigate the effects of some critical factors on the fluorescent signal: the BTBP solvent, laser power, BTBP concentration, fuel pressure, fuel aging, laser beam and fiber end focusing, and photobleaching of the LIF signal. 


\section{5-1-1. Effect of BTBP Solvent}

BTBP was dissolved in a small amount of solvent before it was mixed with isooctane. However, the selection of the solvent was found to be very important although its amount was small. Two solvents having different boiling temperatures were tested.

Figure 5-1 shows the calibration result when 1-heptanol $\left(\mathrm{T}_{\mathrm{bp}}=176^{\circ} \mathrm{C}\right)$ was used as a solvent. It shows that the intensity ratio decreases as the BTBP concentration increases. The curve should not be changed with BTBP concentration because the concentration is expected to increase continuously during the experiment by fuel evaporation. Fluorescent spectra were measured utilizing a monochromator in the optical setup shown in Figure 5-2 to investigate this behavior. The fuel mixture was heated to the boiling temperature of the fuel after preparation and then cooled for better BTBP dissolution. The BTBP concentration was changed by fuel evaporation from the BTBP-fuel mixture assuming no vaporization of the BTBP. This fuel represents the actual changing concentration on the piston crown of the engine. Figure 5-3 is the spectrum at two laser powers in cases when the fuel mixture was both unheated and heated to the fuel boiling point. The intensity axis has been inverted in the figure for convenience. The results show that fuel heating and higher laser power increase the fluorescent intensity, but the peak fluorescence is maintained at the same wavelength. Figure 5-4 shows the fluorescent spectra at different concentrations. It shows that the peak fluorescence location is shifting to the higher wavelength as the concentrations increase, and this is the cause of the decrease in intensity ratio with concentration when 1-heptanol is the solvent. 
When 2-butanol $\left(\mathrm{T}_{\mathrm{bp}}=99^{\circ} \mathrm{C}\right)$ was used as a solvent, the peak fluorescence wavelength was unaffected by concentration as shown in Figure 5-5. Although the intensities increased as the concentrations increased, the intensity normalized by its peak value (lower in Figure 55) was the same at all concentrations. It is not clear why the small amount of solvent having different boiling temperature caused this problem. The amount of solvent was less than $0.5 \%$ of the fuel by volume in each case.

The calibration curve for 0.5\% 2-butanol, however, showed a significant aging tendency. The intensity ratio measured at different times after mixture preparation at the same conditions was not the same. The differences decreased as the amount of 2-butanol decreased. The amount of 2-butanol was found to be the critical factor on the repeatability of the calibration curve. The best amount of 2-butanol was 0.1 cc for 200 cc isooctane $(0.05 \%)$. The fuel mixture was then boiled for a short time for better BTBP dissolution. The fuel heating may have removed the solvent by evaporation. The temperature calibration curve was not changed although the BTBP concentrations were changed.

The fuel used in the following tests was isooctane with a BTBP concentration of $2 \times 10^{-6} \mathrm{M}$. The solvent used to dissolve the BTBP was 2-butanol, which was $0.05 \%$ of isooctane by volume. 


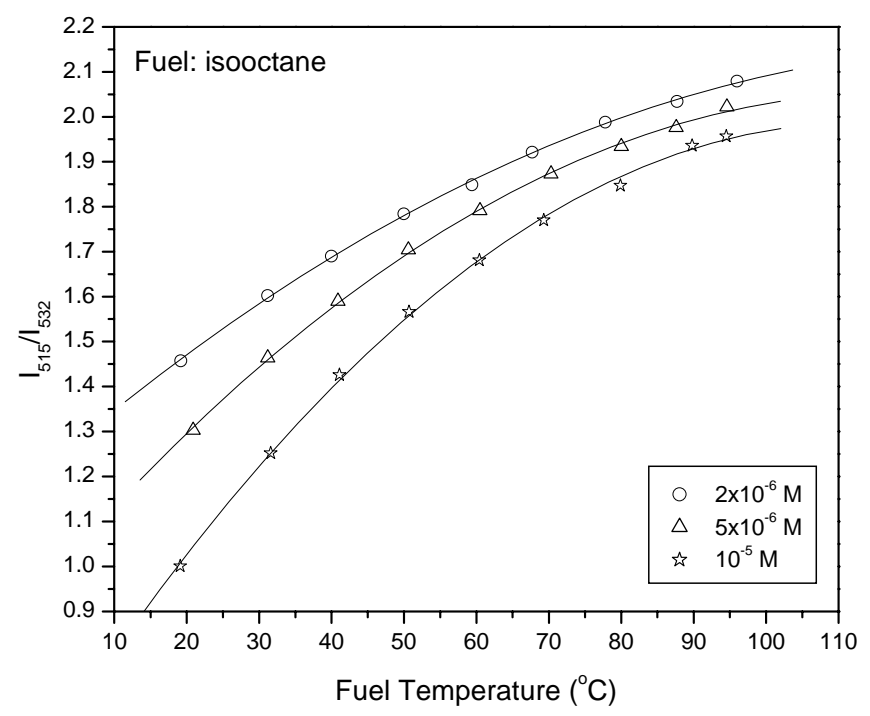

Figure 5-1. BTBP concentration effect on the intensity ratio when 1-heptanol was used as a BTBP solvent. $\mathrm{P}_{\mathrm{L}}=10 \sim 18 \mathrm{~mW}$.

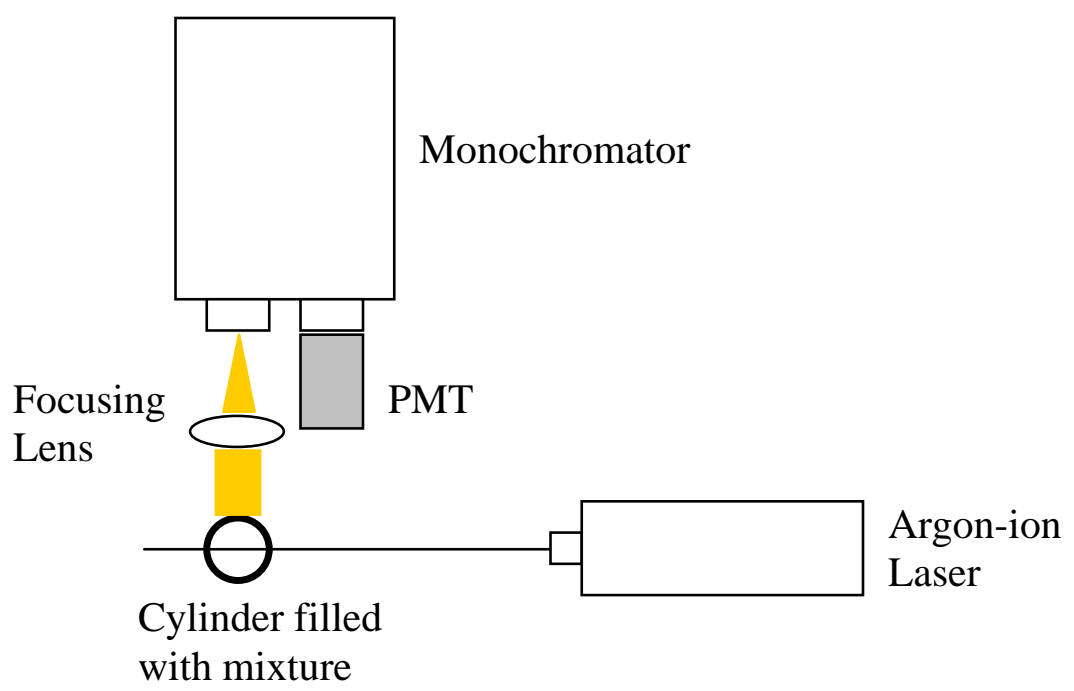

Figure 5-2. Setup for monochromator test. 


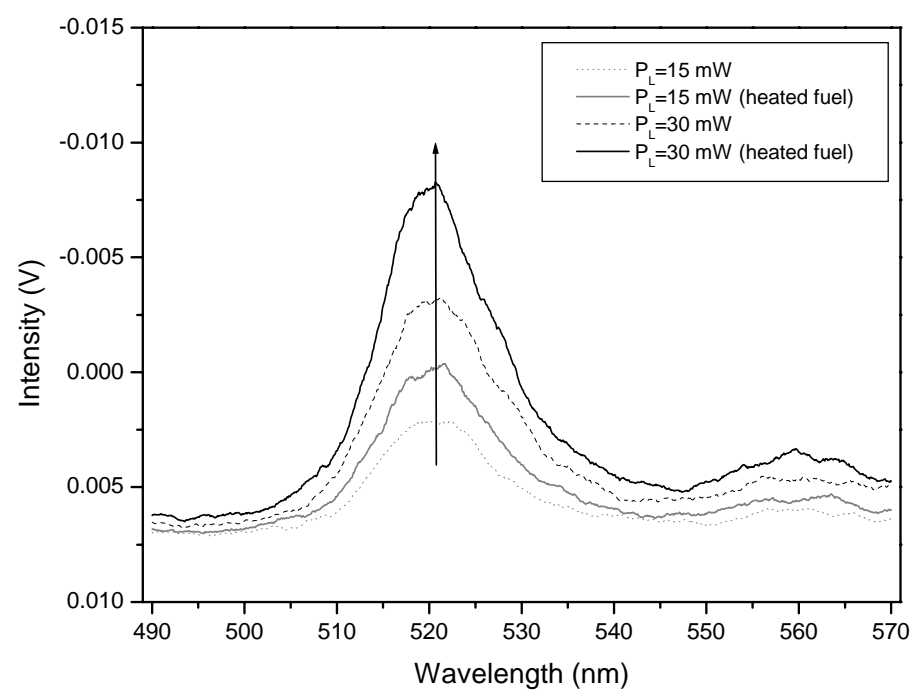

Figure 5-3. Effect of laser power and fuel pre-heating on fluorescent spectra for 1-heptanol solvent. $\mathrm{T}=22^{\circ} \mathrm{C}$, isooctane $+2 \times 10^{-6} \mathrm{M}$ BTBP.

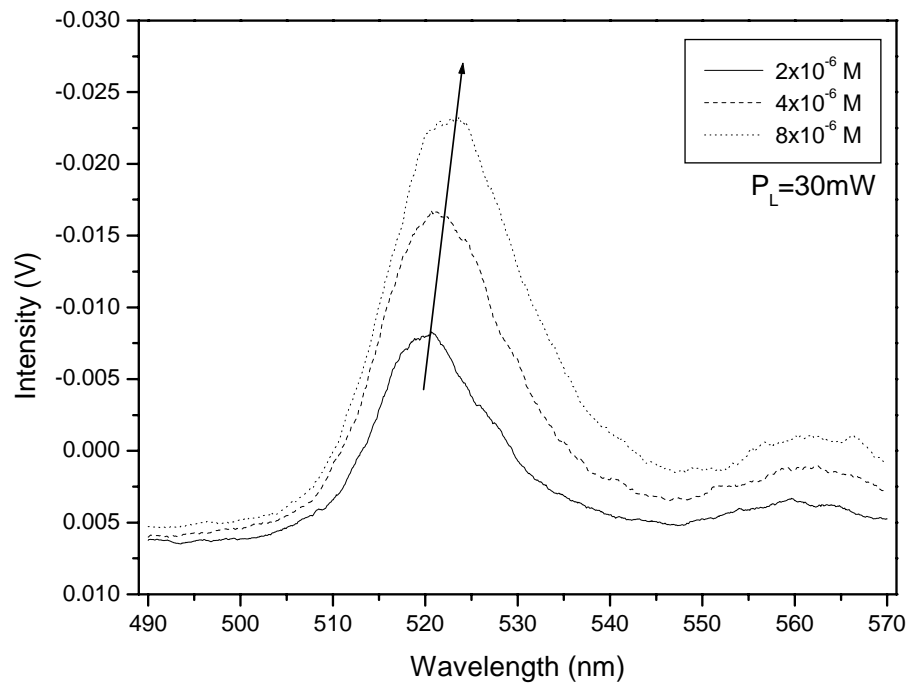

Figure 5-4. Concentration effect on fluorescent intensity spectra for 1-heptanol solvent. $\mathrm{T}=22^{\circ} \mathrm{C}$, isooctane $+2 \times 10^{-6} \mathrm{M}$ BTBP. 
(a)

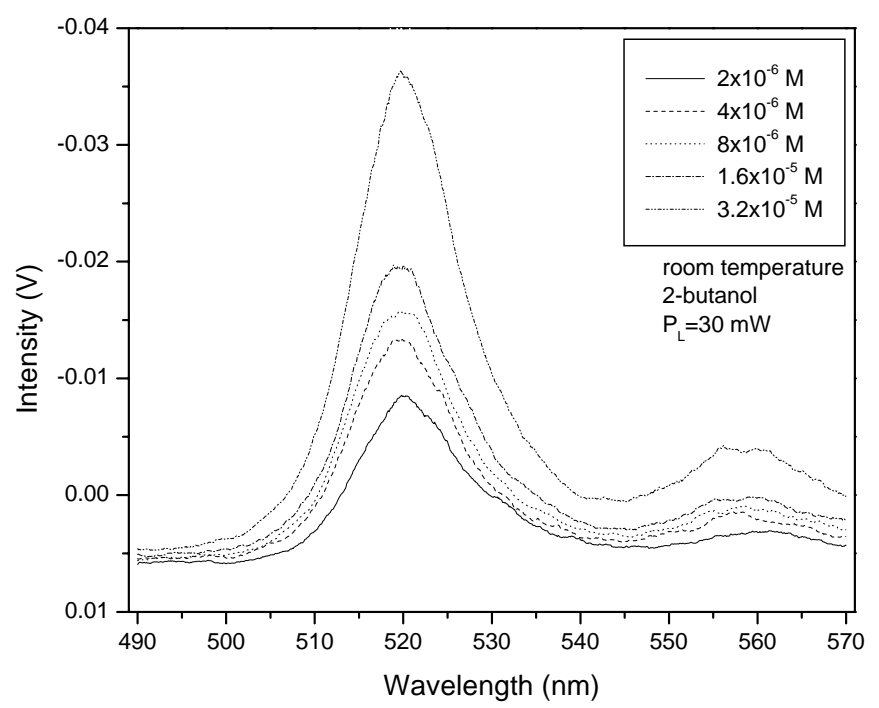

(b)

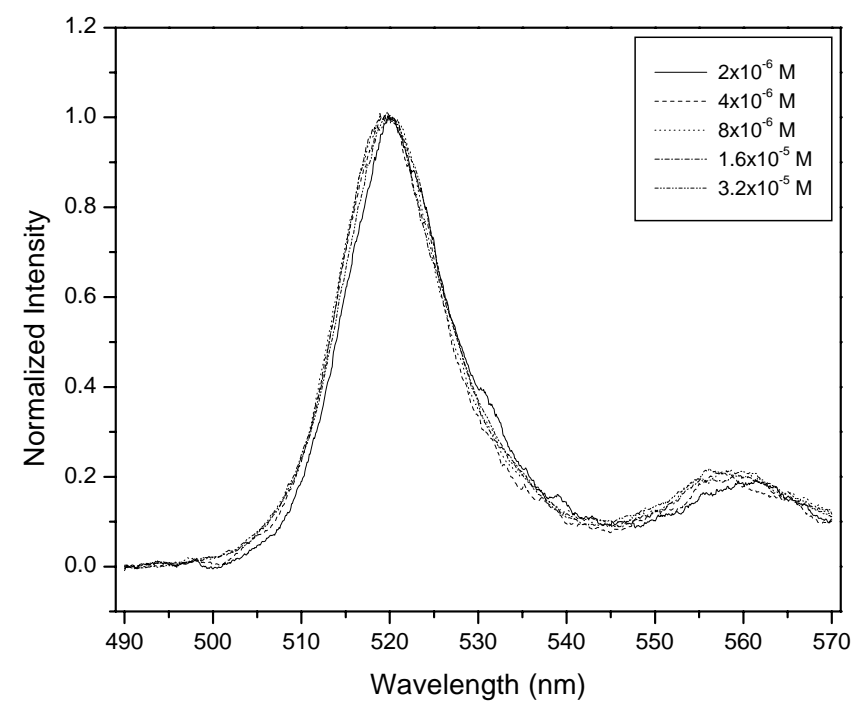

Figure 5-5. Concentration effect on (a) fluorescent intensity spectra and (b) normalized intensity spectra when 0.5\% 2-butanol was used as a solvent for BTBP. Fuel was isooctane. 


\section{5-1-2. Effect of Laser Power and BTBP Concentration}

Before checking the effects of laser power and BTBP concentration, the effect of fuel flow rate in the calibration device was checked at room temperature. Fuel flow rate was controlled and it was normalized based on the highest flow rate tested as shown in Figure 56. The intensity ratio was not changed for different fuel flow rates. Therefore, a minimal amount of fuel was flowed in the calibration device during the calibration to prevent photobleaching caused by continuous laser irradiation.

The laser power effect on the signal intensity and intensity ratio at room temperature are shown in Figure 5-7. The result shows that the signal intensities increased linearly as the laser power increased, however, the ratio of the two signal intensities, $I_{515} / I_{532}$, was not changed. Figure 5-8 shows the effect of laser power at higher temperatures. The temperature was increased up to $140^{\circ} \mathrm{C}$ by pressurizing the fuel to $300 \mathrm{kPa}$. The ratio was not changed significantly for different laser powers at higher temperatures. Therefore, small fluctuations of the laser power during the measurement will not affect the temperature reading.

Figure 5-9 shows the effect of BTBP concentration on the intensity ratio. The concentration was changed by parent fuel evaporation from the initial $2 \times 10^{-6} \mathrm{M}$ BTBP-fuel mixture. The laser power was decreased at higher concentrations to maintain the signal intensities within the saturation limit of the PMT (1V). Test results showed that the intensity ratio was not sensitive to the changes in BTBP concentration and laser power although the intensities of individual signals were changed significantly. 


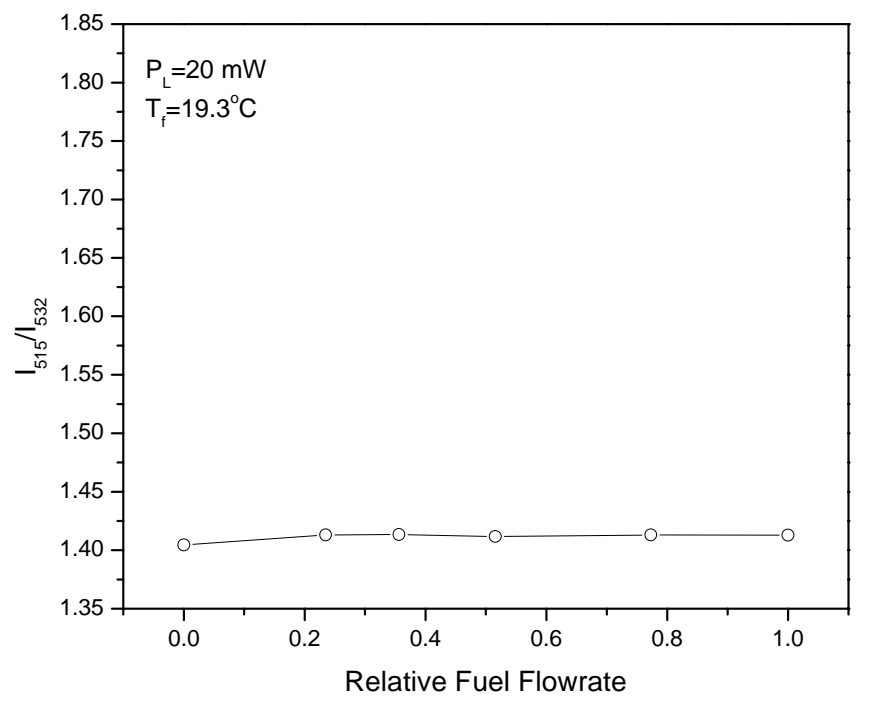

Figure 5-6. Effect of fuel flow rate on the intensity ratio.
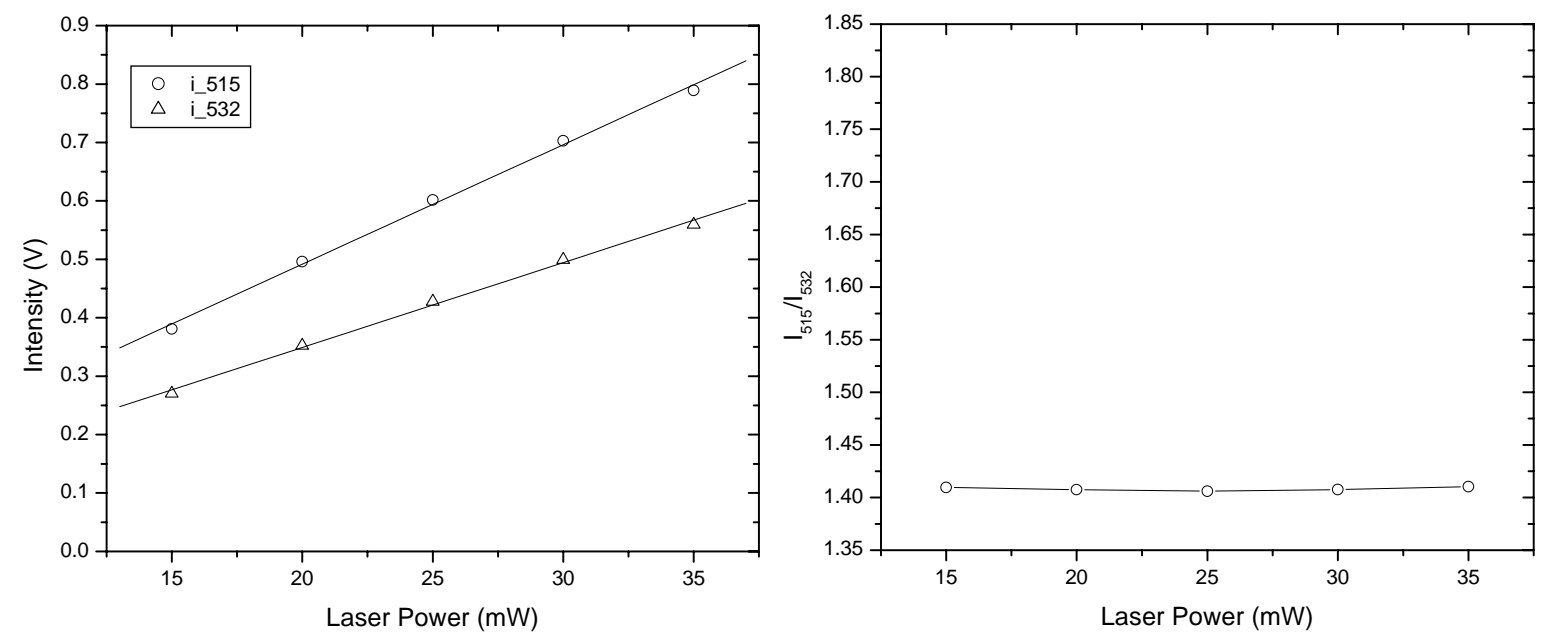

Figure 5-7. Effect of laser power on signal intensities and the intensity ratio. 


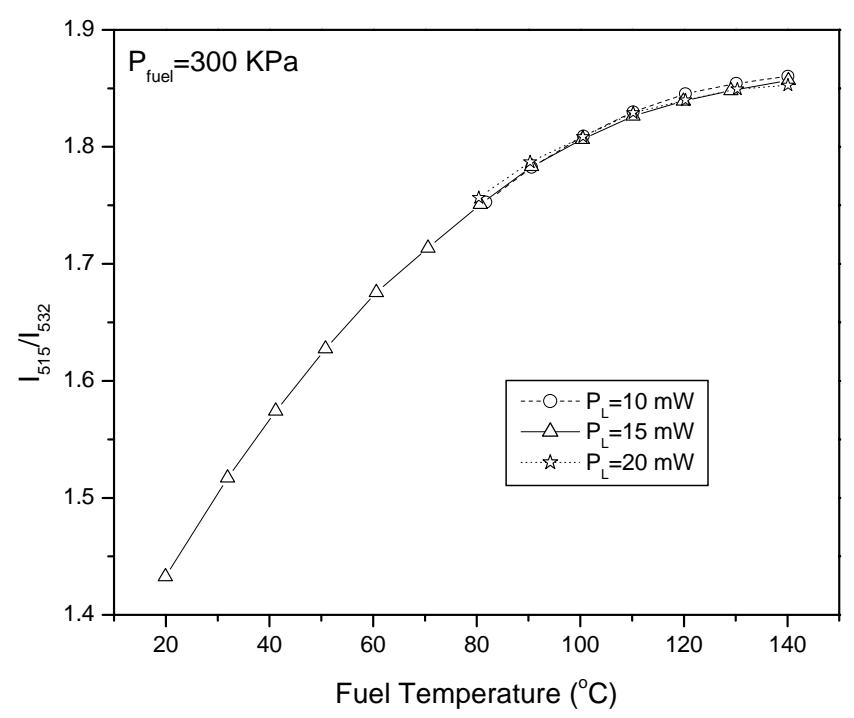

Figure 5-8. Effect of laser power on the intensity ratio at elevated temperature.

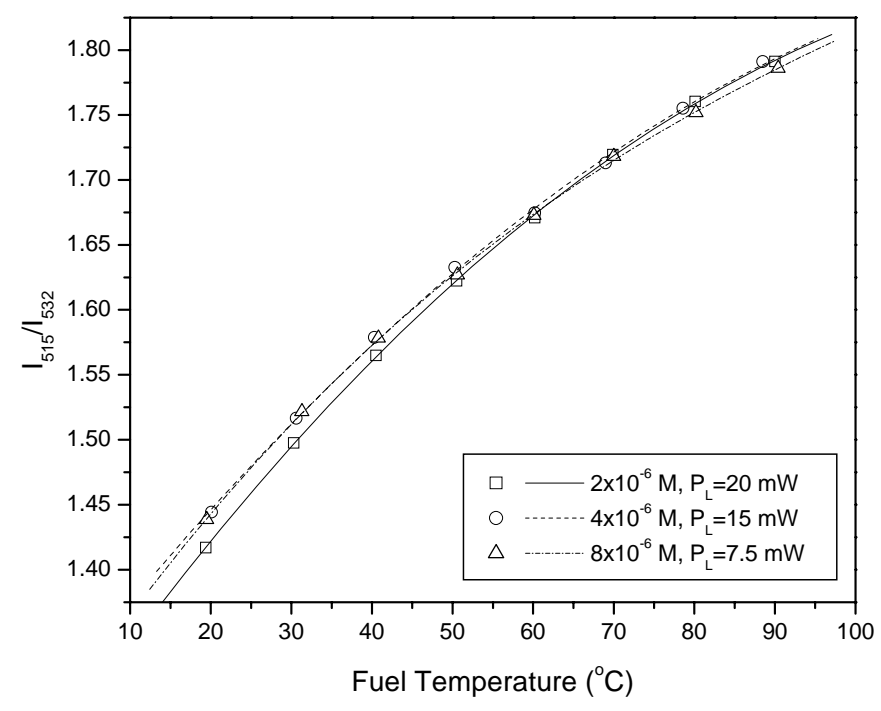

Figure 5-9. Effect of BTBP concentration on the intensity ratio. 


\section{5-1-3. Effect of Photobleaching}

It is known that irreversible destruction, or photobleaching, of the excited fluorophore may occur under high intensity illumination conditions and it may become the factor limiting fluorescence detectability. Figure 5-10 shows the signal intensities at three laser powers and two BTBP concentrations as a function of time when there was no fuel flow in the calibration device. The data were acquired by rapidly removing a shutter that blocked the laser light. The laser light reflected from the blue additive filter was focused onto a photo detector that triggered the data acquisition system. The results showed that photobleaching became high as the laser power and BTBP concentration increased. Photobleaching was seen to occur in a relatively long time scale, but it was not significant during $200 \mathrm{~ms}$. This duration is equivalent to one cycle in the engine when the engine speed is $600 \mathrm{rpm}$. Therefore, photobleaching was not an issue for the application of this method to DISI engines because new fuel is supplied continuously by fuel injection at every cycle. To avoid photobleaching during the calibration, the fuel was continuously flowed in the calibration device. The fuel flow rate was not important as discussed in the previous section. 


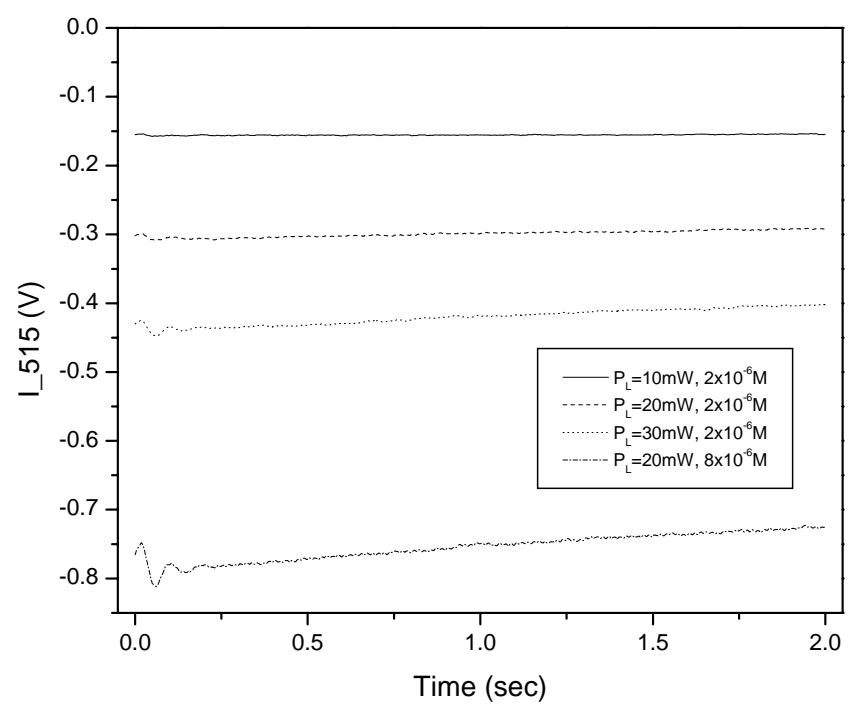

Figure 5-10. Effect of laser power and BTBP concentration on I_515 without fuel flow in the calibration device.

\section{5-1-4.Effect of Fuel Pressure}

The fuel was pressurized for calibration at higher temperatures because the boiling temperature of liquids increases with pressure. The maximum calibration temperature was about $90^{\circ} \mathrm{C}$ for the unpressurized condition because of vapor formation in the fuel. Figure 511 shows the calibration results at different fuel pressures and the results show that the intensity ratio did not change with fuel pressure. Therefore, this technique can be used at high pressures in the engine cylinder with no problem. 


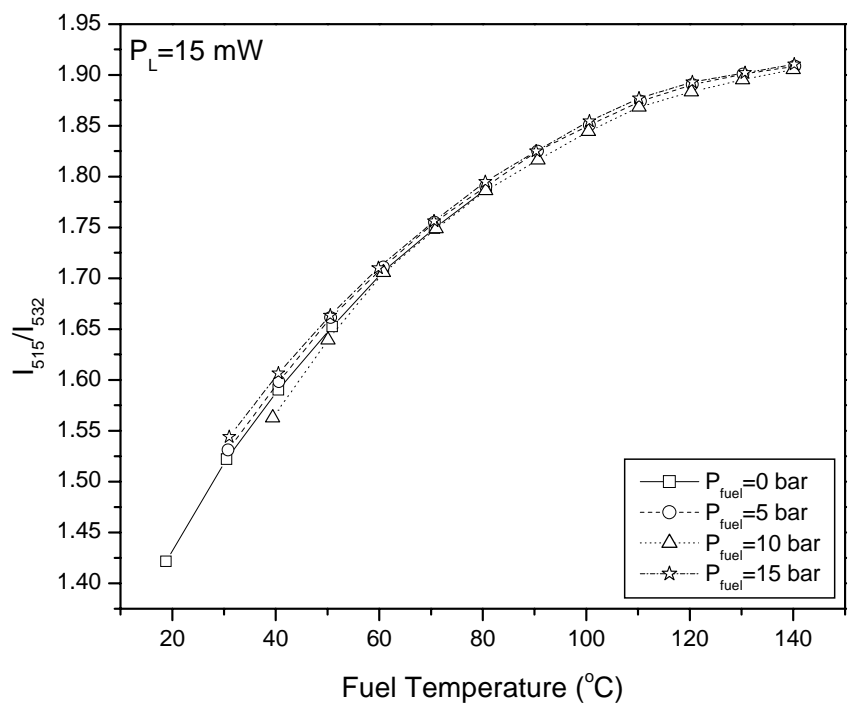

Figure 5-11. Effect of fuel pressure on the intensity ratio.

\section{5-1-5. Effect of Fuel Aging}

The fuel showed an aging tendency as shown in Figure 5-12. The calibration curve converged as the time after the fuel preparation increased. Based on this result, fuel calibration and engine tests were performed seven hours after the fuel preparation. The calibration result also showed that there is a fuel-to-fuel variation everyday. Therefore, a new temperature calibration was performed for every fuel before the engine tests. 

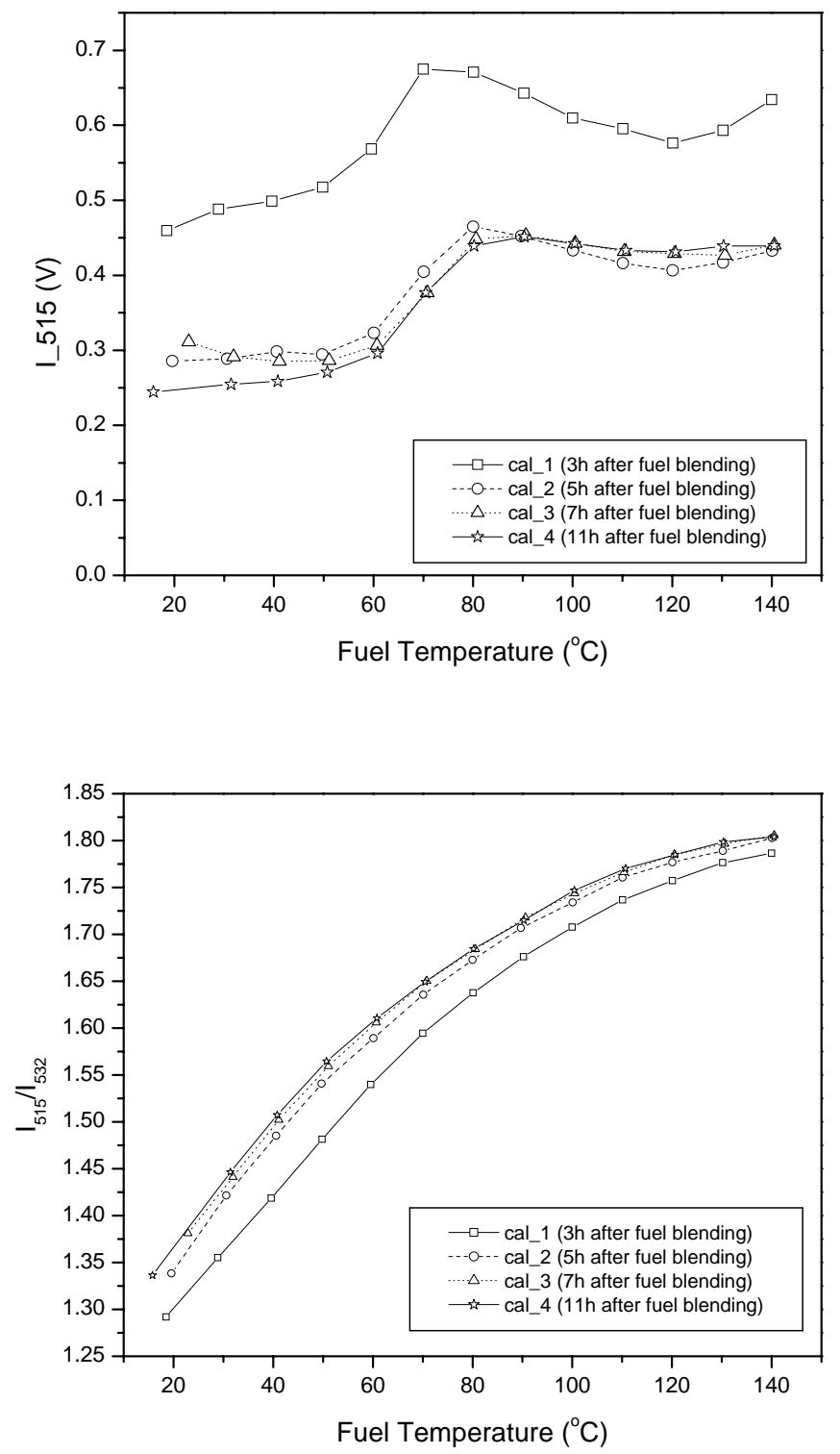

Figure 5-12. Effect of fuel aging on signal intensities and the intensity ratio. 


\section{5-1-6. Effect of Fiber and Laser Focusing}

Initially, the calibration curves were not reproducible for small changes in laser focusing at the end of the fiber, i.e. the results were sensitive to the focusing of the fiber in the fiber coupler. This problem was alleviated by moving the focusing lenses in the PMT unit to make the focused beam 3mm in diameter instead of focusing to a small spot at the sensing surfaces of the PMT as depicted in Figure 5-13. The incoming fluorescent beam diameter was $7 \mathrm{~mm}$. With this change the calibration curves were reproducible within $\pm 1 \%\left(\sim \pm 1^{\circ} \mathrm{C}\right)$ for small changes in focusing. This enables confidence that a calibration performed with the fiber in the calibration device will be the same as that in the engine.

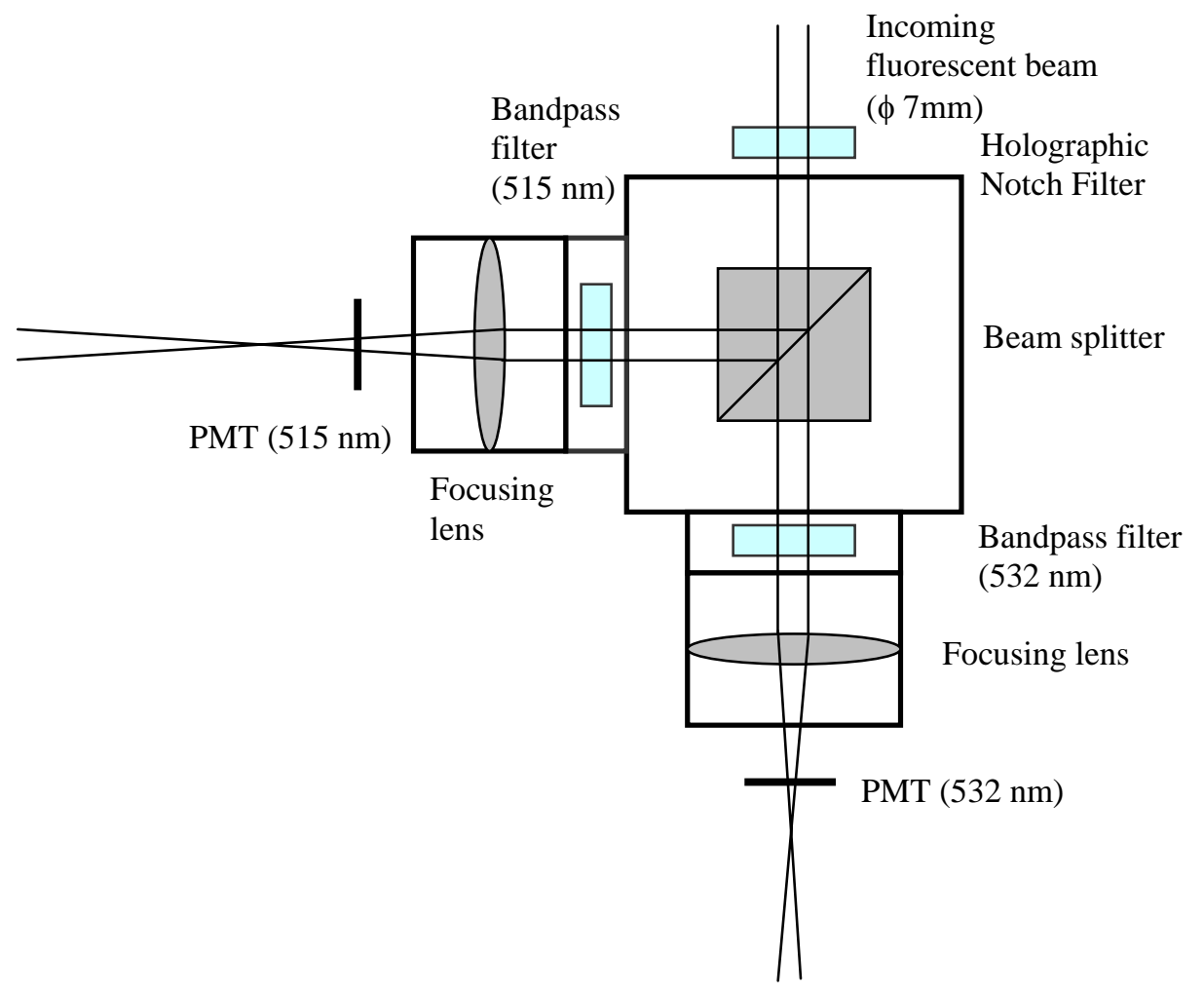

Figure 5-13. PMT unit and the fluorescence beam focusing. 


\section{5-1-7. Summary of the Calibration Tests}

The calibration results of the isooctane-BTBP solution in the calibration device showed the following characteristics:

1. The choice of BTBP solvent affected the response of the temperature calibration curve to different BTBP concentrations.

2. The effect of photobleaching of the signal was negligible at the chosen laser power (20 mW). However, a small amount of fuel was flowed during calibrations to prevent photobleaching by laser irradiation for a long time.

3. Changes in laser power and BTBP concentration did not affect the intensity ratio $\left(\mathrm{I}_{515} / \mathrm{I}_{532}\right)$ although the intensities of the signals were changed significantly.

4. Fuel pressure did not affect the calibration result.

5. The fuel showed a significant aging tendency. Calibration and engine tests were performed seven hours after fuel preparation when the fuel had stabilized. Also, a fuel-to-fuel variation was observed, therefore, calibration was needed for each new fuel mixture.

6. Consistency of the calibration curve for different fibers was achieved by adjusting the focusing lens position in the PMT unit to produce a large $(\sim 3 \mathrm{~mm})$ spot at the PMT sensing surface.

7. The temperature calibration curve was not linear and the increment of the curve decreases as temperature increases. Therefore, the accuracy of this method decreases at higher temperatures. 
The final fuel used for film temperature measurement was a $2 \times 10^{-6} \mathrm{M}$ BTBP solution in isooctane. The BTBP was first dissolved in a small amount of 2-butanol $(0.05 \%$ of isooctane by volume) before mixing with the isooctane to aid the dissolution process. The isooctane-BTBP-2-butanol mixture was heated to its boiling temperature for a short time for better dissolution of BTBP and removal of the solvent (2-butanol) by evaporation. Calibration and engine tests were performed seven hours after solution preparation. 


\section{5-2. Engine Test Results}

Engine tests were performed at 600 and 1200 rpm under motored conditions and at $600 \mathrm{rpm}$ for fired conditions. Fired tests at $1200 \mathrm{rpm}$ were not performed because the piston temperature was too high for accurate measurement by this method. The engine was operated in the late injection mode and the mass of fuel injected was $12 \mathrm{mg}$ for all conditions, comparable to a 0.3 overall equivalence ratio. The laser power measured in front of the fiber coupler was $20 \mathrm{~mW}$ for all tests. All the measurements were performed at the fiber number 3 position in Figure 4-8, because the temperature variations in the piston bowl surface are expected to be small. The fuel was isooctane doped with $2 \times 10^{-6} \mathrm{M}$ BTBP.

It is plausible that the fuel temperature is not constant across the fuel film thickness, i.e., the fuel film temperature may vary from the piston crown to the free surface of the fuel film. The present method measures the average temperature of the fuel film as can be inferred from Figure 5-14 where the non-dimensional form of the modified collection solid angle, $\widetilde{\Omega}$, is shown for distances from the fiber surface when the Gaussian beam profile was assumed. This is a scale-adjusted form of Figure 3-5. The changes in $\widetilde{\Omega}$ up to $50 \mu \mathrm{m}$ from the fiber surface are within $6 \%$, thus the signal contribution to the total fluorescence signal at each distance is almost same. 


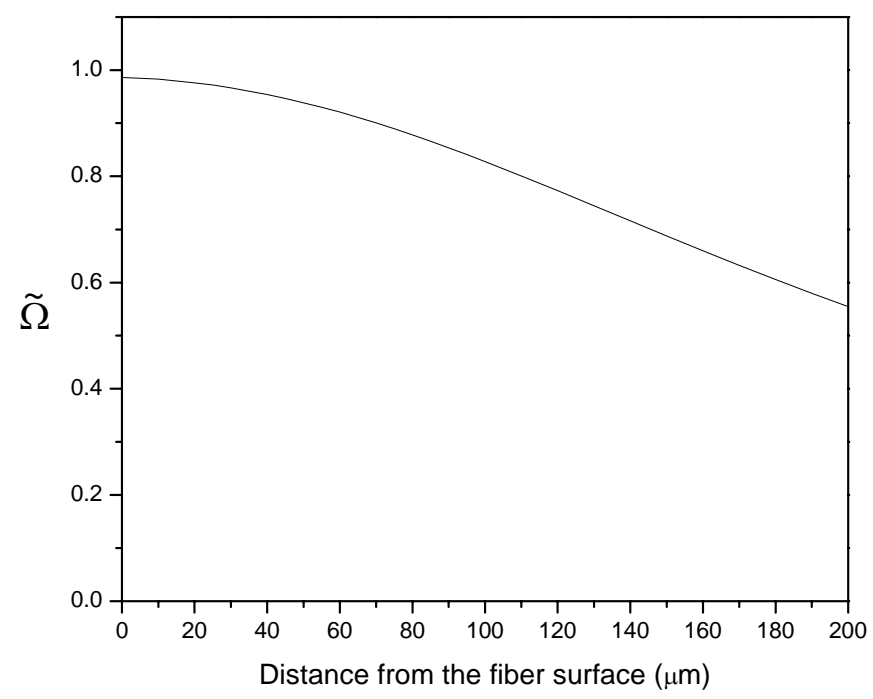

Figure 5-14. Non-dimensional form of the modified collection solid angle versus distances from the fiber surface.

\section{5-2-1. Data Processing Procedure}

Continuous signals of $I_{515}$ and $I_{532}$ were measured for a fixed number of engine cycles using the data acquisition system. The data were then processed as follows to obtain fuel temperatures during the whole engine cycle.

First, 10 to 20 cycles of data were taken at the same engine running condition without fuel injection. The alternating signal intensities caused by laser chopping were separated to laser-on and -off cases by a computer program. The laser-on signal intensities were averaged to use as a background signal, which will be subtracted from the measured signals for fuel injection conditions. The fuel injection tests were performed after the piston temperature became stable. Data were taken for more than 100 cycles under motored condition and 40 cycles for fired condition. Fewer cycles were taken under fired conditions to minimize the 
increase of piston temperature during data acquisition. A computer program was written to separate the laser-on signal from the laser-off signal. The laser-off signal includes the signals from the flame luminosity for fired conditions. The background signal was subtracted from the net fluorescence signal, the difference between the signals when the laser is on and off. The signal intensities of individual cycles were checked and the cycles having too small or no signal intensities were exempted in the averaging process. Also, cycles having a longer fuel film duration, which affects the next cycle, were rejected. The ratios of the two signals, $\mathrm{I}_{515} / \mathrm{I}_{532}$, were calculated at each point and the ratios were ensemble averaged. The ensembleaveraged ratios were then smoothed by 20 -point adjacent averaging method in the Microcal Origin program. The ratios were converted to temperatures by using the calibration curve, which was obtained before the engine tests with the same fuel mixture. A comprehensive error analysis of each test results is given in section 5-2-4.

\section{5-2-2. Motored Results}

Fuel film temperatures were measured for the motored engine condition at 600 and $1200 \mathrm{rpm}$. Measurements were performed for different piston temperatures at $600 \mathrm{rpm}$ by varying the coolant temperature. The injection duration was $1.9 \mathrm{~ms}$, providing a fuel mass comparable to a 0.3 equivalence ratio. The end of injection was $43^{\circ}$ BTDC for $600 \mathrm{rpm}$ and $58^{\circ}$ BTDC for $1200 \mathrm{rpm}$.

Figure 5-15 shows the 203-cycle averaged results of signal intensities ( $\left.\mathrm{I}_{515}, \mathrm{I}_{532}\right)$, intensity ratio $\left(\mathrm{I}_{515} / \mathrm{I}_{532}\right)$, fuel film temperature calculated from the intensity ratio using the calibration curve, and the percent standard deviation of the intensity ratio relative to the mean 
intensity ratio when the engine speed was $600 \mathrm{rpm}$ and the coolant temperature was $38^{\circ} \mathrm{C}$. The actual negative signal intensities $\left(\mathrm{I}_{515}, \mathrm{I}_{532}\right)$ were converted to positive intensities for convenience. The averaged signal intensities did not decrease as time passed after fuel injection because for some cycles the signal intensities increased significantly at later crank angles. The cycle-to-cycle variations of the intensity ratio increased at the end part of the signal that the standard deviations at that crank angle increased. From the graph of the normalized standard deviation of intensity ratio, the reliable region of the intensity ratio was defined where the values were lower than 20\%. For the data of Figure 5-15 this would be up to $180^{\circ}$ ATDC, and this window of repeatable data is shown in each subsequent figure.

The fuel film temperature measurement results show that the fuel film temperature increased to $85^{\circ} \mathrm{C}$ within $5^{\circ} \mathrm{CA}$ after the end of injection timing. The reasons for the high fuel temperature are that the injector was installed on the hot cylinder head, and heat transfer from the compressed hot air to the fuel spray have increased the fuel temperature. Then the fuel film temperature increased up to $97^{\circ} \mathrm{C}$ at TDC and then decreased to $85^{\circ} \mathrm{C}$ at $60^{\circ} \mathrm{ATDC}$, and it remains around $85^{\circ} \mathrm{C}$ until the fuel film evaporates completely. The temperature decrease shown in the figure after $180^{\circ}$ ATDC is not real and it is caused by the averaging of the intensity ratio where the variations of the ratio were high because the end point of the fuel film varies significantly from cycle to cycle. The average piston temperature measured by the thermocouple mounted in the piston at this condition was $71^{\circ} \mathrm{C}$. The piston temperature is much higher than the coolant temperature because of the friction with the cylinder wall and the heat transfer from the hot air when the charge is compressed. The base fuel film temperature, defined as the fuel film temperature prevails for the whole film duration except 
for the TDC region, was about $14^{\circ} \mathrm{C}$ higher than the piston temperature. At TDC, the fuel film temperature is about $12^{\circ} \mathrm{C}$ higher than the base fuel film temperature. The possible reasons of this result are discussed in section 5-3.

The results when the coolant temperature was $55^{\circ} \mathrm{C}$ at $600 \mathrm{rpm}$ are shown in Figure 5-16. The averaged piston temperature was $84^{\circ} \mathrm{C}$. The duration of the fuel film was $80^{\circ}$ shorter than the previous case at a $71^{\circ} \mathrm{C}$ piston temperature. The measured fuel film temperature increased from $90^{\circ} \mathrm{C}$ just after fuel injection to $97^{\circ} \mathrm{C}$ at $\mathrm{TDC}$ and then reduced to $90^{\circ} \mathrm{C}$ at $40^{\circ}$ ATDC. The base fuel film temperature was $6^{\circ} \mathrm{C}$ higher than the measured piston temperature and the maximum fuel film temperature at TDC was $7^{\circ} \mathrm{C}$ higher than the base fuel film temperature at this condition.

Figure 5-17 shows the results for the motored condition at $600 \mathrm{rpm}$ when the coolant temperature was $71^{\circ} \mathrm{C}$. The warmed up piston temperature was $101^{\circ} \mathrm{C}$. At this condition, the fuel film was gone $70^{\circ}$ ATDC, $30^{\circ}$ shorter than the results when the piston temperature was $84^{\circ} \mathrm{C}$. The measured fuel film temperature increased from $110^{\circ} \mathrm{C}$ just after fuel injection to $120^{\circ} \mathrm{C}$ at $\mathrm{TDC}$ and then decreased to $110^{\circ} \mathrm{C}$ again at $50^{\circ}$ ATDC. The base fuel film temperature was $9^{\circ} \mathrm{C}$ higher than the piston temperature and the peak fuel film temperature at TDC was about $10^{\circ} \mathrm{C}$ higher than the base fuel film temperature.

For 1200 rpm the laser chopping did not work as desired because of the Bragg cell signal processor (IntraAction Corp.) used. The TTL signal input adjusts the signal for the Bragg cell and it was not matched well for higher frequencies to block the laser light completely. Therefore, one more Flip-Flop was serially added to reduce the frequency of laser chopping. In this case, two signals were measured for both laser-on and -off case 
because the data acquisition system acquires data at every rising edge of the A-pulse from the encoder. The computer program was modified to find the lowest and highest signals between the two signals at each laser condition. Motored results at an engine speed of $1200 \mathrm{rpm}$ are shown in Figure 5-18. The warmed up piston temperature was $113^{\circ} \mathrm{C}$. The measured fuel film temperature increased to about $133^{\circ} \mathrm{C}$ within $20^{\circ} \mathrm{CA}$ after the end of injection. It remained almost the same temperature during the whole fuel film duration. The fuel film persisted up to $70^{\circ}$ ATDC, which was the same duration in the crank angle basis as for the condition when the coolant temperature was $71^{\circ} \mathrm{C}$ at $600 \mathrm{rpm}$. The time duration is a half, however. The fuel film temperature was $20^{\circ} \mathrm{C}$ higher than the piston temperature in this case. The fuel film temperature sharply increased more than $10^{\circ} \mathrm{C}$ around $10^{\circ}$ ATDC. 

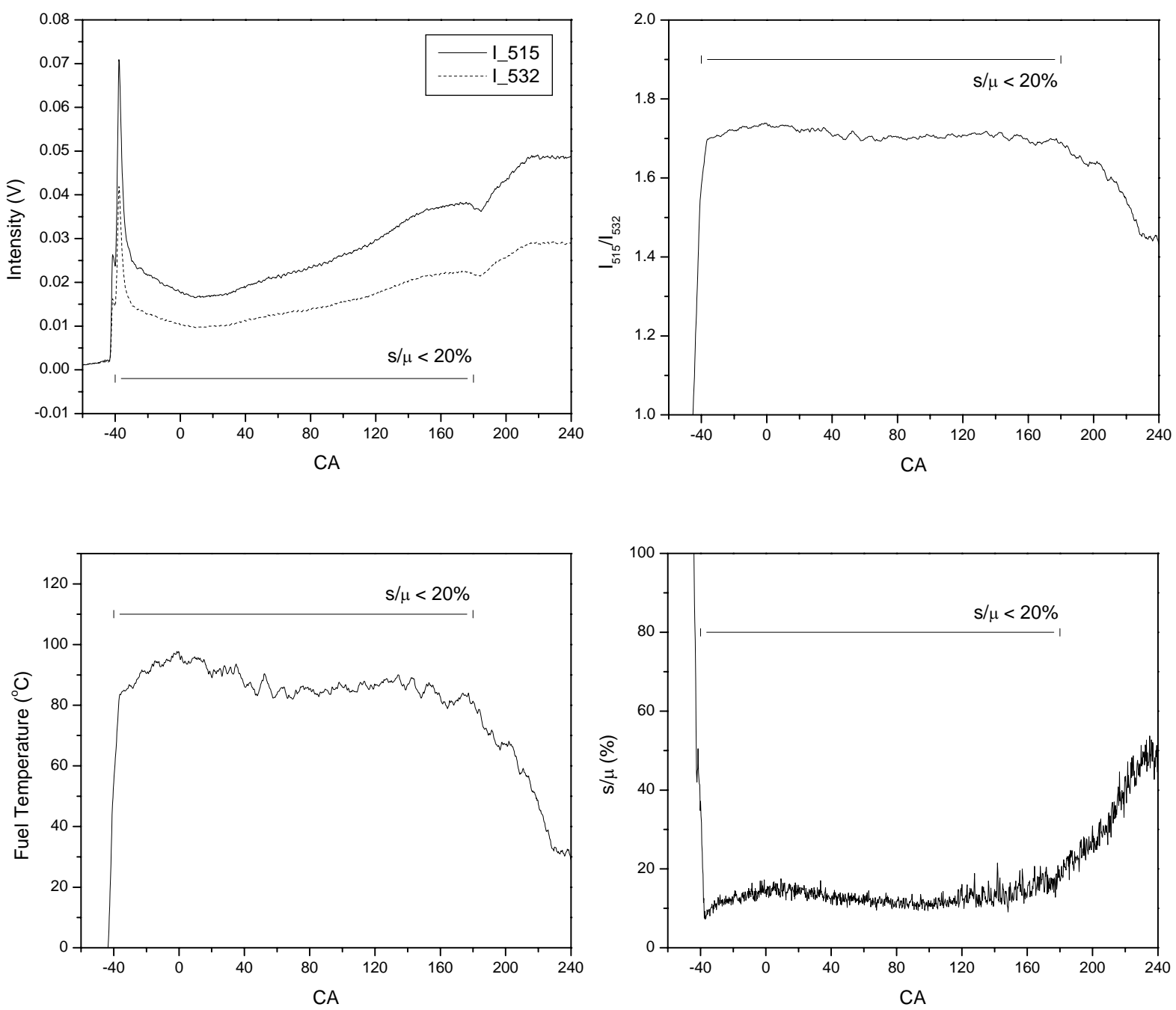

Figure 5-15. 203-cycle averaged signal intensity, intensity ratio, fuel film temperature, and normalized standard deviation of intensity ratio for motored condition at $600 \mathrm{rpm}$, $\mathrm{T}_{\text {Coolant }}=38^{\circ} \mathrm{C}, \mathrm{T}_{\mathrm{P}}=71^{\circ} \mathrm{C}$. The horizontal bar in each graph represents the region for which $\mathrm{s} / \mu<20 \%$. 

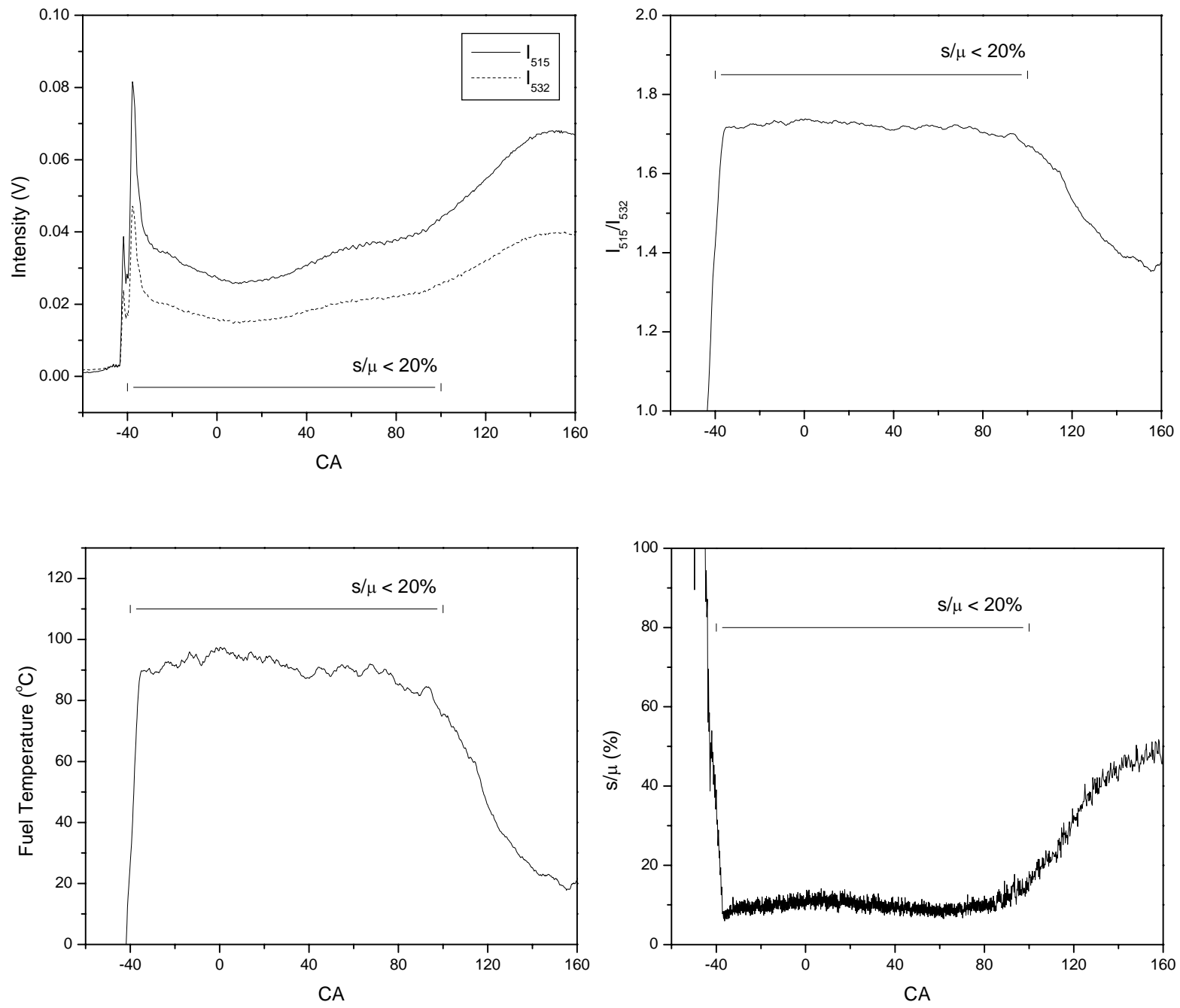

Figure 5-16. 192-cycle averaged signal intensity, intensity ratio, fuel film temperature, and normalized standard deviation of intensity ratio for motored condition at $600 \mathrm{rpm}$, $\mathrm{T}_{\text {Coolant }}=55^{\circ} \mathrm{C}, \mathrm{T}_{\mathrm{P}}=84^{\circ} \mathrm{C}$. 

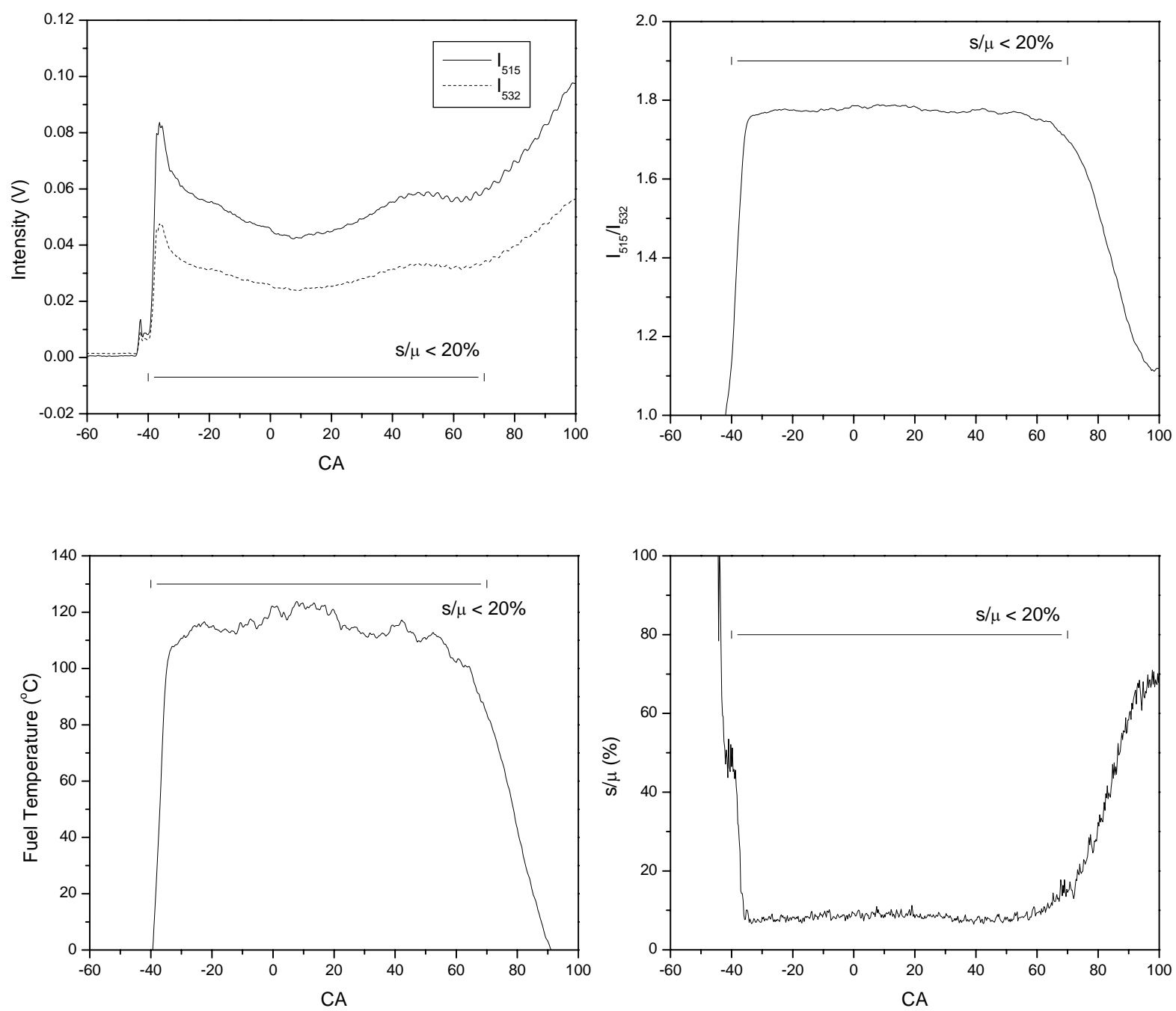

Figure 5-17. 167-cycle averaged signal intensity, intensity ratio, fuel film temperature, and normalized standard deviation of intensity ratio for motored condition at $600 \mathrm{rpm}$, $\mathrm{T}_{\text {Coolant }}=71^{\circ} \mathrm{C}, \mathrm{T}_{\mathrm{P}}=101^{\circ} \mathrm{C}$. 

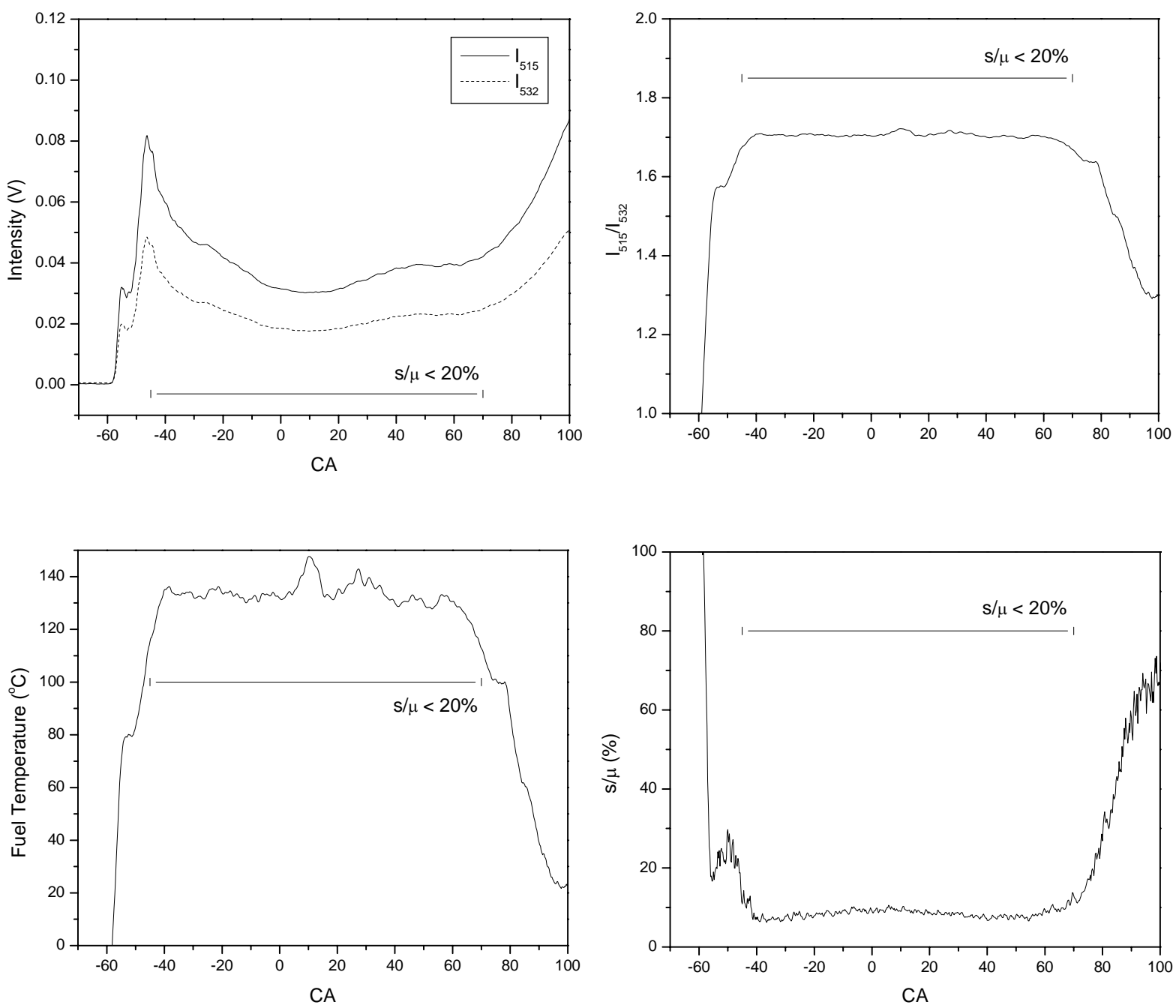

Figure 5-18. 241-cycle averaged signal intensity, intensity ratio, fuel film temperature, and normalized standard deviation of intensity ratio for motored condition at $1200 \mathrm{rpm}$, $\mathrm{T}_{\text {Coolant }}=71^{\circ} \mathrm{C}, \mathrm{T}_{\mathrm{P}}=113^{\circ} \mathrm{C}$. 


\section{5-2-3. Fired Results}

The fuel film temperature was measured under fired engine conditions at $600 \mathrm{rpm}$. The end of fuel injection was $43^{\circ}$ BTDC and the spark timing was $10^{\circ}$ BTDC. Only 40 cycles were acquired because the piston temperature increases quickly. The piston temperature increase during the 40 cycles, as measured with the thermocouple, was about $4^{\circ} \mathrm{C}$.

Figure 5-19 shows the 40-cycle averaged results. The upper left graph shows the cycle averaged $\mathrm{I}_{515}$ signal for both laser-on and -off cases. The small signal peak appeared at $50^{\circ}-35^{\circ}$ BTDC for both laser-on and -off signal was the injector noise. The signal observed from $5^{\circ}-40^{\circ}$ ATDC in the laser-off signal was combustion luminosity, but the laser-on signal was also significant in this crank angle. The timing of the laser-off signal increase was related to the pool fires as observed in the results of 3-pentanone LIF images at the same engine [Strand, 2001]. Figure 5-20 shows four different images at a condition ( $48^{\circ} \mathrm{BTDC}^{\mathrm{T}}$ EOI, $15^{\circ}$ BTDC ST, pictured at $10^{\circ}$ ATDC) comparable to the present condition. The outer circle represents the boundary of the piston bowl. The pool fires were clearly seen at the edges of the bowl, and the four fiber installation positions are marked with small white circles in the figure. The pool fires appear in the area where the fuel wetting is expected by late fuel injection. The bright point at the center is the reflected luminosity from the electrode of a spark plug.

The middle graph in Figure 5-19 shows the net fluorescence signal intensities at both PMTs ( $\left.\mathrm{I}_{515}, \mathrm{I}_{532}\right)$. The signal intensities were continuously decreased from just after the fuel 
injection until $5^{\circ}$ ATDC, but started to increase significantly after that crank angle when the pool fires were observed.

The fuel film temperature measurement results show that it is increasing from $107^{\circ} \mathrm{C}$ just after fuel injection to $130^{\circ} \mathrm{C}$ just before the pool fires appeared ( $5^{\circ} \mathrm{ATDC}$ ). The average piston temperature was $112^{\circ} \mathrm{C}$ at this condition. However, the fuel temperature measurement by this LIF method did not work after the appearance of the pool fires because the LIF signal in this region was not from the BTBP only. The luminosity of the pool fires and the laser scattering from the particulate matter produced by the pool fires affected the signals.

The average of three different runs at the same condition is shown in Figure 5-21. The fuel film temperature increased continuously from just after the fuel injection to the start of the pool fires. The fuel film temperature just after the fuel injection is about $5^{\circ} \mathrm{C}$ lower than the piston temperature, unlike the results for motored conditions where the base fuel film temperature was about $6-14^{\circ} \mathrm{C}$ higher than the piston temperature. One possible cause of this result is the existence of particulate matter on the piston crown from the previous cycle. The fuel film temperature just after the fuel injection for fired condition was the same level as for the warmed up motored condition as shown in Figure 5-22 although the piston temperature was $11^{\circ} \mathrm{C}$ higher. Then, the fuel film temperature increased as for motored condition until the pool fires affected the signal. The fired results showed that fuel film temperature was not significantly affected by the spark ignition $\left(10^{\circ} \mathrm{BTDC}\right)$ and the initial flame propagation. 

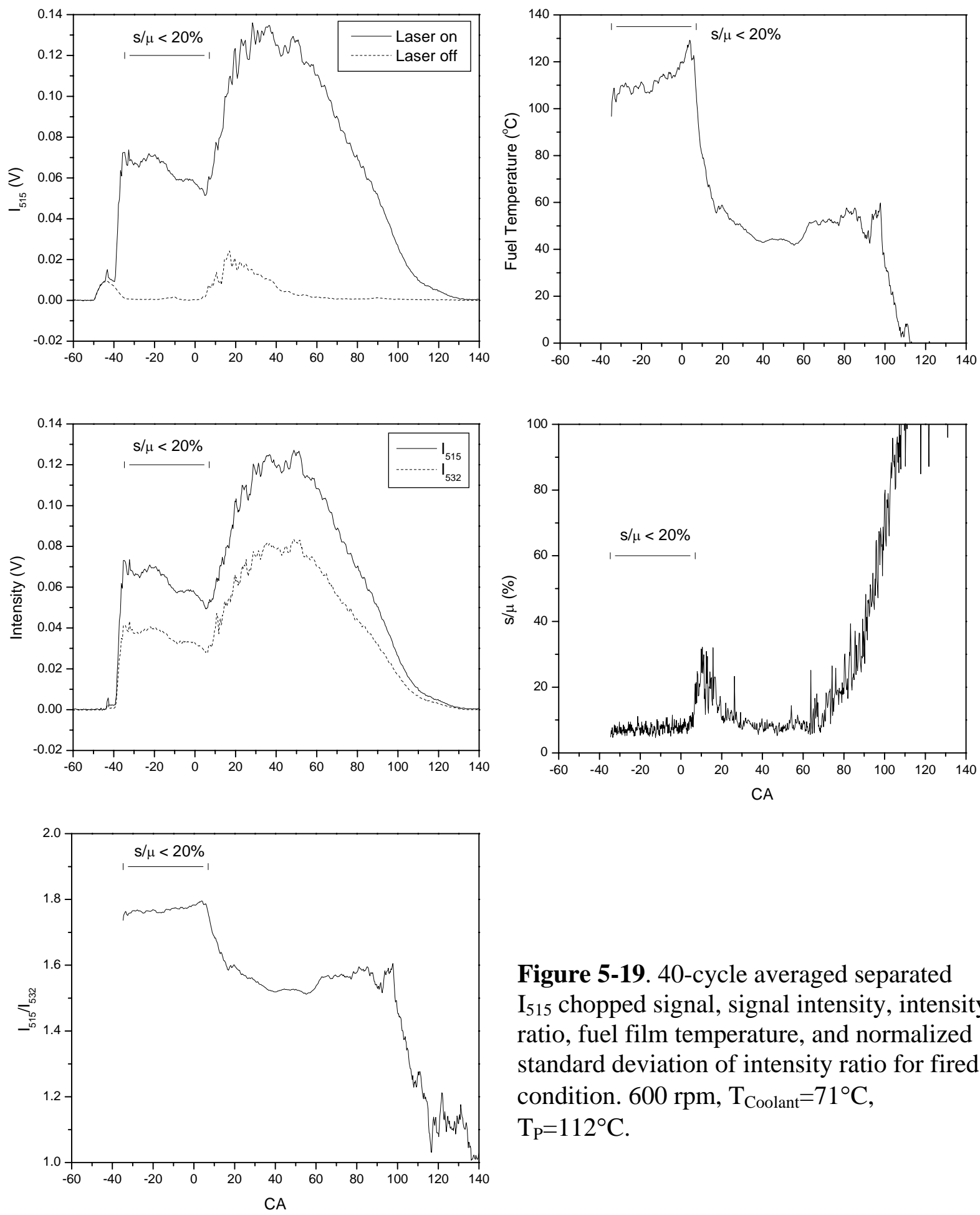

Figure 5-19. 40-cycle averaged separated $\mathrm{I}_{515}$ chopped signal, signal intensity, intensity ratio, fuel film temperature, and normalized standard deviation of intensity ratio for fired condition. $600 \mathrm{rpm}, \mathrm{T}_{\text {Coolant }}=71^{\circ} \mathrm{C}$, $\mathrm{T}_{\mathrm{P}}=112^{\circ} \mathrm{C}$. 

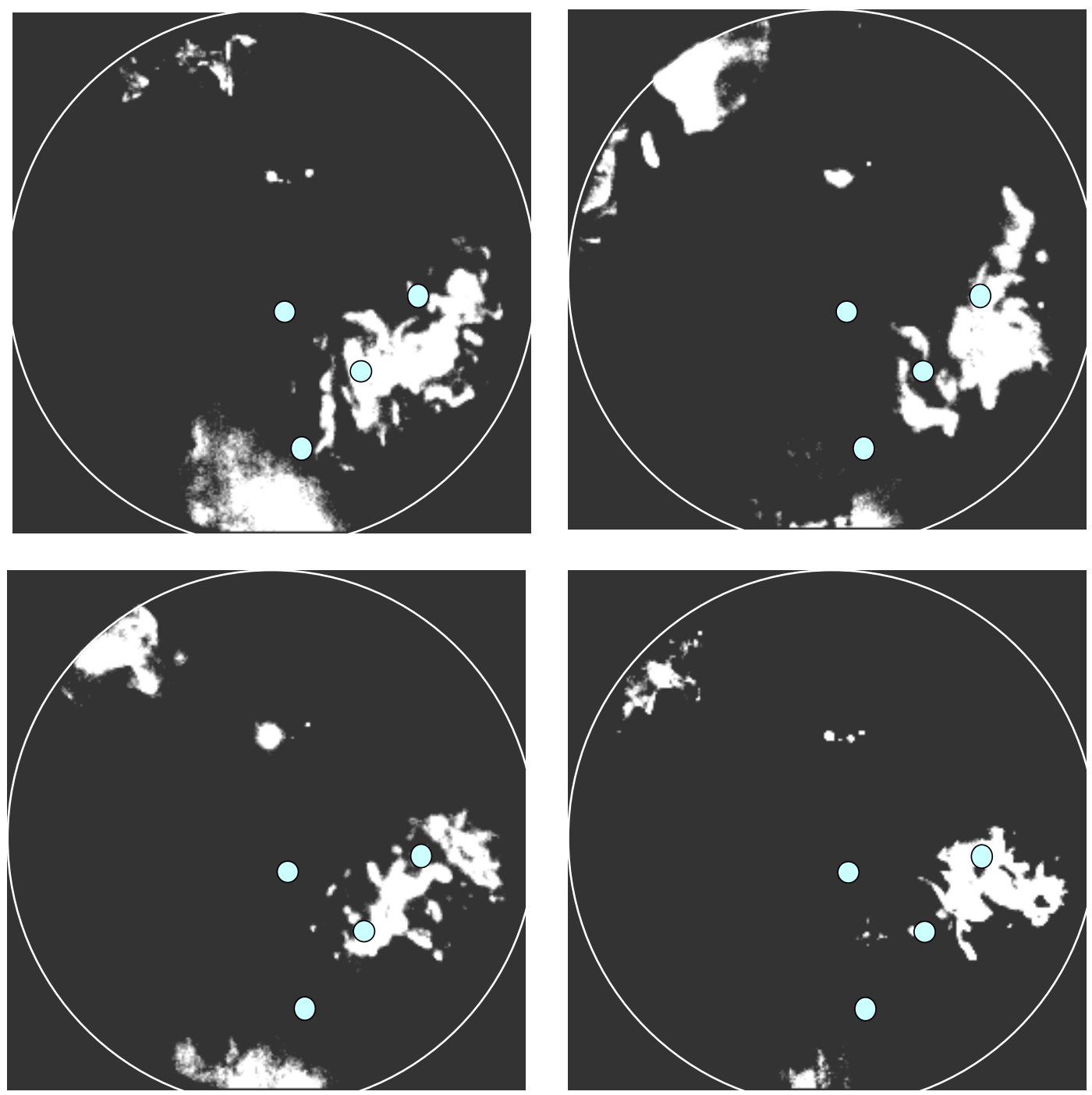

Figure 5-20. Pool fire images at $10^{\circ}$ ATDC when $\Phi=0.3$

(48 ${ }^{\circ}$ BTDC EOI, $15^{\circ}$ BTDC ST). 


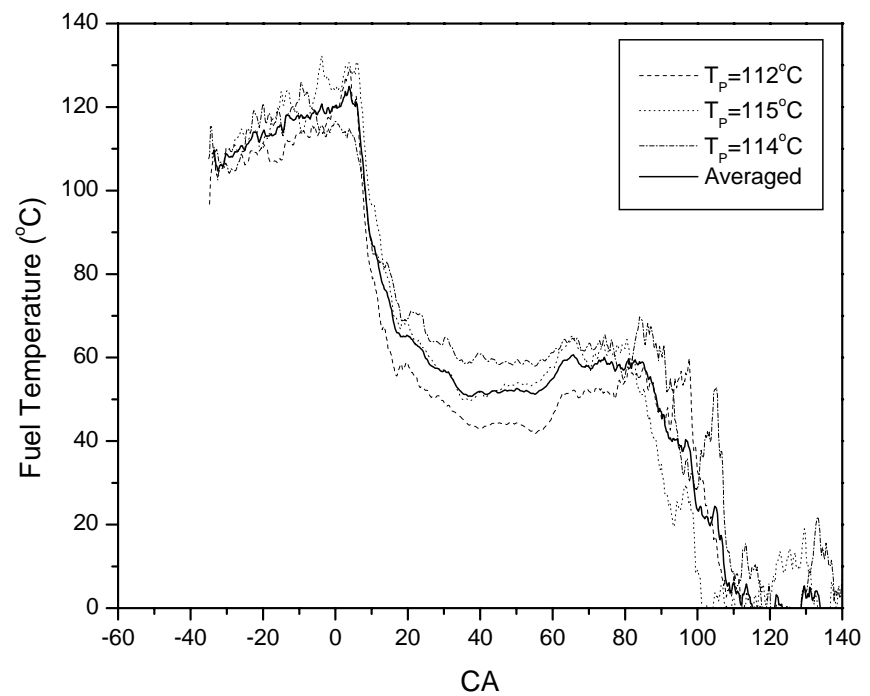

Figure 5-21. Three sets of 40-cycle averaged fuel film temperature and average of them for fired condition. $600 \mathrm{rpm}, \mathrm{T}_{\text {Coolant }}=71^{\circ} \mathrm{C}$.

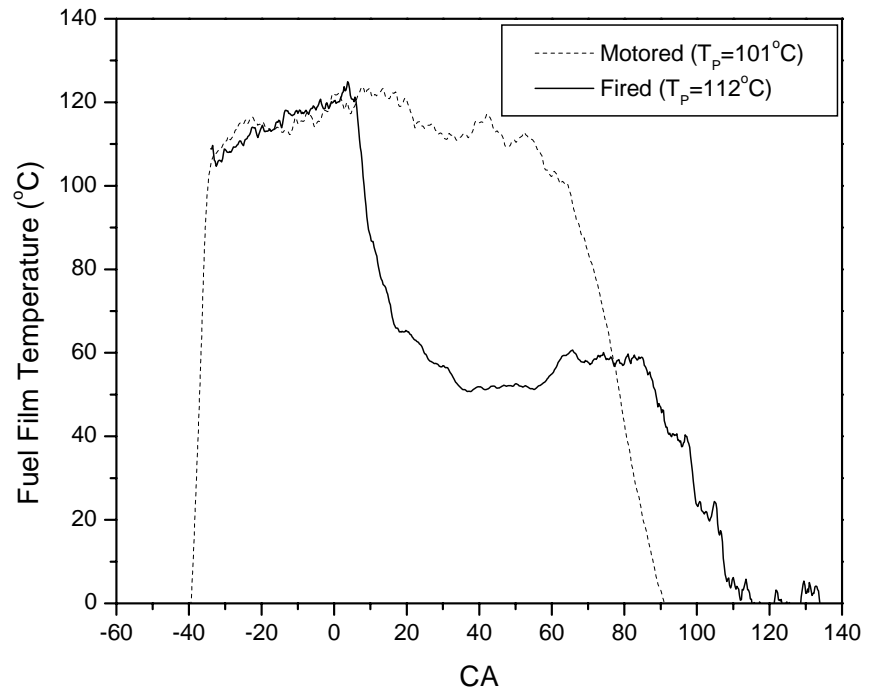

Figure 5-22. Comparison of fuel film temperature for motored and fired condition. $600 \mathrm{rpm}, \mathrm{T}_{\text {Coolant }}=71^{\circ} \mathrm{C}$. 


\section{5-2-4. Uncertainty Analysis}

At each quarter crank angle, the intensity ratio was calculated and averaged for a certain number of cycles. The number of cycle was from 40 to 250 and we are interested in how reliable the average is, especially when the fluctuation levels are significant.

Assuming the data are normally distributed, the uncertainty in the mean value can be shown [Lipson and Sheth, 1973] to be

$$
\Delta \bar{x}=t_{\alpha / 2 ; v} \frac{S}{\sqrt{N}}
$$

where the value $t_{\alpha / 2 ; v}$, comes from the $t$-distribution with 1- $\alpha$ confidence and $v=N-1$, and $s$

is the standard deviation of the data. The true sample mean is then $\mu=\bar{x} \pm \Delta \bar{x}$ with the specified level of confidence.

The uncertainty analysis was applied to the intensity ratio. When the engine speed was $600 \mathrm{rpm}$ and the coolant temperature was $38^{\circ} \mathrm{C}$, the value of the standard deviation was approximately 0.2 for the whole fuel film duration. In this case, the uncertainty in the mean intensity ratio was 0.028 with $95 \%$ confidence. Then the true mean value of the intensity ratio, for example, at $80^{\circ} \mathrm{ATDC}$ was $1.704 \pm 0.028$. The corresponding temperature was obtained from the calibration curve shown in Figure 5-23. The average temperature was $85.4^{\circ} \mathrm{C}$ and the variation of the average temperature corresponding to the uncertainty in the intensity ratio was from $77.1^{\circ} \mathrm{C}$ to $95.1^{\circ} \mathrm{C}$. The results of the uncertainty analysis for other engine conditions are summarized in Table 5-1. The uncertainty range is not symmetric at the averaged temperature. That is, the difference from the averaged value is much higher at higher temperature side because the slope of the calibration curve is decreasing as 
temperature increases. Therefore, the uncertainty in the fuel film temperature, $\mathrm{T}_{\text {Fuel }}$, increases as the fuel temperature increases and it limits the application of this method.

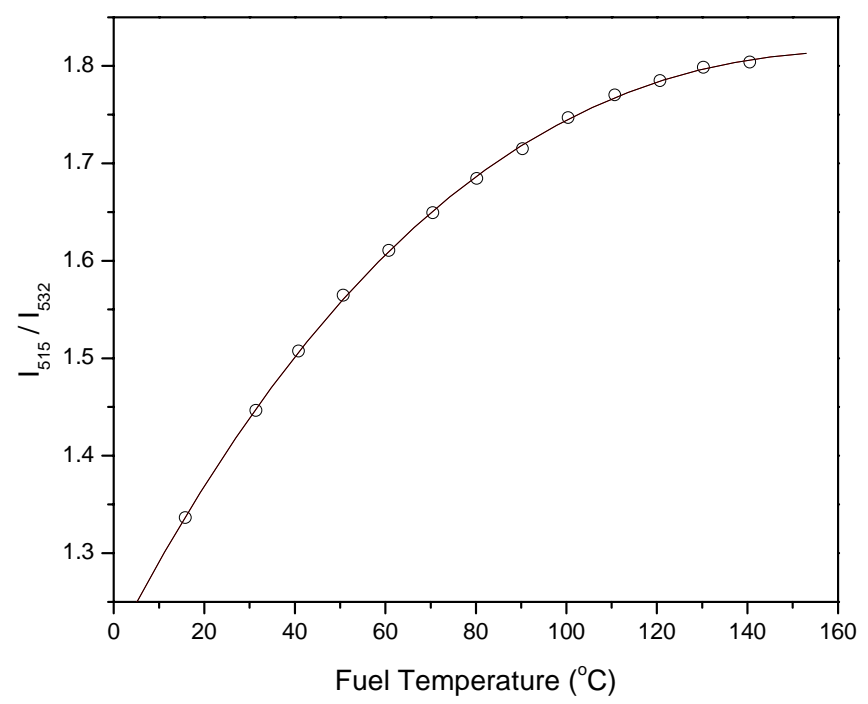

Figure 5-23. Temperature calibration curve for isooctane $+2 \times 10^{-6} \mathrm{M}$ BTBP.

Table 5-1. Summary of uncertainty analysis with 95\% confidence level.

\begin{tabular}{|l|c|c|c|c|c|}
\hline \multicolumn{1}{|c|}{$\begin{array}{c}\text { Engine } \\
\text { Condition }\end{array}$} & $\begin{array}{c}\mathrm{T}_{\text {Coolant }} \\
\left({ }^{\circ} \mathrm{C}\right)\end{array}$ & $\begin{array}{c}\mathrm{T}_{\text {Piston }} \\
\left({ }^{\circ} \mathrm{C}\right)\end{array}$ & $\begin{array}{c}\text { Averaged } \\
\mathrm{T}_{\text {Fuel }}\left({ }^{\circ} \mathrm{C}\right)\end{array}$ & $\begin{array}{c}\text { Uncertainty of } \\
\mathrm{T}_{\text {Fuel }}\left({ }^{\circ} \mathrm{C}\right)\end{array}$ & $\begin{array}{c}\text { Analyzed } \\
\text { Crank Angle }\end{array}$ \\
\hline \multirow{2}{*}{\begin{tabular}{l} 
Motored \\
\cline { 2 - 6 }
\end{tabular}} & 38 & 71 & 85.4 & $77.1 \sim 95.1$ & $80^{\circ}$ \\
\cline { 2 - 6 } & 55 & 84 & 89.7 & $82.0 \sim 98.6$ & $60^{\circ}$ \\
\hline $\begin{array}{l}1200 \mathrm{rpm} \\
\text { Motored }\end{array}$ & 71 & 101 & 114.9 & $103.3 \sim 131.5$ & $-10^{\circ}$ \\
\hline $\begin{array}{l}600 \mathrm{rpm}^{*} \\
\text { Fired }\end{array}$ & 71 & 114 & 119.8 & $105.6 \sim 144.2$ & $-20^{\circ}$ \\
\hline
\end{tabular}

* 120 cycle average result 


\section{5-2-5. Summary of the Engine Tests}

Fuel film temperature measurement on the piston crown of a DISI engine under motored and fired conditions showed the following results.

1. For motored $600 \mathrm{rpm}$, the base fuel film temperatures for different piston temperatures were about $6-14^{\circ} \mathrm{C}$ higher than the piston temperature, measured with the thermocouple $1 \mathrm{~mm}$ below the piston surface, and the peak temperatures at TDC were $7-12^{\circ} \mathrm{C}$ higher than the base fuel film temperature. The base fuel film temperature was about $20^{\circ} \mathrm{C}$ higher than the piston temperature for motored measurements at $1200 \mathrm{rpm}$.

2. For fired condition, the fuel film temperature measurements were not possible just after the occurrence of pool fires on the piston crown because the fluorescence intensities $\left(\mathrm{I}_{515}, \mathrm{I}_{532}\right)$ were significantly affected by the luminescent flame and the impurities from the flame.

3. The fuel film temperature for fired condition at $600 \mathrm{rpm}$ increased continuously just after the fuel injection until the appearance of the pool fires, as observed for motored conditions with the same temperature level although the piston temperature was $11^{\circ} \mathrm{C}$ higher.

4. The uncertainty analysis of the intensity ratio provides a confidence level and the variation range of the average temperatures. The uncertainty increased as the fuel film temperatures increased because the slope of the calibration curve decreased as the temperature increased, and this deteriorated the accuracy of the present method at higher temperatures. 


\section{5-3. Discussion}

The motored engine test results at $600 \mathrm{rpm}$ showed that the fuel film temperatures increased just after fuel injection to a base fuel film temperature, which was $6-14^{\circ} \mathrm{C}$ higher than the piston temperature, and the film temperature increased about $7-12^{\circ} \mathrm{C}$ from the base fuel film temperature near TDC, and then decreased to the base fuel film temperature around $40-60^{\circ}$ ATDC. It seems that the increase in fuel film temperature is related to the hot incylinder air during the compression and expansion stroke. The polytropic in-cylinder air temperature calculated from the measured in-cylinder pressure trace at $600 \mathrm{rpm}$ motored condition is shown in Figure 5-24. The polytropic index, $n$, was 1.27 in this case from the pressure-volume curve, and is low due to leakage past the piston rings. Also shown in Figure 5-24 is the change in the boiling point of isooctane according to the in-cylinder pressure by using the Clausius-Clapeyron equation. The in-cylinder air temperature is high when the fuel is injected and increases up to $240^{\circ} \mathrm{C}$ at TDC. Therefore, it is possible that there would be a significant amount of convection heat transfer to the piston surface and fuel film.

There are four possible reasons for the higher fuel film temperatures than the measured piston temperatures. They are the temperature gradient between the thermocouple point and the piston crown surface by conduction, the convection heat transfer to the fuel film from the compressed hot charge, the temperature calibration error caused by the temperature differences between the thermocouple and fiber positions in the calibration device, and the temperature difference between the piston and the thermocouple because the 
thermocouple may not have good thermal contact with the piston. These facts are discussed in detail in this section. The engine operating condition considered was motored at $600 \mathrm{rpm}$.

The first possibility is that the piston surface temperature is different from the temperature $1 \mathrm{~mm}$ below the piston surface because of the convection heat transfer from the hot in-cylinder gas. It seems that the base fuel film temperatures are closely related with the piston surface temperature as can be seen from the test results. The piston surface temperatures were calculated during the compression, expansion, and exhaust strokes for motored conditions by applying an unsteady one dimensional explicit finite difference method [Incropera and Dewitt, 1996]. The piston was discretized for the thickness of $1 \mathrm{~mm}$ from the piston surface as shown in Figure 5-25. The finite-difference equation used for the internal nodes is

$$
T_{m}^{P+1}=F O\left(T_{m-1}^{p}+T_{m+1}^{p}\right)+(1-2 F o) T_{m}^{p}
$$

where, Fourier number, $F o=\frac{\alpha \Delta t}{\Delta x^{2}}=\frac{k \Delta t}{\rho c_{p} \Delta x^{2}}, m$ is the node number and $p$ is the index for time sequence. The equation for the surface node is

$$
T_{L}^{p+1}=2 F o\left(T_{L-1}^{p}+B i \cdot T_{\infty}\right)+(1-2 F o-2 B i \cdot F o) T_{L}^{p}
$$

where, Biot number, $B i=\frac{h \Delta x}{k}$, and for stability of the calculation $F o(1+B i) \leq \frac{1}{2}$.

The temperature $1 \mathrm{~mm}$ below the piston surface was assumed constant during the cycle and the piston surface was exposed to the convection heat transfer condition from the compressed hot charge. Two convection heat transfer conditions were considered. One uses 
the conventional spatial averaged Woschni model, and the other utilizes measured heat flux data by using a Vatel HFM heat flux sensor [Kim, 2003, unpublished data]. The Woschni model [Heywood, 1988] is

$$
h_{c}\left(W / m^{2} \cdot K\right)=3.26 \cdot B(m)^{-0.2} \cdot p(k P a)^{0.8} \cdot T(K)^{-0.55} \cdot w(m / s)^{0.8}
$$

where, $B$ is bore, $p$ is cylinder pressure, $T$ is gas temperature, and average cylinder gas velocity, $w=C_{1} \bar{S}_{p}$, where $C_{1}=2.28$ for compression period, and the mean piston speed, $\bar{S}_{p}=2 L N$, where $L$ is stroke and $N$ is the engine speed (rps). 


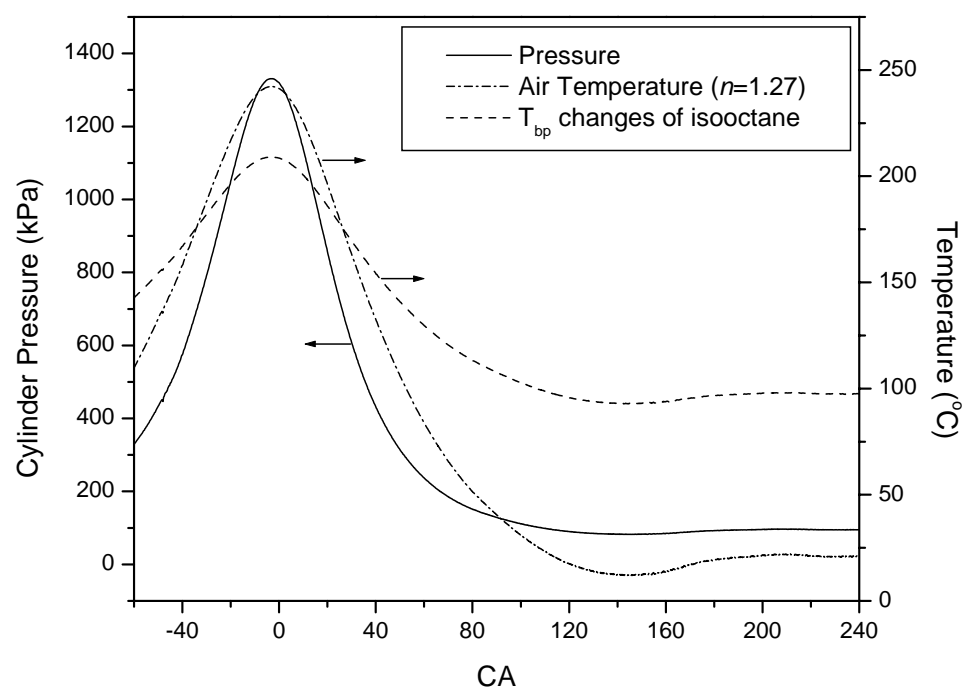

Figure 5-24. Measured in-cylinder pressure for motored $600 \mathrm{rpm}$ and calculated air temperature and the boiling point changes according to the pressure for isooctane.

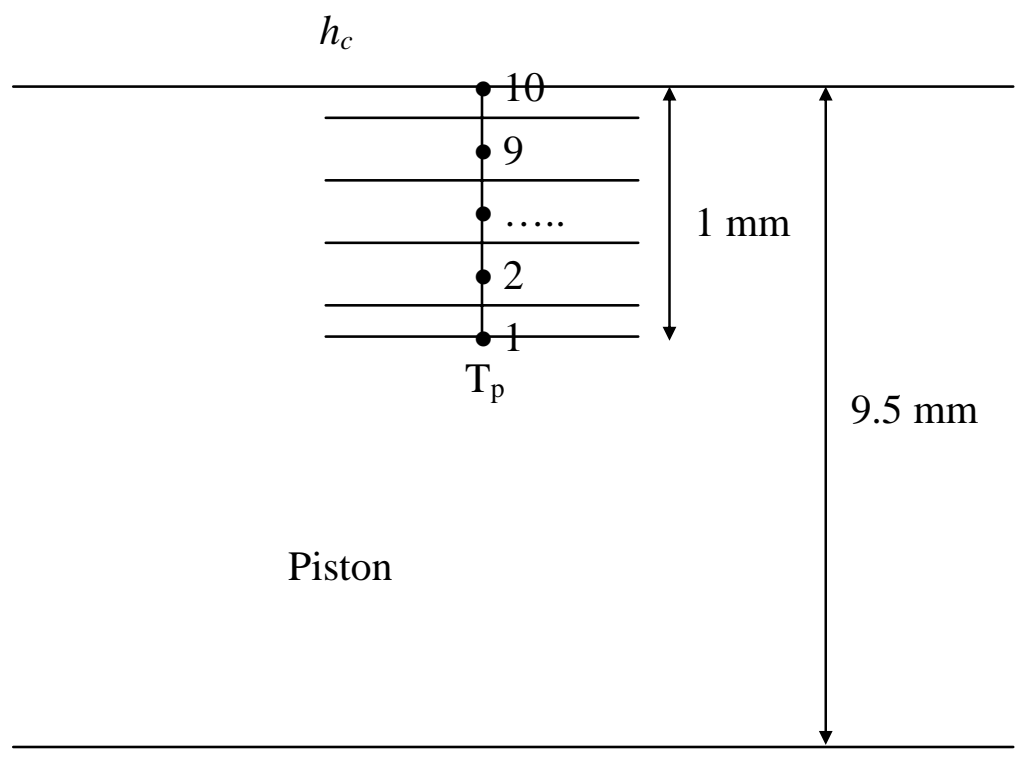

Figure 5-25. Nodes for 1-D FDM of the piston. 
For the heat flux boundary condition, the heat flux was measured at the spark plug position for the compression ratio of 15.2 and 12.5. The extrapolated heat flux data for the compression ration of 10, used for the calculation, are shown in Figure 5-26. For the heat flux boundary condition, the surface node equation becomes

$$
T_{L}^{p+1}=\frac{2 \Delta t}{\rho c_{p} \Delta x} q+2 F o \cdot T_{L-1}^{p}+(1-2 F O) T_{L}^{p}
$$

where, $q$ is the heat flux $\left(\mathrm{W} / \mathrm{m}^{2}\right)$.

Figure 5-27 shows the calculation results for both convection boundary conditions. The piston temperature $1 \mathrm{~mm}$ below the surface was assumed to be $100^{\circ} \mathrm{C}$. The maximum increase in the piston surface temperature for the Woschni model was $0.1^{\circ} \mathrm{C}$, and for heat flux boundary condition it was $0.7^{\circ} \mathrm{C}$. For both convection boundary conditions, the piston surface temperature was not significantly increased from the piston temperature measured 1 mm below the piston surface. 


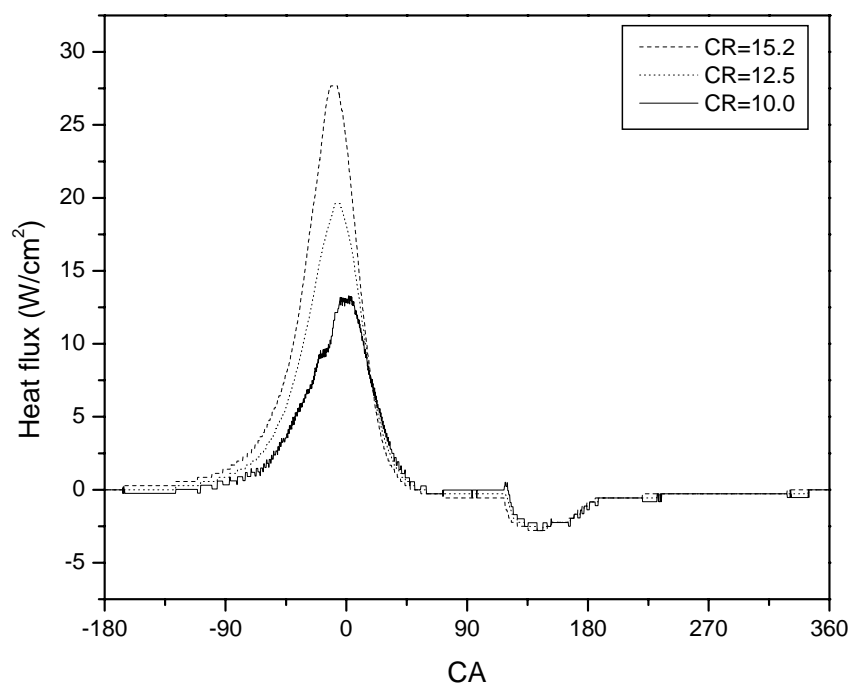

Figure 5-26. Measured heat flux data for $\mathrm{CR}=15.2$ and 12.5, and extrapolated heat flux for $\mathrm{CR}=10.600 \mathrm{rpm}$ motored condition.

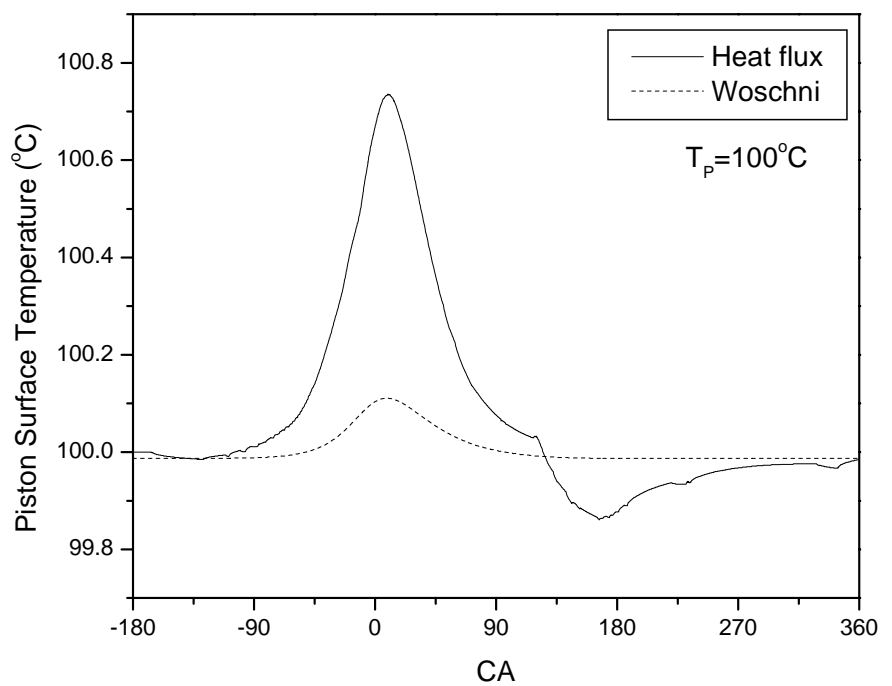

Figure 5-27. Calculated piston surface temperature for two convection boundary conditions. 
The second possibility of the higher fuel film temperature than the measured piston temperature is the convection heat transfer from the hot charge to the fuel film during the compression and expansion strokes due to the low thermal diffusivity of the liquid fuel ( $\left.0.046 \times 10^{-6} \mathrm{~m}^{2} / \mathrm{s} @ 100^{\circ} \mathrm{C}\right)$ compared to aluminum $\left(\sim 48.4 \times 10^{-6} \mathrm{~m}^{2} / \mathrm{s} @ 20^{\circ} \mathrm{C}\right)$. The same 1-D FDM was used and the discretized fuel film is shown in Figure 5-28. The fuel evaporation was not considered in the calculation, therefore, it is expected that the present calculation will over-predict the fuel film temperature. The equations used in the calculation were the same as the equation (5-1), (5-2), and (5-4). The thermal conductivity of the fuel (for gasoline) [Borman, 1998] was obtained from

$$
k=0.117(1-0.00054 \cdot T) s g \quad[\mathrm{~W} / \mathrm{m}-\mathrm{K}]
$$

where, $T$ is in $\mathrm{K}$, and $s g$ is the specific gravity.

The specific heat of isooctane was calculated from the following equation [Turns, 1996].

$$
\bar{c}_{p}(k J / k m o l \cdot K)=4.184\left(a_{1}+a_{2} \theta+a_{3} \theta^{2}+a_{4} \theta^{3}+a_{5} \theta^{-2}\right)
$$

where, $\theta \equiv T(K) / 1000$ and $a_{1}-a_{5}$ are constants.

For the convection boundary condition, both the measured heat flux and the Woschni model, equation (5-3), were used as before. The fuel film thickness was assumed to be 20 microns and the piston temperature was taken as $100^{\circ} \mathrm{C}$ in this calculation and can be considered constant based on the results of Figure 5-27. 


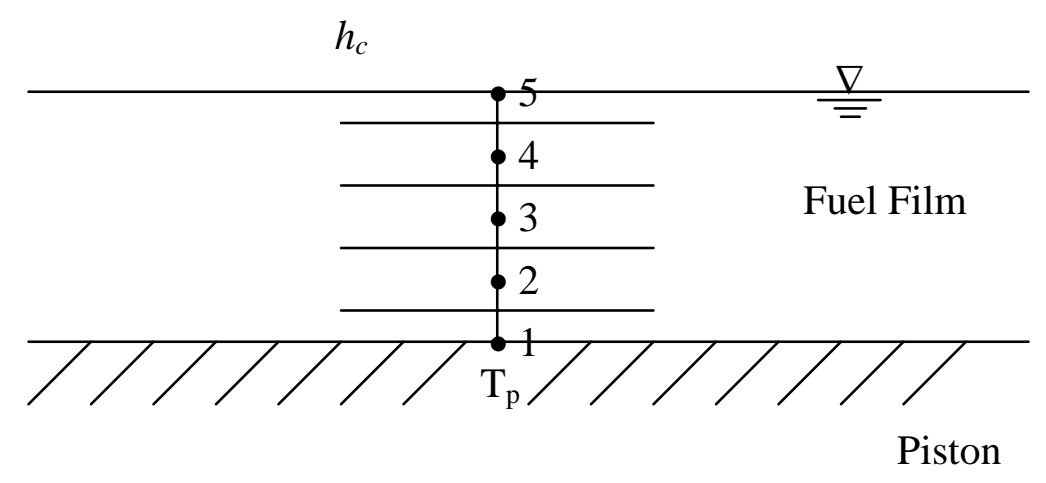

Figure 5-28. Nodes of 1-D FDM in the fuel film.

The calculated mean fuel film temperatures for both interface boundary conditions and for two initial fuel temperatures $\left(70^{\circ} \mathrm{C}\right.$ and $\left.100^{\circ} \mathrm{C}\right)$ are shown in Figure 5-29. For the Woschni convection model, the mean fuel film temperature increased by about $2.5^{\circ} \mathrm{C}$ just after TDC for both initial fuel film temperature conditions. Using the measured heat flux, the maximum mean fuel film temperature was about $27^{\circ} \mathrm{C}$ higher than the piston temperature at TDC for both initial fuel film temperatures. The fuel film temperature decreases from the peak region, and matched the piston temperature between $60-80^{\circ}$ ATDC. There are significant differences between the Woschni model and measured heat flux boundary condition. Furthermore, the calculation did not consider the fuel evaporation effect that would decrease the fuel film temperature. Therefore, it is postulated that the actual convection heat transfer at the piston bowl might be between the two extreme conditions.

This calculation can explain the engine test results where the peak fuel film temperatures were $7-12^{\circ} \mathrm{C}$ above the base fuel film temperature at TDC and then decrease to the base film temperature at about $40-60^{\circ}$ ATDC. However, the calculation results showed 


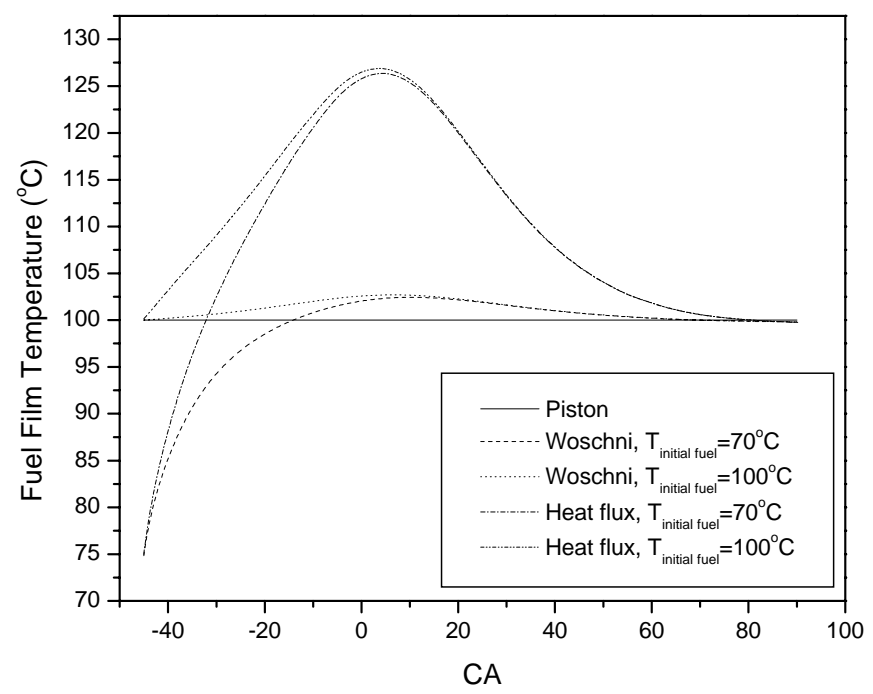

Figure 5-29. Calculated mean fuel film temperatures for two convection boundary conditions and two initial fuel film temperature conditions $\left(70,100^{\circ} \mathrm{C}\right)$.

that convection heat transfer does not affect the fuel film temperature after $60-80^{\circ}$ ATDC. Therefore, the cause of the higher base fuel film temperature, which was $6-14^{\circ} \mathrm{C}$ higher than the measured piston temperature, came from the other sources.

The effect of engine speed on the convection heat transfer is shown in Figure 5-30 when Woschni model was used. As engine speed increased from $600 \mathrm{rpm}$ to $1200 \mathrm{rpm}$, the convection heat transfer increased and the fuel film temperature increased, also. Furthermore, the peak temperature point is moved to $10^{\circ}$ ATDC and the same result was obtained in the engine test as shown in Figure 5-18. However, the test results did not show the clear temperature bump caused by convection heat transfer as observed in the calculation result and the engine test results at $600 \mathrm{rpm}$. 


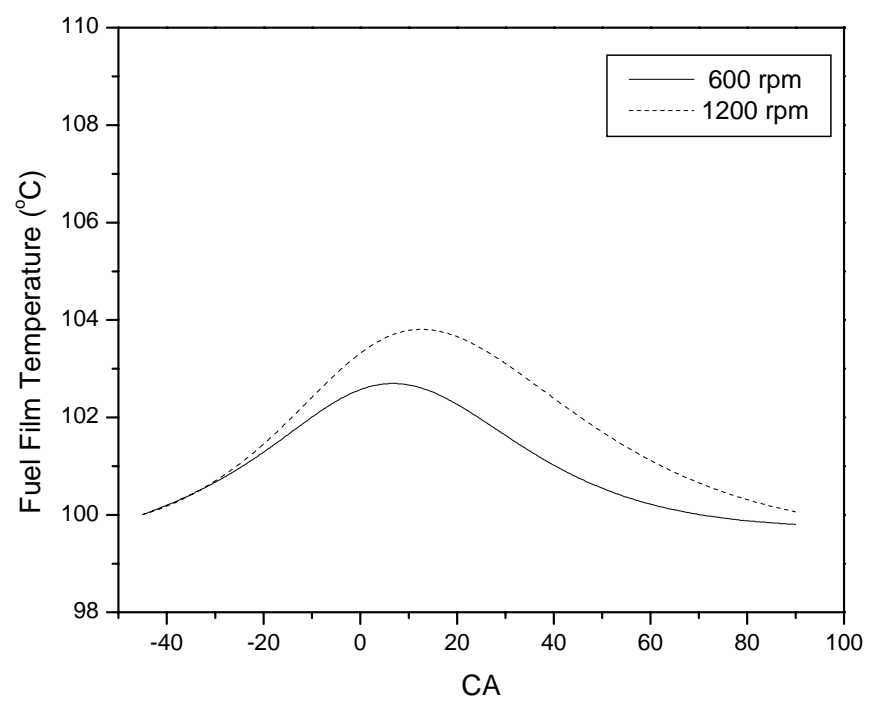

Figure 5-30. Effect of engine speed on the convection heat transfer to the fuel film.

One possibility of higher base fuel film temperature than the piston temperature is the error during the temperature calibration in the calibration device. As shown in Figure 4-13 the fiber was installed $10 \mathrm{~mm}$ away from the thermocouple position in the calibration device. The fuel was flowed during the calibration from the thermocouple to the fiber location. It is possible that the fuel temperature when the fuel flowed past the fiber, where the fuel thickness is about $0.3 \mathrm{~mm}$, is different from the temperature at the thermocouple position where the fuel flow speed is low. In the fiber position, the fuel thickness was maintained by a gasket between the heating body and a cover. Therefore, the cover temperature might be lower than the body temperature, and it can cause the decrease in the fuel temperature during the fuel flow from the reservoir where the thermocouple is installed. The difference in temperature at the two positions will directly affect the measurement results. 
The other possibility of higher base fuel film temperature is that the temperature reading of the thermocouple is different from the piston temperature because of the bad thermal contact between them. The rod type junction style thermocouple was inserted to a lager hole in the piston, which was drilled up to $1 \mathrm{~mm}$ below the piston bowl surface. Therefore, the thermal resistance may increase if the junction of the thermocouple does not contact well with the piston. 
Chapter 6

\section{Results of Fuel Film Thickness Measurement}

Fuel film thickness on the piston crown of the DISI engine was measured at four locations by the fiber-based LIF method. The main purpose of this research was to quantify the fuel film thickness from the measured LIF intensity by applying the photophysical equations derived for a circular fiber in chapter 3 . The fuel used was isooctane, however, it does not fluoresce for the selected wavelength $(457.9 \mathrm{~nm})$ of the laser, and choosing the right dopant was critical for the evaporating conditions. The requirements of the dopant are: it should be miscible with isooctane, the fluorescence of the mixture should not photobleach, the fluorescence intensity should not be affected by ambient pressure, and finally, the dopant should co-evaporate with isooctane.

Two $\alpha$-diketones were used: 2,3-hexanedione and 2,3-butanedione (biacetyl). The absorption and fluorescence band of $\alpha$-diketones are within the visible range. Before the 
quantification of fuel film thickness using the diketones, measurements were made of BTBP fluorescence because the signal is strong and can provide information on the fuel film persistence. However, it was not possible to quantify the film thickness with BTBP because it does not co-evaporate with isooctane.

The engine was operated in a late injection, wide-open throttle condition and the equivalence ratio was 0.3 in all cases. The tested engine speeds were 600 and $1200 \mathrm{rpm}$ for both motored and fired conditions. 


\section{6-1. Qualitative Measurement with BTBP}

There were two purposes in performing tests using BTBP. One of them was to provide information on the isooctane fuel film duration for comparison with the results when the diketone dopants were used. The other purpose was to compare the fuel film duration for fuels having different boiling points. The fuels used for this test were n-pentane $\left(T_{b p}=36^{\circ} \mathrm{C}\right)$, isooctane $\left(\mathrm{T}_{\mathrm{bp}}=99^{\circ} \mathrm{C}\right)$, and $\mathrm{n}$-decane $\left(\mathrm{T}_{\mathrm{bp}}=174^{\circ} \mathrm{C}\right)$. The fuels represent the initial, middle, and final boiling point of the gasoline, respectively. BTBP, the same dopant used for the fuel film temperature measurement in the previous chapter, was used as the tracer to measure the fuel film duration. The molar concentration of BTBP was $2 \times 10^{-6} \mathrm{M}$ as before. The BTBP solvent for n-pentane and isooctane was 2-butanol and the solvent for n-decane was 1-heptanol. However, the fluorescence intensity could not be translated to film thickness because BTBP would not co-evaporate with the base fuel. The laser power measured before the blue reflective filter was $10 \mathrm{~mW}$. The filter used in the PMT unit was the $515 \mathrm{~nm}$ bandpass filter having a $10 \mathrm{~nm}$ FWHM.

\section{6-1-1. Engine Test Results for Isooctane/BTBP}

Figure 6-1 shows the 40-cycle averaged results of BTBP fluorescence at all four fiber locations for warmed up motored operation at $600 \mathrm{rpm}$. The negative signal intensities from the PMT were inverted for the convenience of the reader. The tests for each fiber were performed at different times after changing the fibers. The piston temperatures were in the range of $96-100^{\circ} \mathrm{C}$ for all tests. At all fiber locations, the signal was strong from $45^{\circ} \mathrm{BTDC}$ 
for a short duration because the fuel was injected between $50^{\circ}$ and $43^{\circ}$ BTDC. The peak signal was related to the droplet impingement on the fiber surface. Figure 6-2 shows the results from a test performed outside of the engine. The test was performed on a fiberinstalled surface where the injector was aligned to direct the hollow cone spray to the fiber surface. In this test, the fuel was n-dodecane and the injection duration was $3.6 \mathrm{~ms}$ instead of $1.9 \mathrm{~ms}$ in the engine test. The resistance used for current-to-voltage conversion was $100 \mathrm{k} \Omega$, but the response time of this circuit was not enough to follow the abruptly changing signals. Therefore, the actual peaks would have been higher than measured. These results show that there are many peaks during the injection period due to droplet impingement. All these peaks were summed up in the strong signals shown in Figure 6-1.

In Figure 6-1, the fluorescence decreased quickly just after the fuel injection. Fiber 2 showed the strongest signal during the injection period. The strong signal during the injection period and the longer fuel duration at fiber 2 was related to the initial fuel slug during the early injection stage, which was injected toward the center of the hollow cone (see Figure 63). Fiber 2 was close to the center of the hollow cone spray at this test condition. However, it should be noted that comparison of the signal intensity between fibers is difficult because the light transmission characteristics of each fiber may not be same.

For fibers 3 and 4, the cycle-to-cycle variations of the signal were high and some of the cycles, which showed completely different pattern, were excluded in the averaging process. The high variations of the signal at those locations were related to the fact that the hollow-cone fuel spray impinged strongly on those locations. The fuel film footprint after these tests is shown schematically in Figure 6-4. The fuel film might not be evenly 
distributed on the hot piston surface causing the variation. Figure 6-5 shows photos taken with a CCD camera $30 \mathrm{~ms}$ after fuel injection at a quiescent ambient condition. The injection duration was $3.6 \mathrm{~ms}$. The fuel film is seen to be evenly distributed when the surface temperature was low $\left(25^{\circ} \mathrm{C}\right)$, but it was not evenly distributed when the surface temperature was $72^{\circ} \mathrm{C}$. At higher temperature, the coherent force between the fuel decreased and the fuel film started to disintegrate. Therefore, the output signal could be varied according to the existence of the fuel film on the fiber surface at higher piston temperature conditions. In the Figure 6-1, the fuel film duration at four fiber locations were $83^{\circ}, 135^{\circ}, 190^{\circ}$, and $113^{\circ}$, respectively.

The fired results at $600 \mathrm{rpm}$ condition are shown in Figure 6-6. The piston temperatures were $112-117^{\circ} \mathrm{C}$ compared with $96-100^{\circ} \mathrm{C}$ for the motored condition. The spark timing was $10^{\circ}$ BTDC. The separated laser-on and -off signals are shown in Figure 6-7 and the results in Figure 6-6 represent the difference between the two signals. The small peak near $45^{\circ} \mathrm{BTDC}$ when the laser was turned off was due to electronic noise from the injector. The net fluorescence signal abruptly increased for all fibers about $5^{\circ}$ after TDC due to the pool fires. The signal increase in this region is related to the flame luminosity and the laser scattering from the particulate matter formed by pool fires. Therefore, the signal after the pool fires could not represent the fuel film thickness and film duration.

The fluorescence intensity, especially for fibers 1 and 2, after the fuel injection up to the occurrence of the pool fires were the same level as the results for motored case as shown in Figure 6-8 although the piston temperature was $16^{\circ} \mathrm{C}$ higher than the motored case. This is similar to the result of Hochgreb (2001) that the effect of piston temperature increase (30- 
$180^{\circ} \mathrm{C}$ ) on the extent of the fuel film decrease was relatively small when a gasoline was used as the fuel.

The results for the motored $1200 \mathrm{rpm}$ case are shown in Figure 6-9. The injection timing was from $72^{\circ}$ to $58^{\circ} \mathrm{BTDC}$ for the equivalence ratio of 0.3 . The piston temperatures were between $103^{\circ} \mathrm{C}$ and $112^{\circ} \mathrm{C}$ for all tests. The peak signal intensity at each fiber location changed compared to the results of $600 \mathrm{rpm}$, and the peak intensities became more comparable between the fiber locations. The signal intensities during the fuel film duration were similar in level at four locations, perhaps due to enhanced mixing of the fuel spray by the higher air motion at a higher engine speed. The durations of the fuel film at four fiber locations were $107^{\circ}, 197^{\circ}, 222^{\circ}$, and $143^{\circ}$, respectively. The fuel film duration was slightly longer $\left(20^{\circ}-60^{\circ}\right)$ than at $600 \mathrm{rpm}$ in crank angle basis, but the film duration in time was decreased. The reason that the fuel film duration was the same for 600 and $1200 \mathrm{rpm}$ in crank angle basis for motored condition is related to the close in-cylinder pressure traces as shown in Figure 4-6. The boiling point of the fuel increases as the pressure increases (Figure 5-24). The in-cylinder pressure decreased to atmospheric between $110^{\circ}$ and $135^{\circ}$ ATDC, and the fuel films were fully evaporated at this crank angle for both 600 and $1200 \mathrm{rpm}$. Another reason was that the exhaust valve started to open at $90^{\circ}$ ATDC. The air motion increased after this event, and would cause active fuel film evaporation. It was observed in the experiment of Alger et al. (2001) that the fuel on the piston surface started to evaporate just after the exhaust valve opened.

Figure 6-10 shows the results for fired conditions at $1200 \mathrm{rpm}$. The spark timing was $22^{\circ}$ BTDC. The piston temperatures were between $126^{\circ} \mathrm{C}$ and $129^{\circ} \mathrm{C}$. As in the case of 600 
rpm, the signal intensities were significantly increased within $0-10^{\circ}$ ATDC due to the occurrence of the pool fires. The traces of the fuel films from the fuel injection to just before the appearance of pool fires were almost the same level as for motored conditions at all fiber locations as shown in Figure 6-11. Generally, the intensity duration was longer for fired conditions than motored conditions and it might be related to particulate matter produced by the pool fires.

The uncertainty analysis, discussed in section 5-2-4, was performed for the averaged signal intensities at $10^{\circ} \mathrm{BTDC}$ for all test conditions. The percentage uncertainty level was defined as the percentage of uncertainty to the average value, $(\Delta \bar{x} / \bar{x}) \times 100(\%)$, and the results are summarized in Table 6-1. The numbers of cycles averaged were 31-40 for 600 rpm and 26-40 for $1200 \mathrm{rpm}$. The results showed that the uncertainty levels were higher for higher engine speed at the chosen crankangle, that is, it was $10-20 \%$ of the average values at $600 \mathrm{rpm}$ and $20-40 \%$ at $1200 \mathrm{rpm}$. The number of cycles should have been increased for $1200 \mathrm{rpm}$ to reduce the uncertainty level.

These results were helpful in comparing the motored and fired results, such as shown in Figure 6-8 and Figure 6-11. At $600 \mathrm{rpm}$ (Figure 6-8), the signal intensities at $10^{\circ}$ BTDC for both motored and fired conditions were the same level except for fiber 3 if the uncertainty levels were considered. And the intensities were the same level within the uncertainty level for all fibers at $1200 \mathrm{rpm}$ (Figure 6-11). 
Table 6-1. Percentage uncertainty levels of the averaged signal intensities at $10^{\circ} \mathrm{BTDC}$ for isooctane/BTBP.

\begin{tabular}{|c|c|c|c|}
\hline & Fiber \# & Motored (\%) & Fired (\%) \\
\hline \multirow{3}{*}{$600 \mathrm{rpm}$} & 1 & 11.4 & 27.5 \\
\cline { 2 - 4 } & 2 & 10.1 & 15.1 \\
\cline { 2 - 4 } & 3 & 18.2 & 14.7 \\
\cline { 2 - 4 } & 4 & 14.7 & 12.0 \\
\hline \multirow{3}{*}{$1200 \mathrm{rpm}$} & 1 & 32.2 & 41.6 \\
\cline { 2 - 4 } & 2 & 23.2 & 31.3 \\
\cline { 2 - 4 } & 3 & 23.0 & 24.9 \\
\cline { 2 - 4 } & 4 & 41.7 & 25.4 \\
\hline
\end{tabular}



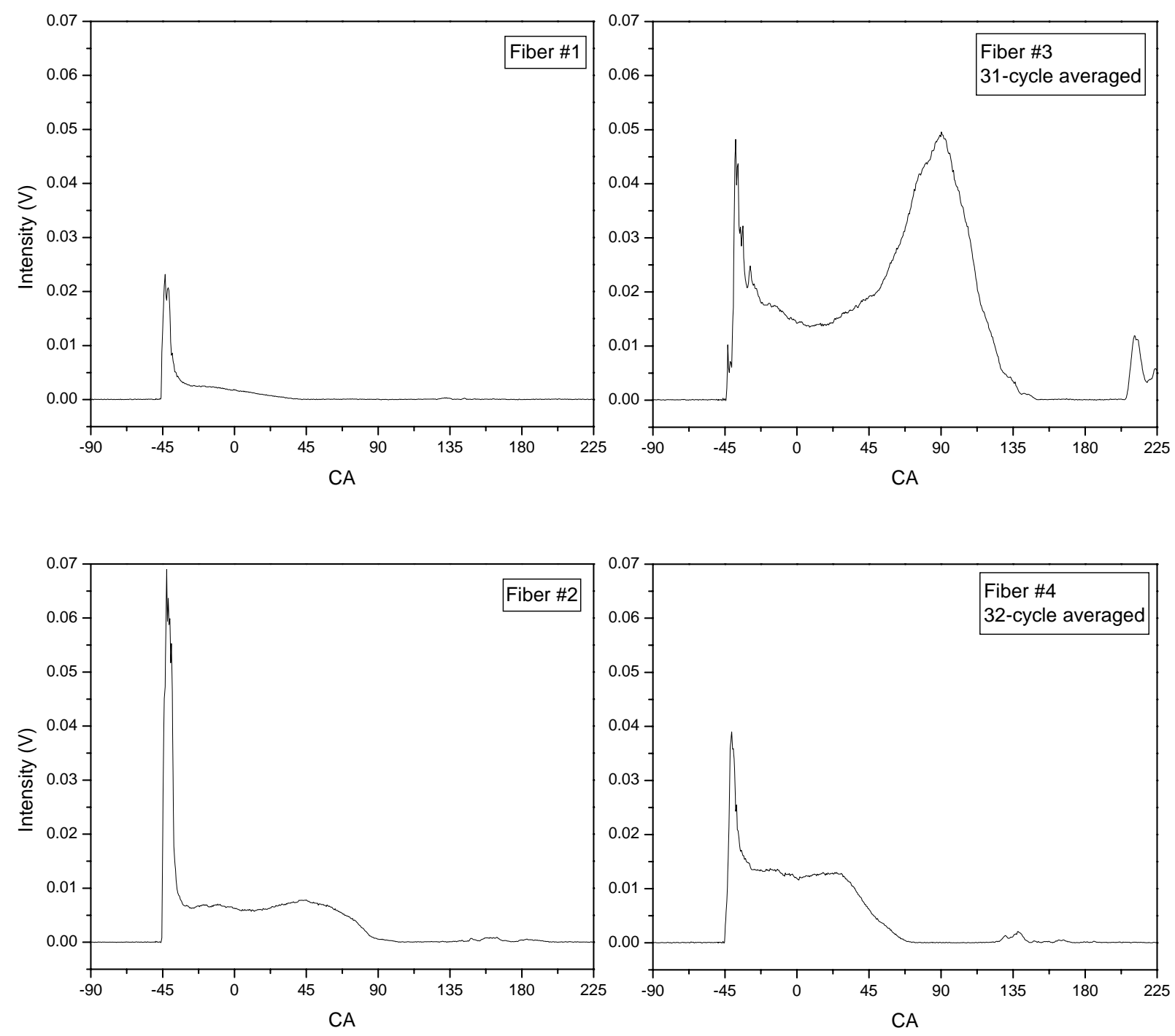

Figure 6-1. Fluorescence intensity at four fiber locations for the mixture of isooctane and $2 \times 10^{-6} \mathrm{M} \mathrm{BTBP}$ for motored condition at $600 \mathrm{rpm}$. 


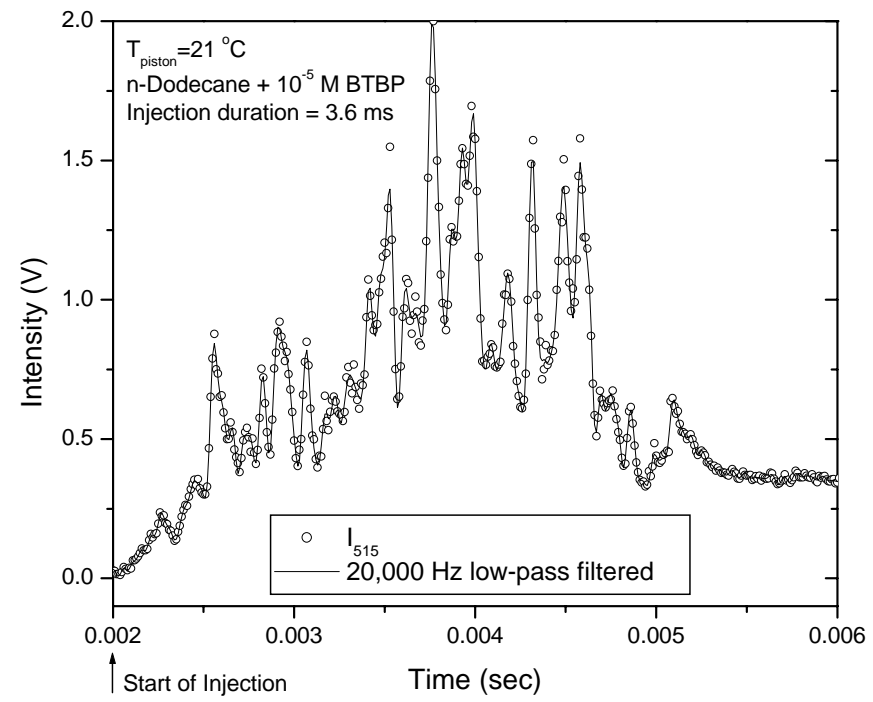

Figure 6-2. Effect of droplet impingement on the fluorescence intensity during the fuel injection. Test was performed outside of the engine and the fuel was n-dodecane/BTBP.

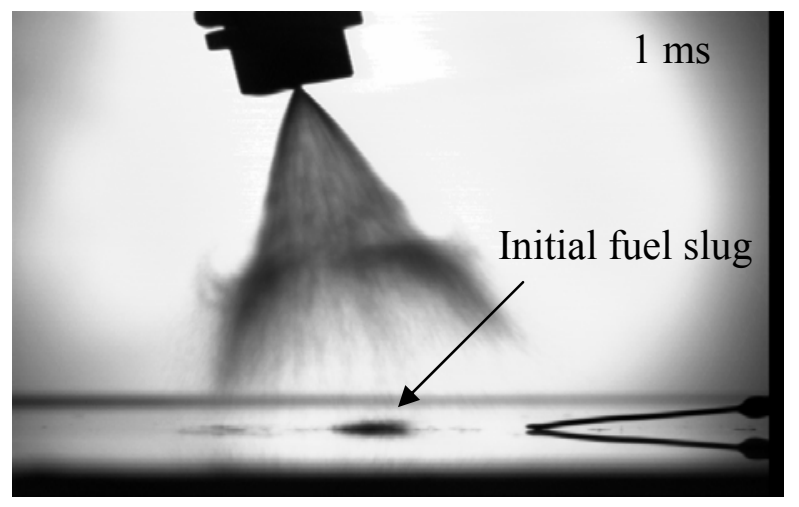

Figure 6-3. Formation of initial fuel slug on the surface $1 \mathrm{~ms}$ after the fuel injection. 


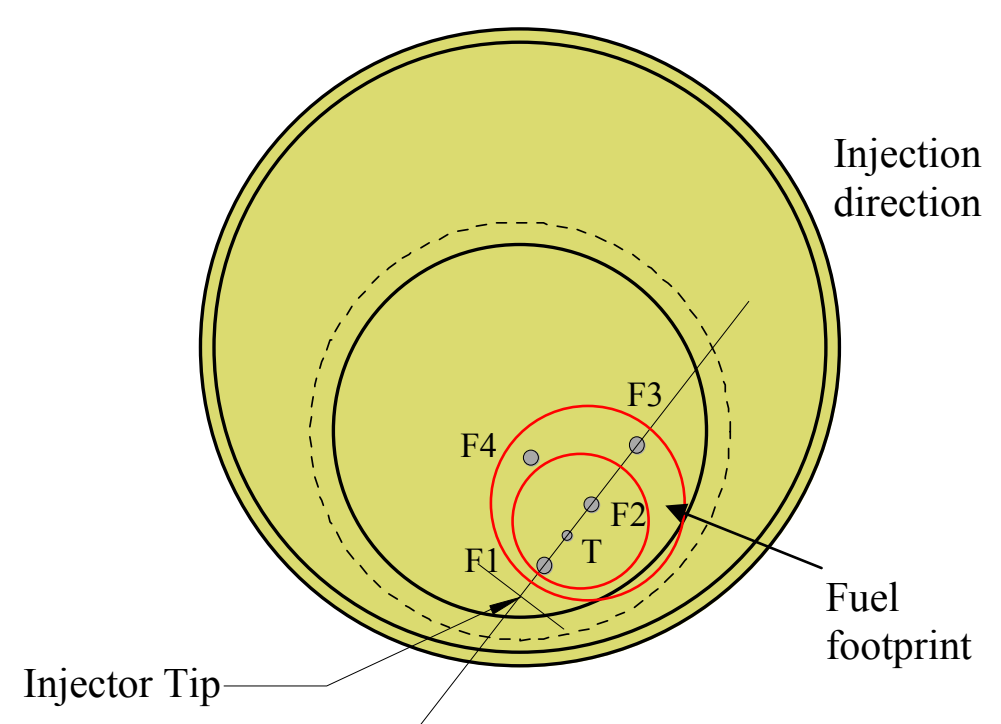

Figure 6-4. Schematic drawing of the fuel footprint observed after the engine test at $600 \mathrm{rpm}$. 

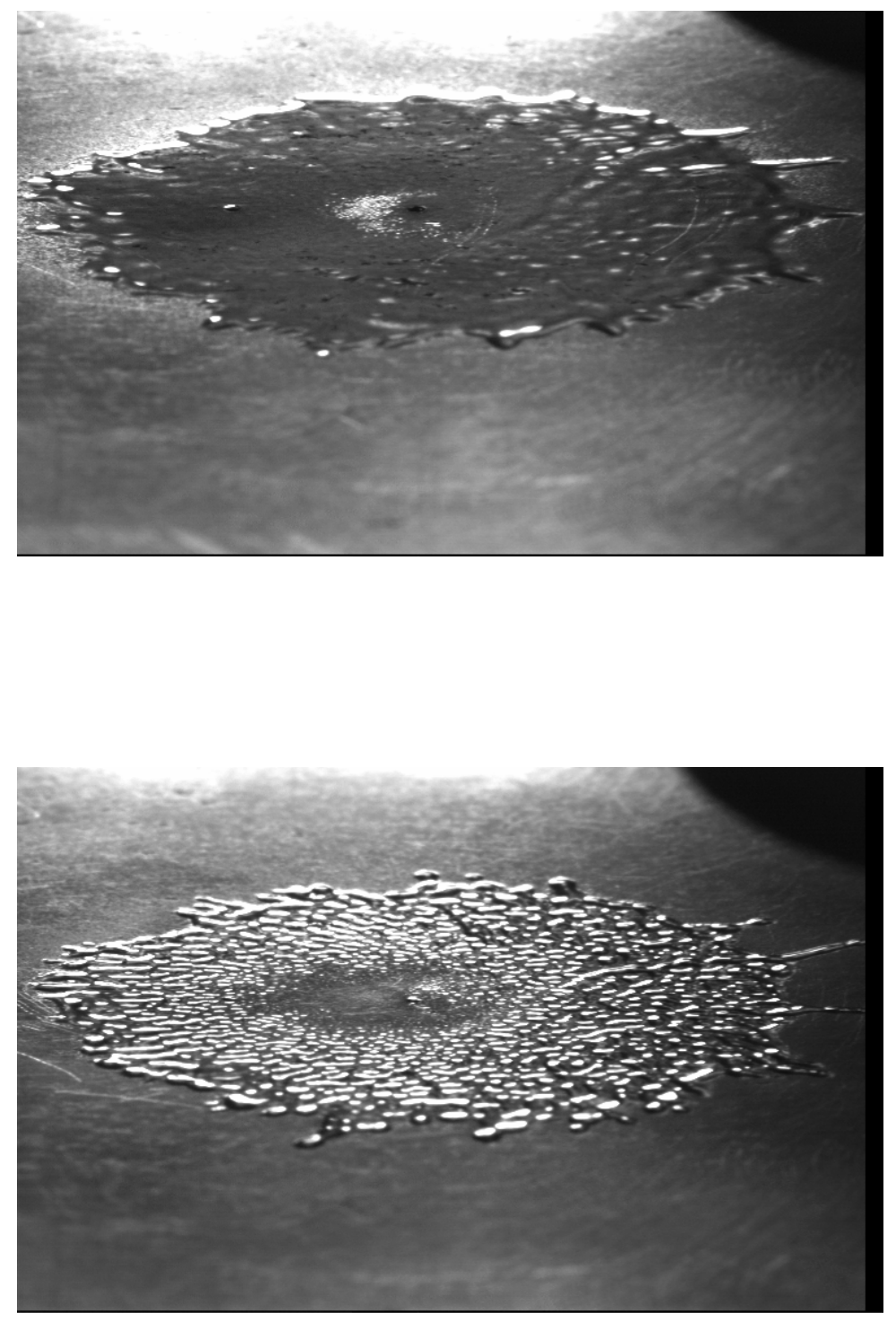

Figure 6-5. Shape of the fuel film $30 \mathrm{~ms}$ after isooctane injection for different surface temperatures (upper: $25^{\circ} \mathrm{C}$, lower: $72^{\circ} \mathrm{C}$ ) at atmospheric conditions. Injection duration was $3.6 \mathrm{~ms}$. 

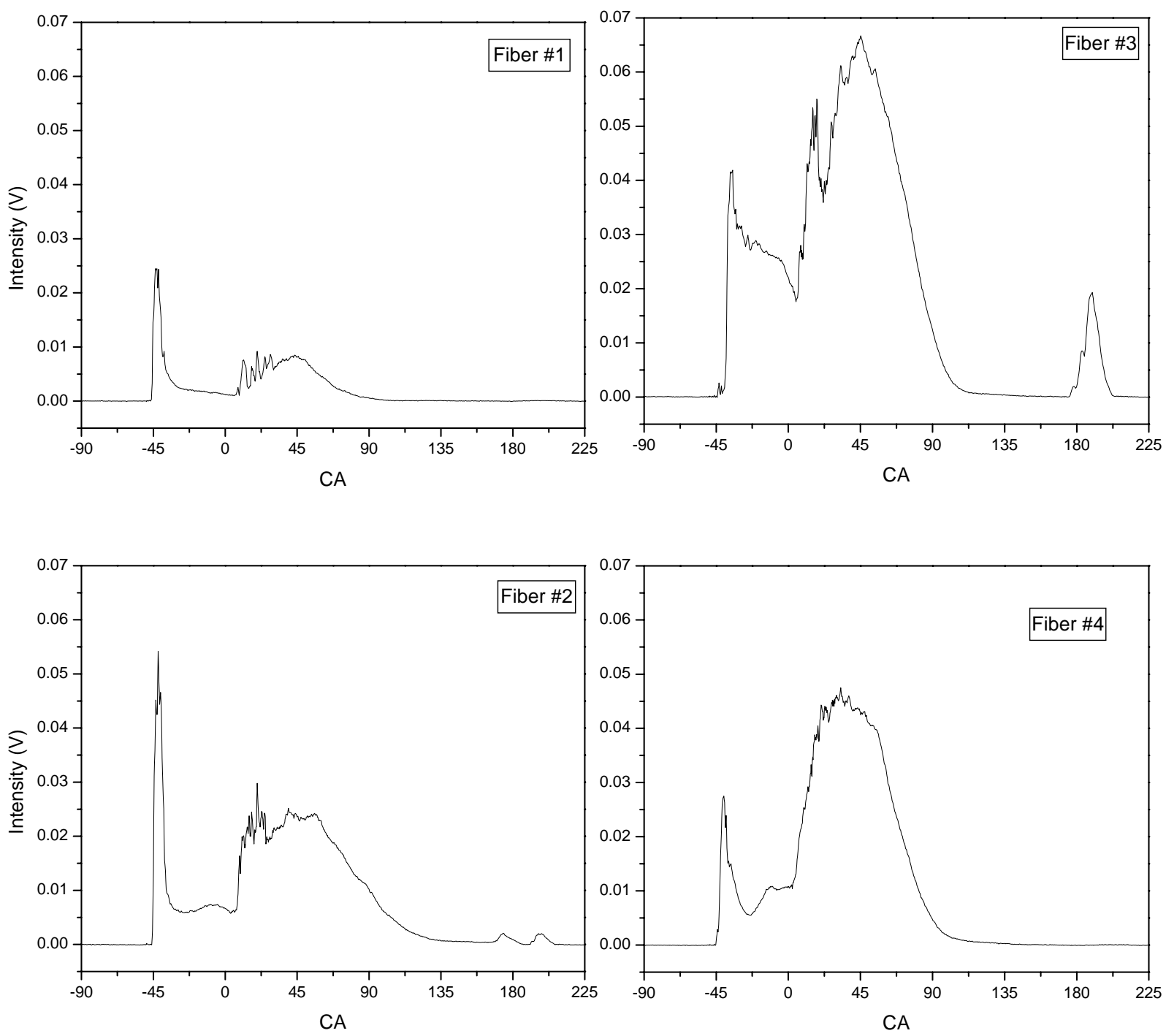

Figure 6-6. Fluorescence intensity at four fiber locations for the mixture of isooctane and $2 \times 10^{-6}$ M BTBP for fired condition at $600 \mathrm{rpm}$. 

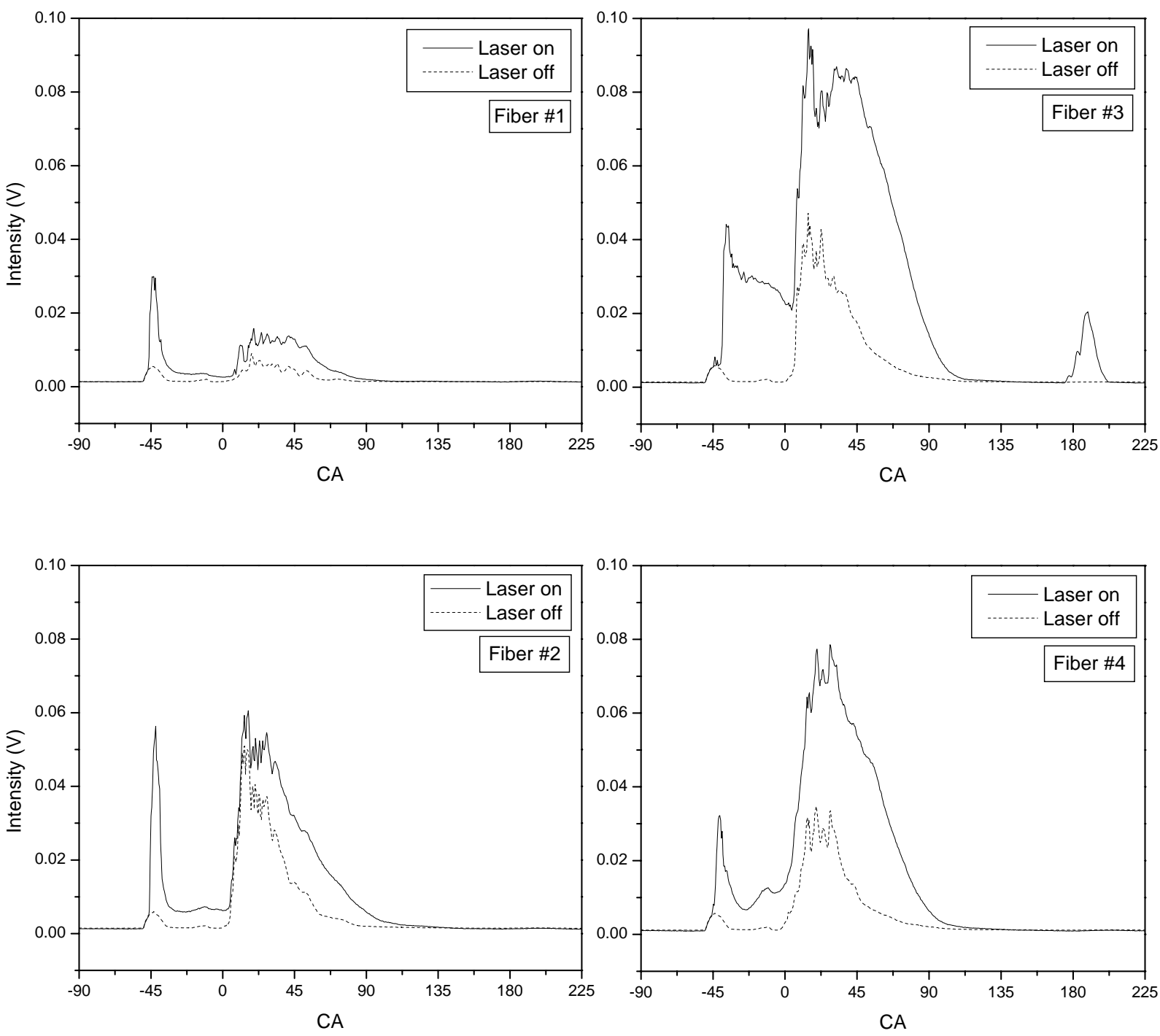

Figure 6-7. Separated signals when the laser is turned on and off for fired condition at 600 rpm. Figure 6-6 shows the difference between the two signals (net fluorescence). 

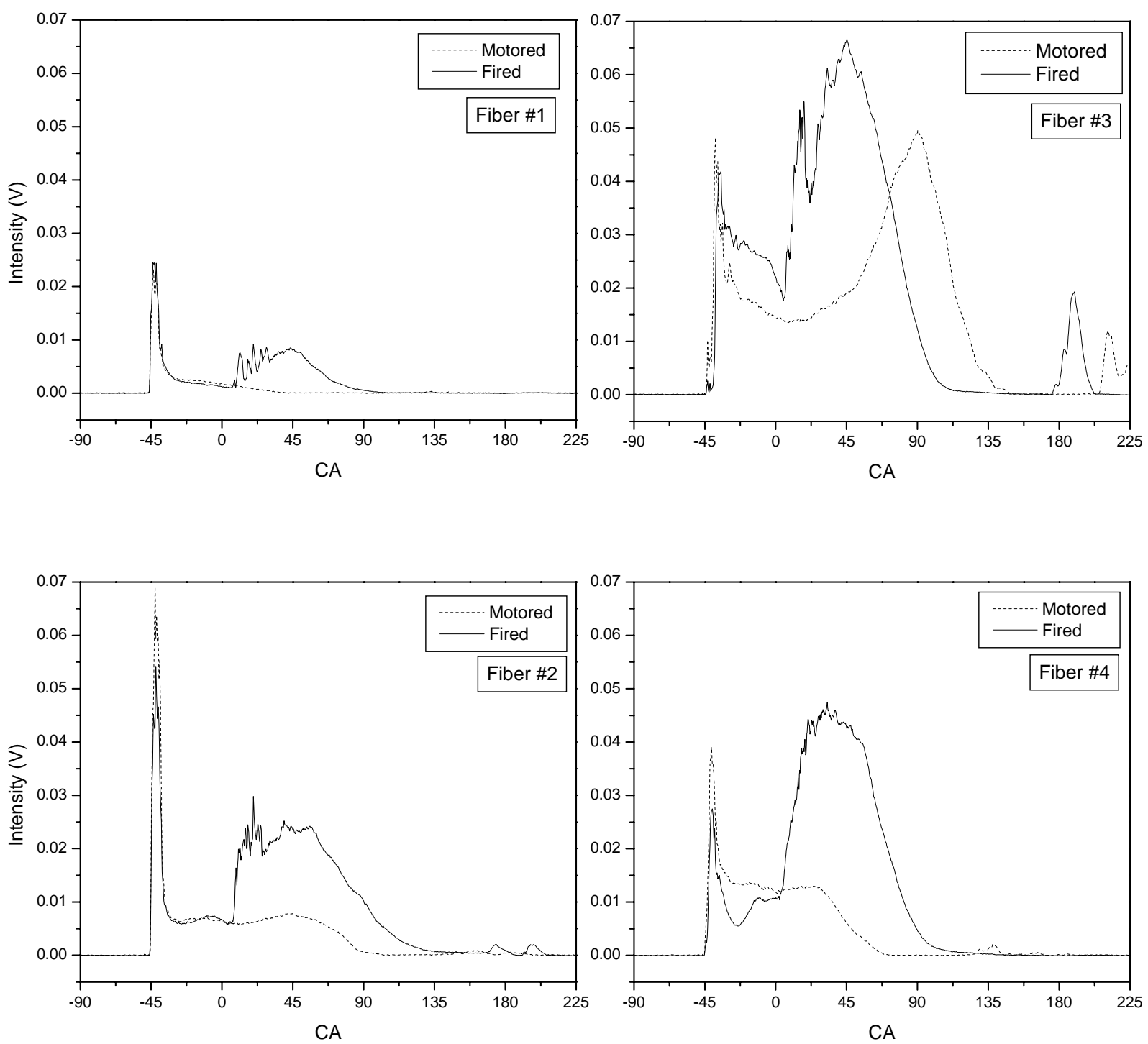

Figure 6-8. Comparison of the fluorescence intensity for motored and fired conditions at $600 \mathrm{rpm}$. 

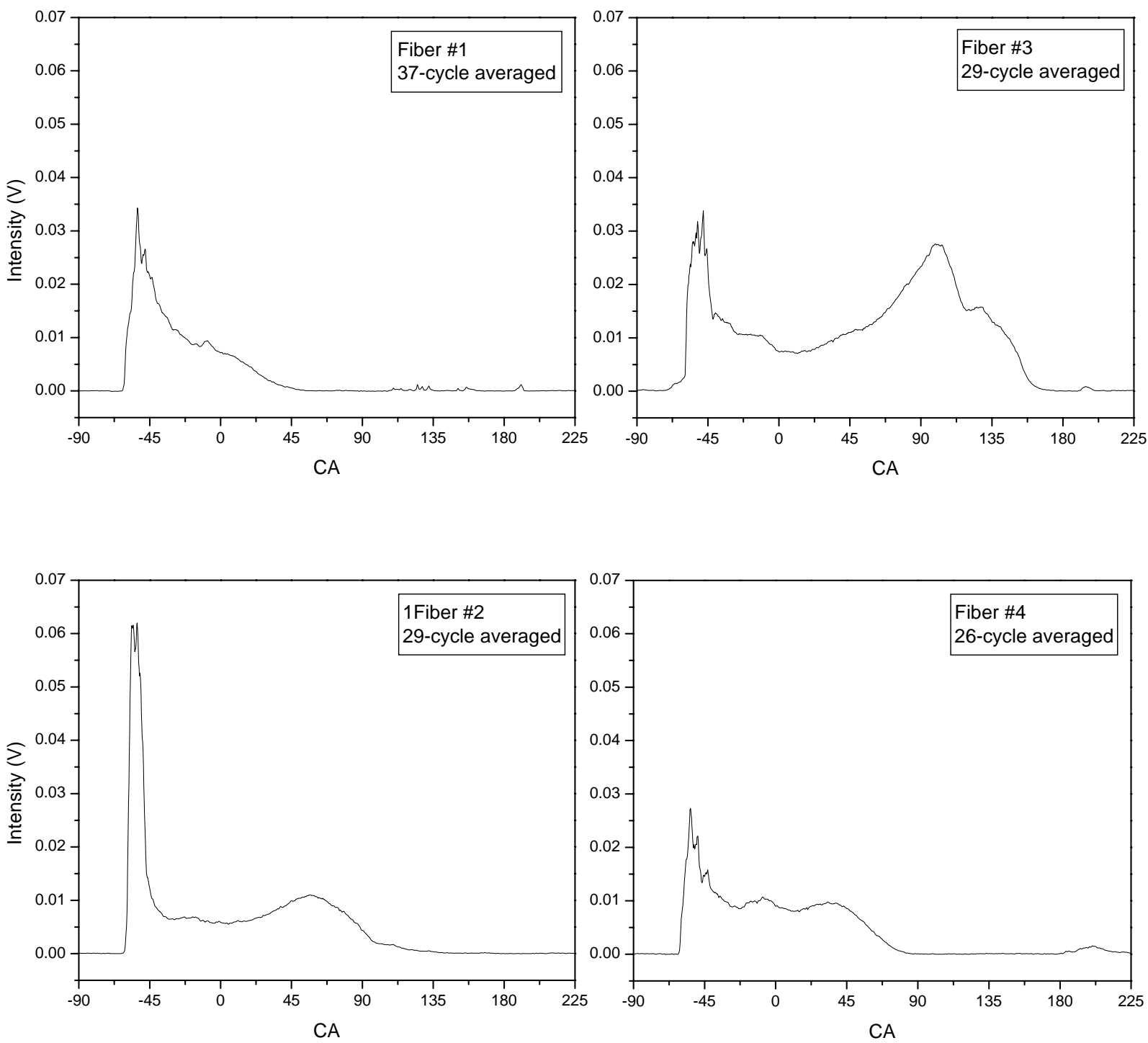

Figure 6-9. Fluorescence intensity at four fiber locations for the mixture of isooctane and $2 \times 10^{-6}$ M BTBP for motored condition at $1200 \mathrm{rpm}$. 

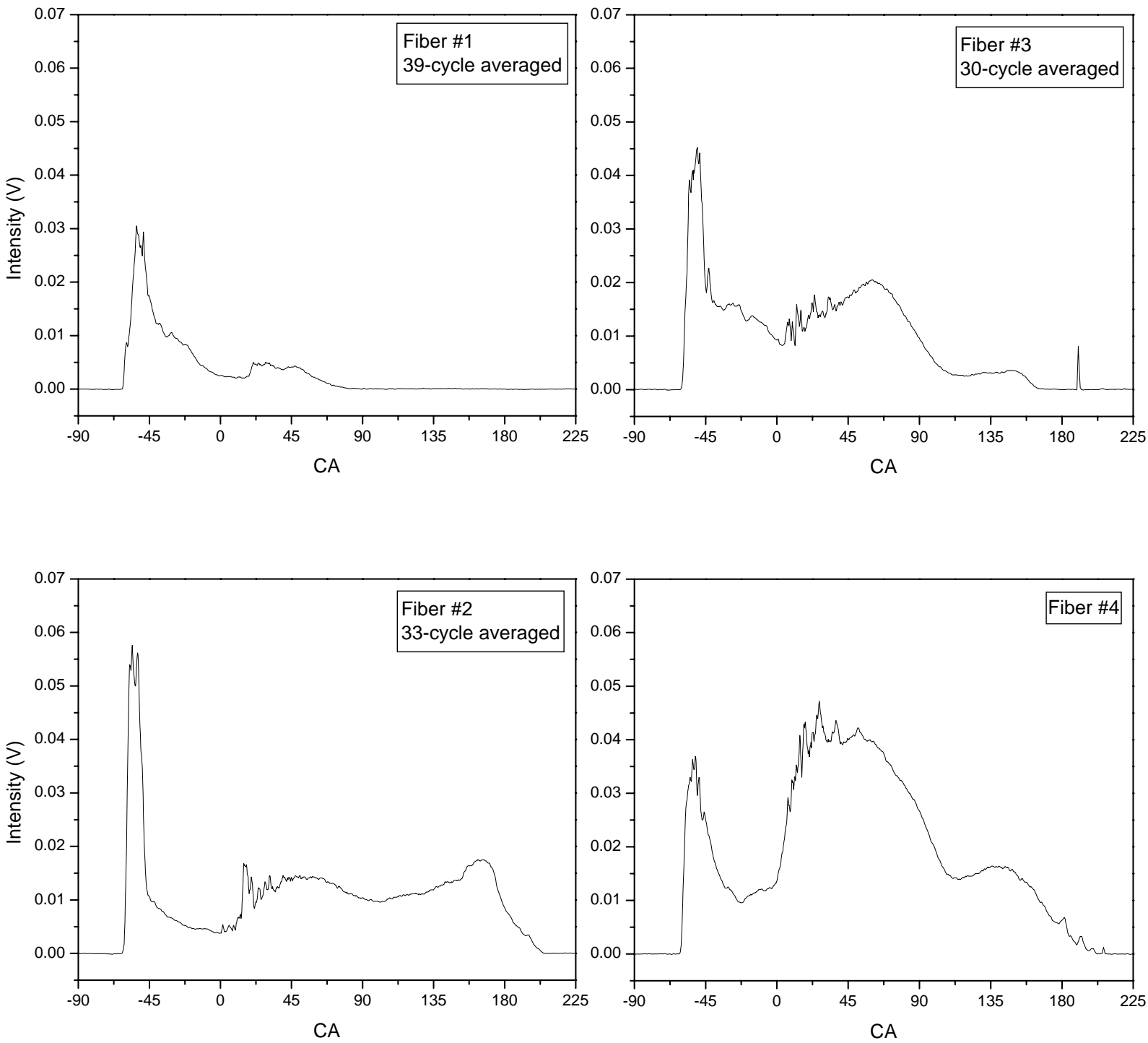

Figure 6-10. Fluorescence intensity at four fiber locations for the mixture of isooctane and $2 \times 10^{-6} \mathrm{M}$ BTBP for fired condition at $1200 \mathrm{rpm}$. 

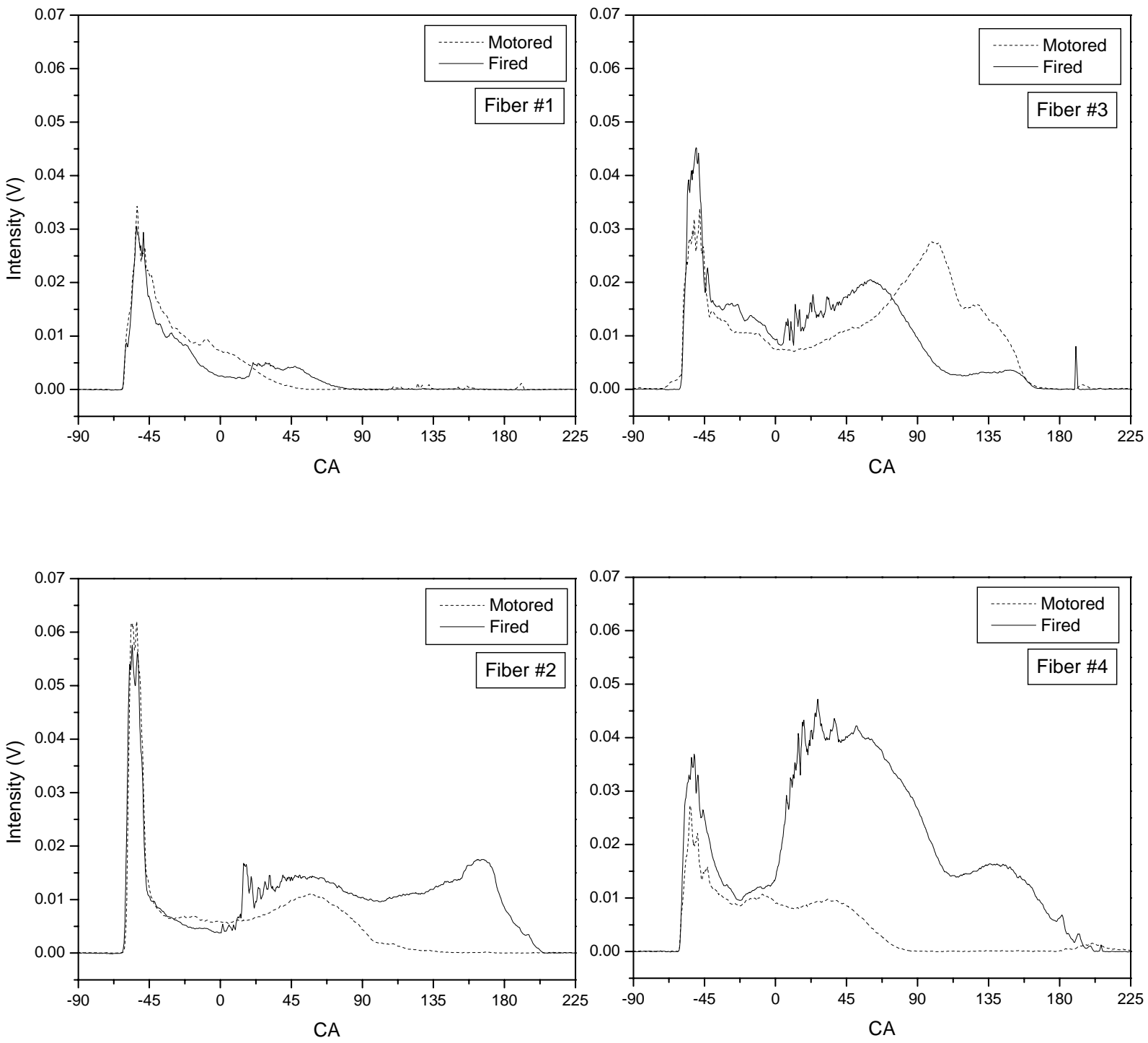

Figure 6-11. Comparison of the fluorescence intensity for motored and fired conditions at $1200 \mathrm{rpm}$. 


\section{6-1-2. Engine Test Results for n-Pentane/BTBP}

Motored engine tests were performed for n-pentane to see the effect of fuel volatility on the fuel film duration. The boiling point of $n$-pentane is $36^{\circ} \mathrm{C}$ and it represents the initial boiling point of gasoline.

Figure 6-12 shows the motored results at $600 \mathrm{rpm}$. At fiber locations 1 and 2, the fuel film duration was very short $\left(\sim 25^{\circ}\right)$ compared with the results of isooctane although the peak intensities were the same, suggesting that the fuel film evaporated just after it hit the piston bowl surface. The measured piston temperature was $97-99^{\circ} \mathrm{C}$, higher than the boiling point of n-pentane, even at the high in-cylinder pressures. The signal intensity at fiber 3 was higher than isooctane, but the duration of the fuel film was only a half of isooctane. The signal intensity and fuel film duration at fiber 4 were the same as those of isooctane. The differences in the result of n-pentane and isooctane were also contributed by the changes in spray pattern for the two different fuels having different volatility.

The motored results at $1200 \mathrm{rpm}$ are shown in Figure 6-13. The fuel film duration at all fiber locations were very short although the peak intensities during the fuel injection were the same level as for isooctane except for fiber 3 . The fact that the signal intensities were the same as for isooctane during the injection period suggests that the initial fuel film thicknesses were similar. However, the signal decreased quickly after the fuel injection at all fiber locations. The piston temperatures were $110-113^{\circ} \mathrm{C}$ at this condition. It is clear from the results that the fuel film duration is shorter for the fuel having lower boiling point. This result does not coincide with the result of Alger et al. (2001) who acquired fuel vapor images near the piston surface using the Schlieren method. They observed that the duration of the fuel 
vapor for n-pentane near the piston surface was a little bit longer than that of isooctane and the fuel vapor remained on the piston surface until the early part of the exhaust stroke. It seems that the fuel vapor remained on the piston surface for a long time after the quick fuel film vaporization because the air motion near the piston surface during the power stroke was not strong enough for active mixing with the charge.

\section{6-1-3. Engine Test Results for n-Decane/BTBP}

The volatility effect test was also performed for $n$-decane. The boiling point of ndecane is $174^{\circ} \mathrm{C}$ and it corresponds to the final boiling point of gasoline.

Figure 6-14 shows the 40-cycle averaged fuel film traces at the location of fiber 3 at $600 \mathrm{rpm}$ for motored condition. The fuel film remained during the whole engine cycle in this case. The signal intensities at all crank angles were higher than that of isooctane and npentane. The piston temperature was $101^{\circ} \mathrm{C}$ and it was much lower than the boiling point of n-decane. In that situation, the cohesion force of the fuel becomes higher and it reduced the spread of fuel film and resulted in a thicker fuel film.

However, it was not possible to take more data at other fiber locations because the engine started to auto-ignite after the test. The auto-ignition temperature of n-decane for atmospheric pressure is $210^{\circ} \mathrm{C}$ [Glassman, 1987] and the in-cylinder air temperature was higher than the temperature at TDC position as shown in Figure 5-24. 

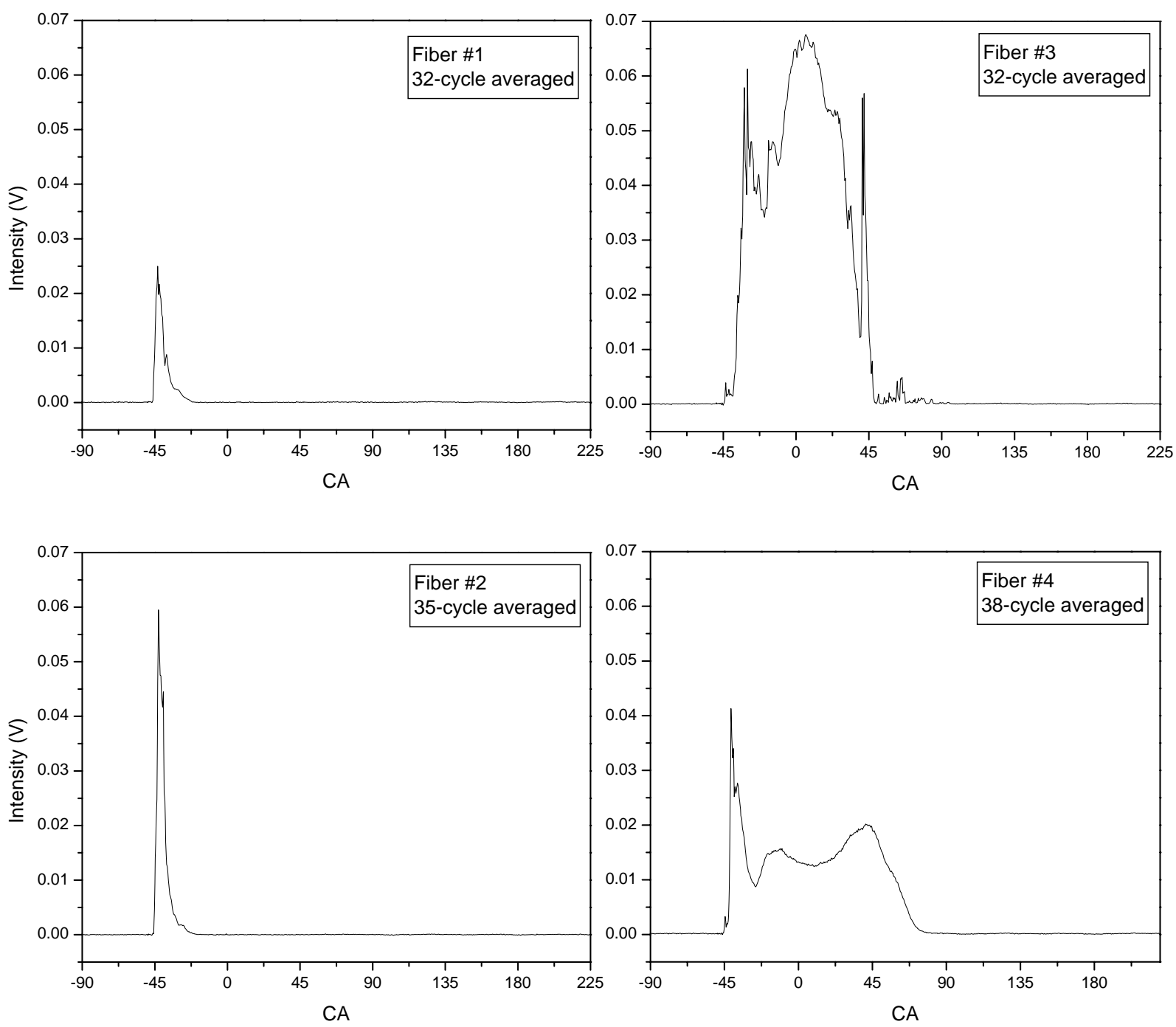

Figure 6-12. Fluorescence intensity at four fiber locations for the mixture of n-pentane and $2 \times 10^{-6} \mathrm{M}$ BTBP for motored condition at $600 \mathrm{rpm}$. 

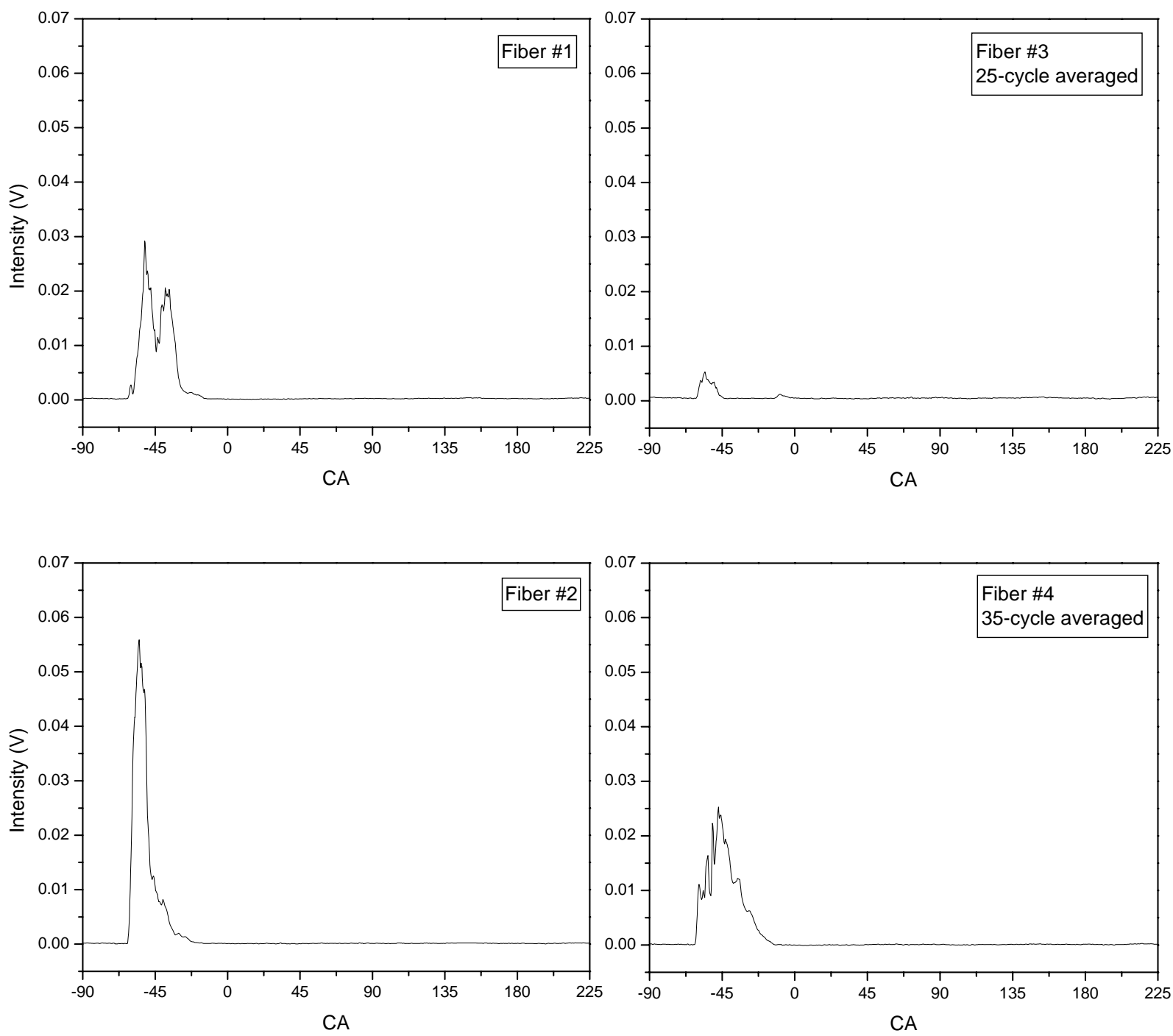

Figure 6-13. Fluorescence intensity at four fiber locations for the mixture of $n$-pentane and $2 \times 10^{-6}$ M BTBP for motored condition at $1200 \mathrm{rpm}$. 


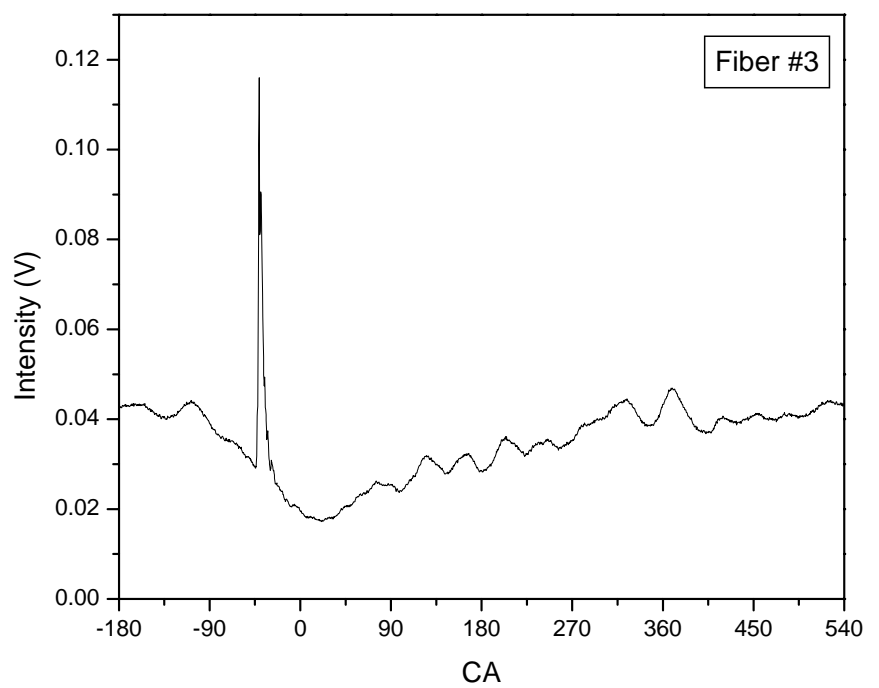

Figure 6-14. Fluorescence intensity at fiber 3 location for the mixture of n-decane and $2 \times 10^{-6}$ M BTBP for motored condition at $600 \mathrm{rpm}$. 


\section{6-2. Fuel Film Thickness Measurement using 2,3-hexanedione as a Dopant}

The fuel used in this experiment was isooctane. However, it does not fluoresce for the laser wavelength of $457.9 \mathrm{~nm}$, therefore, $4 \%$ of 2,3-hexanedione (by volume) was added to the fuel as a dopant. The boiling point of 2,3 -hexanedione $\left(128^{\circ} \mathrm{C}\right)$ is higher than that of isooctane $\left(99^{\circ} \mathrm{C}\right)$. However, Le Coz and Baritaud (1994) showed through an experiment that 2,3-hexanedione is a satisfactory tracer of isooctane in a vaporizing condition. The reason given was that the minority compound in a mixture is expelled to the vapor phase by the majority compound and the vapor pressure of the minority compound became higher in the mixture than in a pure liquid tracer. Therefore, the tracer needs to have a higher boiling point than isooctane to follow the evaporation of isooctane.

The fluorescence from 2,3-hexanedione is weak because the molar absorption coefficient of 2,3-hexanedione $(\varepsilon \sim 20 \mathrm{l} / \mathrm{mol}-\mathrm{cm})$ is low compared to that of BTBP $(\varepsilon \sim 19,000$ $\mathrm{l} / \mathrm{mol}-\mathrm{cm}$ ) at $457.9 \mathrm{~nm}$. The fluorescence occurs at $460-550 \mathrm{~nm}$ when the $457.9 \mathrm{~nm}$ laser was used. Therefore, the filter in the PMT unit was changed to the combination of a $457.9 \mathrm{~nm}$ holographic notch filter and two of $495 \mathrm{~nm}$ Schott glass filters instead of the $515 \mathrm{~nm}$ bandpass filter used for BTBP fluorescence.

\section{6-2-1. Preliminary Tests}

The mixture of isooctane and 4\% 2,3-hexanedione was tested before engine tests to check its suitability for fuel film thickness measurements under evaporating conditions. The tests performed included the effects of photobleaching, fuel film thickness, fuel temperature, 
pressure, and the evaporation characteristics of the mixture on the fluorescence intensity. The details are described in this section.

The fluorescence intensity from the mixture should not decrease (or photobleach) at least for $200 \mathrm{~ms}$, which corresponds to one cycle at $600 \mathrm{rpm}$, for the accurate fuel film thickness measurement during the whole cycle. Photobleaching of the mixture was checked first in a calibration device where the fuel was not in contact with the air. The fluorescence intensity when the fuel was flowed providing a bleach-free condition was compared to the results when there was no fuel flow. The fuel temperature was $140^{\circ} \mathrm{C}$ and the fuel was pressurized for the test at this high temperature. The intensity decrease after $50 \mathrm{~ms}$ and 200 ms for $10 \mathrm{~mW}$ laser irradiation was $9 \%$ and $13 \%$, respectively. The same photobleaching test was performed in the piston bowl at room temperature for a relatively thick fuel film $(\leq 1$ $\mathrm{mm}$ ). In this case, the fuel surface was open to the atmospheric air and it was closer to the actual condition in the engine except for the fuel temperature. The signal decrease was less than 5\% within $200 \mathrm{~ms}$ in this condition. Therefore, photobleaching of the fluorescence was not considered in the engine test.

The fuel film thickness will be obtained based on the measured fluorescence signal and the calculation result of the cumulative signal as discussed in chapter 3. It was shown in Figure 3-7 that the measured fluorescent intensities followed well the cumulative signal curve for the thin fuel films. The comparison for thick fuel films was not verified and is important because equation (3-2) needs the fluorescent intensity at infinite film thickness. A test was performed in the piston bowl at room temperature by adding a known amount of fuel. The fuel thickness was calculated from the piston bowl geometry and volume of the 
fuel. The fluorescence intensities were normalized for comparison with the normalized cumulative signals. The measured signals followed well the calculated cumulative signal (Figure 6-15) and the fluorescence intensity of the thickest fuel film can be used as an infinite condition. Small errors are associated with using any thickness greater than $2 \mathrm{~mm}$.

The effect of the fuel temperature on the fluorescent intensity is a necessary parameter for the fuel film thickness calculation as can be seen in equation (3-2). Tests were performed in the calibration device. Fuel flowed during the test to get the bleach-free result and the laser power was $10 \mathrm{~mW}$ and the fuel pressure was 3.9 bar to allow testing at higher fuel temperatures. Figure 6-16 shows the temperature effect on fluorescence intensity and intensity ratio, relative to the fluorescence intensity at room temperature $\left(\mathrm{I} / \mathrm{I}_{20^{\circ} \mathrm{C}}\right)$, at different times after fuel and dopant were mixed. The result clearly showed that the mixture should be used at least four hours after being mixed, and the fluorescence intensity decreased about $40 \%$ at $140^{\circ} \mathrm{C}$ compared with the intensity at $20^{\circ} \mathrm{C}$.

The effect of fuel pressure on the fluorescence is shown in Figure 6-17. The test was conducted in the calibration device and the pressure was increased up to 15 bar. The fluorescence intensity did not change at higher fuel pressures. Another test was performed in a pressure vessel where the fuel was placed with the free surface. It was pressurized with air and nitrogen up to 20 bar to check the decrease in the fluorescence intensity by oxygen quenching. The result showed that there was no oxygen quenching for this liquid fuel mixture and it can be used for the engine application.

The final question is whether the dopant co-evaporates with the isooctane. The test results for evaporating conditions are shown in Figure 6-18. First, the mixture of isooctane 
and 4\% 2,3-hexanedione was tested and then the mixture was vaporized (boiled) using a heater. The mixture when half the volume remained was tested at the same condition. The measured fluorescence intensity for both mixtures showed a very close result and it indicates that the dopant (2,3-hexanedione) co-evaporates with the isooctane. This result agrees with the result of Le Coz and Baritaud (1994). 


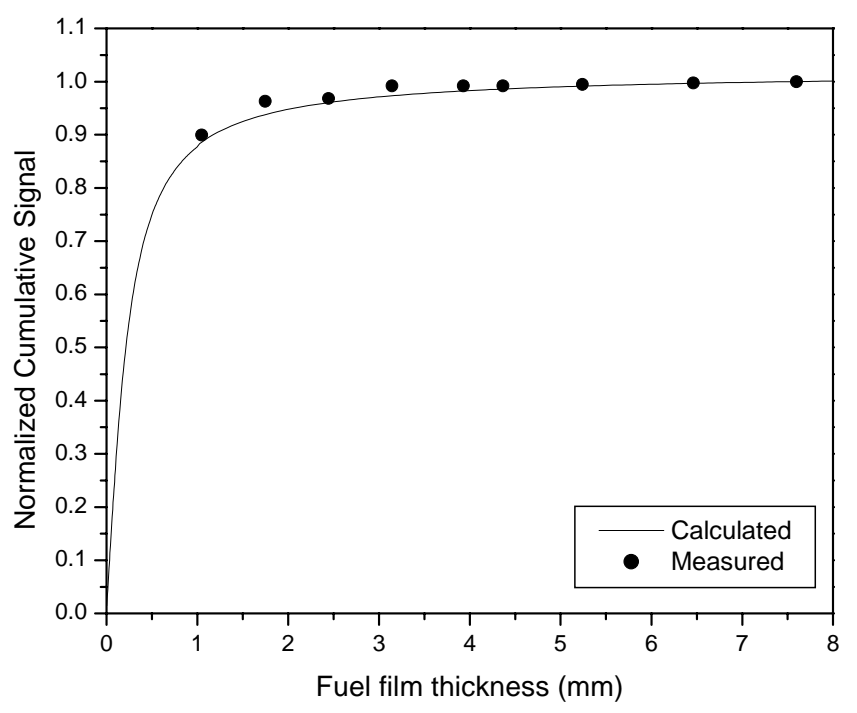

Figure 6-15. Comparison of the measured fluorescence intensity and the calculated cumulative signal for thick fuel thicknesses. Fuel was a mixture of isooctane and $4 \%$ 2,3-hexanedione. 

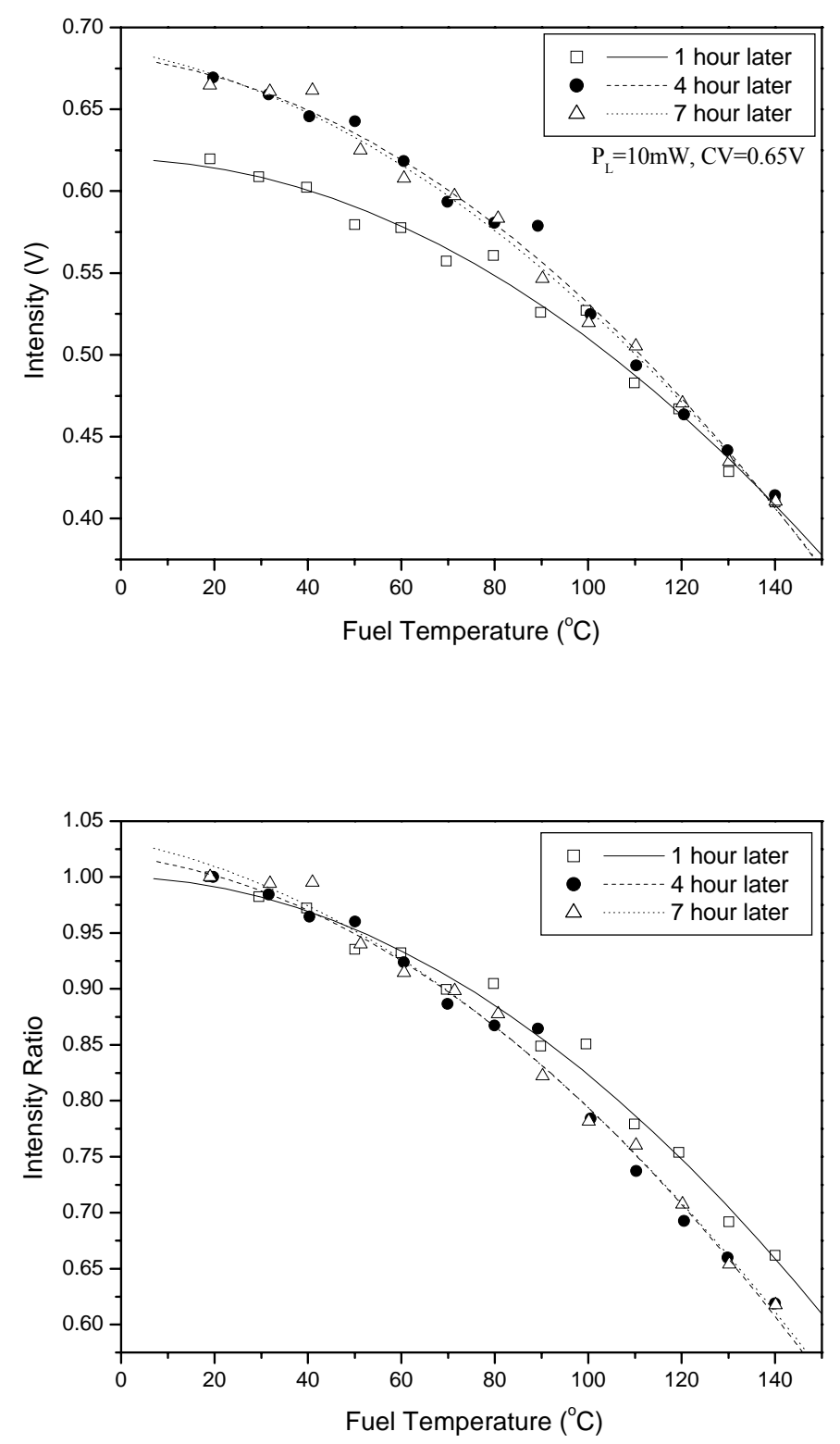

Figure 6-16. Fuel temperature and aging effects on the fluorescence intensity. Fuel was a mixture of isooctane and 4\% 2,3-hexanedione. 


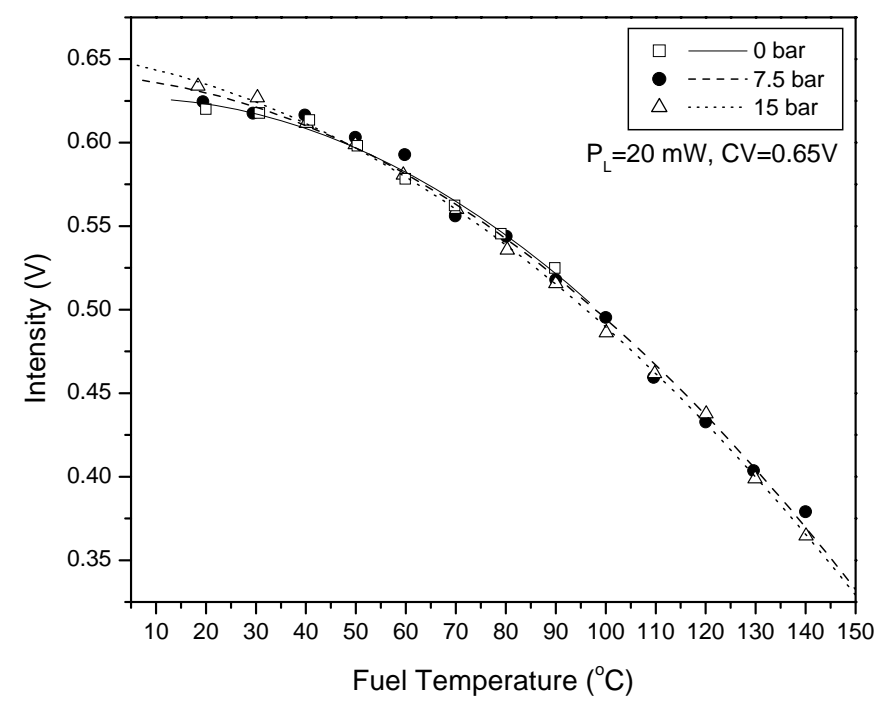

Figure 6-17. Fuel pressure effect on the fluorescence intensity. Fuel was a mixture of isooctane and $4 \%$ 2,3-hexanedione. 

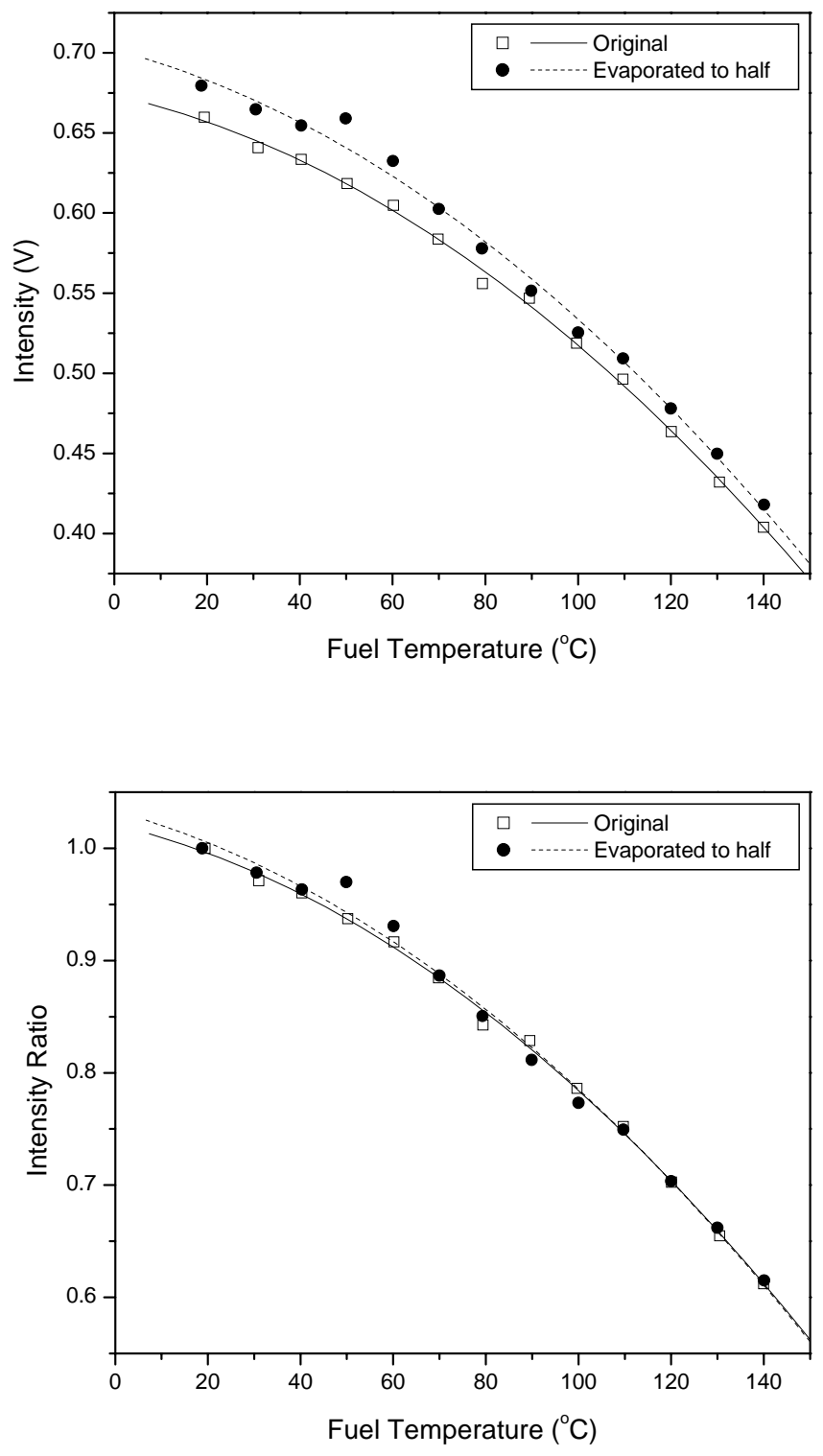

Figure 6-18. Dopant co-evaporation test. Fuel was a mixture of isooctane and $4 \% 2,3-$ hexanedione. 


\section{6-2-2. Engine Test Results}

The mixture of isooctane and 4\% 2,3-hexanedione was used in the engine test. The engine was operated in the late injection mode with an equivalence ratio of 0.3 . Engine tests were performed at 600 and $1200 \mathrm{rpm}$ for motored and fired conditions. The control voltage of the PMT was set to $0.6 \mathrm{~V}$. The fluorescence intensities were measured for 40 cycles and the signals were averaged. Piston temperatures were also measured using the thermocouple at the same time. The cycle-averaged fluorescence intensity was transformed to the film thickness through the method explained in chapter 3. The fuel film temperature was obtained from the measured piston temperature based on the results of the previous chapter. The fluorescence intensity for infinite fuel thickness at room temperature was measured at each fiber location after the engine test using the same mixture. The measured fluorescence intensities for infinite fuel thickness $(\sim 8 \mathrm{~mm})$ at each fiber were varied from $0.15 \mathrm{~V}$ to 0.19 $\mathrm{V}$. The variation might be caused by the differences in the transmission characteristics of each fiber and the small changes in fiber alignment in the fiber coupler between the tests. However, it was not a problem because the engine test and the infinite film test were performed at the same fiber setup condition for each fiber. In this section, all the results of the fluorescence intensity were converted to the fuel film thickness and the discussions will be made based on it.

Figure 6-19 is the fuel film thickness results at four fiber locations for motored 600 rpm engine condition. The durations of fuel films for fiber 1 and 2 was about $90^{\circ}$ and $150^{\circ}$, respectively. It was very close to the results of BTBP where they were $83^{\circ}$ and $135^{\circ}$. The shape of the fuel film thickness signal was very similar to the BTBP results. The maximum 
fuel film thickness of fiber 1 was about $30 \mu \mathrm{m}$ just after fuel injection and then reduced to about $3 \mu \mathrm{m}$. The peak fuel film thickness for fiber 2 was $85 \mu \mathrm{m}$ and then decreased to $5 \mu \mathrm{m}$ after that. The reason why the peak thickness at this fiber location was thicker than the other fibers was that the initial fuel slug was injected to the fiber 2 location as discussed in the previous section.

However, fibers 3 and 4, where the sprays were injected directly toward these locations, showed different results from the BTBP results. The fuel film did not evaporate completely during a cycle at those fiber locations and the minimum film thickness before fuel injection was about $12 \mu \mathrm{m}$. The piston surface was inspected after the test and it was found that a light yellow, highly viscous liquid was left on the piston surface at those locations. It was postulated that it came from the impurities in the 2,3-hexanedione whose purity levels were only $90 \%$, the highest purity level available. These impurities were accumulated at the fiber locations 3 and 4 through the repetitive fuel injection. Another possibility was that the expected fuel film temperature $\left(113^{\circ} \mathrm{C}\right), 15^{\circ} \mathrm{C}$ higher than the piston temperature $\left(98^{\circ} \mathrm{C}\right)$, was not high enough for complete vaporization of 2,3-hexanedione in a cycle.

For the $600 \mathrm{rpm}$ fired engine condition, the luminosity from the pool fires significantly increased the signal intensity and, therefore, the apparent film thickness at late times in the cycle as shown in Figure 6-20. It was not possible to discern the fluorescence signal from the total signal correctly during the pool fire period because the signal from the flame luminosity was too strong compared with the fluorescence signal. Also, the signals after the pool fires were strong, possibly due to laser scattering from the particulate matter 
that was stuck to the liquid remains of the dopant (for fiber 3,4 ) or to the fiber surface (for fiber 1, 2).

The viscous, light yellow liquid was also found on the piston bowl surface after the fired engine test as in the motored case. For fiber 1 and 2, it seemed that the fuel injection from the next cycle cleared the surface because the peak fuel film thickness and the traces of the fuel film thickness before the occurrence of the pool fires were the same level as in the motored case as shown in Figure 6-21. However, the fuel film thickness from the fuel injection to the appearance of the pool fires at fiber 3 and 4 was significantly increased compared with the results of motored condition. It seemed that the newly injected fuel could not clear the fiber surface because the liquid remaining from the previous cycle existed through the whole cycle. In this test, the average piston temperature was $112^{\circ} \mathrm{C}$ and the estimated fuel film temperature was $122^{\circ} \mathrm{C}$, which was $10^{\circ} \mathrm{C}$ higher than the piston temperature, and it was still lower than the boiling point of the dopant.

The motored results for $1200 \mathrm{rpm}$ are shown in Figure 6-22. The fuel film thickness at all fiber locations was less than $15 \mu \mathrm{m}$ except for the peak regions just after fuel injection. The peak fuel film thickness at fiber 2 was about $83 \mu \mathrm{m}$ and then decreased to $5 \mu \mathrm{m}$. The fuel film duration for fiber 2 and 3 were about $210^{\circ}$ and $260^{\circ}$, respectively, close to the BTBP results where it was $197^{\circ}$ and $222^{\circ}$. The fuel film completely disappeared only for fibers 2 and 3 at this engine speed. However, the fuel film never completely disappeared at fibers 1 and 4. Again, the light yellow liquid was found on the piston surface after the test and was believed to have affected the signals at fibers 1 and 4 as in the case of $600 \mathrm{rpm}$. The piston temperatures were $111-115^{\circ} \mathrm{C}$ and the estimated fuel film temperature was $133^{\circ} \mathrm{C}\left(20^{\circ} \mathrm{C}\right.$ 
higher than the piston temperature), which is higher than the boiling point of 2,3hexanedione at atmospheric pressure $\left(128^{\circ} \mathrm{C}\right)$. The fuel film thickness of fiber 1 was negligible compared with the noticeable signal in the BTBP result. This may have been caused by small changes in spray pattern by day-to-day variation, and changes in viscosity and boiling point of the mixtures by addition of $4 \%$ 2,3-hexanedione.

The results for fired conditions at $1200 \mathrm{rpm}$ are shown in Figure 6-23 with the results of motored conditions for comparison. The fuel film thickness at fibers 2 and 3 from the fuel injection to the start of the pool fires were the same level as for motored case. Also, the fuel film thickness just before fuel injection was close to zero at those fiber locations. The fuel film thickness at fibers 1 and 4 were also not significantly different from the results of motored condition, and the fuel film persisted during the whole cycle as in the motored condition because of the liquid residue that remained on the surface. The average piston temperatures were $126^{\circ} \mathrm{C}$ at this conditions and the fuel film temperature was assumed to be $15^{\circ} \mathrm{C}$ higher $\left(141^{\circ} \mathrm{C}\right)$ than the piston temperature. The yellow liquid remains were also found on the piston surface after the test although the assumed fuel film temperature was higher than the boiling point of 2,3-hexanedione at atmospheric pressure. 

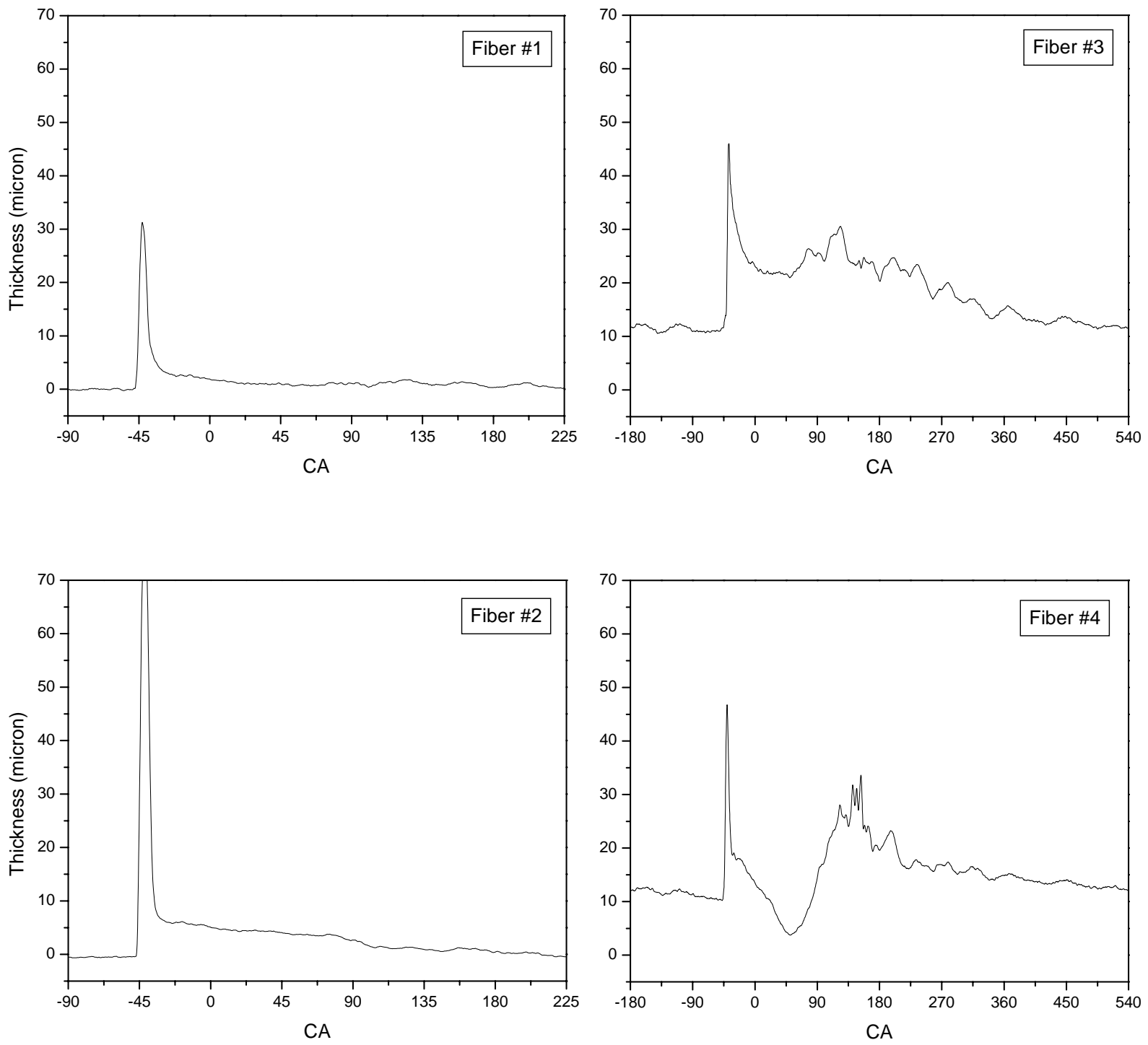

Figure 6-19. Fuel film thickness at four fiber locations for the mixture of isooctane and 2,3hexanedione for motored condition at $600 \mathrm{rpm}$. 

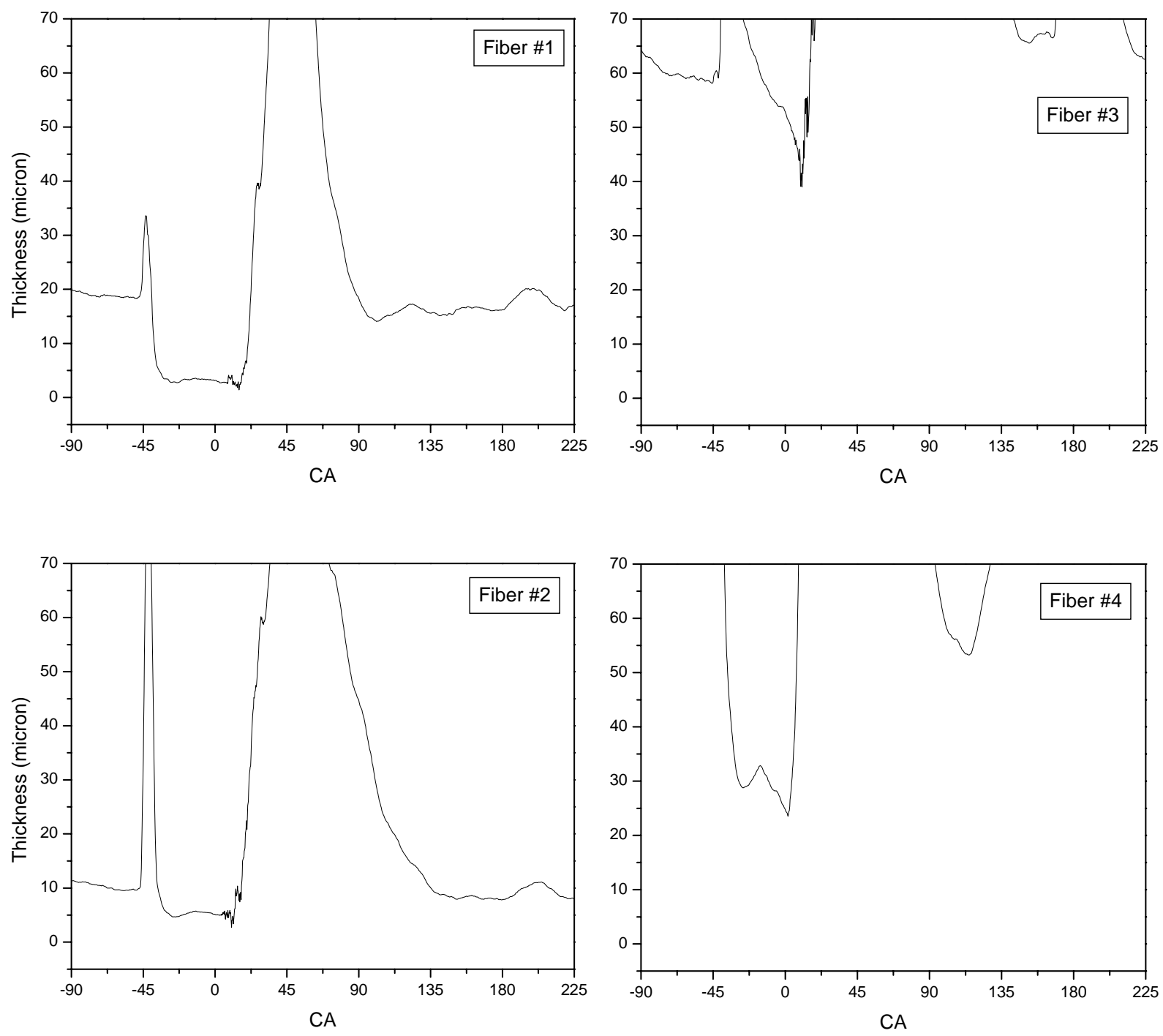

Figure 6-20. Fuel film thickness at four fiber locations for the mixture of isooctane and 2,3hexanedione for fired condition at $600 \mathrm{rpm}$. 

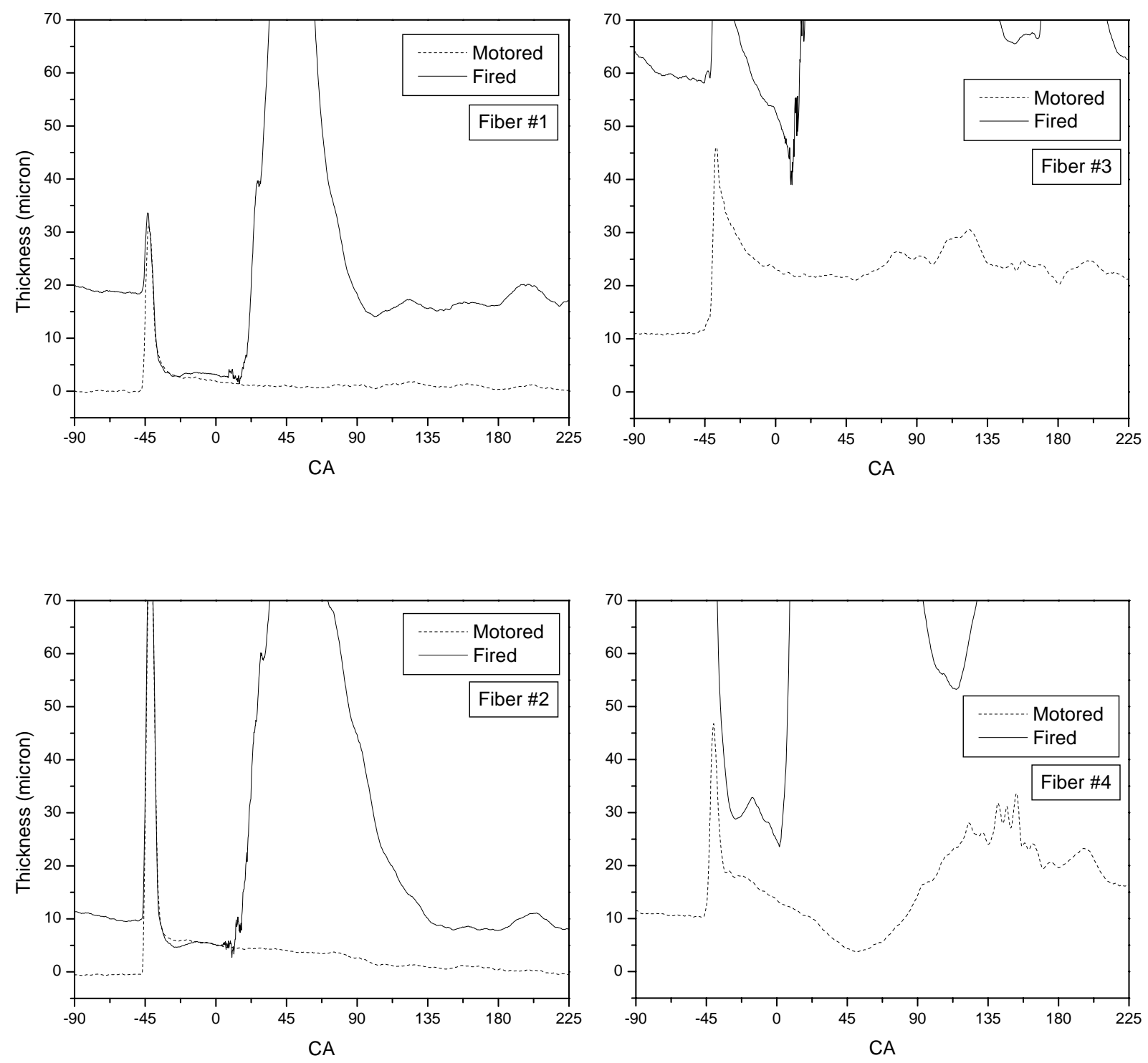

Figure 6-21. Comparison of the fuel film thickness for motored and fired conditions at 600 $\mathrm{rpm}$ for the mixture of isooctane and 2,3-hexanedione. 

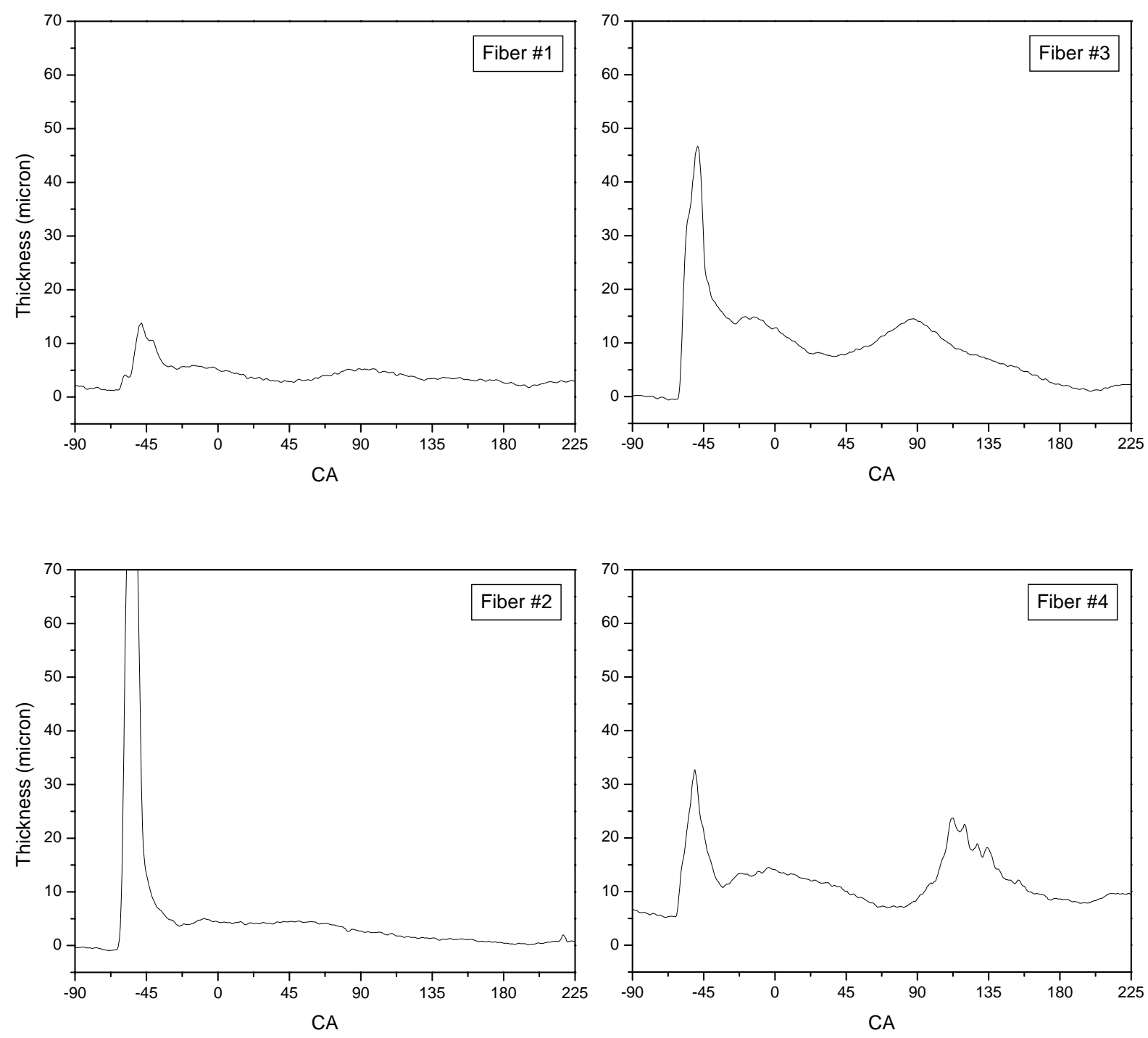

Figure 6-22. Fuel film thickness at four fiber locations for the mixture of isooctane and $4 \%$ 2,3-hexanedione for motored condition at $1200 \mathrm{rpm}$. 

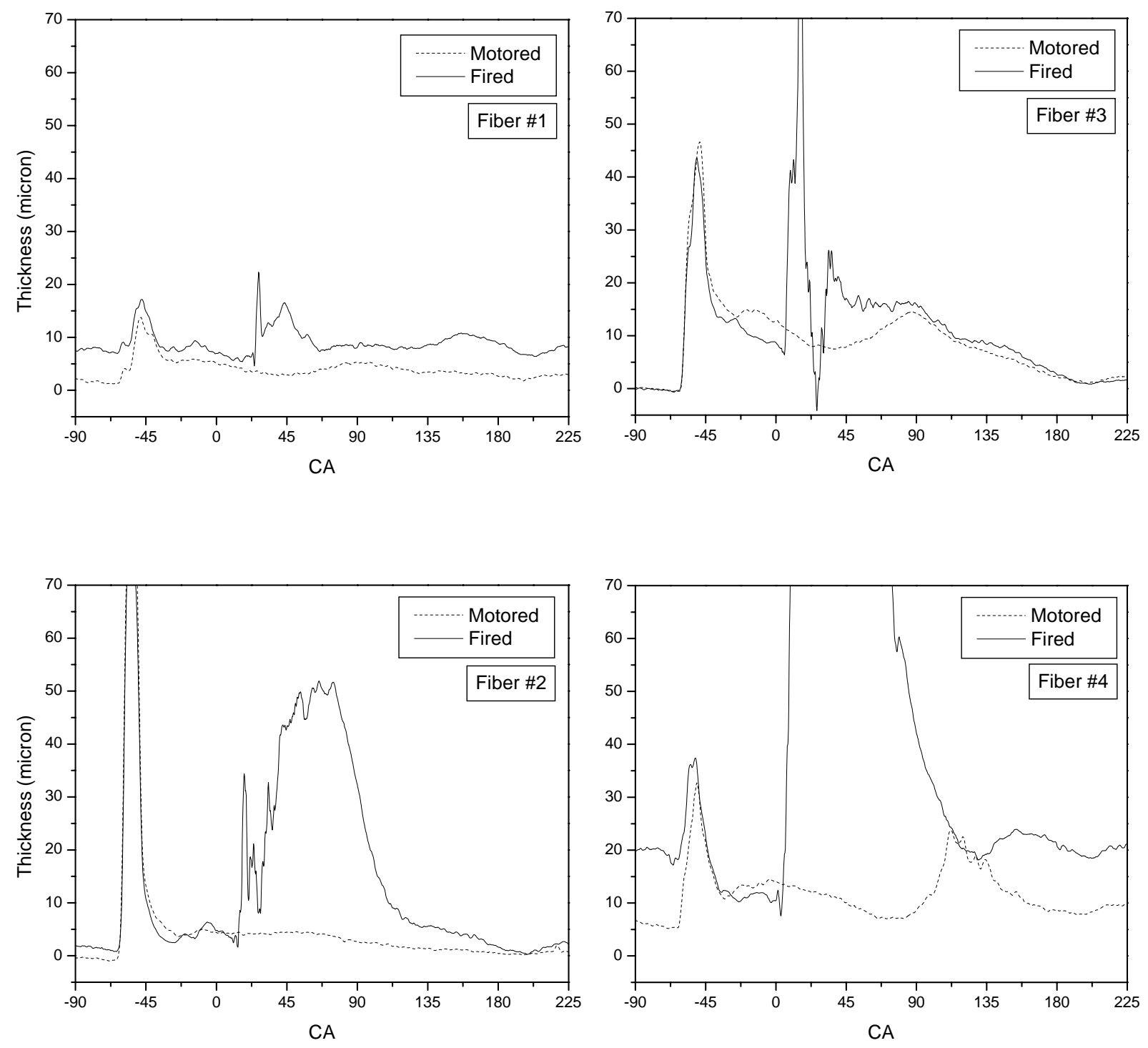

Figure 6-23. Comparison of the fuel film thickness for motored and fired conditions at 1200 rpm for the mixture of isooctane and 2,3-hexanedione. 


\section{6-3. Fuel Film Thickness Measurement using Biacetyl as a Dopant}

In the previous section, 2,3-hexanedione was used as a dopant of isooctane. However, the results showed that the liquid fuel film persisted during the whole engine cycle at those fiber locations where the spray was directly injected. The result did not coincide with the results when BTBP was used as a dopant. The reason was that 2,3-hexanedione was not completely evaporated from the piston bowl surface within a cycle at the tested piston temperature conditions.

To eliminate that problem, the same amount of biacetyl was used in this test as a dopant instead of 2,3-hexanedione. Biacetyl has a boiling point $\left(88^{\circ} \mathrm{C}\right)$ close to isooctane and it has been widely used as a dopant for isooctane [Baritaud et al., 1992; Deschamps et al., 1994] in engine tests.

\section{6-2-1. Preliminary Tests}

The mixture of isooctane and $4 \%$ biacetyl was tested to obtain the fuel temperature effect on the fluorescence intensity in the calibration device. The changes in signal intensity and the intensity ratio $\left(\mathrm{I} / \mathrm{I}_{20^{\circ} \mathrm{C}}\right)$ for higher fuel temperature at different times after being mixed are shown in Figure 6-24. The result also showed that the fluorescence of the mixture changed slightly as the mixture aged. However, the variations were not significant and the intensity ratio result after 6 hours being mixed was used in the fuel film thickness calculation. The mixture boil-off test was performed as in 2,3-hexanedione. The result showed that 
biacetyl evaporated much faster than isooctane and the fluorescence signal was very weak after half of the mixture was evaporated.

The other tests which were performed for 2,3-hexanedione were not performed because the other fluorescence characteristics would be the same for the two $\alpha$-diketones as could be inferred from the results of Richtol et al. (1966).

\section{6-2-2. Engine Test Results}

Figure 6-25 shows the fuel film thickness measurements at all four fiber locations for motored and fired conditions at $600 \mathrm{rpm}$. The piston temperatures for the motored condition were $99^{\circ} \mathrm{C}$ for all tests and the expected fuel film temperature was $15^{\circ} \mathrm{C}$ higher than the piston temperature. The maximum fuel film thicknesses just after the fuel injection were significantly reduced compared with that of 2,3-hexanedione at all fiber locations. The fuel film durations were also reduced significantly except for fiber 4 . The decrease in the peak fuel film thickness at all fiber locations and the decrease in fuel film durations were related to the faster vaporization of biacetyl as observed in the boil-off test. The light yellow liquid residue was again found on the piston bowl surface after the test, although the amount was negligible in comparison to the 2,3-hexanedione.

The fired results at $600 \mathrm{rpm}$, also shown in Figure 6-25 with motored results, showed very similar results to the motored case. The maximum fuel film thicknesses at fiber 1 and 2 were the same level as those of the motored conditions, but were increased significantly at fiber 3 and 4 locations. This thick fuel films at those fibers before the occurrence of pool fires were the result of the dopant residue and the particulate matter, which were stuck to the 
liquid residue, as in the previous section. The piston temperatures were $109-114^{\circ} \mathrm{C}$ for this condition and the fuel film temperatures were estimated $10^{\circ} \mathrm{C}$ higher than the piston temperature as before.

The results at $1200 \mathrm{rpm}$ for the motored and fired engine conditions are shown in Figure 6-26. The piston temperature for motored condition was $100-116^{\circ} \mathrm{C}$ and it was 126 $131^{\circ} \mathrm{C}$ for fired condition. The decrease of the peak thickness, especially fiber 2 , compared with that of 2,3-hexanedione was more significant at this higher engine speed. The air motion and turbulence increased at higher engine speed and it caused more active evaporation of biacetyl just after the fuel injection before it hit the piston bowl surface. 

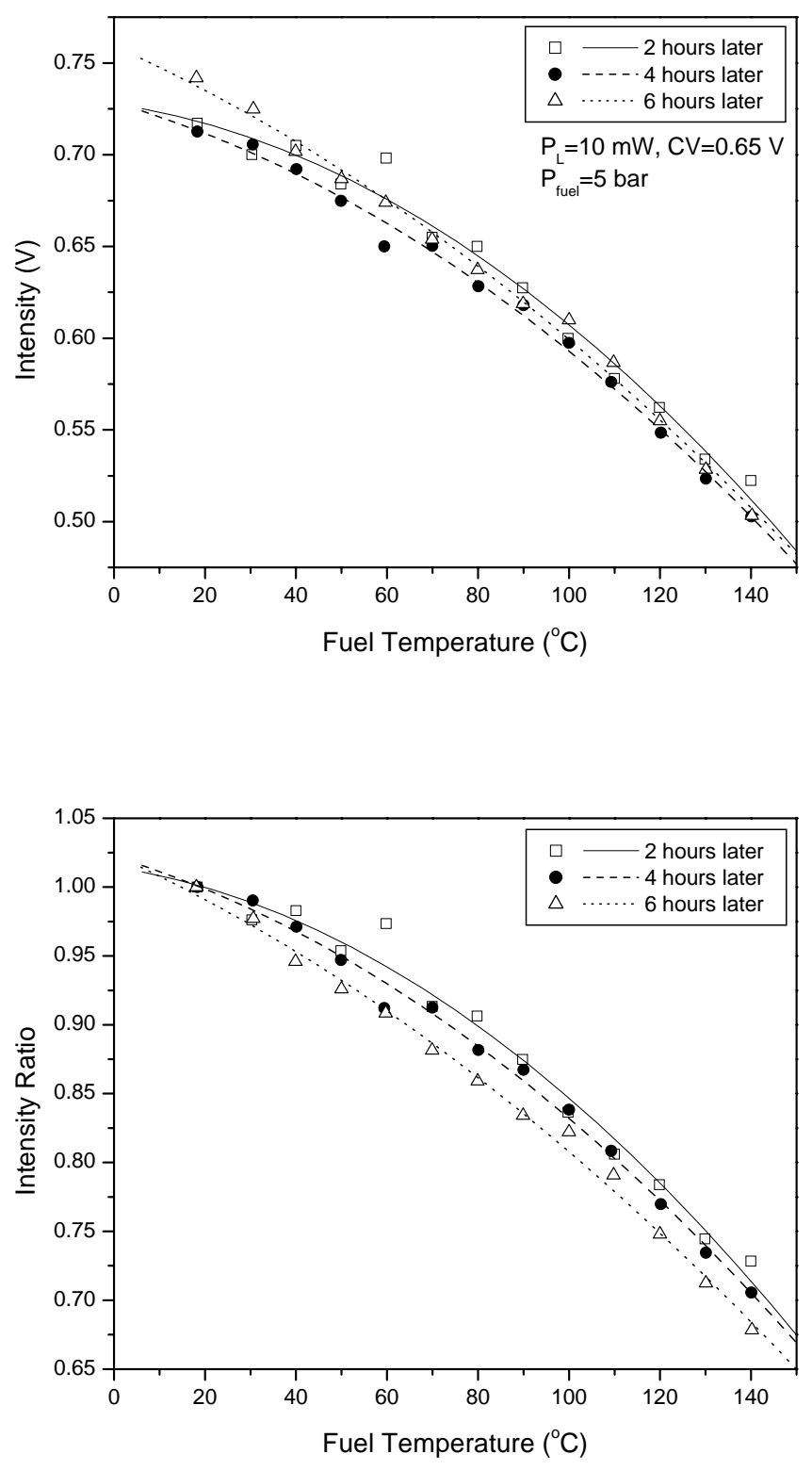

Figure 6-24. Fuel temperature and aging effects on the fluorescence intensity. Fuel was a mixture of isooctane and $4 \%$ biacetyl. 

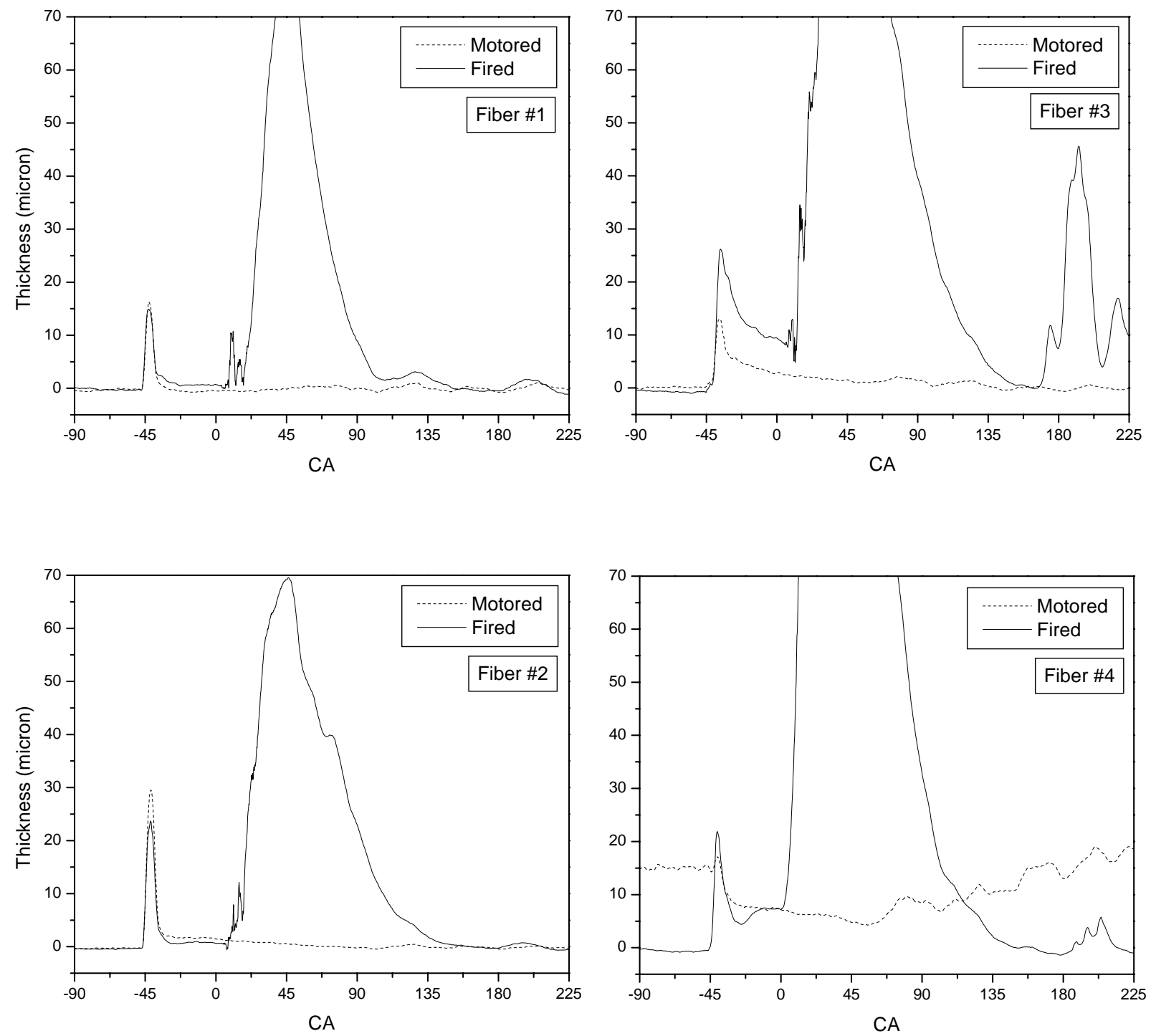

Figure 6-25. Fuel film thickness for motored and fired conditions at $600 \mathrm{rpm}$ for the mixture of isooctane and $4 \%$ biacetyl. 

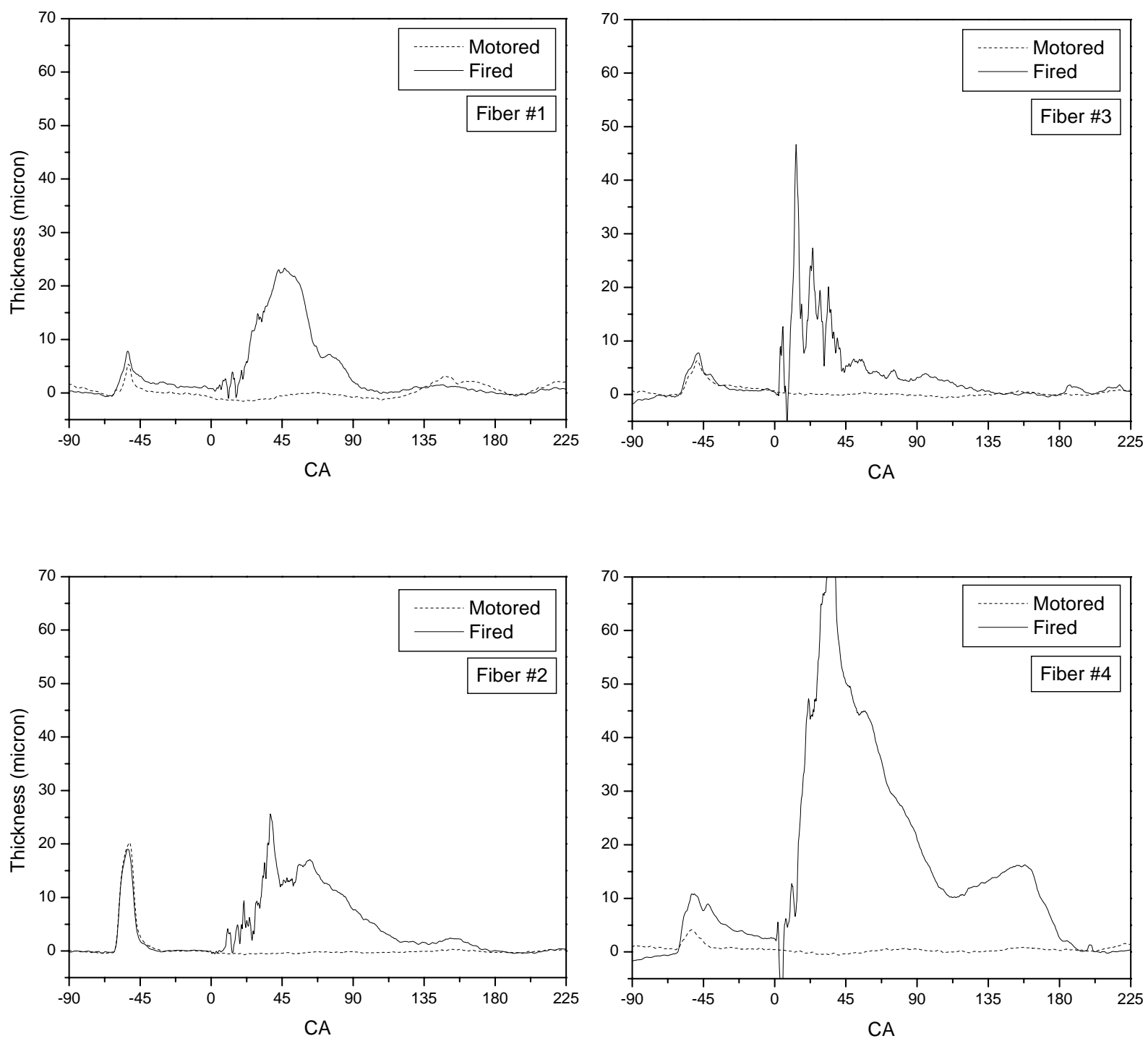

Figure 6-26. Fuel film thickness for motored and fired conditions at $1200 \mathrm{rpm}$ for the mixture of isooctane and $4 \%$ biacetyl. 


\section{6-4. Summary of the Fuel Film Thickness Measurement}

Before the quantification of the fuel (isooctane) film thickness on the piston crown of the DISI engine using the liquid dopants (diketones), the same tests were performed with BTBP as a dopant. Although BTBP does not co-evaporate with the fuel, it was a satisfactory dopant because it is highly fluorescent and there were no remains left on the surface after the fuel film evaporated completely. The fuel film duration results for BTBP were used for comparison with the results of liquid dopants for evaluation.

The engine test results with BTBP showed that the fuel spray impinged on all fiber locations although the fuel spray was a hollow cone shape and the main fuel spray was directed only to two fibers. The intensity variation between the cycles was high for the fiber locations where the main sprays were directed. The fluorescence intensity was strong just after the fuel injection at all fibers due to droplet impingement on the fiber surface. The results for fired engine conditions showed that the signal intensities increased significantly after the pool fires were observed. This was caused by the flame luminosity and the laser scattering from the particulate matter produced by the pool fires. The fluorescence signal before the appearance of pool fires was the same level for motored and fired conditions although the piston temperatures were slightly different. However, relatively higher differences were observed at the fiber locations where the main fuel sprays were directly injected. The fluorescence intensity at higher engine speed (1200 rpm) was evenly distributed at all fiber locations because of the spray mixing by higher air motion. The crank angle positions where the fuel film disappeared were almost the same for different engine speeds 
(600 and $1200 \mathrm{rpm}$ ) and it was related to the exhaust valve opening which reduced incylinder pressure and increased air motion.

The volatility effect of the fuels on fuel film thickness and fuel film duration was performed with fuels having different boiling points than isooctane: n-pentane $\left(\mathrm{T}_{\mathrm{bp}}=36^{\circ} \mathrm{C}\right)$ and $n$-decane $\left(\mathrm{T}_{\mathrm{bp}}=174^{\circ} \mathrm{C}\right)$. The fuel film duration was strongly affected by the volatility of the fuel. The fuel film evaporated quickly for n-pentane and the fuel film remained during the whole engine cycle for $n$-decane.

Fuel film thickness was measured with the mixture of isooctane and $4 \%$ of $2,3-$ hexanedione as a dopant. Preliminary tests showed that 2,3-hexanedione co-evaporated with isooctane. The measured fuel film thickness was less than $5 \mu \mathrm{m}$ for the fibers where the main fuel spray was not directly injected. For those locations, the fuel film duration was the same as the results measured with BTBP. But the fuel films for fibers where the hollow cone spray was directly injected were not completely evaporated during a cycle. The persistence of the fluorescence was related to the light yellow fuel residue that was found after the test. The effect of the fuel residue became more significant for fired engine conditions. The reason was that the particulate matters stuck to the fuel remains in the previous cycle persisted to the next cycle and they were not removed by the fuel injection from the next cycle. Therefore, the fluorescence intensity in the region between the fuel injection and the start of pool fires was high and it caused thicker fuel film thickness than that of motored condition where the piston temperature was lower. The situation was the same for the higher engine speed (1200 rpm). The cause of the fuel residue is believed to be that the piston temperature was not high 
enough for the evaporation of the dopant whose boiling point was higher than that of the fuel (isooctane), and the impurities in the dopant.

To alleviate the fuel remain problem of 2,3-hexanedione, biacetyl was tested because it has a lower boiling point $\left(\mathrm{T}_{\mathrm{bp}}=89^{\circ} \mathrm{C}\right)$ than 2,3 -hexanedione and isooctane. However, the results showed that the fuel film thickness and fuel film duration was significantly reduced compared with the results of BTBP and 2,3-hexanedione because of the quick evaporation of biacetyl just after the injection. Furthermore, a fuel residue was observed for this liquid dopant, also. The purity level of biacetyl was high (99.8\%). It seemed that the remains were not from the impurities in the dopant and they were from the third components produced by some chemical reactions between isooctane and the liquid dopant (polymerization). 


\section{Chapter 7}

\section{Conclusions and Recommendations}

\section{7-1. Conclusions}

Fuel film temperature and thickness were measured on the piston crown of a DISI engine under both motored and fired conditions by using the fiber-based LIF method. The fuel used in this research for the fuel film temperature measurement was a $2 \times 10^{-6} \mathrm{M}$ solution of BTBP in isooctane. Two $\alpha$-diketones (2,3-hexanedione and biacetyl) were used as dopants for fuel film thickness measurement. The following conclusions can be drawn from the experiments.

The base fuel film temperature was found to follow the piston surface temperature for all engine conditions tested. Test results showed that the base fuel film temperatures were 
higher than the piston temperature measured with a thermocouple installed $1 \mathrm{~mm}$ below the piston bowl surface at 600 and $1200 \mathrm{rpm}$ motored condition. Possible causes for this behavior are that there is a temperature difference between the thermocouple and fiber positions in the flow path of the calibration device, or is that the thermocouple installed in the piston may not have good thermal contact with the piston.

The convection heat transfer from the hot compressed air during the compression and early part of the expansion stroke was found to directly affect the fuel film temperature at $600 \mathrm{rpm}$. The mean peak fuel film temperature at compression TDC was approximately $10^{\circ} \mathrm{C}$ higher than the base fuel film temperature.

For fired conditions at $600 \mathrm{rpm}$ the trace of the fuel film temperature was nearly the same as that for the motored condition although the piston temperature was $11^{\circ} \mathrm{C}$ higher. The fuel film temperature measurement was not possible just after the occurrence of the pool fires because of the strong flame luminosity and the laser scattering from the particulate matter produced by the pool fires, but, the measurement was not affected by the spark ignition and the initial flame propagation.

The maximum temperature that can be measured with this LIF method for isooctane and BTBP was limited to $140^{\circ} \mathrm{C}$ because the slope of the calibration curve decreased as fuel temperature increases.

The delivery pattern of the laser produced by the fiber shows a Gaussian distribution at any distance from the fiber end. The calculation of the modified collection solid angle was 
modified for the Gaussian distribution assumption and the calculated cumulative signals match well with the measured total signal intensity for thin and thick fuel films.

Reliable measurement of the fuel film thickness on the piston crown was only possible before the occurrence of the pool fires for fired condition because of interference from the flame luminosity and the laser scattering from the particulate matter produced by the pool fires.

The fuel films were actively evaporated after the exhaust valve opening crank angle in the qualitative measurement with BTBP because of the improved evaporating condition by reduced in-cylinder pressure and increased in-cylinder air motion after the exhaust valve opening.

The fuel film thickness from the fuel injection to just before the occurrence of pool fires was the same level for motored and fired engine conditions although the piston temperature was slightly higher for fired condition. It was less than $5 \mu \mathrm{m}$ at the tested conditions for the fiber locations where the spray was not directly injected. In this crank angle region the fuel film temperature is much lower than the boiling point of the fuel at the in-cylinder pressure for both conditions.

The fuel film duration and thickness on the piston crown were strongly affected by the volatility of the fuel. The tested fuels were n-pentane $\left(\mathrm{T}_{\mathrm{bp}}=36^{\circ} \mathrm{C}\right)$, isooctane $\left(\mathrm{T}_{\mathrm{bp}}=99^{\circ} \mathrm{C}\right)$, and n-decane $\left(\mathrm{T}_{\mathrm{bp}}=174^{\circ} \mathrm{C}\right)$. The measured piston temperatures were $99^{\circ} \mathrm{C}$ at $600 \mathrm{rpm}$ and $110^{\circ} \mathrm{C}$ at $1200 \mathrm{rpm}$. The fuel film evaporated quicker for n-pentane than for isooctane, and the fuel film remained during the whole cycle for n-decane. 
The mixture of isooctane and 4\% 2,3-hexanedione co-evaporates although the boiling point of 2,3-hexanedione $\left(128^{\circ} \mathrm{C}\right)$ is higher than that of isooctane. However, it produces the light yellow and very viscous residue, which does not evaporate during a cycle, only at the locations where the main spray was directly injected. It prevented accurate fuel film thickness measurement and the errors at those fiber locations were significantly increased for fired conditions.

The fuel film thickness at the fiber 1 and 2 were 2-3 $\mu \mathrm{m}$ and 3-4 $\mu \mathrm{m}$, respectively, for both motored and fired conditions at $600 \mathrm{rpm}$. At $1200 \mathrm{rpm}$, the fuel film thickness was approximately $5 \mu \mathrm{m}$ at fiber 1, 2-3 $\mu \mathrm{m}$ at fiber 2, and 5-10 $\mu \mathrm{m}$ at fiber 3 for both motored and fired conditions.

The mixture of isooctane and $4 \%$ biacetyl cannot be used for the co-evaporating condition because biacetyl evaporates much faster than isooctane because of its lower boiling point $\left(88^{\circ} \mathrm{C}\right)$.

\section{7-2. Recommendations}

The present measurement method of the fuel film temperature and thickness was proven to be efficient and reliable. However, it was also found that some improvements are needed for more accurate and reliable measurement. They are summarized in this section. 
The base fuel film temperatures were about $10^{\circ} \mathrm{C}$ higher than the piston temperature, measured with a thermocouple $1 \mathrm{~mm}$ below the piston bowl surface, at $600 \mathrm{rpm}$ motored condition. One cause of this result is the temperature difference between the thermocouple and fiber positions in the calibration device. The other cause is that the thermocouple in the piston may not have good thermal contact with the piston. Therefore, the thermocouple should be installed close to the fiber position in the calibration device (Figure 4-13) to reduce the calibration error. For the piston temperature measurement, it is not easy to install the junction of the thermocouple to the surface of the piston in a long hole with small diameter from the bottom of the piston as in the present research. Instead, it is recommended to use the surface thermocouple and install it on the piston crown surface.

The result of the fuel film temperature measurement for fired condition showed that the film temperature trace from the fuel injection to just before the pool fires was the same level as that of the motored condition although the piston temperature was $10^{\circ} \mathrm{C}$ higher. It is not clear whether the results are correct, and the cause of this result is not clear although it was postulated that the laser scattering from the particulate matter produced by the pool fires affected the signal of the next cycle.

The shape of the Gaussian intensity distribution function of the fiber, equation (3-6), was sensitive to the selection of the standard deviation, $s$, and it affected the calculation result of the modified collection solid angle, $\Omega^{*}$. In this research, the standard deviation was assumed to be a third of the radius of the numerical aperture at all distances from the fiber surface. In that case, the calculated modified collection solid angle at the fiber surface was $98.6 \%$ of the reference collection solid angle (equation 2-2). Therefore, it affected the non- 
dimensional form of the modified collection solid angle, $\tilde{\Omega}$, and the cumulative signal, $\tilde{I}$, and finally slightly over-estimated the fuel film thickness. For more accurate approximation, more attention is needed to measure the laser delivery pattern of the fiber to find the effective numerical aperture.

The fuel film thickness measurement results with diketones showed that a light yellow and very viscous liquid was remained on the piston crown. It did not evaporate during a cycle and affected the signal intensity, especially at the fiber locations where the main spray was directly injected. One plausible source of the liquid residue is the impurities in the diketones. However, the liquid residue was also found for biacetyl mixture where the purity level of the biacetyl was high (99.8\%). It seems that the residue is coming from the third component produced by chemical reactions between isooctane and the diketone (polymerization). To find the source of this phenomenon is important for accurate measurement of fuel film thickness.

Fuel film thickness measurement results showed that most of the fuel impinged to the piston crown remained as fuel film even after the spark ignition and main flame propagation although the measurement was hindered by the appearance of the pool fires after TDC. The fuel films started to evaporate actively after the exhaust valve opening. It is expected that lots of particulate and hydrocarbons will be emitted during the exhaust stroke. Therefore, it will be helpful to measure the time-resolved particulate and hydrocarbon emissions to get the information on the relationship between the fuel film thickness and the particulate and hydrocarbon emissions in the DISI engine. 


\section{References}

Alger, T., Huang, Y., Hall, M., and Matthews, R. D., "Liquid Film Evaporation Off the Piston of a Direct Injection Gasoline Engine," SAE paper 2001-01-1204, 2001.

Almkvist, G., and Denbratt, I., "Measurements of Fuel Film Thickness in the Inlet Port of an S.I. Engine by Laser Induced Fluorescence,” SAE paper 952483, 1995.

Bai, F., and Melton, L. A., "High-Temperature, Oxygen-Resistant Molecular Fluorescence Thermometers,” Applied Spectroscopy, Vol. 51, Number 9, pp. 1276-1280, 1997.

Baritaud, T. A., and Heinze, T. A., "Gasoline Distribution Measurements with PLIF in a SI Engine,” SAE Paper 922355, 1992.

Berlman, I. B., Handbook of Fluorescence Spectra of Aromatic Molecules, $2^{\text {nd }}$ ed., Academic press, 1971.

Borman, G. L., and Ragland, K. W., Combustion Engineering, McGraw-Hill, 1998.

Brehob, D. D., Fleming, J. E., Haghgooie, M., and Stein, R. A., "Stratified-Charge Engine Fuel Economy and Emission Characteristics,” SAE paper 982704, 1998.

Casarella, M. V., and Ghandhi, J. B., "Emission Formation Mechanisms in a Two-Stroke Direct-Injection Engine,” SAE paper 982697, 1998.

Cathcart, G., and Zavier, C., "Fundamental Characteristics of an Air-Assisted Direct Injection Combustion System as Applied to 4 Stroke Automotive Gasoline Engines," SAE paper 2000-01-0256, 2000.

Cole, R. L., Poola, R. B., and Sekar, R., "Exhaust Emissions of a Vehicle with a Gasoline Direct-Injection Engine,” SAE paper 982605, 1998.

Deschamps, B., Snyder, R., and Baritaud, T., "Effect of Flow and Gasoline Stratification on Combustion in a 4-Valve SI Engine,” SAE Paper 941993, 1994.

Drake, M. C., Fansler, T. D., Solomon, A. S., and Szekely Jr., G. A., "Piston Fuel Films as a Source of Smoke and Hydrocarbon Emissions from a Wall-Controlled Spark-Ignited DirectInjection Engine,” SAE Paper 2003-01-0547, 2003.

Fansler, T. D., French, D. T., Drake, M. C., "Fuel Distributions in a Firing Direct-Injection Spark-Ignition Engine Using Laser-Induced Fluorescence Imaging,” SAE paper 950110, 1995. 
Frank, R. M., and Heywood, J. B., “The Effect of Piston Temperature on Hydrocarbon Emissions from a Spark-Ignited Direct-Injection Engine,” SAE paper 910558, 1991.

Geiger, J., Grigo, M, Lang, O., Wolters, P., and Hupperich, P., “Direct Injection Gasoline Engines - Combustion and Design,” SAE paper 1999-01-0170, 1999.

Ghandhi, J. B., and Bracco, F. V., "Fuel Distribution Effects on the Combustion of a DirectInjection Stratified-Charge Engine,” SAE paper 950460, 1995.

Ghandhi, J. B., and Bracco, F. V., "Mixture Preparation Effects on Ignition and Combustion in a Direct-Injection Spark-Ignition Engine,” SAE paper 962013, 1996.

Ghandhi, J. B., and Felton, P. G., "On the Fluorescent Behavior of Ketones at High Temperatures,” Experiments in Fluids, Vol. 21, pp. 143-144, 1996.

Ghandhi, J. B., "Single- and Dual-fiber Fluorescence Probes: Application to Oil-film Measurements in an Internal Combustion Engine,” Applied Optics, Vol. 39, No. 30, pp. 5456-5464, 2000.

Giovanetti, A. J., Ekchian, J. A., Fort, E. F., and Heywood, J. B., “Analysis of Hydrocarbon Emissions Mechanisms in a Direct Injection Spark-Ignition Engine,” SAE paper 830587, 1983.

Glassman, I., Combustion, $2^{\text {nd }}$ Ed., Academic Press, 1987.

Han, D., and Steeper, R. R., "Examination of Iso-octane/Ketone Mixtures for Quantitative LIF Measurements in a DISI Engine,” SAE Paper 2002-01-0837, 2002.

Harada, J., Tomita, T., Mizuno, H., Mashiki, Z., and Ito, Y., “ Development of Direct Injection Gasoline Engine,” SAE paper 970540, 1997.

Hentschel, W., Grote, A., and Langer, O., "Measurement of Wall Film Thickness in the Intake Manifold of a Standard Production SI Engine by a Spectroscopic Technique," SAE paper 972832, 1997.

Heywood, J. B., Internal Combustion Engine Fundamentals, McGraw-Hill, 1988.

Hochgreb, S., "Liquid Fuel Impingement on the Piston Bowl of a Direct-Injection, SparkIgnited (DISI) Engine Under Stratified Operation,” SAE paper 2001-01-3646, 2001.

Hoult, D. P., Lux, J. P., and Wong, V. W., "Calibration of Laser Fluorescence Measurements of Lubricant Film Thickness in Engines,” SAE paper 881587, 1988. 
Houston, R., and Cathcart, G., "Combustion and Emissions Characteristics of Orbital's Combustion Process Applied to Multi-Cylinder Automotive Direct Injected 4-Stroke Engines,” SAE paper 980153, 1998.

Huang, Y., Alger, T., Matthews R., and Ellzey, J., “The Effects of Fuel Volatility and Structure on HC Emissions from Piston Wetting in DISI Engines,” SAE Paper 2001-011205, 2001.

Hudak, E. B., and Ghandhi, J. B., ”Time-Resolved Emission Sampling in a Direct-Injection Engine," SAE paper 1999-01-3309, 1999.

Incropera, F. P., and Dewitt, D. P., Fundamentals of Heat and Mass Transfer, $4^{\text {th }}$ ed., John Wiley \& Sons, 1996.

Iwamoto, Y., Noma, K., Nakayama, O., Yamauchi, T., and Ando, H., "Development of Gasoline Direct Injection Engine,” SAE paper 970541, 1997.

Johnen, T., and Haug, M., "Spray Formation Observation and Fuel Film Development Measurements in the Intake of a Spark Ignition Engine,” SAE paper 950511, 1995.

Kaiser, E. W., Siegl, W. O., Brehob, D. D., and Haghgooie, M., "Engine-Out Emissions from a Direct-Injection Spark-Ignition (DISI) Engine,” SAE paper 1999-01-1529, 1999.

Kanda, M., Baika, T., Kato, S., Iwamuro, M., Koike, M., and Saito, A., “Application of a New Combustion Concept to Direct Injection Gasoline Engine,” SAE paper 2000-01-0531, 2000.

Koike, M., Saito, A., Tomoda, T., and Yamamoto, Y., "Research and Development of a New Direct Injection Gasoline Engine,” SAE paper 2000-01-0530, 2000.

Kume, T., Iwamoto, Y., Iida, K., Murakami, M., Akishino, K., and Ando, H., “ Combustion Control Technologies for Direct Injection SI Engine,” SAE paper 960600, 1996.

Lancaster, D. R., Krieger, R. B., and Lienesch, J. H., "Measurement and Analysis of Engine Pressure Data,” SAE paper 750026, 1975.

Le Coz, J. F., and Baritaud, T., “Application of Laser Induced Fluorescence for Measuring the Thickness of Evaporating Gasoline Liquid Films," Proceedings of the $7^{\text {th }}$ International Symposium, Lisbon, Portugal, 11-14 July, 1994.

Li, J., Matthews, R. D., Stanglmaier, R. H., Roberts, C. E., and Anderson R. W., "Further Experiments on the Effects of In-Cylinder Wall Wetting on HC Emissions from Direct Injection Gasoline Engines,” SAE Paper 1999-01-3661, 1999. 
Lipson, C., and Sheth, N. J., Statistical Design and Analysis of Engineering Experiments, McGraw-Hill, 1973.

Maricq, M. M., Podsiadlik, D. H., Brehob, D. D., and Haghgooie, M., "Parculate Emissions from a Direct-Injection Spark-Ignigion (DISI) Engine,” SAE Paper 1999-01-1530, 1999.

Mitchell, E., and Alperstein, M., "Texaco Controlled-Combustion System - Multifuel, Efficient, Clean and Practical,” Combustion Science and Technology, Vol. 8, pp. 39-49, 1973.

Ostroski, G. M., "The Use of a Dual-Fiber Probe and the Laser-Induced Fluorescence Technique to Study Oil Consumption in a Diesel Engine,” M.S. Thesis, University of Wisconsin-Madison, 1998.

Park, J., Xie, X., Im, K., Kim, H., Lai, M, Yang, J., Han, Z., and Anderson, R. W., "Characteristics of Direct Injection Gasoline Spray Wall Impingement at Elevated Temperature Conditions,” SAE paper 1999-01-3662, 1999.

Richardson, D. E., and Borman, G. L, "Using Fiber Optics and Laser Fluorescence for Measuring Thin Oil Films with Application to Engines,” SAE paper 912388, 1991.

Richtol, H. H., and Klappmeier, F. H., "Luminescence and Energy Transfer in Some Aliphatic $\alpha$-Diketones,” The Journal of Chemical Physics, Vol. 44, No. 4, 1966.

Salters, D., Williams, P, Greig, A., and Brehob, D., "Fuel Spray Characterisation within an Optically Accessed Gasoline Direct Injection Engine Using a CCD Imaging System, SAE paper 961149, 1996.

Schrum, K. F., Williams, A. M., Haerther, S. A., and Ben-Amotz, D., "Molecular Fluorescence Thermometry,” Analytical Chemistry, Vol. 66, No. 17, pp. 2788-2790, 1994.

Senda, J., Ohnishi, M., Takahashi, T., Fujimoto, H., Utsunomiya, A., and Wakatabe, M., "Measurement and Modeling on Wall Wetted Fuel Film Profile and Mixture Preparation in Intake Port of SI Engine,” SAE paper 1999-01-0798, 1999.

Sharma, A., and Schulman, S. G., Introduction to Fluorescence Spectroscopy, John Wiley \& Sons, Inc., 1999.

Stanglmaier, R. H., Li, J., and Matthews, R. D., "The Effect of In-Cylinder Wall Wetting Location on the HC Emissions from SI Engines,” SAE paper 1999-01-0502, 1999.

Stanglmaier, R. H., Roberts, C. E., and Moses, C. A., "Vaporization of Individual Fuel Drops on a Heated Surface: A Study of Fuel-Wall Interactions Within Direct-Injected Gasoline (DIG) Engines,” SAE Paper 2002-01-0838, 2002. 
Stevens, E., and Steeper, R., "Piston Wetting in an Optical DISI Engine: Fuel Films, Pool Fires, and Soot Generation,” SAE paper 2001-01-1203, 2001.

Stovell, C., Matthews, R., Johnson, B. E., Ng, H., and Larsen, B., "Emissions and Fuel Economy of a 1998 Toyota with a Direct Injection Spark Ignition Engine,” SAE paper 199901-1527, 1999.

Strand, T. E., "Experimental Investigation of Bulk Flame Quenching in a Direct-Injection Spark Ignition Engine,” M.S. Thesis, University of Wisconsin-Madison, 2001.

Tabata, M., Kataoka, M., Tanaka, T., and Yamakawa, M., “ Measurement of Fuel Distribution in the Piston Cavity of Direct Injection SI Engine by Using LIF,” SAE 2000-010240, 2000.

Takagi, Y., Itoh, T., Muranaka, S., Iiyama, A., Iwakiri, Y., Urushihara, T., and Naitoh, K., "Simultaneous Attainment of Low Fuel Consumption, High Output Power and Low Exhaust Emissions in Direct Injection SI Engines,” SAE paper 980149, 1998.

Turns, S. R., An Introduction to Combustion, McGraw-Hill, 1996.

Warey, A., Huang, Y., Matthews, R., and Hall, M., "Effects of Piston Wetting on Size and Mass of Particulate Matter Emissions in a DISI Engine,” SAE Paper 2002-01-1140, 2002.

Zhao, F., Lai, M.-C., and Harrington, D. L., “Automotive Spark-Ignited Direct-Injection Gasoline Engines,” Progress in Energy and Combustion Science 25, 437-562, 1999.

Zhao, F., Harrington, D. L., and Lai, M.-C., Automotive Gasoline Direct-Injection Engines, SAE Inc., 2002.

Zhengbai, L., Jingwei, Z., and Yueshang, L., "Experimental Investigation of Film-Space Atomization Combustion in D.I. Diesel Engines,” SAE paper 901578, 1990. 